\title{
Standard Review Plan \\ Update and Development Program
}

Implementing Procedures Document

Manuscript Completed: January 1992

Date Published: May 1992

Program Management, Policy Development, and Analysis Staff

Office of Nuclear Reactor Regulation

U.S. Nuclear Regulatory Commission

Washington, DC 20555
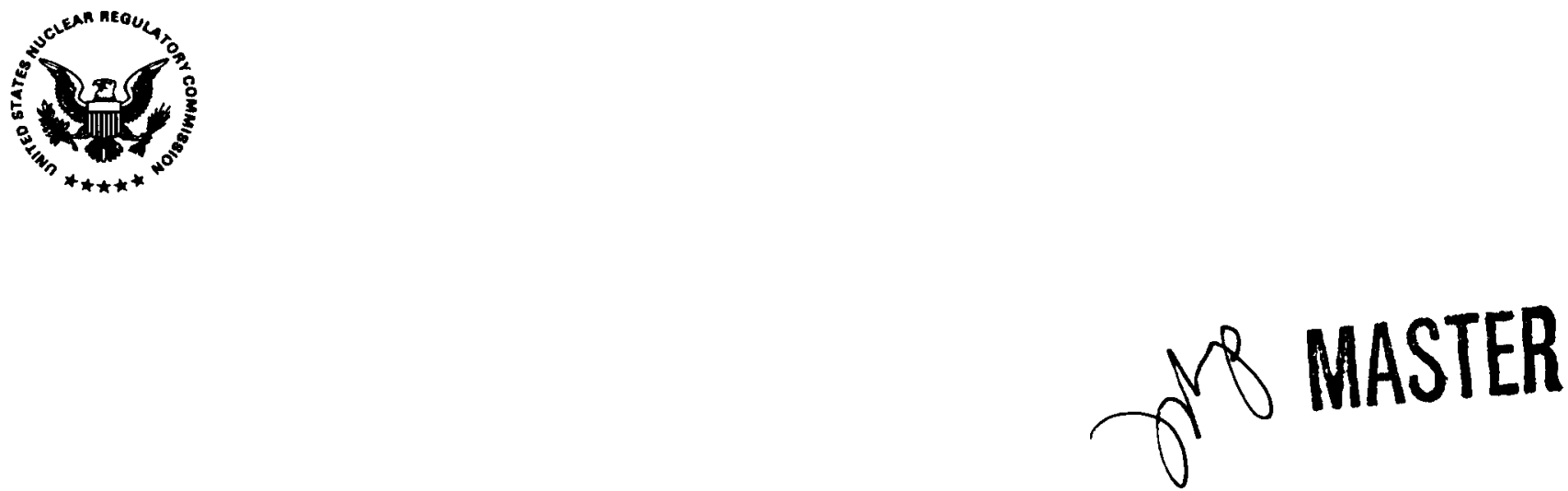


\section{DISCLAIMER}

This report was prepared as an account of work sponsored by an agency of the United States Government. Neither the United States Government nor any agency Thereof, nor any of their employees, makes any warranty, express or implied, or assumes any legal liability or responsibility for the accuracy, completeness, or usefulness of any information, apparatus, product, or process disclosed, or represents that its use would not infringe privately owned rights. Reference herein to any specific commercial product, process, or service by trade name, trademark, manufacturer, or otherwise does not necessarily constitute or imply its endorsement, recommendation, or favoring by the United States Government or any agency thereof. The views and opinions of authors expressed herein do not necessarily state or reflect those of the United States Government or any agency thereof. 


\section{DISCLAIMER}

Portions of this document may be illegible in electronic image products. Images are produced from the best available original document. 


\section{AVAILABILITY NOTICE}

\section{Availability of Reference Materials Cited in NRC Publications}

Most documents cited in NRC publications will be available from one of the following sources:

1. The NRC Public Document Room, 2120 L Street, NW., Lower Level, Washington, DC 20555

2. The Superintendent of Documents, U.S. Government Printing Office, P.O. Box 37082, Washington, DC 20013-7082

3. The National Technical Information Service, Springfield, VA 22161

Although the listing that follows represents the majority of documents cited in NRC publications, it is not intended to be exhaustive.

Referenced documents available for inspection and copying for a fee from the NRC Public Document Room include NRC correspondence and internal NRC memoranda; NRC bulletins, circulars, information notices, inspection and investigation notices; licensee event reports; vendor reports and correspondence; Commission papers; and applicant and licensee documents and correspondence.

The following documents in the NUREG series are available for purchase from the GPO Sales Program: formal NRC staff and contractor reports, NRC-sponsored conference proceedings, international agreement reports, grant publications, and NRC booklets and brochures. Also available are regulatory guides, NRC regulations in the Code of Federal Regulations, and Nuclear Regulatory Commission Issuances.

Documents available from the National Technical Information Service include NUREG-series reports and technical reports prepared by other Federal agencies and reports prepared by the Atomic Energy Commission, forerunner agency to the Nuclear Regulatory Commission.

Documents available from public and special technical libraries include all open literature items, such as books, journal articles, and transactions. Federal Register notices, Federal and State legislation, and congressional reports can usually be obtained from these libraries.

Documents such as theses, dissertations, foreign reports and translations, and non-NRC conference proceedings are available for purchase from the organization sponsoring the publication cited.

Single copies of NRC draft reports are available free, to the extent of supply, upon written request to the Office of Administration, Distribution and Mail Services Section, U.S. Nuclear Regulatory Commission, Washington, DC 20555.

Copies of industry codes and standards used in a substantive manner in the NRC regulatory process are maintained at the NRC Library, 7920 Norfolk Avenue, Bethesda, Maryland, for use by the public. Codes and standards are usually copyrighted and may be purchased from the originating organization or, if they are American National Standards, from the American National Standards Institute, 1430 Broadway, New York, NY 10018. 


\begin{abstract}
The Implementing Procedures Document (IPD) was developed by the Policy Development and Technical Support Branch, Program Management, Policy Development and Analysis Staff, Office of Nuclear Reactor Regulation, with assistance from Pacific Northwest Laboratory for the Standard Review Plan Update and Development Program (SRP-UDP). The IPD provides comprehensive guidance and detailed procedures for SRP-UDP tasks. The IPD is mandatory for contractors performing work for the SRP-UDP. It is guidance for the staff. At the completion of the SRP-UDP, the IPD will be revised (to remove the UDP aspects) and will replace NRR Office Letter No. 800 as long-term maintenance procedures.

One of the principal objectives of the IPD is to ensure consistent application of methodology in developing and revising SRP sections. Because of the variety of groups and organizations involved in this program, considerable effort has gone into clearly stating the process involved for each task under the program. This has led to some redundancy and what could be considered a wordy document. The reader should be aware that this was a conscious decision with the intended goal of ensuring clear and self-sufficient procedures.
\end{abstract}




\section{Organization of This Document}

This Implementing Procedures Document (IPD) contains three divisions. The first division, Preparatory Work, includes IPD Sections 1.0 through 3.5. The procedures in this division will be performed primarily by contractors under the direction of the appropriate NRC organization. The second division, Revision of SRP Sections, includes IPD Sections 3.6 through 4.1. The procedures in this IPD division will be performed primarily by the Primary Review Branches (PRBs) and contractors of the PRB's choice. The third division, Review, Approval, and Publication, includes IPD Sections 4.2 through 8.0. The procedures in this IPD division will be performed primarily by the NRC and the NRC's contractors.

IPD divisions and sections are indicated on the tabs of this document.

\section{Notice of Update}

This document will be periodically updated with new and/or replacement pages as appropriate to incorporate additional information.

Technical errors in this reports should be brought to the attention of:

Mr. George Barber

U.S. Nuclear Regulatory Commission

Office of Nuclear Reactor Regulation

Program Management, Policy Development and Analysis Staff

Mail Stop 12E4

Washington, D.C. 20555 


\section{Contents}

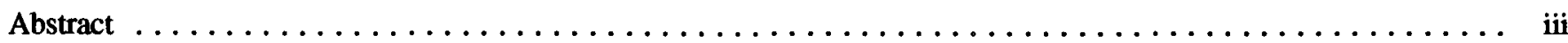

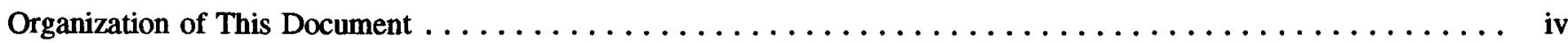

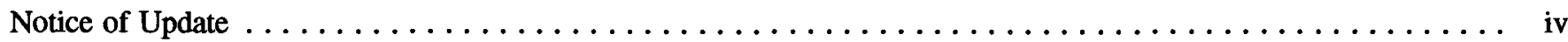

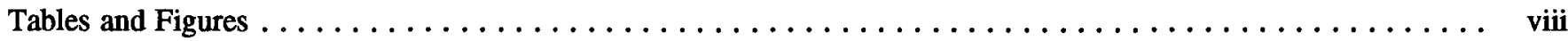

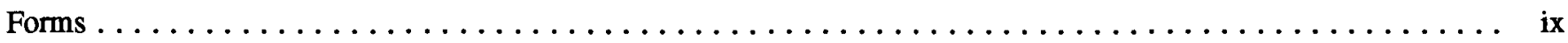

Executive Summary $\ldots \ldots \ldots \ldots \ldots \ldots \ldots \ldots \ldots \ldots \ldots \ldots \ldots \ldots \ldots \ldots \ldots \ldots \ldots \ldots \ldots \ldots \ldots \ldots$

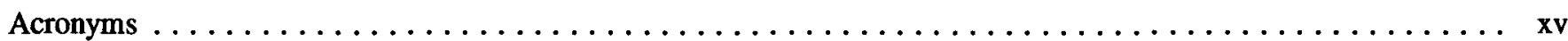

Preparatory Work

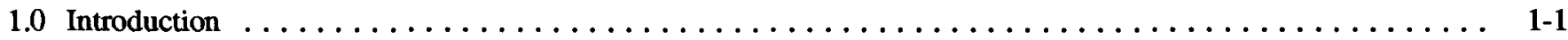

1.1 Background and History of the SRP Including Its Modifications $\ldots \ldots \ldots \ldots \ldots \ldots \ldots \ldots \ldots \ldots$

1.2 Purpose and Scope of the SRP . . . . . . . . . . . . . . . . . . . . . .

1.3 Scope and Purpose of This Implementing Procedures Document $\ldots \ldots \ldots \ldots \ldots \ldots \ldots \ldots \ldots \ldots$

1.4 Revision of This Implementing Procedures Document $\ldots \ldots \ldots \ldots \ldots \ldots \ldots \ldots \ldots \ldots \ldots \ldots \ldots$

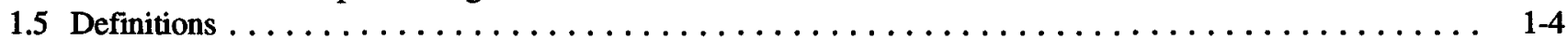

1.6 NRR Responsibilities Regarding SRP Update and Development $\ldots \ldots \ldots \ldots \ldots \ldots \ldots \ldots \ldots \ldots$

1.7 Overview of This Implementing Procedures Document $\ldots \ldots \ldots \ldots \ldots \ldots \ldots \ldots \ldots \ldots \ldots \ldots$

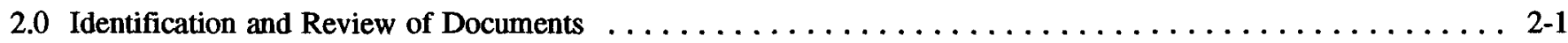

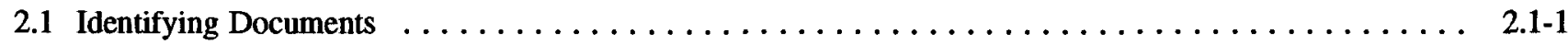

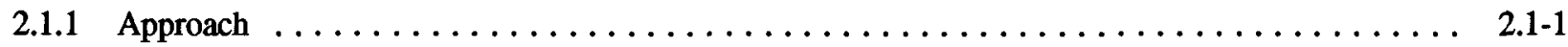

2.1.2 Procedure for Identifying Documents $\ldots \ldots \ldots \ldots \ldots \ldots \ldots \ldots \ldots \ldots \ldots \ldots \ldots \ldots \ldots \ldots \ldots \ldots$

2.2 Identifying Documents by Other Staff $\ldots \ldots \ldots \ldots \ldots \ldots \ldots \ldots \ldots \ldots \ldots \ldots \ldots \ldots \ldots \ldots \ldots \ldots \ldots \ldots$

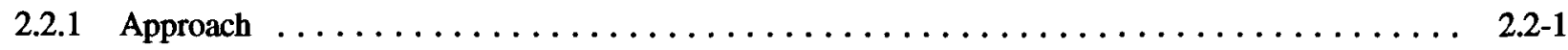

2.2.2 Procedure for Identifying Documents by Other Staff $\ldots \ldots \ldots \ldots \ldots \ldots \ldots \ldots \ldots \ldots \ldots \ldots \ldots$

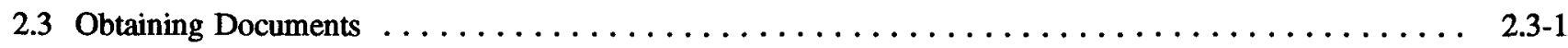

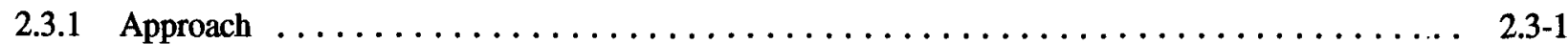

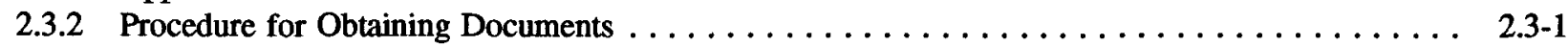

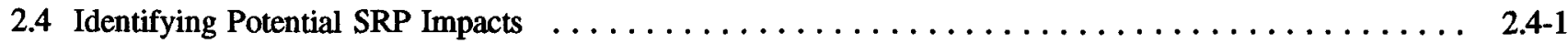

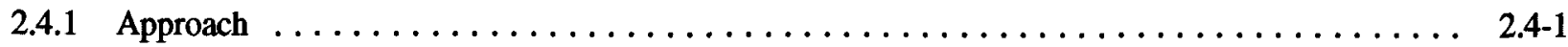

2.4.2 Procedure for Identifying Potential SRP Impacts $\ldots \ldots \ldots \ldots \ldots \ldots \ldots \ldots \ldots \ldots \ldots \ldots \ldots \ldots \ldots .4 .2$

2.5 Ascertaining the Status of Industry-Consensus Codes and Standards $\ldots \ldots \ldots \ldots \ldots \ldots \ldots \ldots$. $\ldots \ldots$

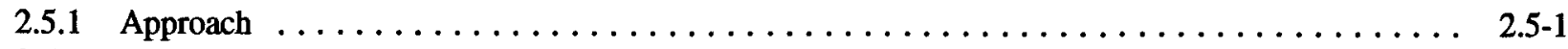

2.5.2 Procedure for Code and Standard Comparison $\ldots \ldots \ldots \ldots \ldots \ldots \ldots \ldots \ldots \ldots \ldots \ldots \ldots \ldots \ldots$ 
3.0 Update and Upgrade of the SRP for Future Reactor License Applications $\ldots \ldots \ldots \ldots \ldots \ldots \ldots \ldots$

3.1 Identifying the Need for New SRP Sections $\ldots \ldots \ldots \ldots \ldots \ldots \ldots \ldots \ldots \ldots \ldots \ldots \ldots \ldots \ldots \ldots \ldots$

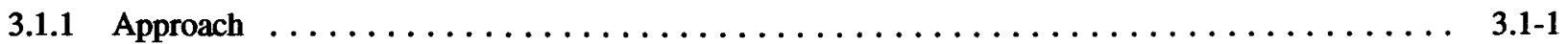

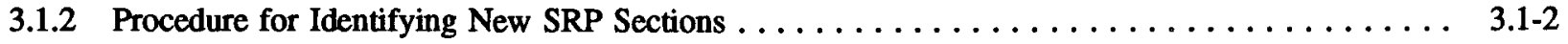

3.2 Prioritizing SRP Sections for Updating and Upgrading $\ldots \ldots \ldots \ldots \ldots \ldots \ldots \ldots \ldots \ldots \ldots$

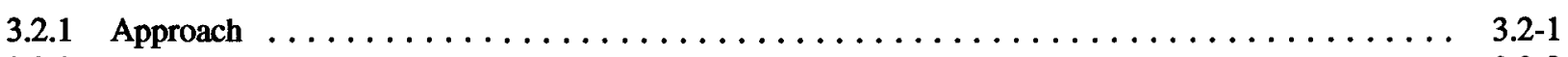

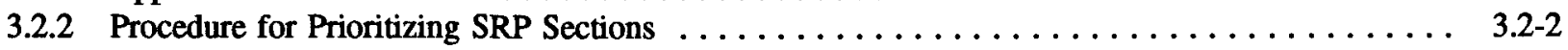

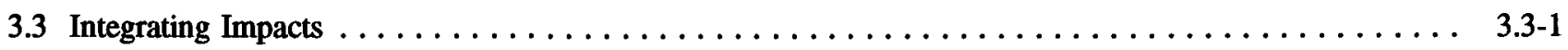

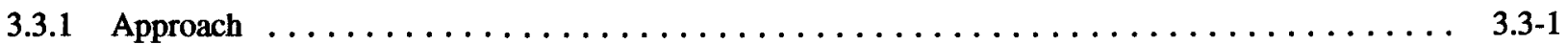

3.3.2 Procedure for Evaluating Impacts $\ldots \ldots \ldots \ldots \ldots \ldots \ldots \ldots \ldots \ldots \ldots \ldots \ldots \ldots \ldots \ldots \ldots \ldots .3 .2$

3.4 Reviewing USIs/GSIs for Applicability to Future Reactor Designs $\ldots \ldots \ldots \ldots \ldots \ldots \ldots \ldots \ldots$

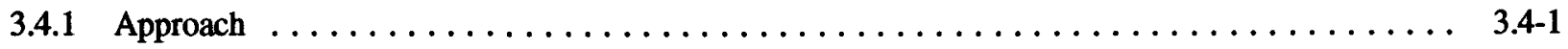

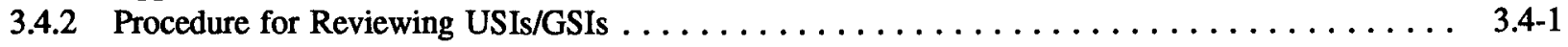

3.5 Integrating Impacts for Future Reactor Designs $\ldots \ldots \ldots \ldots \ldots \ldots \ldots \ldots \ldots \ldots \ldots \ldots \ldots \ldots \ldots$

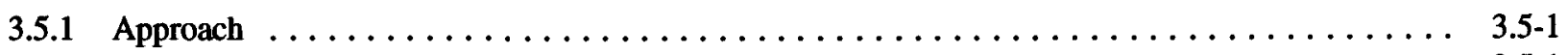

3.5.2 Procedure for Integrating Impacts for Future Reactor Designs $\ldots \ldots \ldots \ldots \ldots \ldots \ldots \ldots \ldots$.5

\section{Revision of SRP Sections}

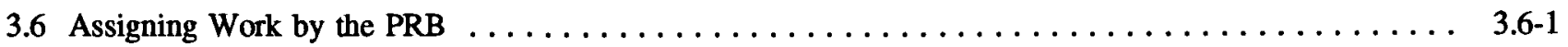

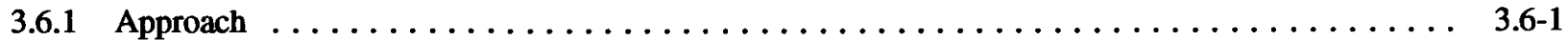

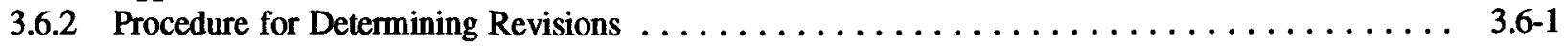

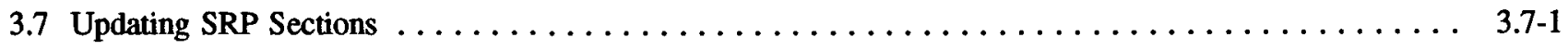

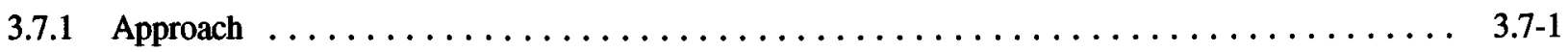

3.7.2 Procedure for Updating and Developing SRP Sections $\ldots \ldots \ldots \ldots \ldots \ldots \ldots \ldots \ldots \ldots$ 3.7-6

3.8 Upgrading SRP Sections for Future Reactor Designs $\ldots \ldots \ldots \ldots \ldots \ldots \ldots \ldots \ldots \ldots \ldots \ldots \ldots$

3.8.1 Approach $\ldots \ldots \ldots \ldots \ldots \ldots \ldots \ldots \ldots \ldots \ldots \ldots \ldots \ldots \ldots \ldots \ldots \ldots \ldots \ldots .1$

3.8.2 Procedure for Upgrading and Developing SRP Sections for Future Reactor Technology . . . . . . 3.8-5

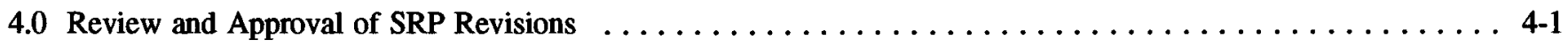

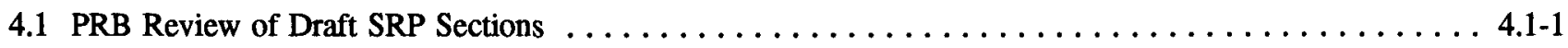

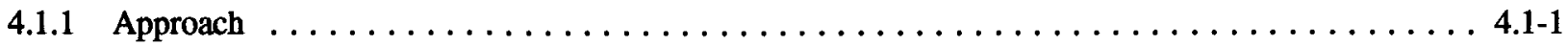

4.1.2 Procedure for PRB Review of Draft SRP Sections $\ldots \ldots \ldots \ldots \ldots \ldots \ldots \ldots \ldots \ldots \ldots \ldots .1$ 


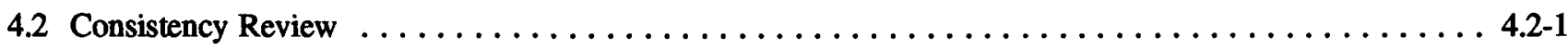

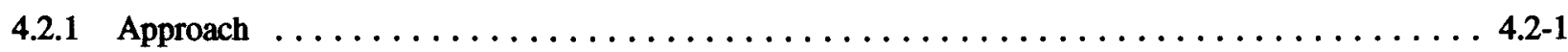

4.2.2 Procedure for Performing Consistency Review $\ldots \ldots \ldots \ldots \ldots \ldots \ldots \ldots \ldots \ldots \ldots \ldots \ldots \ldots \ldots$

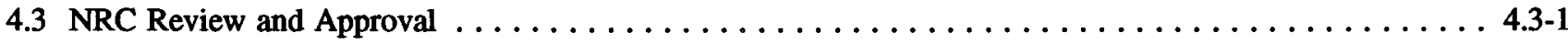

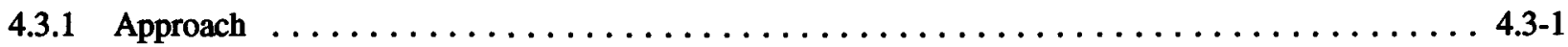

4.3.2 Procedure for Obtaining NRC Review and Approval $\ldots \ldots \ldots \ldots \ldots \ldots \ldots \ldots \ldots \ldots .3-1$

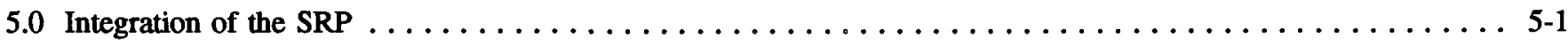

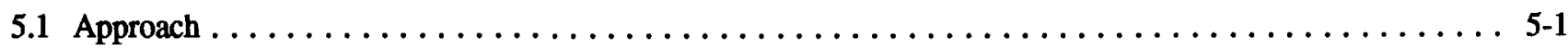

5.2 Procedure for Integration of the SRP $\ldots \ldots \ldots \ldots \ldots \ldots \ldots \ldots \ldots \ldots \ldots \ldots \ldots \ldots \ldots \ldots \ldots \ldots \ldots \ldots$

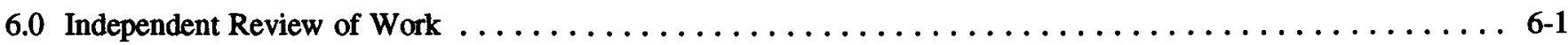

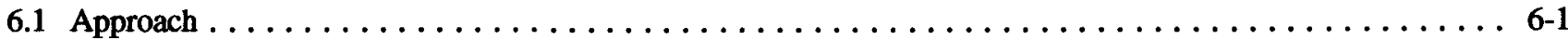

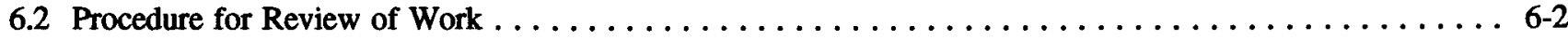

7.0 Identification of Candidates for Future Work $\ldots \ldots \ldots \ldots \ldots \ldots \ldots \ldots \ldots \ldots \ldots \ldots \ldots \ldots \ldots \ldots \ldots$

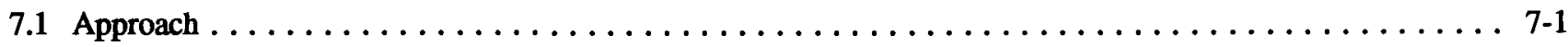

7.2 Procedure for Identification of Candidates for Future Work $\ldots \ldots \ldots \ldots \ldots \ldots \ldots \ldots \ldots \ldots \ldots$ 7-1

8.0 Control and Revision of Implementing Procedures Document $\ldots \ldots \ldots \ldots \ldots \ldots \ldots \ldots \ldots \ldots \ldots \ldots$

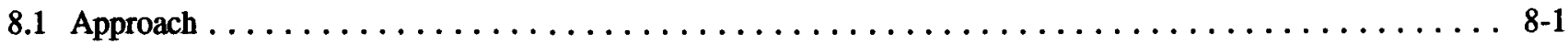

8.2 Procedure for Controlling Revisions $\ldots \ldots \ldots \ldots \ldots \ldots \ldots \ldots \ldots \ldots \ldots \ldots \ldots \ldots \ldots \ldots \ldots$

\section{Appendix}

Appendix A: Standard Review Plan Format $\ldots \ldots \ldots \ldots \ldots \ldots \ldots \ldots \ldots \ldots \ldots \ldots \ldots \ldots \ldots \ldots \ldots \ldots$ 


\section{Tables and Figures}

Table 1. Summary of Chapter 1

Table 2. Chapters of the Standard Review Plan

Table 3. Summary of Chapter 2

Table 4. Summary of Chapter 3

Table 5. Example of SRP Section Prioritization

Table 6. SRP/ESRP Subsection Correlations

Table 7. Summary of Chapter 4

Table 8. Summary of Chapter 5 $5-1$

Table 9. Summary of Chapter 6 6-1

Table 10. Summary of Chapter 7 $7-1$

Table 11. Summary of Chapter 8 8-1

Figure 1. Organization of Implementing Procedures Document $1-8$ 


\section{Forms}

\section{- Chapter 2 -}

\section{Sample Forms}

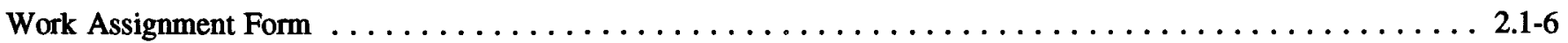

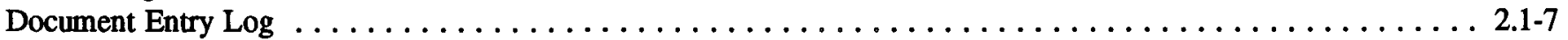

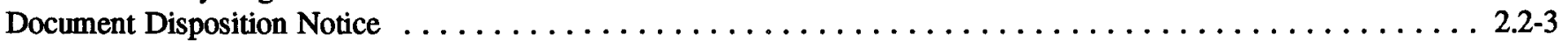

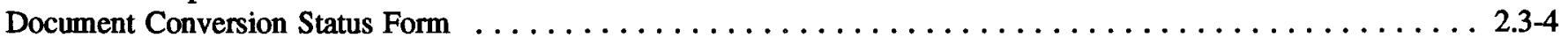

Impact Identification Form (Manual Identification Method)

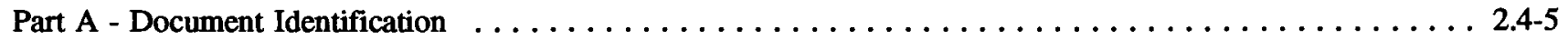

Part B - Impact Identification . . . . . . . . . . . . . .

Impact Identification Form (RECALL Identification Method)

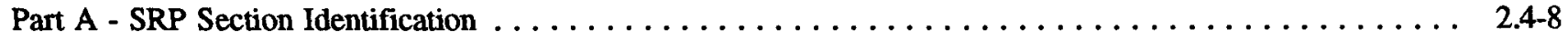

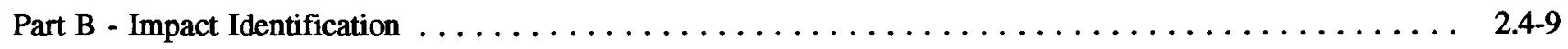

\section{Sample Completed Forms}

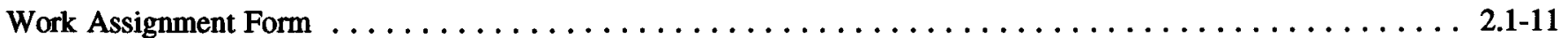

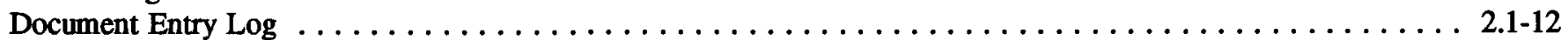

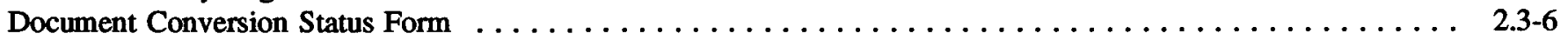

Impact Identification Form (Manual Identification Method)

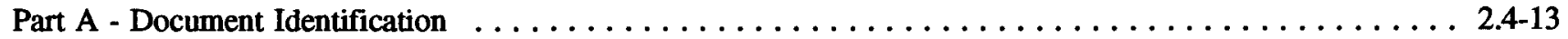

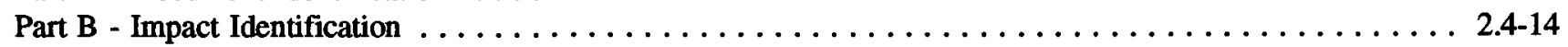

Impact Identification Form (RECALL Identification Method)

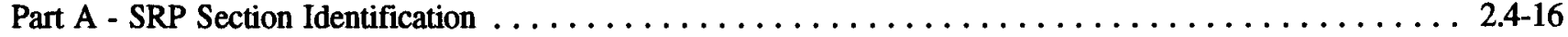

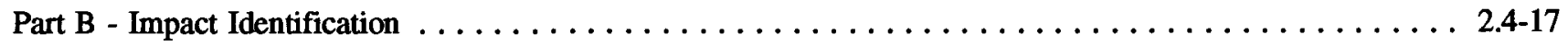

- Chapter 3 -

\section{Sample Forms}

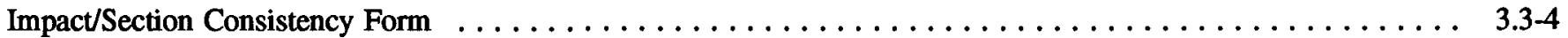

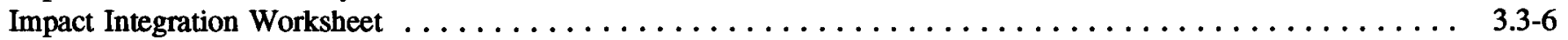

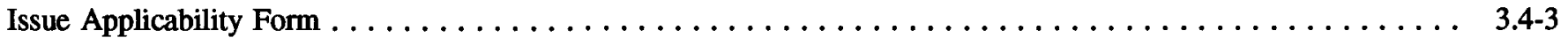

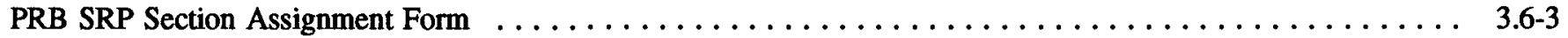

Revision Options Checklist Form

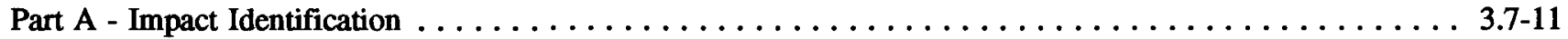

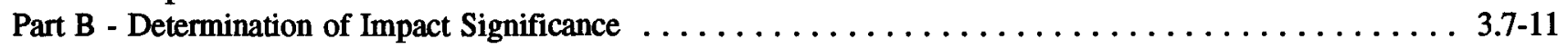

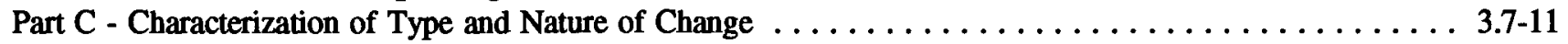

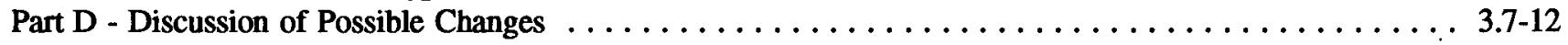

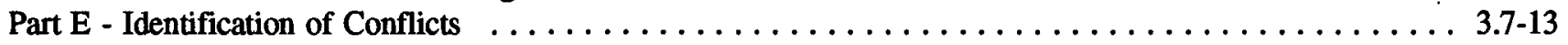

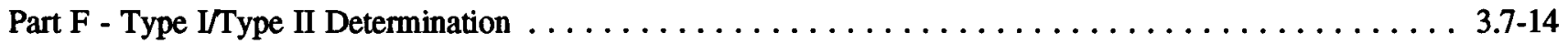

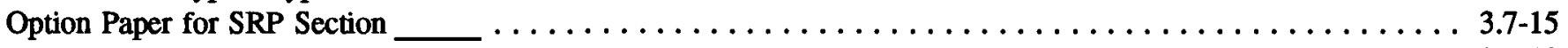

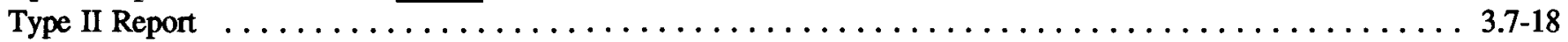

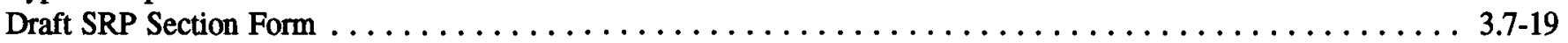

Upgrade Impact Assessment Form

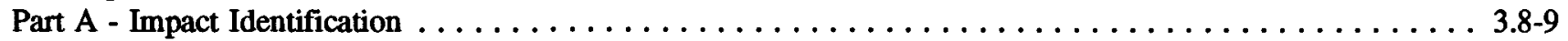

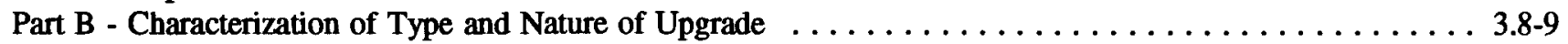

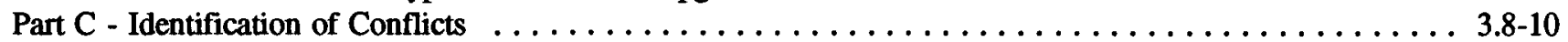

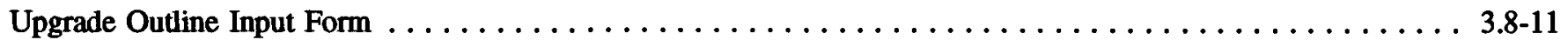

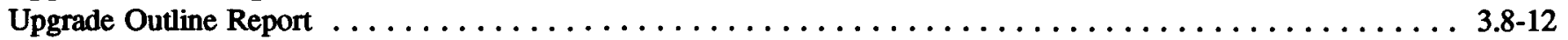




\section{Sample Completed Forms}

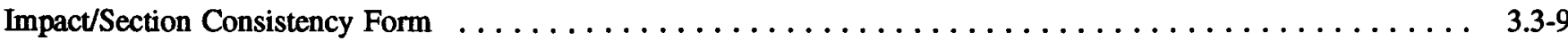

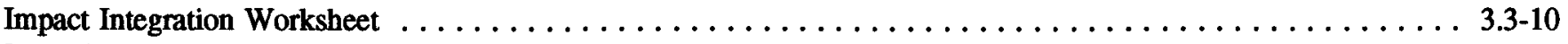

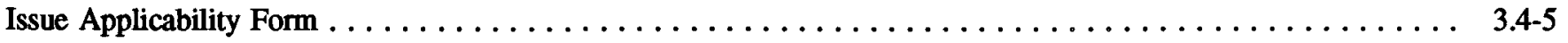

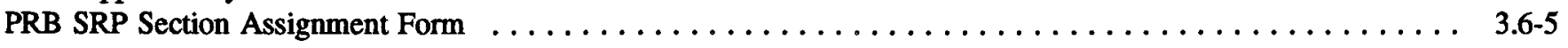

Revision Options Checklist Form (first example)

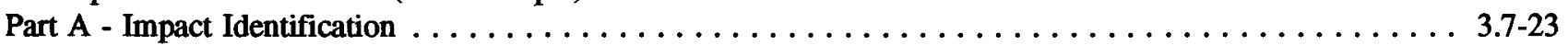

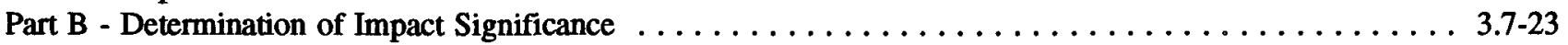

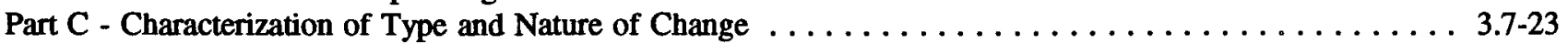

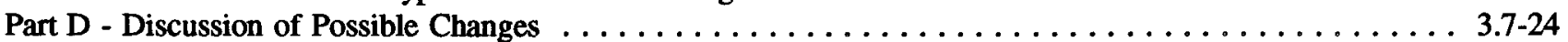

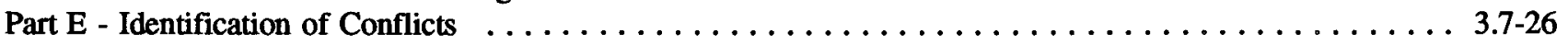

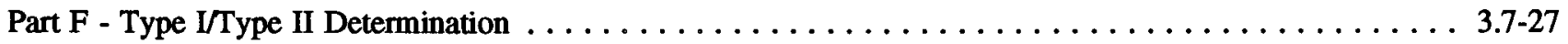

Revision Options Checklist Form (second example)

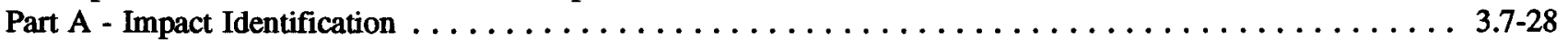

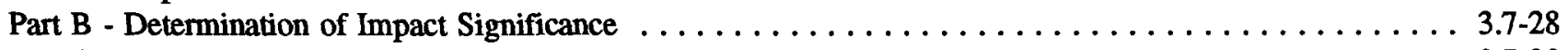

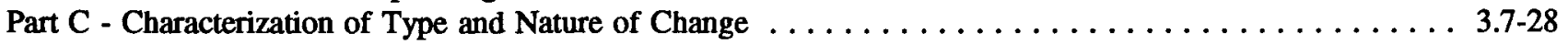

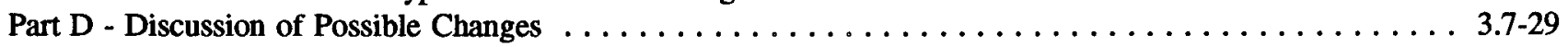

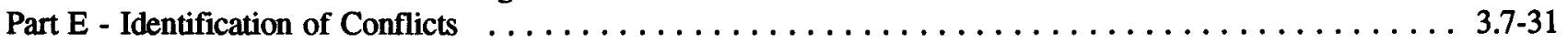

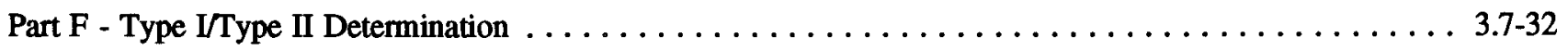

Revision Options Checklist Form (third example)

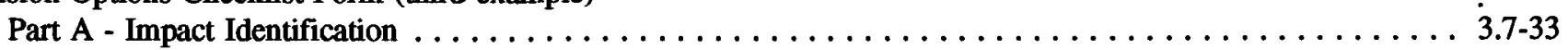

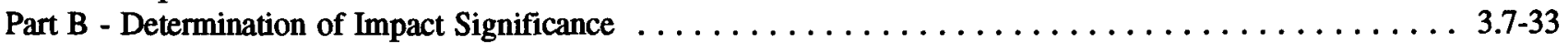

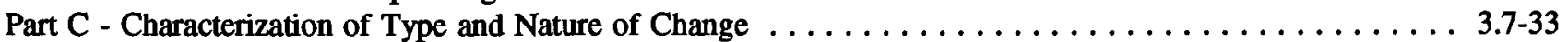

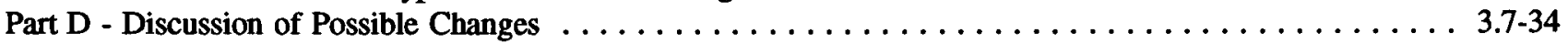

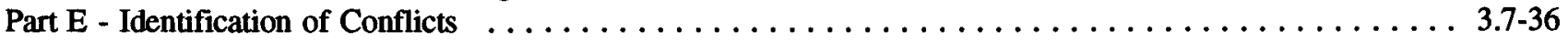

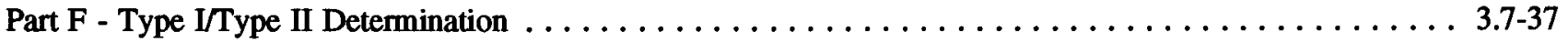

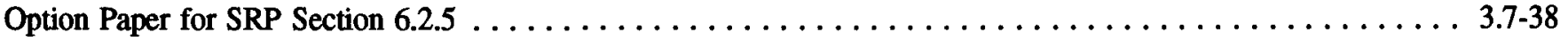

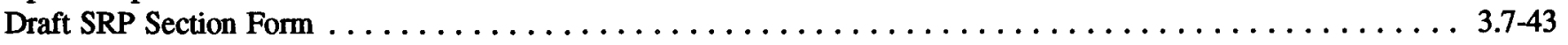

Upgrade Impact Assessment Form

Part A - Impact Identification . . . . . . . . . . . . . . . . . . . . . . . . .

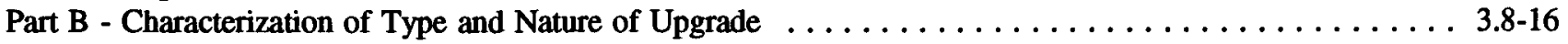

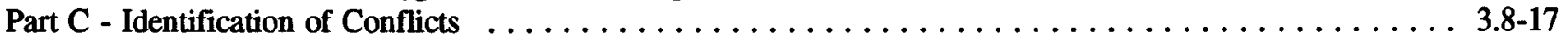

\section{- Chapter 4 -}

\section{Sample Forms}

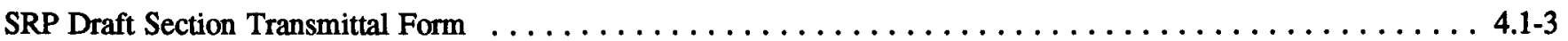

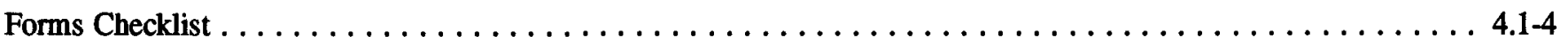

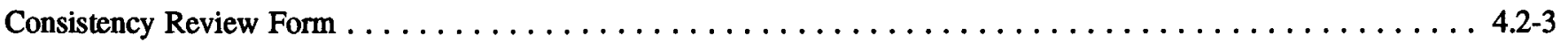

Part A - Requirements Review (Conventional Technology Updates) $\ldots \ldots \ldots \ldots \ldots \ldots \ldots \ldots \ldots \ldots .24$

Part B - Requirements Review (Future Technology Upgrades) $\ldots \ldots \ldots \ldots \ldots \ldots \ldots \ldots \ldots \ldots \ldots \ldots .2 .6 \ldots$

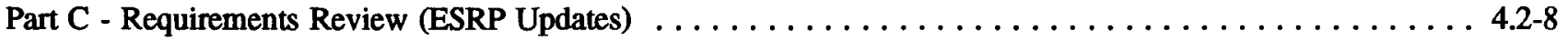

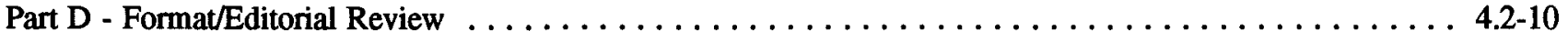

Part E - PRB Review of Non-Technical Changes $\ldots \ldots \ldots \ldots \ldots \ldots \ldots \ldots \ldots \ldots \ldots \ldots \ldots \ldots .2-11$

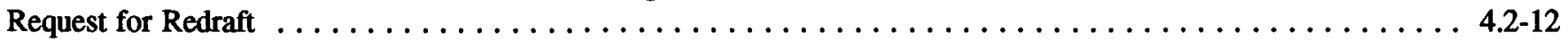

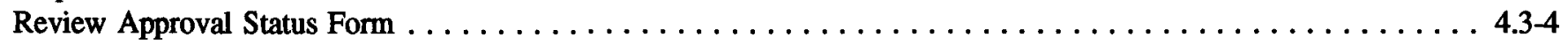

\section{Sample Completed Forms}

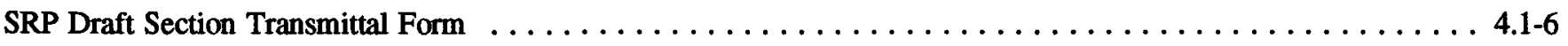

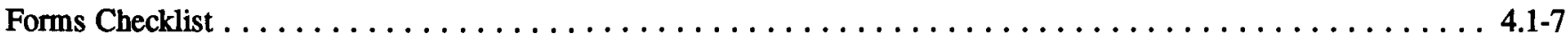

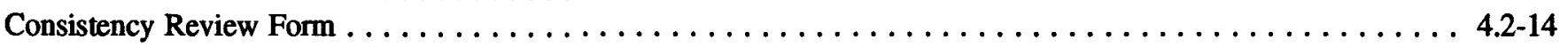

Part B - Requirements Review (Future Technology Upgrades) $\ldots \ldots \ldots \ldots \ldots \ldots \ldots \ldots \ldots \ldots \ldots$ 
Part D - Format/Editorial Review . . . . . . . . . . . . . . . . . . . . . . . . . . . . . $4.2-19$

Part E - PRB Review of Non-Technical Changes . . . . . . . . . . . . . . . . . . . . . . . . . . 4.2-20

Request for Redraft . . . . . . . . . . . . . . . . . . . . . . . . . . . . . . . . . 4.2-21

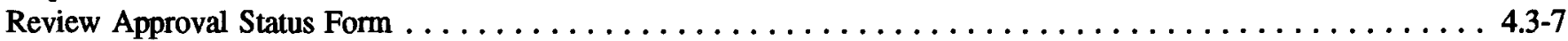

\section{- Chapter 6 -}

\section{Sample Form}

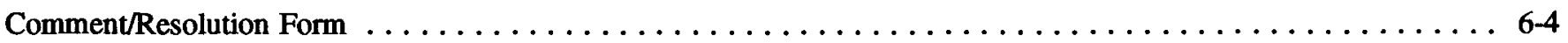

Sample Completed Form

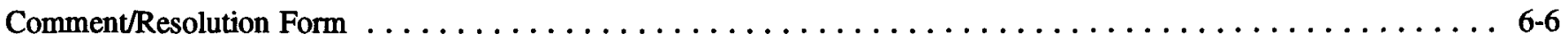

\section{- Chapter 7 -}

\section{Sample Forms}

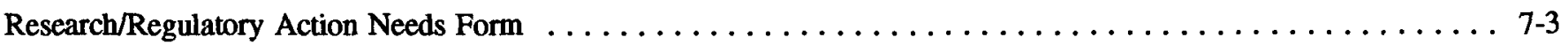

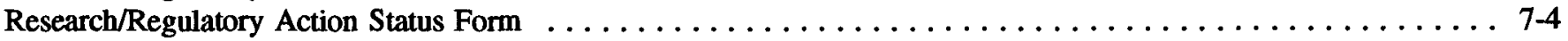

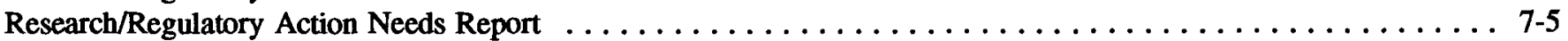

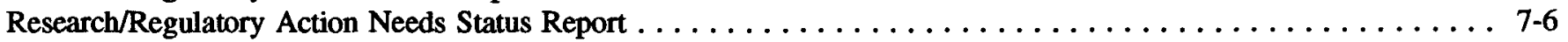

\section{Sample Completed Forms}

Research/Regulatory Action Needs Form $\ldots \ldots \ldots \ldots \ldots \ldots \ldots \ldots \ldots \ldots \ldots \ldots \ldots \ldots \ldots \ldots \ldots \ldots$

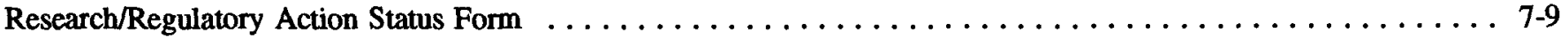

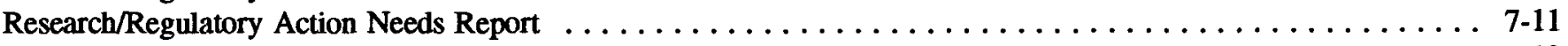

Research/Regulatory Action Needs Status Report $\ldots \ldots \ldots \ldots \ldots \ldots \ldots \ldots \ldots \ldots \ldots \ldots \ldots \ldots \ldots \ldots \ldots$

- Chapter 8 .

\section{Sample Form}

Implementing Procedures Document Receipt Form $\ldots \ldots \ldots \ldots \ldots \ldots \ldots \ldots \ldots \ldots \ldots \ldots \ldots \ldots$

\section{Sample Completed Form}

Implementing Procedures Document Receipt Form $\ldots \ldots \ldots \ldots \ldots \ldots \ldots \ldots \ldots \ldots \ldots \ldots \ldots$ 
-

-

• 


\section{Executive Summary}

The Nuclear Regulatory Commission (NRC) Office of Nuclear Reactor Regulation (NRR) has commenced a program, the Standard Review Plan Update and Development Program (SRP-UDP), to perform an extensive revision of the SRP. The SRP-UDP is described in Chapter 1 of this Implementing Procedures Document (IPD). The IPD establishes procedures to implement the SRP-UDP.

The IPD provides comprehensive guidance, including an overall approach and detailed procedures, for each of the tasks involved in performing the work of the SRP-UDP (except for database and automated SRP development). The IPD is for use by both contractors and NRC staff. For contractors associated with this program, the IPD procedures are controlling. For Primary Review Branches (PRBs), the IPD procedures provide guidance as well as documentation requirements. The documentation requirements will ensure that a historical trail is maintained for the program.

The IPD contains three divisions. The first division, Preparatory Work, includes IPD Sections 1.0 through 3.5. The procedures in this IPD division will be performed primarily by contractors under the direction of the appropriate NRC organization. The second division, Revision of SRP Sections, includes IPD Sections 3.6 through 4.1. The procedures in this IPD division will be performed primarily by the PRBs and contractors of the PRB's choice. The third division, Review, Approval, and Publication, includes IPD Sections 4.2 through 8.0. The procedures in this IPD division will be performed primarily by NRC and the NRC's contractors.

Figure 1 on page 1-8 shows the organization of the IPD. Chapter 1 provides background on the SRP and describes its purpose and scope. Chapter 1 also provides definitions of terms as used in the IPD which differ from common usage. This approach was taken to preclude the use of a variety of terms with the same meaning. The remaining sections of the IPD are grouped into chapters of functionally related tasks: Chapter 2 "Identification and Review of Documents;" Chapter 3, "Update and Upgrade of the SRP for Future Reactor Applications;" Chapter 4, "Review and Approval of SRP Revisions;" Chapter 5, "Integration of the SRP;" Chapter 6, "Independent Review of Work;" Chapter 7, "Identification of Candidates for Future Work;" and Chapter 8, "Control and Revision of IPD." Each of these sections includes a narrative description of the approach to be followed in performing the tasks within its scope as well as detailed procedures. For the sake of clarity and to ensure that the procedures are self sufficient, the procedures are sometimes repetitive. The procedures also include forms for recording data, primarily for use by NRC's contractors in performing tasks within the first division of the IPD (Preparatory Work). The forms associated with procedures in the second IPD division (Revision of SRP Sections) are intended to ensure proper data entry into the automated SRP Modification Database. It is particularly important that revised SRP sections be accompanied by the proper data forms specified in IPD Sections 3.7 and 3.8. 
•

-

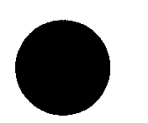




\section{Acronyms}

ACRS Advisory Committee on Reactor Safeguards

BTPs Branch Technical Positions

CRGR Committee to Review Generic Requirements

EDO Executive Director of Operations

EPRI Electric Power Research Institute

ESRP Environmental Standard Review Plan

GSIs Generic Safety Issues

NRC U.S. Nuclear Regulatory Commission

NRR Office of Nuclear Reactor Regulation

PNL Pacific Northwest Laboratory

PRB Primary Review Branch

PTSB Policy Development and Technical Support Branch

SRB Secondary Review Branch

SRP Standard Review Plan

USIs Unresolved Safety Issues 


\subsection{Introduction}

The U.S. Nuclear Regulatory Commission's (NRC's) Standard Review Plan for the Review of Safety Analysis Reports for Nuclear Power Plants (SRP) provides guidance to the Office of Nuclear Reactor Regulation (NRR) staff in performing safety reviews of license applications for the construction, operation, and modification of nuclear power plants. Because the SRP has not been comprehensively updated since 1981 , it does not reflect all subsequent developments in regulatory requirements. In addition, the SRP does not address evolutionary or advanced reactor designs. Further, guidance for other review areas, such as environmental, license renewal, and safeguards is contained in separate standard review plans or other documents. Accordingly, the NRC is undertaking the SRP Update and Development Program for use in the review of future reactor applications to reflect existing Agency requirements and guidance and to add new review criteria to accommodate unique technology or unique application of existing technology in future reactor designs. This Implementing Procedures Document contains the approach and procedures for the tasks to be performed in updating and developing the SRP. Some of these tasks will be performed by NRC staff and others by NRC contractor personnel. However, all regulatory decisions will be made by the NRC. See Table 1 for a summary of this chapter.

\subsection{Background and History of the SRP Including Its Modífications}

The SRP was first issued in 1975 as NUREG-75/087. It evolved from many years of NRC staff experience in establishing safety requirements and applying them in safety evaluations of nuclear facilities. Use of the SRP as a routine tool for the NRC staff in the safety evaluation of nuclear power plants was established by NRR Office Letter No. 2, dated August 12, 1975, which described the SRP as representing "the integrated result of the hundreds of conscious choices made by the staff and by the nuclear industry in developing design criteria and design requirements for nuclear power plants" and "the most definitive basis available for specifying the NRC's interpretation of an 'acceptable level of safety' for light water reactor facilities."

The NRC undertook a major SRP revision program, culminating in a new edition of the SRP issued in July 1981 as NUREG-0800. This revision program had three major objectives: (1) to more completely identify the NRC requirements that are relevant to each review topic, (2) to more fully describe how the review determines that safety requirements have been met, and (3) to incorporate a number of newly established regulatory positions. To accomplish these objectives and to conform the SRP to the revised NRR organization, some SRP sections were added, deleted, split, or combined. NRR Office Letter No. 2, Revision 1, dated November 23, 1981 described this new edition as "the product of the integrated efforts and results of all NRR branches in assuring that each SRP section is congruent with the requirements of current $\mathrm{NRC}$ regulations and conforms with current regulatory guides and previously approved staff requirements and positions."

NRR Office Letter No. 800 dated November 24, 1987 established a procedure for NRC management approval of SRP revisions. Office Letter No. 800 distinguished Type I revisions, which represent accepted NRC positions and are issued without public comment, and Type II revisions, which represent new positions and are issued following public comment.

The SRP has not undergone general modification since 1981, although some individual revisions have been made. As of January 1, 1986, for example, 21 individual SRP sections had been revised since the issuance of NUREG-0800. However, the current SRP does not fully reflect the considerable changes in the regulation of the nuclear reactor industry that have occurred since 1981.

\subsection{Purpose and Scope of the SRP}

The main purposes of the SRP are to ensure the quality and uniformity of staff reviews and to present a well-defined base from which to evaluate future reactor applications. Other important purposes of the SRP are to make information about the NRC's approach to reactor safety regulation widely available and to improve understanding of the staff review process by interested members of the public and the nuclear power industry. In short, the SRP plays a primary role in ensuring that the NRC staff performs an adequate review and that all plants licensed include those features that are essential to protect the public health and safety.

The SRP provides guidance for the safety review of construction permit applications, operating license applications, and requests for amendment of operating licenses. The SRP currently addresses only light water reactors (pressurized-water reactors and boiling-water reactors) of conventional design.

The structure of the SRP reflects its purpose and scope. NRR staff's safety review of nuclear power plant construction permit and operating license applications is based on the information provided in the applicant's Safety Analysis Report required by 10 CFR Section 
Table 1. Summary of Chapter 1

\begin{tabular}{|c|c|c|}
\hline Chapter 1 Sections & Pages & Description of Section Content \\
\hline $\begin{array}{l}\text { Section 1.1: Background and History } \\
\text { of the SRP Including Its } \\
\text { Modifications }\end{array}$ & $1-1$ & $\begin{array}{l}\text { Describes the development and issuance of the } \\
\text { SRP in } 1975 \text { and its early uses. } \\
\text { - Describes periodic revisions and modifications of } \\
\text { the SRP. } \\
\text { - Points out that the SRP has not undergone } \\
\text { comprehensive modification since } 1981 \text {. }\end{array}$ \\
\hline $\begin{array}{l}\text { Section 1.2: Purpose and Scope of } \\
\text { the SRP }\end{array}$ & $1-1$ & $\begin{array}{l}\text { Describes several purposes of the SRP. } \\
\text { Describes the organization of the SRP into } \\
\text { chapters, sections and sub-sections. }\end{array}$ \\
\hline $\begin{array}{l}\text { Section 1.3: Scope and Purpose of } \\
\text { This Implementing Procedures } \\
\text { Document }\end{array}$ & $1-4$ & $\begin{array}{l}\text { - Describes the need to update and upgrade the SRP. } \\
\text { Describes the need for detailed implementation } \\
\text { procedures and the intent to revise the SRP as } \\
\text { needed to keep it current. }\end{array}$ \\
\hline $\begin{array}{l}\text { Section 1.4: Revision of This } \\
\text { Implementing Procedures Document }\end{array}$ & $1-4$ & $\begin{array}{l}\text { Emphasizes that this Implementing Procedures } \\
\text { Document is a living document and will be revised } \\
\text { periodically. }\end{array}$ \\
\hline Section 1.5: Definitions & $1-4$ & $\begin{array}{l}\text { - Provides definitions to assist the reader in } \\
\text { understanding the detailed guidance. }\end{array}$ \\
\hline $\begin{array}{l}\text { Section 1.6: NRR Responsibilities } \\
\text { Regarding SRP Update and } \\
\text { Development }\end{array}$ & $1-6$ & $\begin{array}{l}\text { Describes NRR positions and responsibilities } \\
\text { associated with implementation of this } \\
\text { Implementing Procedures Document. }\end{array}$ \\
\hline $\begin{array}{l}\text { Section 1.7: Overview of This } \\
\text { Implementing Procedures Document }\end{array}$ & $1-6$ & $\begin{array}{l}\text { Identifies a sequence of tasks and indicates where } \\
\text { to find the detailed procedures to be followed to } \\
\text { update and modify the SRP. } \\
\text { - Provides a graphic illustration of this sequence in } \\
\text { Figure } 1 \text {. }\end{array}$ \\
\hline
\end{tabular}

50.34--in the case of a construction permit application, the Preliminary Safety Analysis Report; in the case of an operating license application, the Final Safety Analysis Report. In both cases, the Safety Analysis Report is the primary means by which the applicant provides the information to enable the reviewing staff to determine whether the proposed plant can be built and operated without undue risk to the health and safety of the public. This determination is documented in the Safety Evaluation Report prepared by the reviewing staff at the conclusion of the review.

The general requirements for the technical content of a Safety Analysis Report are specified in 10 CFR Section 50.34. Applications for design certifications and combined licenses must meet the technical content requirements of 10 CFR Sections 52.47 and 52.79, respectively, which incorporate by reference the applicable requirements of $10 \mathrm{CFR} 50.34$. Regulatory Guide 1.70, "Standard Format and Content of Safety
Analysis Reports for Nuclear Power Plants - LWR Edition," provides an acceptable approach for meeting the requirements of $10 \mathrm{CFR}$ Section 50.34. The numbering of SRP sections corresponds to the sections of the Standard Format specified in Regulatory Guide 1.70. As shown in Table 2, the SRP sections are grouped into chapters, each of which addresses a general topic.

Each section of the SRP is organized into six subsections, as follow:

Subsection I - Areas of Review, describes the scope of the review for which that SRP section provides guidance: that is, it specifies what is being reviewed by the NRR branch having primary review responsibility (primary review branch). This subsection contains a description of the systems, components, analyses, data, or other information on which the review will be based. It also identifies inputs to be provided by other NRR branches (secondary review branches) necessary for the primary 
Table 2. Chapters of the Standard Review Plan

\begin{tabular}{|c|c|c|c|}
\hline 1. & $\begin{array}{l}\text { Introduction and General } \\
\text { Description of Plant }\end{array}$ & 10. & $\begin{array}{l}\text { Steam and Power Conversion } \\
\text { System }\end{array}$ \\
\hline 2. & Site Characteristics & 11. & $\begin{array}{l}\text { Radioactive Waste } \\
\text { Management }\end{array}$ \\
\hline 3. & $\begin{array}{l}\text { Design of Structures, } \\
\text { Components, Equipment, and } \\
\text { Systems }\end{array}$ & 12. & Radiation Protection \\
\hline 4. & Reactor & 13. & Conduct of Operations \\
\hline 5. & $\begin{array}{l}\text { Reactor Coolant System and } \\
\text { Connected Systems }\end{array}$ & 14. & Initial Test Program \\
\hline 6. & Engineered Safety Features & 15. & Accident Analysis \\
\hline 7. & Instrumentation and Controls & 16. & Technical Specifications \\
\hline 8. & Electric Power & 17. & Quality Assurance \\
\hline 9. & Auxiliary Systems & 18. & Human Factors Engineering \\
\hline
\end{tabular}

review branch to complete its review under this SRP section. The SRP Update and Development Program will ensure that possible concerns (e.g., probabilistic risk assessments, operational experience, health physics, fire protection, systems interaction, equipment aging) will be identified and captured in each section.

Subsection II - Acceptance Criteria, states the purpose of the review, and identifies which NRC requirements are applicable. The SRP Update and Development Program will add a technical rationale for selecting each Acceptance Criterion. The SRP Update and Development Program will also add separate Acceptance Criteria for 60-year design life review, consistent with SECY 89-013.

Subsection III - Review Procedures, identifies the general steps that the reviewer is to follow in performing the review.

Subsection IV - Evaluation Findings, states the type of conclusion that the reviewer is expected to reach following completion of the review. This conclusion is to be included in the staff's Safety Evaluation Report, which combines the staff's findings under all the SRP sections.

Subsection V - Implementation, provides guidance to applicants and licensees regarding the staff's plans for use of the SRP section. It generally states that unless the applicant proposes an acceptable alternative for demonstrating compliance with applicable requirements, the staff will use the method described in the SRP section.
Subsection VI - References, lists the references used in the review process.

The SRP is intended to provide complete an comprehensive guidance for staff review of applicant submittals within its scope. It is also intended to encompass all NRC requirements within the scope of staff review. While new requirements and guidance may be issued for an interim period, they should be incorporated into the SRP during subsequent revisions.

Guidance addressing other aspects of the NRC staff review of nuclear power plant license applications is contained in other standard review plans or similar documents. For example, environmental reviews are conducted according to NUREG-0555 (the Environmental Standard Review Plan, or ESRP); license renewal reviews are (or will be) conducted according to NUREG-1299; environmental reviews for license renewal are (or will be) conducted according to NUREG-1425; and other review areas rely on their own standard review plan or other documents that serve the same purpose. In this Implementing Procedures Document, Standard Review Plan refers to NUREG-0800 unless the context indicates otherwise.

The ESRP (NUREG-0555) is structured somewhat differently from NUREG-0800. Each ESRP section consists of six subsections. These are described briefly below: 
Subsection I - Purpose and Scope, describes the environmental area or topical concern to be addressed, and establishes the purpose and goals of the review.

Subsection II - Required Data and Information, provides a list of the data and information that the reviewer needs in order to assess environmental impacts and compliance, and provides the typical sources of this information (applicant's environmental report, governmental agency documents and sources, site visit, and the like).

Subsection III - Analysis Procedure, provides the steps to be followed by the reviewer in assessing the environmental information described in Subsection II. Guidance is provided in determining environmental impacts associated with construction and operation of a power plant and in establishing necessary mitigation measures to minimize such impacts.

Subsection IV - Evaluation Findings, states the type of evaluation findings appropriate when a reviewer concludes a satisfactory review.

Subsection V - Input to the Environmental Statement, describes the types of information that are generally to be included in the environmental statement prepared by the staff. It also describes informational interfaces between the reviewer of the subject SRP section and reviewers of other sections.

Subsection VI - References, lists the references used and is helpful in the review process.

The Standard Review Plan for license renewal (NUREG-1299) is structured essentially the same as NUREG-0800, and the ESRP for license renewal is structured essentially the same as NUREG-0555.

\subsection{Scope and Purpose of This Implementing Procedures Document}

For several reasons, the NRC has concluded that the SRP requires a major revision. First, as indicated above, the revisions to the SRP that have been made since the last major revision in 1981 do not fully reflect changes in NRC requirements or the nuclear industry that have occurred in the meantime. Second, the limited scope of the current SRP precludes its effective use in conducting safety reviews of applications for the new types of nuclear power plants now under consideration. The SRP should be updated and upgraded for use in the review of future reactor applications to reflect existing Agency requirements and guidance and to add new review criteria to accommodate unique technology or unique application of existing technology in future reactor designs. Third, guidance for certain review areas exists in separate standard review plans or other documents. These other standard review plans, such as the ESRP (NUREG-0555), will also be updated and put into the standard NUREG-0800 format. These documents will ultimately be merged into a single consistent SRP document set to facilitate the various types of reviews conducted by NRR staff. The decision as to the standard review plans that will actually be incorporated will be determined by NRR program management.

This Implementing Procedures Document provides comprehensive guidance, including an overall approach and detailed procedures, for each of the tasks involved in updating, developing, and maintaining the SRP. The NRC intends that all NRC staff as well as all contractor staff involved in the SRP Update and Development Program (both initial and future updates) will follow this Implementing Procedures Document. Because both NRC staff and contractor staff are involved in this effort, some procedures and forms in this Implementing Procedures Document will be used by NRC staff, some by one or more contractors, and some by both NRC and contractor staff.

\subsection{Revision of This Implementing Procedures Document}

This Implementing Procedures Document will be a living document. It will be used initially to upgrade the SRP for future reactor applications, and to incorporate other review areas into a more comprehensive review document. Thereafter, the Implementing Procedures Document will be used to keep the SRP current. Accordingly, the Implementing Procedures Document itself will be revised over time to reflect (1) the transition from the initial major SRP update and development effort to a maintenance-oriented phase, (2) the experience and knowledge gained during use of the Implementing Procedures Document, and (3) evolving NRC requirements and priorities. In order to produce high quality and internally consistent SRP modifications, this document must be closely followed by all NRC and contractor staff involved in modifying the SRP.

\subsection{Definitions}

\section{NRC Organizations}

The Policy Development and Technical Support Branch (PTSB), NRR, is the branch responsible for managing the SRP Update and Development Program.

Primary Review Branch (PRB) with respect to a particular SRP section means the NRR branch that is 
assigned primary responsibility for conducting the review within the scope of the SRP section. The Primary

Review Branch is also responsible for determining whether the SRP section is current and, if it is to be updated, what organization will perform the work.

Secondary Review Branch (SRB) with respect to an SRP section means a branch which has an interest or responsibility for technical issues found in the SRP section. The Secondary Review Branch provides review and comment on draft revisions of SRP sections.

A matrix identifying PRBs and SRBs for each SRP section is included in Office Letter 800.

\section{Databases}

SRP Modification Database means the database being established by PTSB to catalog SRP modification-related data and information, to track SRP modification activities, and to facilitate administrative and management control over the SRP Update and Development Program.

SRP Reference Document Database means the database being established by PTSB to store full text versions of documents being used in the SRP Update and Development Program.

Updated SRP Database means the system being developed by PTSB to contain the updated and upgraded SRP and to facilitate subsequent revisions.

\section{Position Titles}

Analyst refers to the individual performing work under any procedure except Procedure 6.0 and excluding management activities (e.g., assignment of analysts).

Reviewer refers to the individual who performs an independent review of work according to the guidance provided in Procedure 6.0.

\section{Sections}

SRP Sections, for purposes of the SRP Update and Development Program, are the fundamental units of the SRP. They are numbered in the form (N)N.N or (N)N.N.N or (N)N.N.N.N (e.g., 12.1, 3.8.1, or 5.2.1.1) and contain the complete review procedures for a given review topic. Each SRP section currently contains six subsections, numbered from I through VI. SRP sections contain appendices, which are also considered part of the SRP section. As currently configured, Branch Technical Positions (BTPs) are not supplements to one or more SRP sections, but BTPs are themselves considered SRP sections. Depending upon the exact format for the SRP ultimately selected by NRR, SRP sections may include addenda that address particular reactor designs.

Impact is a document or a part of a document that can be used for updating or upgrading the SRP because it meets one or more of the six criteria specified in Section 2.4.1 of this Implementing Procedures Document.

Conflicts refer to conflicts between impacts (source documents) and not between impacts and the SRP.

\section{Reactor Terminology}

Evolutionary Reactors are light water reactors that include some advanced design (such as the General Electric ABWR, the ABB/Combustion Engineering System 80+, and the Westinghouse SP/90). (The particular reactors meeting this definition are subject to change.)

Advanced Reactors include both passive light water reactors (such as the Westinghouse AP 600, the ASEA/Brown Boveri PIUS, the General Electric SBWR, and the $A B B / C o m b u s t i o n$ Engineering SIR) and passive non-light water reactors (such as the AECL CANDU-3, the General Atomics MHTGR, and the General Electric PRISM). (The particular reactors meeting this definition are subject to change.)

Future Reactors refers to both evolutionary and advanced reactors.

\section{Type I/II Revisions}

Type I Revisions to the SRP are revisions that reflect accepted NRC positions or are administrative in nature and are therefore issued without public comment.

Type II Revisions to the SRP are revisions that incorporate proposed new or revised requirements, positions, or guidance that have not been reviewed and approved, including new SRP sections, and are issued for public comment.

\section{Other}

Development of an SRP section refers to the preparation of a potential new SRP section.

Update refers to a revision to an SRP section for purposes of making an SRP section reflect current technology and current NRC requirements and guidance.

Option Paper refers to a report provided to the PRB to summarize the impacts associated with the updating of an SRP section. For each impact, the Option Paper contains 
suggested options for handling the impact and arguments pro and con associated with each option.

Upgrade refers to a revision to an SRP section for purposes of accommodating review needs for evolutionary or advanced reactor designs.

Upgrade Outline refers to a report provided to the PRB to summarize potential upgrades to an SRP section to accommodate the review needs for evolutionary and advanced reactor designs.

Endorsement in the sense that the NRC endorses industry codes and standards means that the solutions and approaches contained therein are acceptable to the NRC staff, but that they are not required as the only possible solutions and approaches. Applicants may seek to demonstrate that other solutions and approaches are acceptable.

\subsection{NRR Responsibilities Regarding SRP Update and Development}

NRR staff responsibilities regarding SRP modification are as follow:

\section{Director, NRR}

- Establishes and coordinates NRR SRP policies, guidance, and programs.

Associate Director for Inspection and Technical Assessment, NRR

- Assigns Primary and Secondary Review Branch responsibilities for SRP sections to branches within the associate directorship.

Director, PMAS, NRR

- Approves all SRP revisions and additions.

Policy Development and Technical Support Branch, NRR

- Is responsible for the overall management and coordination of the SRP Update and Development Program.

Primary Review Branch, NRR

- Is responsible for revisions and additions to assigned SRP sections and maintains this primary responsibility even when another NRR branch or NRC office performs the majority of the work involved in the revision.
- Is responsible for determining whether an SRP section requires revision and selects one of the following options for performing the revision: (1) performs the SRP revision in-house; (2) enlists a contractor of its choosing to either perform or assist in performing the revision; (3) requests the Policy Development and Technical Support Branch, NRR, to prepare, with contractor assistance, an initial draft of the revision. The PRB remains responsible for revision of the section regardless of the option chosen.

- Ensures that the appropriate NRR organizations and other NRC offices are given the opportunity to participate in the updating and upgrading of SRP sections.

- Reviews all proposed changes to the SRP to ensure that they are consistent with applicable NRC policies and guidance.

- Coordinates its activities pertaining to revisions or additions with appropriate Secondary Review Branches.

Secondary Review Branch, NRR

- Is responsible for an assigned technical area with respect to an SRP section.

- Provides proposed changes and review and comment on draft changes prepared by others to the Primary Review Branch in a timely manner.

\section{Other NRC Organizations}

- Review and provide comments on the Implementing Procedures Document.

- Respond to PRB requests for assistance or review.

- Address identified conflicts or needs for regulatory action, research, or codes/standards development.

- Review information in the SRP Modification Database, as appropriate, to maintain cognizance of ongoing activities performed by other NRC organizations.

\subsection{Overview of This Implementing Procedures Document}

This Implementing Procedures Document is intended to provide complete guidance for all NRC and contractor management and staff involved in updating and upgrading the SRP as part of the SRP Update and Development Program. It identifies the sequence of tasks to be 
performed to update and upgrade the SRP and establishes a general approach and specific procedures for the accomplishment of each task.

The organization of this Implementing Procedures Document is depicted in Figure 1. The procedures are grouped into chapters of functionally related tasks. Following this Introduction (Chapter 1), Chapter 2 contains the procedures for identifying the documents that will be used in updating and upgrading the SRP (Procedures 2.1 and 2.2), obtaining those documents and entering them into the SRP Reference Document Database (Procedure 2.3), reviewing the documents in order to identify information potentially pertinent to updating and upgrading the SRP (Procedure 2.4), and ascertaining the status of industry-consensus codes and standards (Procedure 2.5). Chapter 3 contains the procedures for updating and upgrading the SRP to include current requirements and guidance and to include the unique technology and unique application of existing technology in future reactor designs (Procedures 3.1 through 3.8). Chapter 4 contains the procedures for review and approval of SRP revisions (Procedures 4.1 through 4.3). The revised and newly established SRP sections are merged into an integrated SRP through the procedure specified in Chapter 5 . Work is independently reviewed in accordance with the procedure set forth in Chapter 6. Information identified in the course of implementing any of these procedures may indicate a need for regulatory action other than SRP updating or upgrading, such as research or rulemaking. Chapter 7 contains a procedure for identifying such candidates for future work. Finally, Chapter 8 specifies the procedures for controlling and revising this Implementing Procedures Document itself.

NOTE: Successful completion of the SRP Update and Development Program requires the recording and entry into the SRP Modification Database of certain information specified in the procedures in this document. Therefore, it is required that all organizations participating in this program ensure that all procedurally mandated forms are completed and forwarded to the PTSB. 


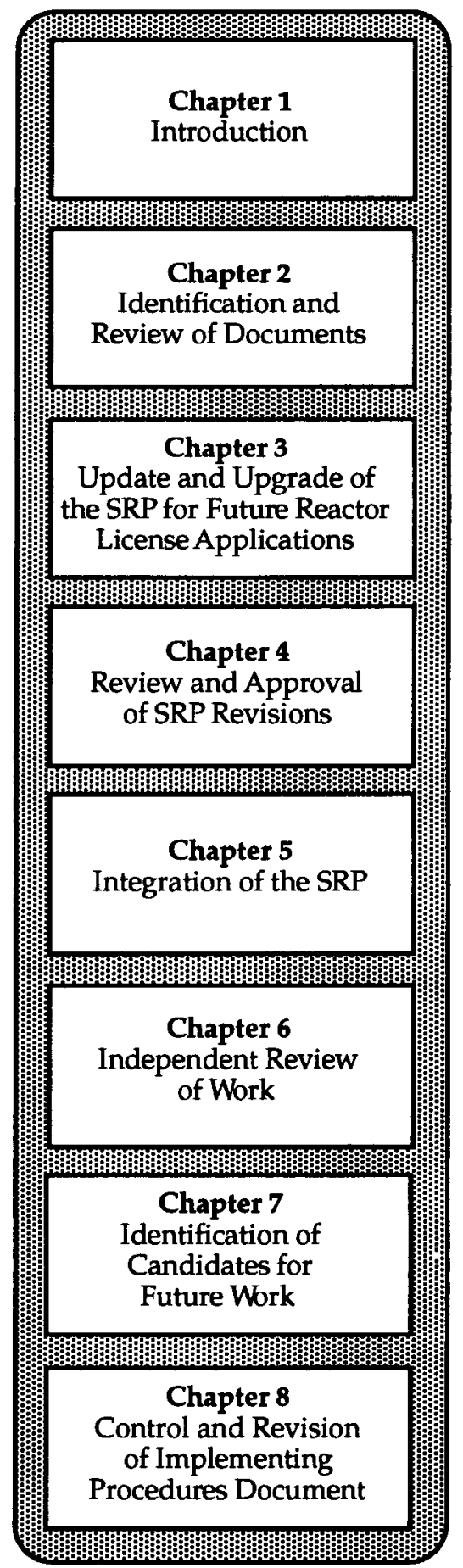

Figure 1. Organization of Implementing Procedures Document 


\subsection{Identification and Review of Documents}

A prerequisite for updating and upgrading the SRP is identifying and reviewing documents that contain requirements, guidance, staff positions, and other potentially relevant information. Chapter 2 specifies the processes for identifying, obtaining, and reviewing documents that contain such information, which should be reflected in the SRP. The information from these document reviews is then used in the subsequent SRP section updating and upgrading tasks described in the remaining chapters of this Implementing Procedures Document.

Chapter 2 is organized as follows, and is summarized in Table 3.

- Procedures are presented for identifying documents pertinent to updating and upgrading the SRP (Section 2.1).
- Procedures are presented that provide an opportunity for personnel not specifically assigned document identification responsibilities to identify potentially relevant documents (Section 2.2).

- Procedures are presented for obtaining documents, converting hard-copy documents into electronic form, and transferring documents to the SRP Reference Document Database (Section 2.3).

- Procedures are presented for reviewing documents to identify specific potential impacts on the SRP (Section 2.4).

- Procedures are presented for identifying industryconsensus codes and standards pertinent to updating and upgrading the SRP (Section 2.5). 
Table 3. Summary of Chapter 2

\begin{tabular}{|c|c|c|}
\hline Chapter 2 Sections & Pages & Description of Section Content \\
\hline Section 2.1: Identifying Documents & 2.1-1 & $\begin{array}{l}\text { Presents the types and sources of documents with } \\
\text { potential SRP impacts. } \\
\text { - Presents criteria and procedures for identifying } \\
\text { individual documents of those types. } \\
\text { - Presents procedures for recording bibliographic and } \\
\text { other summary information about the document } \\
\text { and entering that information into the SRP } \\
\text { Modification Database. }\end{array}$ \\
\hline $\begin{array}{l}\text { Section 2.2: Identifying Documents } \\
\text { By Other Staff }\end{array}$ & $2.2-1$ & $\begin{array}{l}\text { Presents procedures for personnel not assigned to } \\
\text { perform SRP Update and Development Program } \\
\text { document review to identify documents potentially } \\
\text { relevant to the update and upgrade effort. }\end{array}$ \\
\hline Section 2.3: Obtaining Documents & $2.3-1$ & $\begin{array}{l}\text { - Presents procedures for obtaining documents. } \\
\text { - Presents procedures for conversion of documents to } \\
\text { electronic form. } \\
\text { - Presents document control procedures. } \\
\text { - Presents procedures for the transfer of documents } \\
\text { into the SRP Reference Document Database. }\end{array}$ \\
\hline $\begin{array}{l}\text { Section 2.4: Identifying Potential } \\
\text { SRP Impacts }\end{array}$ & $2.4-1$ & $\begin{array}{l}\text { - Establishes criteria for determining what constitutes } \\
\text { an SRP impact. } \\
\text { - Presents procedures for reviewing documents to } \\
\text { identify SRP impacts. } \\
\text { - Presents a method of identifying impacts from the } \\
\text { documents in the SRP Reference Document } \\
\text { Database that are relevant to specific SRP sections. }\end{array}$ \\
\hline $\begin{array}{l}\text { Section 2.5: Ascertaining the Status } \\
\text { of Industry-Consensus Codes and } \\
\text { Standards }\end{array}$ & $2.5-1$ & $\begin{array}{l}\text { - Presents procedures for re-evaluating references to } \\
\text { codes and standards cited in regulatory documents. } \\
\text { - Presents procedures for identifying unreferenced } \\
\text { codes and standards of interest. } \\
\text { - Presents procedures for assessing the need for } \\
\text { additional codes or standards in future applications. } \\
\text { - Presents procedures for comparing commitment to } \\
\text { codes and standards in the EPRI Requirements } \\
\text { Document with NRC positions. }\end{array}$ \\
\hline
\end{tabular}




\subsection{Identifying Documents}

\subsubsection{Approach}

Information potentially relevant to updating and upgrading the SRP is contained in numerous NRC documents as well as documents originating from the NRC's contractors, industry, and the technical community. The purpose of Procedure 2.1 is to identify the specific documents that will be obtained and reviewed for "SRP impacts" through implementation of Procedures 2.3 and 2.4 .

To facilitate the document identification process, Procedure 2.1 specifies several categories of document sources or types judged likely to contain relevant documents. Through implementation of Procedure 2.1, the analyst examines each document category to identify specific documents that meet each of the three criteria listed below for subsequent acquisition and review.

1. Documents must have the potential to provide information that will be useful in updating or upgrading SRP sections for future nuclear power plant applications, making Type I versus Type II revision determinations, establishing bases for Acceptance Criteria, or upgrading SRP sections for unique technology or unique applications of existing technology in future reactor designs.

2. Documents must contain regulatory requirements or non-mandatory guidance or otherwise have sufficient technical authority to merit consideration for use in updating or developing the SRP. Documents are generally considered to have sufficient technical authority if they meet one or more of the following criteria:

- The document was issued by the Commission or staff for use by staff or licensees (this includes reports and generic correspondence).

- The document is a formal report of work performed by a contractor for the NRC and has been endorsed by the NRC in the licensing process.

- The document was prepared by an organization that clearly has the expertise to address the technical issues involved (e.g., vendor reports describing their designs or product lines) and supports stated NRC positions.

- The document was prepared by individuals recognized as experts in their fields or has been peer reviewed by such individuals and has direct reference to NRC positions.
3. Documents must have generic applicability. The only situation in which a non-generic document might be considered is when a non-generic document is specifically referenced in a generic document that meets the first two criteria above.

The following document categories have been judged likely to contain documents meeting all of the above criteria 1-3. Documents within each category should be identified for subsequent review.

\section{Documents in the RECALL System}

Certrec Corporation's RECALL computerized database includes many of the NRC's principal regulatory documents:

- NRC Regulations (Rules). The NRC's rules in 10 CFR Parts 0-199 include the basic regulatory requirements governing the licensing and operation of nuclear power plants.

- Standard Review Plan. RECALL contains the Standard Review Plan itself. Included are Branch Technical Positions and appendices, which set forth solutions and approaches determined to be acceptable in the past by the NRC staff in dealing with a specific safety problem or safety-related design area for some sections of the SRP. These solutions and approaches are codified in this form to enable NRC staff reviewers to take uniform and well-understood positions on recurring safety issues. The trend is toward deletion of Branch Technical Positions, which are being changed to SRP section appendices or incorporated as part of the SRP section itself.

- Regulatory Guides. Regulatory Guides are published by the NRC to inform applicants, licensees, the nuclear industry, and the public of various solutions and approaches to meeting requirements that are acceptable to the NRC staff. However, they are not required as the only possible solutions and approaches. Regulatory Guides are issued in ten subject areas known as "divisions." All ten divisions are in RECALL.

- NRC Bulletins. Bulletins transmit information to licensees regarding safety, safeguards, or environmental matters and may request specified actions and a written response. Compliance bulletins request action from licensees regarding safety matters that are necessary to continue or achieve compliance with existing requirements and positions. Emergency bulletins request immediate action from licensees that are necessary to maintain or achieve an adequate level of public health and safety protection. 
- NRC Circulars. Now discontinued, NRC Circulars were issued to licensees to provide information on a somewhat less urgent basis than Bulletins.

- NRC Generic Letters. Generic Letters are prepared to inform applicants and licensees of regulatory requirements related to licensing and schedules for compliance. These letters include requests for licensee information pursuant to $10 \mathrm{CFR} \S 50.54(\mathrm{f})$ and are also used to clarify NRC policy.

- NRC Information Notices. Information Notices are issued to licensees to provide information that may be relevant to safety, safeguards, or environmental issues.

- NUREG Abstracts. NUREG reports include formal technical reports prepared by NRC staff (NUREG and NUREG/BR reports) and NRC contractors (NUREG/CR reports), as well as conference proceedings (NUREG/CP reports). Many address topics related to nuclear reactor safety. RECALL contains abstracts of NUREG reports.

- NUREG-0737. The TMI Action Plan, issued as NUREG-0737, describes certain NRC decisions and actions taken or to be taken as a result of the Three Mile Island accident.

- NRC Policy Statements. From time to time, the NRC issues Policy Statements, which authoritatively set forth the NRC's position on matters within the scope of the policy.

All documents in RECALL meeting criteria 1-3 above should be identified. (In addition, other communications with licensees that could have generic application, such as certain Director's Letters that were issued before 1978, should be identified.)

Several of the document types included in the RECALL database will not be considered in the SRP Update and Development Program because they are not generic in scope, do not represent staff resolutions of issues, or do not otherwise meet the three criteria set forth above. The document types not to be considered include Licensee Event Reports, Systematic Assessment of Licensee Performance reports, and the NRC Enforcement Manual.

\section{Industry Codes and Standards}

The SRP itself, as well as many of the other documents in RECALL, makes frequent reference to the codes and standards of such industry and professional groups as the American National Standards Institute, the American Nuclear Society, the American Society for Testing and
Materials, the American Society of Civil Engineers, the American Society of Mechanical Engineers, the Institute of Electrical and Electronics Engineers, and many others.

Consistent with copyright restrictions, pertinent provisions of currently referenced versions of these codes and standards will be available in the SRP Reference Document Database as a result of implementation of Procedure 2.5.

\section{Other Referenced Documents}

The SRP and the other documents in RECALL contain numerous references to other documents that support stated positions or otherwise contain useful, related information. Such referenced documents should be included in the document search. It is anticipated that many of the referenced documents will be identified directly in RECALL or will be industry codes or standards. However, several other types of referenced documents could also be useful, for example:

- Other Contractor, Vendor, and Owner Group Reports. NRC's contractors as well as reactor vendors and owner groups prepare technical reports that may have potential SRP impacts--that is, documents that support NRC positions or NRC-endorsed guidance.

- Technical Literature. The scientific and technical literature that supports NRC positions may include information with potential SRP impacts not included in the above document types. This literature includes articles in technical journals, staff and contractor reports issued by other federal agencies (such as the Department of Energy, the Environmental Protection Agency, the National Bureau of Standards, the National Oceanic and Atmospheric Administration, the Army Corps of Engineers, and others), monographs, and conference proceedings.

Any Regulatory Guide, NUREG Report, other contractor, vendor, or owner group report, or other item of technical literature that is referenced in one or more previously identified RECALL documents and that meets criteria 1-3 should be identified, with particular attention to later revisions of such documents.

NUREG-0933, which summarizes USIs, GSIs, and Three Mile Island action items, is a document that will be reviewed for impacts on the SRP.

\section{NRC "Rules Packages"}

Under the Administrative Procedure Act, the NRC ordinarily follows "notice and comment" procedures in adopting regulations. Depending on the subject matter, 
$\mathrm{NRC}$ regulations are promulgated either by the EDO or by the Commission. In both cases, appropriate "rulemaking paper" is prepared and reviewed internally. The NRC then begins the public part of the process by publishing in the Federal Register an advance notice of proposed rulemaking or may move directly to publication of a notice of proposed rulemaking. The notice of proposed rulemaking includes the full text of proposed regulations, together with background materials, including an explanation of the need for the proposed requirements, a justification for the particular approach proposed, and a call for comments from the public. This discussion, which accompanies the proposed rule, is often referred to as the "preamble." (Previously, the preamble was also known as the "statement of considerations.") Following receipt of public comments, the NRC analyzes them, revises the proposed regulations if appropriate, and adopts them as a final rule through publication in the Federal Register, again with a preamble that summarizes and responds to the public comments and explains the reasons for the contents of the final rule. While not binding, the preambles to proposed and final rules as well as proposed rules themselves (especially when a final rule has not yet been issued) provide important information about NRC thinking on the subject addressed. The NRC may also hold public hearings or public meetings on proposed rules. Sometimes, during the course of this process, the NRC elects not to adopt a proposed regulation, on the understanding that licensees agree to take voluntary action to meet the intent of the proposal. These understandings are also important sources of information. All of the above are contained in a "rules package" maintained by the NRC staff for each rulemaking.

One problem common to several of the previously described document types is how all documents in a series of documents can initially be identified for consideration. A number of the NRC's documents are issued with sequential numbers. Some are continuous sequences over time, others are numbered on a yearly basis. Of particular concern are the documents that are numbered on a yearly basis; such as generic letters, NRC Bulletins, and Information Notices. The last number used in each year can be difficult to establish, and in some cases not all numbers preceding the last number were used. It will be necessary, in the initial identification of documents with potential SRP impacts, to impose special requirements to ensure that relevant documents are identified.

The staff has developed two computerized tools that may facilitate identification of all NRC generic communications. These are the Generic Communications Index, which is a database of categorical information regarding approximately 1,900 generic communications issued since 1971, and the Generic Communications
Electronic Data System, which contains electronic text of generic communications in ASCII format. The Generic Communications Index is described in NUREG/CR-4960, Volumes 1 and 2. The Generic Communications Electronic Data System is available on the NRC's mainframe computer system.

Another potential problem is the possibility that different documents will be found to contain conflicting requirements or recommendations. In such cases, it will be necessary to establish which document will govern or how the conflict will be resolved. Identification of such conflicts for NRC consideration and resolution is addressed in Sections 3.3, 3.7, and 3.8 of this Implementing Procedures Document.

\subsubsection{Procedure for Identifying Documents}

\section{Purpose and Scope of this Procedure}

The purpose of this procedure is to identify and record bibliographic information regarding each document with potential SRP impacts. This procedure is also intended to determine the availability of each document either online or in hard copy at the NRC.

\section{Prerequisites for Performing this Procedure}

Technical Skills and Knowledge Levels. Those performing this procedure should have a working knowledge of reactor systems design or operations; a good understanding of the nuclear regulatory process; familiarity with NRC documents; a working knowledge of the SRP and its uses; a working knowledge of NRC databases and library resources; and a working knowledge of technical databases.

Document Availability. Those performing this procedure will need access to RECALL, NUDOCS, and the online services to which the NRC subscribes, as well as physical access to the NRC Library and the NRC Public Document Room or equivalent document collections and sources.

Completion of Prior Procedures. This is the first procedure to be implemented. No other procedures must be completed before it can proceed.

\section{Overview of Steps in this Procedure}

The process for identifying and obtaining access to documents is similar for each of the document sources described in Section 2.1.1. First, an online or hard-copy list of documents from that type is obtained. Next the list is reviewed and each document from that source is noted. Its title and specified bibliographic information are 


\subsection{Identifying Documents}

entered into the SRP Modification Database. Then a determination is made as to whether each document is available online, in hard copy, or both, and where, and whether the document should be retained for further review. This information is also entered into the SRP Modification Database.

\section{Results of this Procedure}

This procedure is intended to identify and ensure access to documents with potential SRP impacts and to record summary information about the documents and their accessibility in the SRP Modification Database. Initially, this procedure will produce completed Data Entry Logs, as described below. Once the SRP Modification Database is functioning, the information contained in the completed logs will be maintained electronically rather than in hard copy.

\section{Detailed Procedure}

This section specifies the step-by-step sequence to be followed, grouped by directives (major intermediate outputs), to be accomplished through a series of specific steps.

Directive 1: Make assignments (responsibility of project manager or project manager's designee)

Step 1 Identify the analysts who will be responsible for implementing this procedure.

Step 2 Record assignments on the Work Assignment Form.

Directive 2: Identify all pertinent documents in RECALL.

\section{Step 1 Obtain access to RECALL.}

Step 2 Scan the title, or as necessary and if available, the abstract or full text of each document in RECALL to determine whether it meets criteria 1-3 specified in Section 2.1.1 above.

Step 3 Perform a sufficient check of documents that are in RECALL that are numbered in a year-sequential number format (e.g., NRC Bulletins, Circulars, Information Notices, Generic Letters) to ensure that all such documents are considered in identification of applicable documents. Notify Certrec Corporation if this review indicates the need to add documents to the RECALL database.
Step 4 For each document scanned, complete the Document Entry Log (Directive 7).

Directive 3: Identify Director's Letters prior to 1978 that transmit generic requirements.

Step 1 Obtain access to NUDOCS.

Step 2 Search NUDOCS to identify each Director's Letter prior to 1978.

Step 3 Obtain a hard copy and review it to determine whether it transmits generic requirements.

Step 4 For each Director's Letter identified that transmits generic requirements, complete the Document Entry Log (Directive 7).

Directive 4: Identify pertinent industry codes and standards.

Step 1 Perform the industry codes and standards review described in Procedure 2.5.

Step 2 For each document identified, complete the Document Entry Log (Directive 7).

Directive 5: Identify other referenced documents.

Step 1 Review the documents identified through implementation of Directives 1-3 and identify each Regulatory Guide; NUREG Report; other contractor, vendor, or owner group report, other technical literature items referenced therein; and professional society and university publication lists that meet criteria 1-3.

Step 2 For each document identified, search NUDOCS to determine the most recent revision.

Step 3 For each document identified, complete the Document Entry Log (Directive 7).

Step 4 For each document where more than one version is identified, determine the version that should be used. Whenever any question exists as to the correct version to use, request the PTSB to make the determination. Correct the Document Entry Log to reflect the selected document version.

Directive 6: Identify pertinent NRC Rules Packages.

Step 1 From the NRC Public Document Room or the Commission Secretary, obtain a list of all rulemaking proceedings (whether or not such proceedings resulted in final rules). 
Step 2 For each rulemaking, determine which of them address nuclear power plants.

Step 3 For each Rules Package identified, complete the Document Entry Log (Directive 7).

Directive 7: Log all documents identified into the SRP Modification Database.

Step 1 Note the number and title of each document, the date of publication, and the issuing organizations and author(s) (if any).

Step 2 Determine whether the document is available in RECALL, through NUDOCS, or online through a service to which the NRC subscribes.

Step 3 If the document is not available from one of these online sources, determine whether and where the document is available in hard copy at the NRC.

Step 4 For each document which is not currently available at the NRC online or in hard copy, identify the least costly source (online or hard copy).

Step 5 For each document, complete the Document Entry Log (except for accession number and data entry).

Step 6 Transmit the Document Entry Log electronically or in hard copy to data entry clerk(s) for entry into the SRP Modification Database.

Forms

Two forms are used to implement this procedure: the Work Assignment Form and the Document Entry Log. The Work Assignment Form is used to record work assignments associated with the production procedures contained in this Implementing Procedures Document. The Document Entry Log is used to record bibliographic information about each document with potential SRP impact identified and its accessibility to the NRC for entry into the SRP Modification Database. It should be updated as necessary to reflect the latest information on the document's accessibility. 
Sample Form

Work Assignment Form

Manager's Name

Date

Assignment

Document(s)

Assigned Analyst

Start

Finish Review Required? Assigned Reviewer

Start

Type

Date

Date Yes No

Date

Finish

$+2$

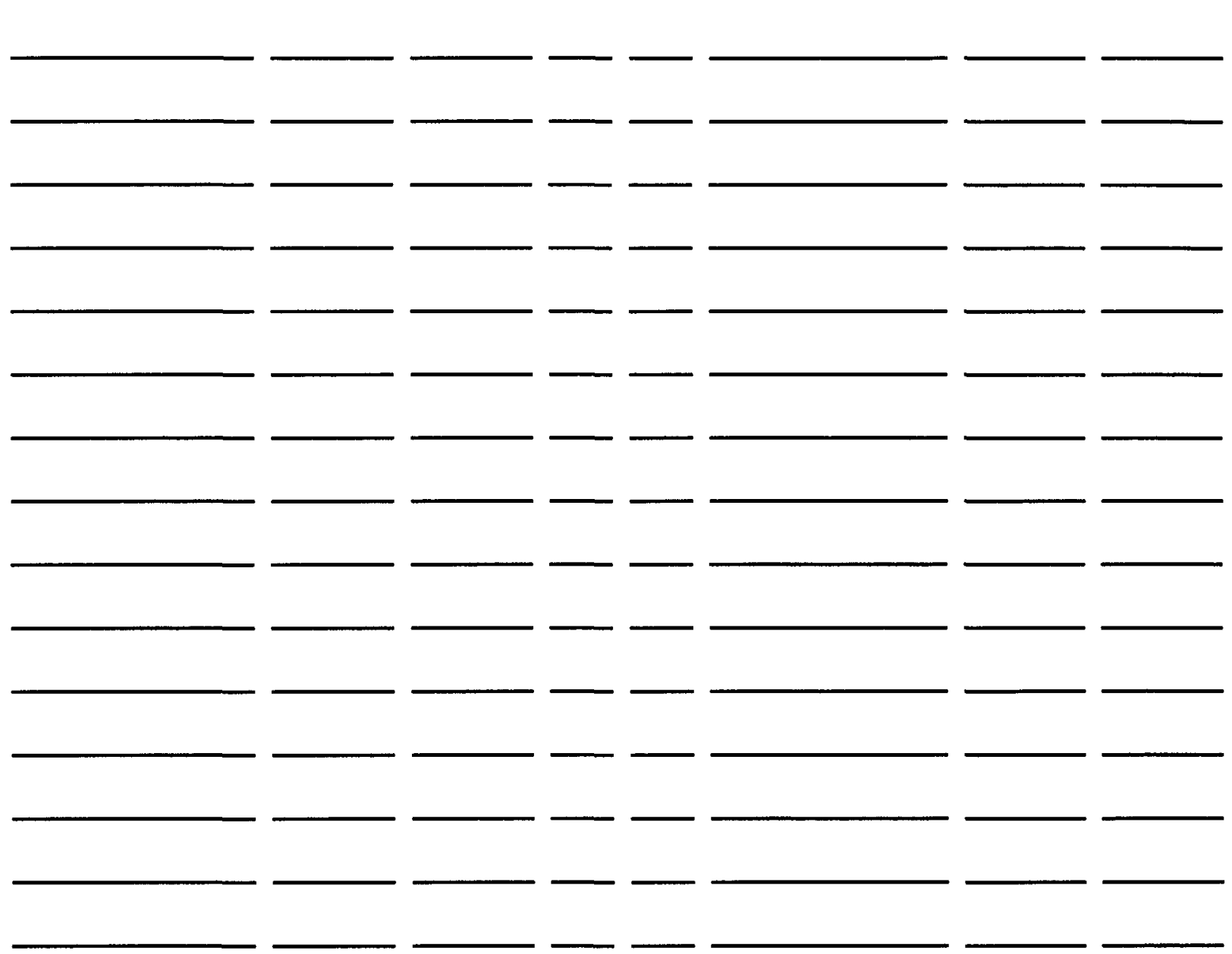


Document Entry Log

Accession No.

Document No.

Document Title

Publication/Revision Date

Revision No.

Current Version of Document (from NUDOCS):

Publication/Revision Date

Revision No.

Has this document been referenced by the SRP or another document cataloged in the SRP Modification Database?

Yes No

The following information is to be provided if the previous question is answered "Yes."

Referenced Version of Document:

Publication/Revision Date

Revision No.

Referencing Document Information (the document that references this document, if any):

Accession No.

Document Type

Document No.

Document Title

Publication/Revision Date

Revision No.

Issuing Organization

Author(s) (if any)

Retain? Yes _ No _ 
2.1 Identifying Documents

Document Entry Log (continued)

Full Text Location

RECALL

NUDOCS

PNL Project Library

Other:

Analyst's Org.

PNL

Other:

Analyst's Name

Analyst's Tel.

Date Prepared

Review Date

Reviewer

Action Items

To be resolved by (name)

Resolution (brief description)

The following information is only provided for documents identified by individuals not performing Procedure 2.1:

Name of Document Identifier

Affiliation

Telephone No.

Mailing Address

Person Receiving Notification

Date of Notification

Date of Data Entry

Data Entry Clerk 


\section{How to Complete the Form}

Work Assignment Form

- Enter the name of the manager making the assignment and the date of the assignment on the first line of the form.

- Enter the three-character assignment code in the blank in the first column. A listing of the assignment codes to be used may be obtained from the Pacific Northwest Laboratory (PNL) Database Administrator.

- Enter the document number of the document(s) associated with the assignment. The documents could include source documents, SRP sections, or codes or standards. Considerable latitude is allowed the manager in the naming or grouping documents in this blank. If the row is being used to make a review assignment only, then enter the work assignment number of the work being reviewed.

- Enter the name of the assigned analyst. The form of the name entered here must match the form that the name is recorded in the SRP Modification Database. Leave this column blank if the row is being used to make a review assignment only.

- Enter the start and finish dates for the analyst's work assignment. Leave these columns blank if the row is being used to make a review assignment only.

- Indicate whether the work will require an independent review per Procedure 6.0 by checking the "Yes" or "No" blank in the next column.

- If a review will be required, enter the name of the assigned reviewer in the same form as the name is recorded in the SRP Modification Database. The reviewer may be assigned at a later time if so desired. Leave this column blank if a review assignment is not required or is not being made at this time.

- Enter the start and finish dates for the review. Leave these columns blank if a review assignment is not required or is not being made at this time.

- Repeat the above instructions for as many assignments as are to be made using the additional rows provided on the form.

\section{Document Entry Log}

Analyst:

- Assign and enter document accession number or leave blank. The computer will assign the formal accession number at the time of data entry.

- Enter the document number.

- Enter the title of the document.

- Enter the publication or revision date and revision number (N/A if none) of the version of the document that will actually be obtained and read.

- Enter the most recent revision date and number of this document (from the NUDOCS search).

- Indicate whether the document was found via a reference from the SRP or another regulatory document by placing an " $\mathrm{X}$ " in the "Yes" or "No" blank. If "Yes," perform the next step. If "No," skip the next step.

- Indicate the referenced version of the document by publication/revision date and revision number (N/A if none). Enter the referencing document's accession number, document type, number, title, publication/revision date, and revision number (N/A if none).

- Enter the issuing organization and the author(s) (if any) (N/A if none).

- Review the document and indicate whether the document should be retained for further review--that is, documents that meet criteria 1-3. For documents not to be retained, enter the reason.

- Check the blank(s) indicating where the document is available in full text.

- Indicate your own organization by checking the appropriate blank, together with your name, telephone number, and date of preparation.

- Confirm that the data have been entered into the SRP Modification Database.

Reviewer (See definition in Section 1.5 of this Implementing Procedures Document):

- Enter the date of review.

- Enter your name. 


\subsection{Identifying Documents}

\section{Analyst/Reviewer:}

- Indicate any Action Items.

- Assign Action Items to appropriate individual.

- Upon resolution, enter brief description of how Action Items were resolved.

Individual Contacted by Document Identifier (only for documents identified outside of the performance of Procedure 2.1 by persons not working for the program):
- Enter your name and the date on which you received the suggested document notification.

- Complete as many of the blanks on this form as possible based on information provided by the document identifier.

Data Entry Clerk:

- Indicate the date on which data was entered.

- Enter your name.

- Enter the name of the document identifier and the document identifier's telephone number and mailing address. 
Sample Completed Forms

\section{Work Assignment Form}

Manager's Name Scott Steele

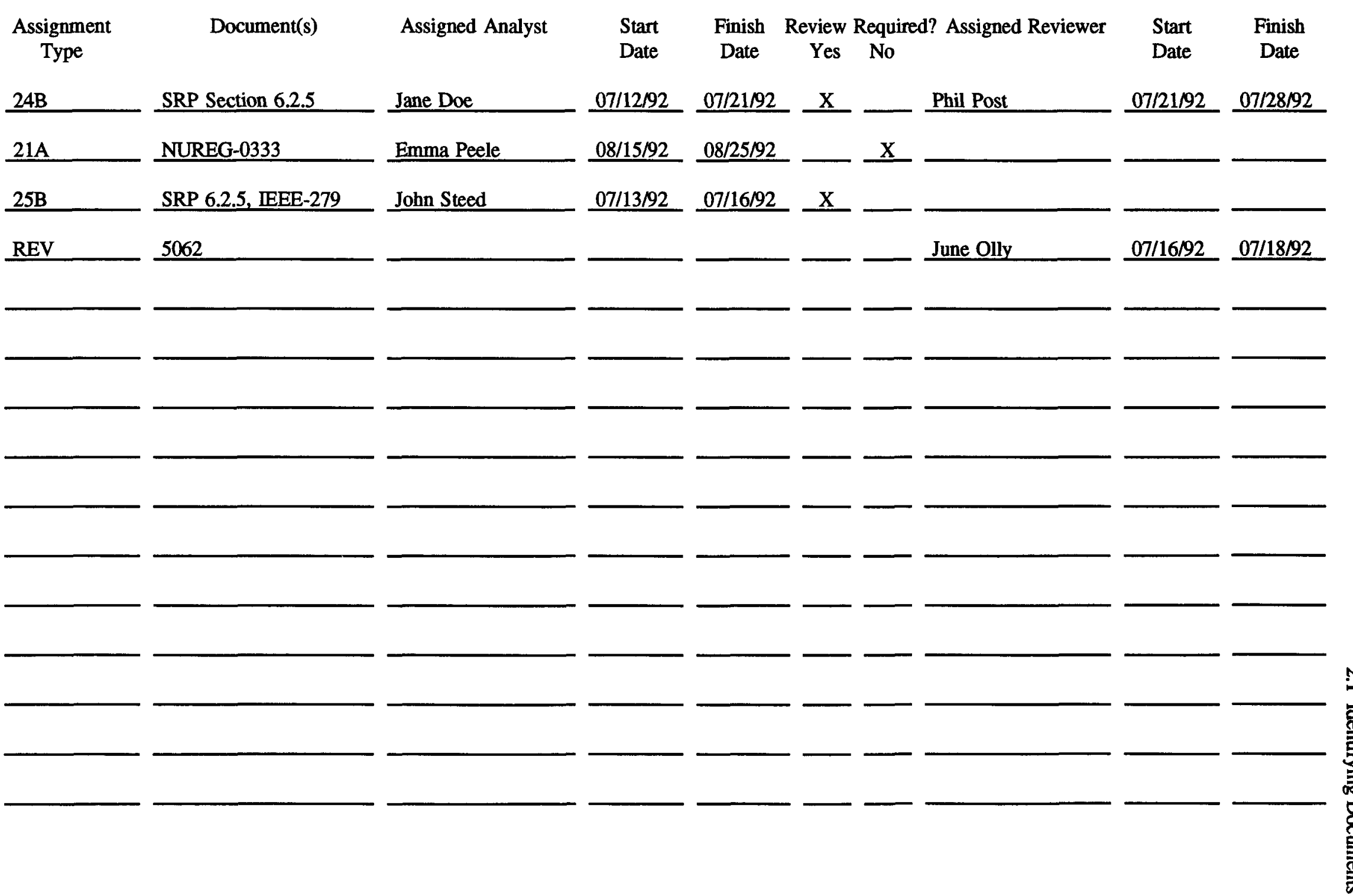


2.1 Identifying Documents

\section{Document Entry Log}

Accession No. 1268

Document No. NUREG-0800

Document Title Standard Review Plan for the Review of Safety Analysis Reports for Nuclear Power Plants

Publication/Revision Date June 1987

Revision No. 6

Current Version of Document (from NUDOCS):

Publication/Revision Date June 1987

Revision No. 6

Has this document been referenced by the SRP or another document cataloged in the SRP Modification Database?

Yes $\longrightarrow$ No $\underline{\mathrm{X}}$

The following information is to be provided if the previous question is answered "Yes."

Referenced Version of Document:

Publication/Revision Date

Revision No.

Referencing Document Information (the document that references this document, if any):

Accession No.

Document Type

Document No.

Document Title

Publication/Revision Date

Revision No.

Issuing Organization NRR

Author(s) (if any) N/A

Retain? Yes $\mathrm{X}$ No $\_$because: 


\section{Document Entry Log (continued)}

Full Text Location

$\begin{array}{ll}\mathbf{X} & \text { RECALL } \\ - & \text { NUDOCS } \\ & \text { PNL Project Library } \\ & \text { Other: }\end{array}$

Analyst's Org. $\quad \mathrm{X}$ PNL

Other:

Analyst's Name John Smith

Analyst's Tel. (509) 376-9999

Date Prepared 07/14/91

Review Date 08/01/91

Reviewer Sam Jones

Action Items None

To be resolved by (name) N/A

Resolution (brief description) N/A

The following information is only provided for documents identified by individuals not performing Procedure 2.1:

Name of Document Identifier N/A

Affiliation N/A

Telephone No. N/A

Mailing Address N/A

Person Receiving Notification N/A

Date of Notification N/A 
-

-

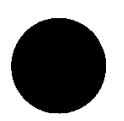




\subsection{Identifying Documents by Other Staff}

\subsubsection{Approach}

This procedure is included to provide a vehicle for considering documents that may have an impact on the SRP but are not identified through Procedure 2.1. This procedure is intended primarily to facilitate document identification by personnel working outside of the SRP Update and Development Program or by personnel within the program not assigned to implement Procedure 2.1. Potentially useful documents may not have been identified through Procedure 2.1 because they did not fall within the document categories established in Procedure 2.1 or were inadvertently overlooked.

This procedure is structured to make it as simple as possible for individuals to identify potentially useful documents to program personnel. A telephone call or other means of notifying appropriate program personnel is all that is required of the person not working in the program and identifying a document. Program personnel will be responsible for obtaining bibliographic information for documents that they identify, but will not be responsible for document conversion to electronic format. Once identified, a document is processed through the same procedures as those used to process the documents identified through Procedure 2.1.

\subsubsection{Procedure for Identifying Documents by Other Staff}

\section{Purpose and Scope of This Procedure}

The purpose of this procedure is to provide a means to consider potentially useful documents for entry into the SRP Reference Document Database when such documents are identified outside of the scope of activities described in Procedure 2.1.

\section{Prerequisites for Performing This Procedure}

Technical Skills and Knowledge Levels. No particular technical skills or knowledge levels are assumed on the part of the individual identifying a document other than general awareness of the SRP Update and Development Program. Since most of the activity involved in processing newly identified documents will be per other procedures, no specific technical skills are established here.

Document Availability. Identified documents will need to be available in order to process them. However, the actual documents that will be identified, if any, cannot be anticipated by this procedure.
Completion of Prior Procedures. No other procedures need be completed nor initiated prior to implementing this procedure.

\section{Overview of This Procedure}

It is assumed that an individual outside of the program identifying a potential new document has not reviewed this procedure or its requirements. Therefore, all requirements for such a person are stated in terms of personnel working on the SRP Update and Development Program. It is presumed that an individual will contact someone known to work in the program. That program person is responsible for obtaining as much information as possible about the document and recording the information on the Document Entry Log (see Procedure 2.1). Any bibliographic information that is missing from the $\log$ is found and entered. From this point, the form is processed according to Procedure 2.1. Once the document is entered into the system, further processing is ensured by implementing the regular procedures. A notification is also sent to the individual who identified the document describing its disposition (accepted or rejected, and if rejected, why).

In those cases where a document is identified by a person working in the program, that person will be responsible for completing the Document Entry Log (Procedure 2.1). Further processing is ensured through implementation of the regular procedures.

\section{Results of This Procedure}

Written Product. The written products resulting from implementation of this procedure are a completed Document Entry Log and a notification of document disposition.

Other. Other results of this procedure are the processing of identified documents according to existing procedures and consideration of otherwise unidentified documents.

\section{Detailed Procedure}

This section specifies the step-by-step sequence to be followed, grouped by directives (major intermediate outputs), to be accomplished through a series of specific steps. Directives 1 and 2 apply to identification of documents by persons outside of the program and it is assumed that the person identifying the document is unaware of this procedure. Directive 3 applies to persons working in the program who are not otherwise assigned to implementation of Procedure 2.1. 
Directive 1: Process newly identified documents.

Step 1 Receive document identifications either by telephone, in person, or in writing. Obtain the name, address, affiliation, and telephone number of the person making the identification.

Step 2 Apply criteria 1-3 of Section 2.1.1 to determine the likelihood of the document containing potential SRP impacts. Determine whether the document has already been entered into the SRP Reference Document Database.

Step 3 Notify the caller immediately if the document is already logged in the system or if the document is highly unlikely to contain the types of information needed for the program. The document need be considered no further.

Step 4 Complete the bibliographic information portion of the Document Entry Log. Enter as much information as the document identifier can provide. Also enter contact information (name, affiliation, address, telephone number) for the document identifier.

Step 5 Obtain, or ask others to obtain, any bibliographic information, including location, not provided by the document identifier.

Step 6 Continue processing of the document in accordance with Procedure 2.1.

Directive 2: Notify document identifier of the disposition of the document.

Step 1 Request the SRP Modification Database to generate a disposition notice for the identified document. This request should be made after the Document Entry Log has been completed and entered into the database.

Step 2 Forward the document disposition notice to the document identifier for information.

Directive 3: Log in newly identified documents (responsibility of program personnel, not assigned to implement Procedure 2.1, who identify documents needed to accomplish program work).

Step 1 Obtain a Document Entry Log (see Procedure 2.1).

Step 2 Complete the Document Entry Log according to the instructions in Procedure 2.1 and ensure data entry into the SRP Modification Database.

Step 3 Complete Impact Identification Forms, as necessary, according to the instructions in Procedure 2.4.

\section{Forms}

The forms used in the implementation of this procedure are the Document Entry Log, which is described in Procedure 2.1, and the Impact Identification Form (Manual Method) described in Procedure 2.4. No new forms are introduced in this procedure. A report, the Document Disposition Notice, is used in the implementation of this procedure. A sample of this report follows.

All organizations implementing this procedure must record their work on the indicated forms and forward the completed forms to the PTSB upon completing the work. 


\section{Sample Form}

\section{Document Disposition Notice}

To: (Document identifier's name provided by computer from Document Entry Log)

From: (PTSB representative's name provided by computer)

Date: (Provided by computer)

[The following data is taken from the completed Document Entry Form.]

On (date provided by computer), you notified (name provided by computer) that the following document could be applicable to the SRP Update and Development Program:

(Bibliographic information provided by computer)

The suggested document has been reviewed and found to be (applicable to the program) (not applicable to the program. The reason for not considering the document further is as follows:

(Reason provided by computer))

Thank you for your interest in the SRP Update and Development Program. 
-

-

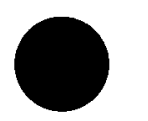




\subsection{Obtaining Documents}

\subsubsection{Approach}

This task consists of three fundamental functions: procuring or otherwise obtaining documents (in electronic or hard-copy form), converting documents into electronic form if obtained in hard copy, and transferring documents to the SRP Reference Document Database. The third function, transferring documents to the SRP Reference Document Database, can be viewed as a final step in each of the first two functions; therefore, the procedure in this section has been developed accordingly. The two functions to be performed are discussed in more detail below.

\section{Procuring or Obtaining Documents}

Some documents are already available (have been previously procured) in electronic form. For example, RECALL contains a number of the documents anticipated to be required for this project in full text electronic form. Other documents will have to be procured or otherwise obtained. In general, obtaining documents in electronic form is preferred. Documents available in-house (e.g., from NUDOCS) are preferred to those that would require procurement from an outside source. Obtaining documents in hard-copy form is the least desirable method, although cost and schedule considerations or unavailability of older documents in electronic form may render this method the best or the only method available. Documents that can be obtained electronically generally will be transferred to the SRP Reference Document Database in the most direct manner available to minimize handling requirements. Direct-line transfer is preferred, although transfer via laser or floppy disks may be the only available means. It may be necessary to store and maintain electronic versions until they can be transferred to the SRP Reference Document Database. Once transfer to the Database is accomplished, internal Database system controls will govern documents and their use.

\section{Conversion From Hard Copy to Electronic Medium}

This function includes maintaining hard-copy documents until they are transferred for scanning, tracking the documents until they are received in electronic form, and controlling the electronic form until it is entered into the SRP Reference Document Database. Procedural requirements for the process of converting hard-copy documents to electronic medium are the responsibility of the organization performing the work and are not included in the scope of this activity. Direct-line transfer of converted documents to the SRP Reference Document Database is preferred, although transfer via laser or floppy disks may be the only available means. Again, it may be necessary to store and maintain these intermediate electronic versions until they can be transferred to the Database. Once transfer to the Database is accomplished, internal Database system controls will govern documents and their use.

For both of the above functions, there is the additional requirement that document status will be periodically updated in the SRP Modification Database (e.g., document obtained, document sent for conversion to electronic medium, document entered into the Database).

\subsubsection{Procedure for Obtaining Documents}

\section{Purpose and Scope of This Procedure}

This procedure is intended to control the process of acquiring documents from online and hard-copy sources, converting hard-copy sources to electronic form, and transferring all documents to the SRP Reference Document Database.

\section{Prerequisites for Performing This Procedure}

Technical Skills and Knowledge Levels. This procedure requires some knowledge of computers and the forms in which electronic information may be transferred. Knowledge regarding the use of online services and hard copy to electronic form conversion is also required, depending on the parts of the procedure being implemented.

Document Availability. Implementation of this procedure requires the availability of documents in electronic form, preferably, or in hard copy free from legal constraints on usage. Although the formal process of obtaining permission for use is covered by this procedure (Directive 2 , Step 5), it is assumed that any permission required to use documents available from online services can be readily obtained.

Completion of Prior Procedures. Performance of this procedure requires input from implementation of Procedure 2.1. This procedure may be initiated anytime after Procedure 2.1 outputs have begun to be generated.

\section{Overview of the Steps in This Procedure}

The first step in this procedure is obtaining documents that are currently available in-house or obtaining them through borrowing or procurement. Typically, an entire series of documents of similar type (e.g., Generic Letters) will be obtained at one time. The second step (in the case of procured documents online) is making the information available to SRP Reference Document 
Database data entry personnel, who will be responsible for actual data entry. There are a number of ways that electronic information may be transferred, including direct line or disk storage. The method of transfer will be dependent on the service providing the documents. The third step is conversion of hard-copy documents into electronic form. The fourth step, for those documents subject to the third step, is transfer to the SRP Reference Document Database.

\section{Results of This Procedure}

Written Product. Written product associated with this procedure is the completed Document Status Form described in the Forms section.

Other. The results of this procedure will be the obtaining and transfer of documents into the SRP Reference Document Database.

\section{Detailed Procedure}

This section specifies the step-by-step sequence to be followed, grouped by directives (major intermediate outputs), to be accomplished through a series of specific steps. Implementation of the following steps will depend, to some extent, on the form in which information is obtained and transferred.

Directive 1: Make assignments (responsibility of Project Manager or Project Manager's designee).

Step 1 Identify the analysts who will be responsible for implementing this procedure.

Step 2 Record assignments on the Work Assignment Form (see Procedure 2.1).

Directive 2: Obtain documents.

Step 1 Review information in the SRP Modification Database regarding the documents that are to be obtained and the form in which they are available. This information will result from implementation of Procedures 2.1 and 2.2.

Step 2 Determine the document source to be used. There may be one or more sources recommended; where more than one source is available, select the best source based on cost, schedule, and compatibility considerations.

Step 3 Establish and maintain a PNL project library for documents that will be obtained in hard-copy form. Maintain such documents in the library at least until they have been converted into electronic form and entered into the SRP Reference Document Database.

Step 4 Make necessary arrangements for obtaining the needed documents (in cases where the documents are not already available in-house), including procurement when needed. Procurement will be accomplished in accordance with established procurement regulations and procedures.

Step 5 Determine the need for obtaining permission to use documents and obtain permission, if needed.

Step 6 Proceed to Directive 4 for documents procured or obtained in electronic form.

Directive 3: Make arrangements for conversion services for documents obtained in hard-copy form.

Step 1 Perform a survey of organizations that have the capability to convert hard-copy documents into electronic form. Make sure that the systems used by such organizations provide outputs that are compatible with the SRP Reference Document Database.

Step 2 Select the organization which best meets project needs (using appropriate procurement procedures). Interface with database personnel to assure compatibility of products with the SRP Reference Document Database.

Step 3 Prepare the appropriate form of agreement (e.g., a contract) with the selected organization. Include all relevant specifications of the inputs that will be provided to, and the outputs that will be received from, and the selected organization.

Directive 4: Convert hard-copy documents to electronic form.

Step 1 Transmit documents to the conversion organization.

Step 2 Complete appropriate entries on the Document Conversion Status Form and ensure entry into the SRP Modification Database.

Step 3 Monitor progress of the organization performing document conversion services.

Step 4 Receive electronic versions of converted documents; maintain them until they are transferred to the SRP Reference Document Database. 
Directive 5: Transfer documents to the SRP Reference Document Database.

Step 1 Interface with personnel responsible for the SRP Reference Document Database system to make arrangements for receiving documents.

Step 2 Transfer documents; follow up to ensure that document transfer was successfully completed. When electronic transmission from another organization is involved, appropriate controls will be in place to prevent the introduction of computer viruses into the SRP Reference Document Database.

\section{Forms}

Two forms are associated with this procedure. The Work Assignment Form is used in Procedure 2.3 to record assignments for obtaining documents; this form is described in Procedure 2.1. The second form is the Document Conversion Status Form. Its purpose is to record the status of document conversion to electronic format. The SRP Modification Database will be able to identify the status of the transfer of documents into the SRP Reference Document Database along with the associated dates. Together, these sources of information will provide adequate tracking of the status of documents being obtained. 


\title{
2.3 Obtaining Documents
}

\section{Sample Form}

\author{
Document Conversion Status Form
}

Accession No(s)

Assigned Conversion Organization

Date Document Transmitted to Conversion Organization

Date Document Received from Conversion Organization

Form of Converted Document

Location of Converted Document

Limits on Distribution (if any)

Assigned Analyst

Date 


\section{How to Complete the Form}

- Enter the document accession number(s) on the first line.

- Enter the organization to which the document was sent for conversion and the date on which it was sent.

- Upon receipt of the converted document, enter the date of receipt, the form in which the document was received (e.g., floppy disk, laser disk), and the location where it is being stored until entry into the SRP Reference Document Database.

- Enter the copyright/proprietary status of the document so that appropriate Database controls may be imposed after document entry.

- Enter your name and the date on the next line. 


\subsection{Obtaining Documents}

Sample Completed Form

\section{Document Conversion Status Form}

Accession No(s) 1615

Assigned Conversion Organization PDQ Systems

Date Document Transmitted to Conversion Organization $\underline{08 / 15 / 91}$

Date Document Received from Conversion Organization 09/15/91

Form of Converted Document Floppy Disk

Location of Converted Document SRP Document Library

Limits on Distribution (if any) None

Assigned Analyst John Trent

Date $\underline{09 / 30 / 91}$ 


\subsection{Identifying Potential SRP Impacts}

\subsubsection{Approach}

The purpose of Procedure 2.4 is to identify potential SRP impacts that are contained in the documents identified and obtained in Procedures 2.1 through 2.3. The term "impact," as used in this program, is defined below. This procedure identifies "potential impacts." Potential impacts are impacts with the additional qualification that they have not yet undergone the integration process described in Procedure 3.3. In Procedure 2.4, the analyst should be liberal in determining if potential impacts exist; analysts should err on the side of including potential impacts if there is any doubt about their applicability. In Procedure 3.3, the potential impacts are appropriately combined to form substantive impacts that may be provided to the PRBs for disposition.

It should be recognized that Procedure 2.4 has the potential to identify a large number of potential impacts, many of which could be viewed as insignificant when viewed in isolation. Procedure 3.3 will eliminate many of the potential impacts and combine the remainder into a smaller number of significant impacts. Insignificant potential impacts need to be identified here, however, because they establish important links between documents and the SRP, which may become useful in the future review of advanced reactor designs.

Two different methods of identifying potential impacts are described in this procedure. The first method, called the "manual method," requires that documents be read in their entirety by analysts in order to find potential impacts. This method is not completely manual, in that the analyst does use the computer system to assist in correlating potential impacts with the SRP sections that are affected. The second method, called the "RECALL method," identifies potential impacts associated with each SRP section through use of electronic key-word searches. Both of these methods are used in this procedure.

In the context of this procedure, an impact is defined to be the linkage between an SRP section and a document or part of a document that is relevant to updating or developing the SRP because it meets one or more of the following criteria relative to one or more SRP sections:

1. Contains generic requirements or established staff positions directed at applicants or licensees.

2. Contains conclusions or recommendations suggesting that current requirements or guidance are inadequate, overly restrictive, or otherwise need some revision.
3. Contains design or analysis information, or evaluation of design or analysis information, that can be used in establishing licensing requirements for evolutionary reactor designs.

4. Contains design or analysis information, or evaluation of design or analysis information, that can be used in establishing licensing requirements for advanced reactor designs.

5. Contains design, operational, or analysis information, or evaluation of design, operational, or analysis information, that can be used in establishing technical rationales for SRP Acceptance Criteria.

6. Contains backfit or other analyses, or requirement approvals that can be used in making Type I/Type II determinations.

The above six criteria are a more specific version of the three criteria discussed in Section 2.1.1. These six criteria are based on the specific uses envisioned for the information to be collected in this program work.

In this procedure, the linkage between an SRP section and a part or portion of a document meeting any of the above criteria is considered a potential impact. Each potential impact will have a specific use in updating or developing the SRP corresponding to each of the six criteria that the potential impact meets.

Each potential impact identified should address a single topic. The topic may be broadly or narrowly defined by the analyst, depending on the nature of the subject, the relationship of the potential impact to the SRP, and the judgment of the analyst identifying the potential impact. If a given document or part of a document meeting any of the six review criteria addresses more than one topic, a separate potential impact should be identified for each topic addressed. All potential impacts should be identified and recorded, regardless of their apparent significance or insignificance. The significance of potential impacts is addressed in Procedure 3.3.

When the manual method is used, the analyst also assigns each document or part of a document to one or more SRP sections. Because analysts may not be thoroughly familiar with the scope and contents of all SRP sections, the analyst should use the search capabilities of RECALL to assist in this task. However, this device is only a tool. The correct assignment of SRP sections will ultimately depend on the analyst's knowledge and judgment. RECALL is used as follows. For each identified part of a document, the analyst develops a set of descriptive words and search strings that capture the topic addressed. Using RECALL, the analyst next performs a string search 
for these words in the SRP. The analyst can then review the SRP sections containing the descriptive words to determine whether the documents or parts of documents should be assigned to those SRP sections. The analyst should also use judgment to identify affected SRP sections that may not have been found by the electronic searches.

In summary, a potential impact is the link between an SRP section and a document or a part of a document that meets one or more of the six criteria given above. A particular document may have any number of potential impacts contained within it, including no potential impacts.

In general, the entirety of a potential impact should apply to the SRP section to which it is assigned. In cases where part of a document applies to one SRP section and part of a document applies to one or more other SRP sections, several potential impacts should be created. As an example of the foregoing requirement, consider 10 CFR 50.44. This regulation contains a number of requirements regarding combustible gas control. Two of those requirements (among a number of others) include the provision of hydrogen recombiners and training in the use of the recombiner equipment. Recombiners are appropriately addressed in SRP Section 6.2.5; training in SRP Section 13.2. Therefore, $\$ 50.44$ should result in at least two different potential impacts. In actuality, this regulation would result in at least six potential impacts (and perhaps more) if all requirements contained therein were considered.

The procedure that follows uses both the manual and RECALL methods to identify potential impacts. The RECALL method is preferred because of its accuracy, speed, and efficient use of resources. The manual search is used in three specific circumstances. First, it is used if pertinent documents are not located in the full-text database. Second, it is used to review those documents in the electronic database that received no hits in any of the key-word searches performed for all SRP sections. Third, it may be used as a check or review of the key-word search method.

\subsubsection{Procedure for Identifying Potential SRP Impacts}

\section{Purpose and Scope of This Procedure}

This procedure establishes guidance for reviewing documents to identify potential SRP impacts. It provides criteria for performing this review and a methodology for using descriptive words to assist in assigning potential impacts to the specific SRP sections they affect.

\section{Prerequisites for Performing This Procedure}

Technical Skills and Knowledge Levels. An analyst implementing this procedure needs to have expert knowledge of the terminology used in the nuclear power community, the SRP, and regulatory documents; working knowledge of nuclear power plant systems and operations and the nuclear regulatory process; knowledge of the objectives of the SRP Update and Development Program; and an understanding of the use of the information generated by this procedure.

Document Availability. This procedure requires the availability of documents identified and obtained per Procedures 2.1 through 2.3. This procedure may be performed concurrently with those three procedures, provided that those procedures have begun to make documents available.

Completion of Prior Procedures. As indicated above, Procedures 2.1 through 2.3 must be under way before the document reviews governed by this procedure may be initiated.

\section{Overview of Steps in This Procedure}

Two different methods are used to accomplish this procedure, depending on the form of the source documents. Documents included in the RECALL system are electronically searched using key-words; this process is performed on an SRP section-by-section basis. All "hits" are read in detail to determine whether a potential impact exists and, if so, an Impact Identification Form is completed. Those documents in the database that do not receive any hits for any of the SRP sections are manually reviewed to check for impacts.

Documents not included in RECALL are manually reviewed to identify potential SRP impacts using the six criteria described in Section 2.4.1. Potential impacts are assigned to appropriate SRP sections through the analyst's knowledge and judgment. Analysts also use RECALL to search the SRP for sections containing descriptive words and use the search results to supplement SRP section assignments. All potential impacts will be assigned to at least one SRP section. If a document meets one or more of the six criteria but does not appear to affect an existing SRP section, NRR/PTSB will be informed and will determine how the situation should be addressed. Results of this analysis are documented on a standard form, which is used as input for the SRP Modification Database. Independent verification is performed in accordance with Procedure 6.0. 


\section{Results of This Procedure}

Written Product. Written products are the completed Impact Identification Forms. In some cases, the Impact Identification Forms may be completed in electronic format and not exist in hard copy.

Other. This procedure will provide for the entry of all review results into the SRP Modification Database for future reference and use in subsequent procedures.

\section{Detailed Procedure}

This section specifies the step-by-step sequence to be followed, grouped by directives (major intermediate outputs), to be accomplished through a series of specific steps. While Directives 1 through 3 may be implemented any number of times, Directive 4 should be implemented only once after key-word searches have been completed for all of the SRP sections.

Directive 1: Make assignments (responsibility of the Project Manager or the Project Manager's designee).

Step 1 If the manual method is being used, identify the analyst who will be responsible for reading each document, and record the assignment on the Work Assignment Form (see Procedure 2.1). Perform Directive 2 and skip Directive 3.

Step 2 If the RECALL method is to be used, identify the analyst who will be responsible for performing the search and the SRP section for which the analyst will be responsible. Record assignments on the Work Assignment Form (see Procedure 2.1). Skip Directive 2 and perform Directive 3.

Directive 2: Perform manual review method.

Step 1 Review in detail each document identified and obtained through Procedures 2.1, 2.2, and 2.3, excluding those contained in the RECALL database.

Step 2 Identify any potential impacts contained in each document by applying the six review criteria.

Step 3 Assign each potential impact to the appropriate SRP section. Create one potential impact for each identified document to SRP section link. If helpful, assign descriptive words of your choosing to each potential impact (there is no "standard list" of descriptive words) and use descriptive word searches of the SRP on RECALL to assist in correlating potential impacts with SRP sections. Guidance regarding the use of RECALL and performance of string searches therein is available in the RECALL User's Manual.

Step 4 Record results of the review on the Impact Identification Form.

Step 5 Submit completed forms for entry into the SRP Modification Database.

Step 6 Periodically report progress (completed document reviews) to project management.

Step 7 Periodically, query the SRP Modification Database to identify potential impacts that could not be assigned to SRP sections (those reported as "None" on the SRP section affected line on Part B of the Impact Identification Form). Report such potential impacts to PTSB for resolution as to how they will be addressed.

Directive 3: Perform the RECALL review method.

Step 1 Develop the search strings to be used. A minimum of 15 strings is generally required.

Step 2 Perform the computer search using the strings developed in Step 1.

Step 3 Record the hits and associated document text in an electronic format (disk, hard drive, etc.).

Step 4 Read and assess the stored text.

Step 5 Complete Impact Identification Forms for those potential impacts that are identified.

Directive 4: At the completion of the electronic document review for all SRP section, manually review documents in RECALL that did not receive any hits.

Step 1 Identify documents in RECALL that did not receive any hits for any SRP sections in the previously performed key-word searches.

Step 2 Manually review the identified documents which are appropriate to include in the SRP in accordance with the steps outlined under Directive 2. 


\section{Forms}

Two forms are used to implement this procedure. The first is the Work Assignment Form, which is used to record production assignments. This form is described in Procedure 2.1. A second form, the Impact Identification Form, assists the document reviewer in identifying potential impacts by providing a checklist of pertinent criteria. The form then serves as an input medium for entering the information into the SRP Modification Database. Two versions of this form are available, depending on whether the manual or RECALL identification method is used.

All organizations implementing this procedure must record their work on the indicated forms and forward the completed forms to the PTSB upon completion of the work. 


\section{Sample Forms}

\section{Impact Identification Form \\ (Manual Identification Method)}

Part A - Document Identification

Work Assignment No.

Assigned Analyst

Document Accession No.

Document No.

Document Title

Publication/Revision Date

Revision No.

Impact Identified? Yes $\quad$ No

Analyst

Date of Analysis

Reviewer

Date of Review 
2.4 Identifying Potential Impacts

Impact Identification Form (continued)

(Manual Identification Method)

Part B - Impact Identification

(Use a separate Part B for each impact)

Impact No.

Impacted SRP Section(s)

Impact Size and Location

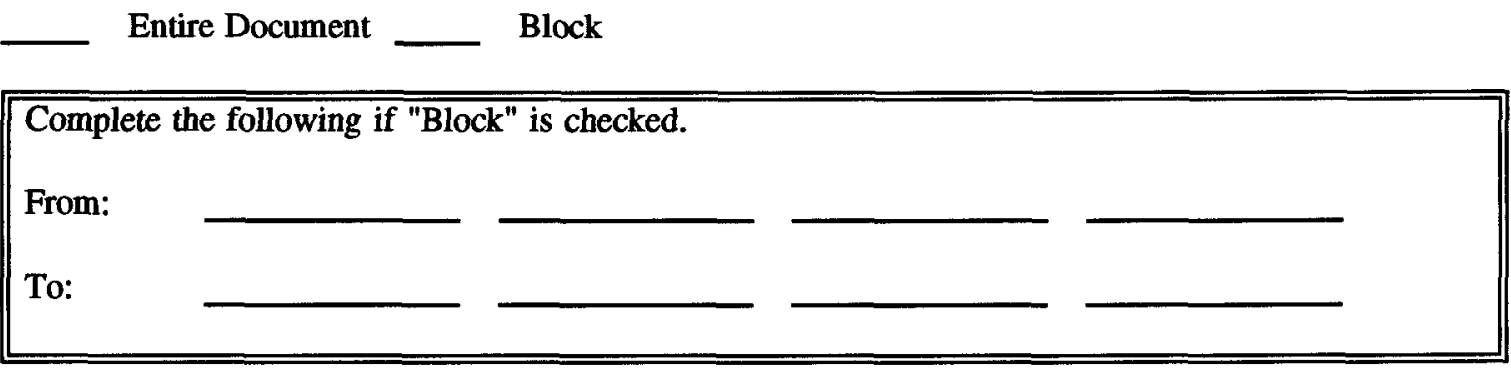

Impact Summary (one-three sentences) 


\section{Impact Identification Form (continued)}

(Manual Identification Method)

Part B - Impact Identification (continued)

RECALL Index(es)

Search Logic

Impact Criteria (check one or more)

1. Requirement or established staff position.

2. Suggestion that requirement or guidance needs revision.

3. Information that can be used for establishing criteria bases or licensing requirements for evolutionary reactors.

4. Information that can be used for establishing criteria bases or licensing requirements for advanced reactors.

5. Information that can be used for establishing technical rationales for Acceptance Criteria.

6. Information that can be used for making Type I/Type II determinations.

Descriptive Words

Analyst

Analysis Date

Another Impact?

Yes $\longrightarrow$ No 
2.4 Identifying Potential Impacts

Impact Identification Form

(RECALL Identification Method)

Part A - SRP Section Identification

Work Assignment No.

Assigned Analyst

SRP Section Accession No.

SRP Section No.

SRP Section Title

Publication/Revision Date

Revision No.

Impact Identified? Yes $\_$No

Analyst

Date of Analysis

Reviewer

Date of Review 


\section{Impact Identification Form (continued)}

(RECALL Identification Method)

Part B - Impact Identification

(Use a separate Part B for each impact)

Impact No.

Impacting Document Accession No.

Impacting Document No.

Impacting Document Title

Publication/Revision Date

Revision No.

Impact Size and Location

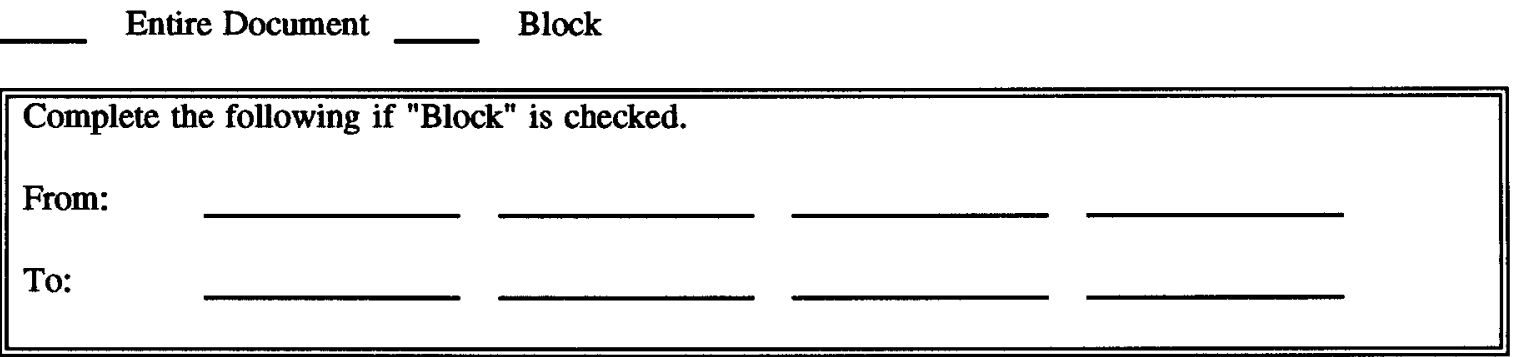

Impact Summary (one-three sentences) 
2.4 Identifying Potential Impacts

Impact Identification Form (continued)

(RECALL Identification Method)

Part B - Impact Identification (continued)

RECALL Index(es)

Search Logic

Impact Criteria (check one or more)

1. Requirement or established staff position.

2. Suggestion that requirement or guidance needs revision.

3. Information that can be used for establishing criteria bases or licensing requirements for evolutionary reactors.

4. Information that can be used for establishing criteria bases or licensing requirements for advanced reactors.

5. Information that can be used for establishing technical rationales for Acceptance Criteria.

6. Information that can be used for making Type VType II determinations.

Descriptive Words

Analyst

Analysis Date

Another Impact? Yes _ـ No 


\section{How to Complete the Form}

Two versions of the Impact Identification Form are used by this procedure, one if the manual method is used, another if the RECALL method is used. The two forms contain essentially the same information but are organized to facilitate entry of data onto the forms.

\section{Impact Identification Form (Manual Identification Method)}

\section{Part A}

- The work assignment number and the name of the assigned analyst are entered by the project clerk.

- The document accession number will be assigned by the computer system upon data entry. The analyst may assign an interim number, if necessary, to accomplish program work, but that number will not be entered into the computer system.

- Enter the document number, title, publication/revision date, and revision number.

- Indicate whether potential impacts were identified in the document by placing an " $\mathrm{X}$ " in the "Yes" or "No" blank.

- Sign and date the form.

- If an independent review (Procedure 6.0) is performed, the reviewer will sign and date the form upon completion of the review and incorporation of comment resolutions.

- If no potential impacts are identified, Part B will not be completed for the document indicated in Part A.

\section{Part B}

- The computer system will assign the impact number at the time of data entry. The analyst may assign an interim number if such assignment is helpful, but the interim number will not be entered into the database.

- Identify the SRP section(s) potentially affected. Any number of SRP section numbers may be entered, provided that the same potential impact criteria are applicable to all SRP section/potential impact linkages. If different criteria apply to different impact/potential impact linkages, multiple Part B forms will have to be completed. If an
SRP section affected by the potential impact cannot be identified, enter "None" on the impacted SRP section(s) line.

- Enter information regarding the location of the potential impact within the source document. Indicate whether the entire document is taken to constitute the potential impact (Entire Document) or the potential impact is taken from certain portions of the source document (Block) by placing an " $\mathrm{X}$ " in the appropriate blank.

- If "Entire Document" is checked, skip to the next bullet. If "Block" is checked, indicate the beginning and end points of the blocks of text that pertain to the potential impact. If the block is made up of an entire chapter or section, such chapter or section number may be entered in the "From" blank with no entry made in the "To" blank. Up to four blocks of text may be indicated. Multiple locations of impacting blocks within a single document should be included on a single form. If more than four blocks are involved, replace them with a single entry of the smallest document subdivision that contains all blocks.

- Enter a brief (one- to three-sentence) description of the potential impact.

- Document the computer search used to locate the SRP sections affected by the potential impact. Record the RECALL index(es) used and the search logic (text strings and logical operators).

- Indicate the pertinent impact criteria. Any number of blanks may be checked; however, at least one blank must be checked. Criteria 3 and 4 should be checked only if the potential impact affects only future reactor designs. If a potential impact affects currently licensed plants as well as one or more future designs, only Criterion 1 should be checked. Most of the information affecting current plants will also apply to future designs.

- Enter a set of descriptive words that are applicable to the potential impact under consideration. These descriptive words may, in part, be based on elements of the search logic, but often they will not be the same.

- Sign and date this Part B.

- Indicate whether there are any additional potential impacts in the source document. If "Yes," complete another Part B. If "No," the analysis of 
2.4 Identifying Potential Impacts

the source document is complete. Any number of Parts B may be completed for each Part A.

\section{Impact Identification Form (RECALL Identification Method)}

Part A

- The work assignment number and assigned analyst are entered by the project clerk or analyst.

- Enter the SRP section accession number. This number is available from the SRP Modification Database.

- Enter the SRP section number, title, publication/revision date, and revision number.

- Indicate whether any potential impacts were found as a result of the search. If "Yes," a Part B will be filled out for each potential impact. If "No," no Part Bs will be completed.

- Enter the signature of the analyst and the date the work is completed.

- If the work is reviewed per Procedure 6.0, enter the signature of the reviewer and the date that incorporation of comment resolutions is completed.

\section{Part B}

- The computer system will assign an impact number at the time of data entry. The analyst may assign an interim number, but it will not be entered into the database.

- Enter the impacting document accession number (available from the SRP Modification Database), document number, title, publication/revision date, and revision number.

- Enter information regarding the location of the potential impact within the source document. Indicate whether the entire document is taken to constitute the potential impact (Entire Document) or the potential impact is taken from certain portions of the source document (Block) by placing an " $\mathrm{X}$ " in the appropriate blank.

- If "Entire Document" is checked, skip to the next bullet. If "Block" is checked, indicate the beginning and end points of the blocks of text that pertain to the potential impact. If the block is made up of an entire chapter or section, such chapter or section number may be entered in the "From" blank with no entry made in the "To" blank. Up to four blocks of text may be indicated. Multiple locations of impacting blocks within a single document should be included on a single form. If more than four blocks are involved, replace them with a single entry of the smallest document subdivision that contains all blocks.

- Enter a brief (one to three sentence) description of the potential impact.

- Document the computerized search for potential impacts by entering the RECALL index(es) and search logic used. The search logic should contain the text and logical operators used.

- Indicate the pertinent impact criteria. Any number of blanks may be checked; however, at least one blank must be checked. Criteria 3 and 4 should be checked only if the potential impact affects only future reactor designs. If a potential impact affects currently licensed plants as well as one or more future designs, only Criterion 1 should be checked. Most of the information affecting current plants will also apply to future designs.

- Enter a set of descriptive words that are applicable to the potential impact under consideration. These descriptive words may, in part, be based on elements of the search logic, but often they will not be the same.

- Sign and date this Part B.

- Indicate whether there are any additional potential impacts in the source document. If "Yes," complete another Part B. If "No," the analysis of the source document is complete. Any number of Part Bs may be completed for each Part A. 
Sample Completed Forms

\author{
Impact Identification Form \\ (Manual Identification Method) \\ Part A - Document Identification
}

Work Assignment No. 4076

Assigned Analyst Ian Wright

Document Accession No. 483

Document No. NUREG-XXXX

Document Title Design and Operational Modifications to Mitigate Plant Occurrences During Outage Conditions

Publication/Revision Date 01/07/87

Revision No. 5

Impact Identified? Yes $\quad \mathrm{X} \quad$ No

Analyst Ian Wright

Date of Analysis $\underline{05 / 12 / 92}$

Reviewer John Smith

Date of Review 06/01/92 
2.4 Identifying Potential Impacts

\section{Impact Identification Form (continued) \\ (Manual Identification Method) \\ Part B - Impact Identification \\ (Use a separate Part B for each impact)}

Impact No. 3721

Impacted SRP Section(s) 13.2.1

Impact Size and Location

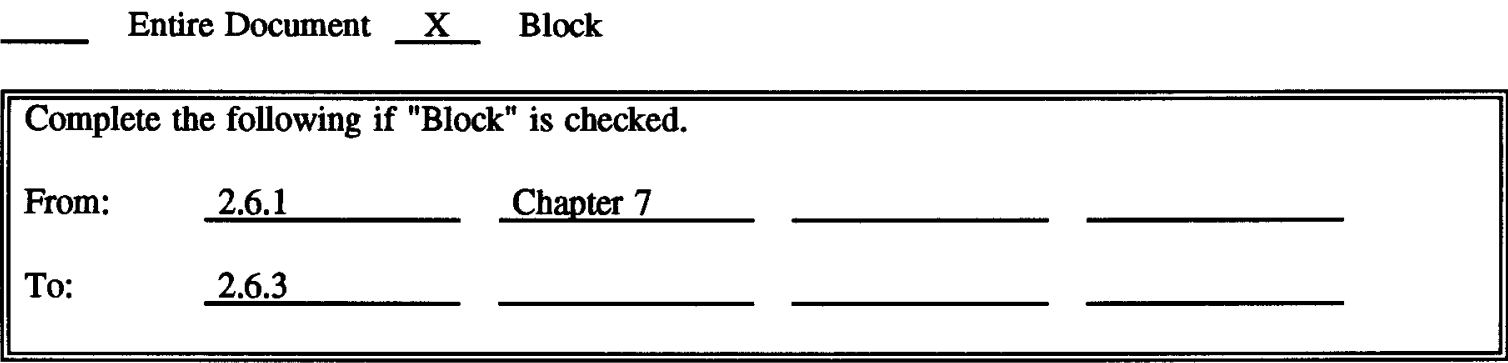

Impact Summary (one-three sentences) The staff has determined that a rule is required to ensure that plant operators are adequately trained in procedures related to plant outage conditions. A regulatory analysis supporting this position is also included. 
Impact Identification Form (continued)

(Manual Identification Method)

Part B - Impact Identification (continued)

RECALL Index(es) ALLDOCS

Search Logic (OPERAT* OR OUTAGE) W/20 TRAINING, PROCEDUR* W/20 OUTAGE, (EVENTS OR OCCURRENCES) W/20 OUTAGE, (EVENTS AND REFUELING) W/20 (TRAINING OR OPERATORS)

Impact Criteria (check one or more)

1. Requirement or established staff position.

2. Suggestion that requirement or guidance needs revision.

3. Information that can be used for establishing criteria bases or licensing requirements for evolutionary reactors.

4. Information that can be used for establishing criteria bases or licensing requirements for advanced reactors.

5. Information that can be used for establishing technical rationales for Acceptance Criteria.

X 6. Information that can be used for making Type I/Type II determinations.

Descriptive Words Training, Operators, Outage

Analyst Ian Wright

Analysis Date 05/12/92

Another Impact? Yes _ No 
2.4 Identifying Potential Impacts

\section{Impact Identification Form \\ (RECALL Identification Method) \\ Part A - SRP Section Identification}

Work Assignment No. 399

Assigned Analyst Allen Austen

SRP Section Accession No. 215

SRP Section No. 13.2 .1

SRP Section Title Reactor Operator Training

Publication/Revision Date 07/81

Revision No. $\underline{0}$

Impact Identified? Yes $\underline{\mathrm{X}}$ No

Analyst Allen Austen

Date of Analysis $\underline{04 / 10 / 92}$

Reviewer N/A

Date of Review N/A 


\section{Impact Identification Form (continued) \\ (RECALL Identification Method) \\ Part B - Impact Identification \\ (Use a separate Part B for each impact)}

Impact No. $\underline{4156}$

Impacting Document Accession No. 993

Impacting Document No. NUREG-XXXX

Impacting Document Title Design and Operational Modifications to Mitigate Plant Occurrences During Outage

Conditions.

Publication/Revision Date 01/07/87

Revision No. 5

Impact Size and Location

Entire Document $\underline{X}$ Block

\begin{tabular}{|l} 
Complete the following if "Block" is checked. \\
From: $\quad 2.6 .1$ \\
To: $\quad 2.6 .3$
\end{tabular}

Impact Summary (one-three sentences) The staff has determined that a rule is required to ensure that plant operators are adequately trained in procedures related to plant outage conditions. A regulatory analysis supporting this position is also included. 
2.4 Identifying Potential Impacts

Impact Identification Form (continued)

(RECALL Identification Method)

Part B - Impact Identification (continued)

RECALL Index(es) ALLDOCS

Search Logic (OPERAT* OR OUTAGE) W/20 TRAINING, PROCEDUR* W/20 OUTAGE, (EVENTS OR OCCURRENCES) W/20 OUTAGE, (EVENTS AND REFUELING) W/20 (TRAINING OR OPERATORS)

Impact Criteria (check one or more)

1. Requirement or established staff position.

X 2. Suggestion that requirement or guidance needs revision.

3. Information that can be used for establishing criteria bases or licensing requirements for evolutionary reactors.

4. Information that can be used for establishing criteria bases or licensing requirements for advanced reactors.

5. Information that can be used for establishing technical rationales for Acceptance Criteria.

$\mathrm{X}$ 6. Information that can be used for making Type I/Type II determinations.

Descriptive Words Training, Operators, Outage

Analyst Allen Austen

Analysis Date $\underline{04 / 10 / 92}$

Another Impact? Yes $\quad$ No 


\subsection{Ascertaining the Status of Industry-Consensus Codes and Standards}

This section describes procedures for ascertaining the status of codes and standards referenced in NRC regulatory documents. Included are industry-consensus codes and standards and other requirements and guidance.

\subsubsection{Approach}

Codes and standards referenced in regulatory documents provide many of the specific Acceptance Criteria presented in the SRP. As part of the SRP-Update and Development Program, references currently cited in regulatory documents will be re-evaluated to ensure that the most appropriate code and standard revisions are used. Industry commitments to codes and standards, as contained in the EPRI Requirements Document, which covers both the Advanced Light Water Reactor Evolutionary Plant and the Advanced Light Water Reactor Passive Plant, should be examined from the same perspective. The NRC should also consider endorsing additional codes and standards, some of which may not yet exist, to anticipate designs that may be used in future applications. "Endorse" in the sense that NRC endorses industry codes and standards means that the solutions and approaches contained therein are acceptable to the NRC staff, but that they are not required as the only possible solutions and approaches. This procedure contains the process to be followed in assessing the status of codes and standards cited in NRC regulatory documents.

From a nuclear regulatory perspective, "codes and standards" include industry consensus codes and standards as well as other sources that provide guidance similar in character to that found in the industry consensus codes and standards. Other sources include such documents as DOT regulations, industry procedures, handbooks, or specifications. In performing this task, all codes and standards cited in regulatory documents are to be evaluated.

Industry-consensus codes and standards are developed in the following process. The participating members of a standards-writing group who represent the various interests of that industry (e.g., product manufacturers, material manufacturers, product users, utilities, insurers, designers, constructors, consultants, and regulators, whether local, regional, or national) develop a standard. An industry-consensus process does not approve, recommend, or endorse any specific or proprietary design or manufacturing process. The standards-writing group members regularly meet on a formal basis to consider revisions of the current requirements, requests for interpretation of current requirements, and new requirements as dictated by technological development. The industry-consensus process satisfies the separate and distinct needs, requirements, and interests of its participants through a process of arriving at mutually agreed-upon rules.

Regulatory documents also contain citations to sources that are not industry-consensus codes and standards but do provide essential guidance or useful information. These may be regulations promulgated by other governmental agencies or documents generated by industry organizations that contain information endorsed in an NRC regulatory document.

A basic source to be used in performing this work is the database of regulatory code and standard citations developed under FIN I-2012, "Technical Assistance in Support of Ascertaining the Status of Codes and Standards Referenced in NRC Regulatory Documents." This database, entitled "Codes and Standards and Other Guidance or Requirements Cited in Regulatory Documents" is to be organized in three parts. Part A is a listing of both endorsed and non-endorsed industryconsensus Code and Standard citations in NRC regulatory documents. Part B is a listing of other endorsed guidance or requirements and Part $\mathrm{C}$ is a listing of nonendorsed citations from other guidance and requirements. Nonendorsed means the citations are used in descriptive text as a general reference or specifically cited as not to be used.

Information presented in the database includes the following: (1) the code or standard title, number, and date, (2) the NRC document containing the citation and date, (3) whether the NRC document endorses the code or standard, (4) comments or exceptions noted in the NRC document, and (5) current version and date of the cited code or standard.

Completion of the code and standard comparison work described below will also serve as a review and verification of the information currently in the database.

In order to assure timely identification of SRP impacts related to codes and standards, priority assignments for code and standard impact reviews will be made in the same manner as SRP section assignments. The results of codes and standards evaluations will be provided to the PRBs on an SRP section basis and will be added to the document impact packages prepared in Section 3.2.

Potential SRP impacts identified through this work will be entered into the SRP Modification Database as described in Section 2.4 of this Implementing Procedures Document. Potential impacts will be of three types. First, a potential impact will be identified where code and 
standard citations found in SRP text are determined to be out-of-date. Second, code or standard citations in other NRC documents (e.g., 10 CFR and Regulatory Guides) that directly impact SRP sections will be cross-referenced from the NRC document to the SRP section, with the issue associated with the code or standard discussed in the impact summary of the Impact Identification form. Third, the need for NRC endorsement of additional codes and standards, some of which may not yet exist, will be identified for the SRP section under consideration. A potential impact will only be entered to the SRP Modification Database when the analyst determines there is potential for the SRP to be modified. In addition, all codes or standards included in the SRP must be publicly available at a reasonable cost. Therefore, such documents as INPO documents that are not publicly available will not be referenced in the revised SRP as standards. Such codes and standards will be identified and the need to replace them will be entered into the SRP Modification Database.

Potential impacts will be identified by analysts who are assigned SRP sections. Code citations appear directly in the text of the SRP. As documents in the RECALL database and other regulatory documents are searched for impacts to a specific SRP section, the analyst should compare the documents found to those listed in the database previously developed under FIN I-2012. For example, given a list of regulatory guides that have potential impacts to the assigned SRP section, a scan of the current code and standard citation list will show whether any codes or standards are endorsed in that group of regulatory guides. This will be the set of codes or standards to be analyzed for impacts relating to the SRP section. The analysts will also identify unreferenced codes and standards of interest and identify needed standards for the assigned SRP sections. The results of code and standard impact searches will be provided to the appropriate PRB. This effort is subdivided into four tasks, as follows:

\section{Codes and Standards Comparison}

Codes and standards currently referenced in regulatory documents will be compared with their latest versions. Recommendations will be developed covering (a) the safety impact of the referenced version versus that of the current version, and (b) which version (referenced or current) should be referenced or endorsed in NRC regulatory documents. The recommendations along with the accompanying technical bases will be provided for NRC staff review.

The results of this work will be provided to NRR technical divisions by the PTSB on an SRP section basis for review and comment. The technical divisions' responses to the issues will be provided to PNL by the PTSB. In addition, the technical divisions' responses to the issues identified in the final report will be provided to PNL by the PTSB. PNL will enter these responses into the SRP Modification Database. This effort may result in the identification of candidates for future work outside the scope of the SRP Update and Development Program. As appropriate, the Research/Regulatory Action Needs Form in Procedure 7.0 will be used to identify potential needs and to obtain PRB and PTSB approvals.

\section{Identification of Unreferenced Codes and Standards of Interest}

Existing or proposed industry codes or standards that are not currently referenced in regulatory documents will be evaluated with respect to potential reference or endorsement by NRC.

The results of this work will be provided to NRR technical divisions by the PTSB on an SRP section basis for review and comments. The technical divisions' comments will be provided to PNL by the PTSB. PNL will enter the responses into the SRP Modification Database. This effort may also result in the identification of candidates for future work.

\section{Identification of Needed Standards}

An assessment will be performed of whether codes or standards are lacking for particular design innovations anticipated in future applications (e.g., for software reliability or fiber optics).

The results of this work and PNL's recommendations will be provided to NRR technical divisions by the PTSB on an SRP section basis for review and comment. The technical divisions' comments will be provided to PNL by the PTSB. PNL will enter the responses into the SRP Modification Database. This effort may also result in the identification of candidates for future work, which would be handled by procedures in Chapter 7.0.

\section{Comparison of Electric Power Research Institute (EPRI) Commitments to Codes and Standards}

Commitment to industry codes and standards cited in the EPRI Requirements Document will be characterized and compared with NRC positions. Examples of issues that should be assessed include identifying whether EPRI has committed to comply with out-of-date codes and standards and whether EPRI proposes to adopt codes and standards that are not currently endorsed by NRC.

The results of this work and PNL's results will be provided to NRR technical divisions by the PTSB for 
review and comment. The technical divisions' comments will be provided to PNL by the PTSB. PNL will enter the divisions' responses into the SRP Modification Database.

\subsubsection{Procedure for Code and Standard Comparison}

\section{Purpose and Scope of this Procedure}

This procedure establishes guidance for performing four activities. The first is performing a comparison of codes and standards currently referenced in regulatory documents with the latest version of the codes and standards. The second is making recommendations as to which codes and standards not currently endorsed in NRC regulatory documents should be considered by the NRC for future endorsement. The third is identifying new industry codes or standards that may need to be developed. The fourth is assessing EPRI's commitments to codes and standards.

\section{Prerequisites for Performing this Procedure}

Technical Skills and Knowledge Level. An analyst performing this procedure requires a technical background and a working knowledge of nuclear power plant designs and systems and applicable regulatory materials, including the SRP. The analyst should possess detailed knowledge of the systems, structures, components, or processes covered by the assigned codes and standards and have an understanding of the function and structure of the assigned code and standard group and familiarity with the various code libraries available to PNL.

Document Availability. Completion of this procedure requires access to both current versions of codes and standards and referenced versions.

Codes and standards referenced in regulatory documents are expected to be added to the SRP reference document database, provided that permission is obtained from the copyright holders.

Completion of Prior Procedures. No prior procedures need to have been initiated or completed prior to performance of this procedure.

\section{Overview of Steps in this Procedure}

Reviewing and verifying information presented in the database developed in FIN I-2012 is accomplished using two complementary approaches. The first approach is to select a block of data from the database (a logical grouping, such as codes and standards issued by the American Nuclear Society or the American National Standards Institute) and analyze the information presented on a line-by-line basis. The analysis would compare current and referenced versions of the cited code, with particular emphasis on exceptions, clarifications, or additions mentioned in the regulatory document.

In the second approach, the analyst uses previously identified relationships between regulatory documents and specific SRP sections and a listing of documents found to contain impacts for specific SRP sections from a search of the RECALL database and other regulatory documents; with this information, the analyst assembles the group of code and standard citations in the identified regulatory documents that are applicable to an assigned SRP section.

In completing document reviews related to an assigned SRP section, multiple codes will be identified and analyzed. Potential impacts to specific SRP sections will be entered into the modification database upon identification to facilitate the development of revised SRP sections.

Making recommendations as to which codes and standards not currently endorsed in NRC regulatory documents should be considered for future endorsement relies upon a review of EPRI-endorsed codes and standards and other codes and standards currently issued and actively used in the United States.

Extensive code committee contact and interaction is anticipated in completing this task. Identifying new industry codes and standards that need to be developed will be accomplished by comparing the SRP review areas with the areas currently covered by existing codes and standards; any areas not covered will be subjects of potential new code and standard development.

In evaluating future reactor designs, unique technology or unique applications will be identified as potential items requiring code or standard development. Analysts will communicate with the various code committees to ascertain the plans of such groups regarding development of new codes and standards.

The review of the EPRI commitments to codes and standards will be accomplished by comparing the EPRI commitments contained in the EPRI Requirements Document to codes and standards currently cited by the NRC and evaluating the implications of observed differences. Where EPRI does not state a specific version or date for a code or standard, it will be assumed to endorse the current version. 


\section{Results of this Procedure}

Written Product. Written products will be as stated in the task descriptions provided in Section 2.5.1 above. In addition, Document Entry Logs (Procedure 2.1) will be completed for each applicable industry code and standard and Impact Identification Forms (Procedure 2.4) will be completed for each identified potential impact between a code or standard and SRP sections. Research/Regulatory Action Needs Forms (Procedure 7.0) will be completed as applicable.

\section{Detailed Procedure}

This section specifies the step-by-step sequence to be followed, grouped by directives (major intermediate outputs), to be accomplished through a series of specific steps.

\section{Directive 1: Perform preparatory activities.}

Step 1 Obtain access to the database completed by PNL for the NRC under FIN I-2012, "Technical Assistance in Support of Ascertaining the Status of Codes and Standards Referenced in NRC Regulatory Documents."

Step 2 Assign analysts to specific code groups or SRP sections, as appropriate, using the Work Assignment Form included in Procedure 2.1 (Manager's responsibility).

Step 3 Obtain any codes and standards not available after completion of Procedure 2.3.

Directive 2: Compare the industry codes and standards currently referenced in NRC regulatory documents with the latest version of these codes and standards. This directive is applicable to work performed under either approach outlined in the overview.

Step 1 Organize the line items from the NRC code and standard Database. Organizing must include placing in alphabetical and ascending numerical order and citing applicable NRC regulatory documents with each code and standard line. Where EPRI has also endorsed the code or standard, include the citation with the listing. Where EPRI does not specify a date or version for a code or standard, assume that the current version is endorsed.

Step 2 Verify that the analyst has the current version of the referenced code or standard. Exceptions noted in the NRC reference document related to each specific code citation must be noted and analyzed relative to the current code or standard. The analyst will note where the current code has adopted a change that allows an exception to be dropped or changed in the NRC regulatory document.

Step 3 Obtain a copy of the referenced or "old" code or standard.

Step 4 Compare the current edition of the code or standard with the referenced edition with respect to the issues identified in the NRC regulatory document related to the specific code citation. Determine whether the current edition of the code or standard has addressed any regulatory positions.

Step 5 Recommend an endorsement category for each code and standard citation. Typical classifications would be:

A - endorse current code (with year stated)

B - endorse current code with exceptions noted

C - endorse referenced code (with year stated)

D - citation should be dropped -- This would apply to obsolete or withdrawn citations.

E - other -- For those citations outside the normal disposition categories, case-by-case explanations are required.

\footnotetext{
${ }^{1}$ This database has been reorganized into three parts: Part A, IndustryConsensus Codes and Standards; Part B, Endorsed Guidance or Requirements; and Part C, Nonendorsed Citations. "Nonendorsed" means that the citations are used in descriptive text as general references or specifically cited as not to be used. Through use of the expanded RECALL database, additional code and standard citations not identified during the original work have been added.
} 
Step 6 Prepare a written summary of the results of Steps 2,4 , and 5. Include in the summary an abstract of the technical evaluation and any recommendations on modifications to NRC endorsements. This applies whether the work is accomplished on a consensus group basis, an SRP section basis, or both. Provide the report in both draft and final forms to the PTSB for PRB review and comment. Include in the written summation an analysis of applicable codes and standards endorsed in the EPRI Requirements Document.

Step 7 Resolve any comments received from the PTSB, and repeat Step 6, if necessary.

Step 8 Prepare Document Entry Logs according to the guidance included in Procedure 2.1 for each code or standard meeting the criteria included in that procedure.

Step 9 Complete Impact Identification Forms according to the guidance included in Procedure 2.4 for each code or standard meeting the impact criteria included in that procedure.

Step 10 For codes and standards that are not publicly available at a reasonable cost, the requirements cited therein will be identified and the need to replace them will be entered into the SRP Modification Database via Procedure 7.0.

Step 11 Candidates for future work identified in the preceding steps should be documented using Procedure 7.0. Future work may involve a need to revise or expand the regulatory base or a need for future NRC research activities.

Step 12 PRB responses to each code and standard evaluation will be entered in the SRP Modification Database.

Directive 3: Identify unreferenced codes and standards of interest.

Step 1 Identify codes and standards referenced in the EPRI Requirements Document that are not currently included in the NRC database.

Step 2 Identify codes and standards that are currently in active use in the U.S.

Step 3 Obtain a copy of each code and standard identified in Steps 1 and 2.
Step 4 Compare the identified codes and standards with the NRC database and make recommendations as to which unreferenced codes or standards should be addressed in NRC documents.

Step 5 Evaluate identified codes and standards with respect to reactor design concepts that are undergoing review. Unique technology or applications associated with designs will be matched to unreferenced codes and standards where possible.

Step 6 Create a list of unreferenced codes and standards that are potential candidates for NRC endorsement with respect to nuclear plant designs. Develop and submit to the PTSB a report summarizing the results of this effort for PRB review and comment.

Step 7 Prepare Document Entry Logs (Procedure 2.1) and Impact Identification Forms (Procedure 2.4), as required.

Step 8 Future work related to regulations or research, which has been identified in the preceding steps, should be documented using Procedure 7.0.

Step 9 PRB responses to each code and standard evaluation will be entered in the SRP Modification Database via the Comment/ Resolution Form (Procedure 6.0).

Directive 4: Identify needed standards that do not currently exist.

Step 1 Consider review areas, on an industry consensus group basis or an SRP section basis, to determine areas in which adequate guidance is not provided currently and for which the development of a new code or standard would be reasonable. As assignments are completed under the previous directives, the analysts will consider the need for new codes and standards for their specific topic. Identified needs will be documented and entered into the SRP Modification Database using the Comment/Resolution Form in Procedure 6.0 or the Research Regulatory Action Needs Form in Procedure 7.0.

Step 2 Evaluate unique technology and the unique application of existing technology associated with reactor designs where a need for new codes or standards could exist. 
Step 3 Contact code committees to ascertain industry plans for future code and standard applications

Step 4 Identify any other aspect of nuclear plant design where additional codes and standards may be required. Concurrence from recognized experts or organizations may be solicited to validate identified concerns.

Step 5 Evaluate the results of the foregoing steps and consolidate the developed information in a report.

Provide the report to the PTSB for PRB review and comment. Impacts would be entered via Procedure 2.4 at this time.

Step 6 Resolve any comments received from the PTSB and repeat Step 5, as necessary.

Step 7 Future work related to regulations or research, which is identified in the preceding steps, should be documented using Procedure 7.0.

Step 8 PRB responses to each code and standard evaluation will be entered in the SRP Modification Database via the Comment/ Resolution Form (Procedure 6.0).

Directive 5: Review EPRI commitment to codes and standards.
Step 1 Review the EPRI Requirements Document and list all code and standard citations.

Step 2 For each item identified in Step 1, assess the level of EPRI commitment to the particular code or standard.

Step 3 Compare the EPRI code and standard list with the NRC database. Identify those codes or standards cited by the NRC and not by EPRI. Identify those codes or standards cited by EPRI but not by NRC.

Step 4 Identify those instances where EPRI endorses an edition of the code different from the current or latest revision. Also, identify those instances where EPRI cites a different edition than that referenced by the NRC. ${ }^{2}$

Step 5 Prepare a written summary of results. Provide the report in both draft and final stages to the PTSB for PRB review and comment.

Step 6 Resolve any comments received from the PTSB, and repeat Step 5, if necessary.

Step 7 Prepare Document Entry Logs (Procedure 2.1) and Impact Identification Forms (Procedure 2.4), as required.

\footnotetext{
${ }^{2}$ The completion of Directive 2, Code and Standard Comparison, will also evaluate the appropriate EPRI code and standard citations with respect to: (a) which edition of the code or standard is most appropriate to endorse, (b) in which situations the endorsement of the latest revision is appropriate, and (c) where conflicts exist between EPRI endorsements and NRC citations. This information will be summarized in step 6 of Directive 2.
} 


\subsection{Update and Upgrade of the SRP for Future Reactor License Applications}

This chapter contains the procedures to be followed in updating and upgrading the SRP for use in the review of future reactor license applications to reflect existing Agency requirements and guidance and to add new review criteria to accommodate unique technology or the unique application of existing technology in future reactor designs.

Chapter 3 is organized as follows, and is summarized in Table 4.

- Needed new SRP sections are identified (Section 3.1).

- NRC will prioritize SRP sections for updating and upgrading (Section 3.2).

- For a given SRP section, SRP impacts that were identified through Procedure 2.4 are integrated (Section 3.3).
- Unresolved Safety Issues and Generic Safety Issues documents are reviewed to determine their applicability to evolutionary and advanced reactors (Section 3.4).

- SRP impacts applicable to evolutionary and advanced reactor technology are identified and integrated (Section 3.5).

- The PRB determines the organization that will be assigned to perform impact evaluation and drafting of SRP sections (Section 3.6).

- Draft updates and upgrades are prepared through one of three management options selected by the PRB (Sections 3.7 and 3.8). 
Table 4. Summary of Chapter 3

\begin{tabular}{|c|c|c|}
\hline Chapter 3 Sections & Pages & Description of Section Content \\
\hline $\begin{array}{l}\text { Section 3.1: Identifying the Need for } \\
\text { New SRP Sections }\end{array}$ & $3.1-1$ & $\begin{array}{l}\text { Presents criteria for deciding whether to expand an } \\
\text { SRP section or create a new one. } \\
\text { Presents procedures for identifying potential new } \\
\text { review areas that could result in new SRP sections, } \\
\text { evaluating the potential review areas, and } \\
\text { developing a list of new SRP sections. }\end{array}$ \\
\hline $\begin{array}{l}\text { Section 3.2: Prioritizing SRP } \\
\text { Sections for Updating and Upgrading }\end{array}$ & $3.2-1$ & $\begin{array}{l}\text { - Provides examples of safety categories. } \\
\text { Presents procedures for determining the safety } \\
\text { significance of SRP sections and ranking them } \\
\text { according to safety significance for purposes of } \\
\text { SRP updating and upgrading. } \\
\text { - Presents procedures for assigning relative update } \\
\text { and development priority to existing and newly } \\
\text { identified SRP sections. }\end{array}$ \\
\hline Section 3.3: Integrating Impacts & $3.3-1$ & $\begin{array}{l}\text { - Presents procedures for integrating impacts } \\
\text { identified through Procedure 2.4. }\end{array}$ \\
\hline $\begin{array}{l}\text { Section 3.4: Reviewing USIs/GSIs } \\
\text { for Applicability to Future Reactor } \\
\text { Designs }\end{array}$ & 3.4-1 & $\begin{array}{l}\text { Presents criteria and procedures for identifying } \\
\text { Unresolved Safety Issues (USIs) and Generic } \\
\text { Safety Issues (GSIs) that should be evaluated in } \\
\text { relation to future reactors. }\end{array}$ \\
\hline $\begin{array}{l}\text { Section 3.5: Integrating Impacts for } \\
\text { Future Reactor Designs }\end{array}$ & $3.5-1$ & $\begin{array}{l}\text { Presents procedures for identifying and obtaining } \\
\text { documents that contain information needed to } \\
\text { upgrade or develop SRP sections for future reactor } \\
\text { designs. } \\
\text { - Presents procedures for integrating SRP impacts. }\end{array}$ \\
\hline Section 3.6: Assigning Work by the & 3.6-1 & $\begin{array}{l}\text { Presents procedures for obtaining PRB } \\
\text { determination of the organization that will be } \\
\text { assigned to perform impact evaluation and drafting } \\
\text { of SRP section updates and upgrades. }\end{array}$ \\
\hline Section 3.7: Updating SRP Sections & $3.7-1$ & $\begin{array}{l}\text { - Presents procedures for determining the } \\
\text { significance of identified impacts, characterizing } \\
\text { and assessing potential changes, and characterizing } \\
\text { potential revisions as Type I or Type II. } \\
\text { - Provides measures of impact significance. } \\
\text { - Presents procedures for PRB determination of the } \\
\text { impacts to be incorporated in each SRP section. } \\
\text { - Presents procedures for drafting revised or newly } \\
\text { identified SRP sections to reflect current } \\
\text { technology. } \\
\text { - Includes guidance for drafting each subsection of } \\
\text { an SRP section, including guidance for drafting } \\
\text { technical rationales for Acceptance Criteria. }\end{array}$ \\
\hline
\end{tabular}


Table 4. Summary of Chapter 3 (continued)

\begin{tabular}{lcl}
\hline \multicolumn{1}{c}{ Chapter 3 Sections } & Pages & \multicolumn{1}{c}{ Description of Section Content } \\
\hline Section 3.8: Upgrading SRP Sections & $3.8-1$ & $\begin{array}{l}\text { Presents procedures for characterizing SRP } \\
\text { impacts. }\end{array}$ \\
\hline for Future Reactor Designs & & $\begin{array}{l}\text { Presents procedures for identifying areas where } \\
\text { current regulations are inadequate or where } \\
\text { additional research is required to establish a } \\
\text { licensing basis for future reactor designs. }\end{array}$ \\
& & $\begin{array}{l}\text { Presents procedures for PRB determination of the } \\
\text { impacts to be incorporated in each SRP section. }\end{array}$ \\
& $\begin{array}{l}\text { Presents procedures for generating Upgrade } \\
\text { Outlines that will be used by the PRB in deciding } \\
\text { how SRP sections will be upgraded. }\end{array}$ \\
& $\begin{array}{l}\text { Presents procedures for drafting upgrades to } \\
\text { existing SRP sections and for drafting newly } \\
\text { identified SRP sections to provide the review } \\
\text { guidance for evolutionary and advanced reactor } \\
\text { designs. }\end{array}$ \\
\hline
\end{tabular}


-

-

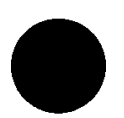




\subsection{Identifying the Need for New SRP Sections}

\subsubsection{Approach}

The SRP section is the fundamental unit of the SRP (see Section 1.5, Definitions, of this Implementing Procedures Document). Most of the work to be performed in updating and upgrading the SRP will be accomplished on a section-by-section basis. The term "section" is used in this procedure to represent either an actual SRP section or subsection, or some type of addendum to an existing section or the entire SRP.

The current SRP consisting of 221 sections, through years of use and development, can reasonably be taken to represent the minimum set of sections needing to be considered.

New SRP sections will only address future reactor technology, not current reactors. However, if a currently licensed plant wanted to incorporate future reactor technology into its design, i.e., a plant modification, then it would have to satisfy the pertinent new SRP section.

Three sources of items that could result in the need for additional sections are: (1) the appendices and branch technical positions (BTPs) contained in the SRP, (2) review guidance for new systems, unique technology, or the unique application of existing technology in future reactor license applications, and (3)generically applicable topics which are not currently addressed. Each of the three potential sources of new sections is discussed in more detail below. There may also be cases where SRP sections could be combined.

For the most part, the appendices and BTPs contained in the SRP are supplementary to existing SRP sections, usually providing additional detailed information. Each SRP appendix and BTP will be reviewed to determine whether its contents would be more appropriately merged into existing SRP sections or developed into a unique section. Ordinarily, the supplementary information should be merged into existing sections. However, where the amount of supplementary information is so extensive that merging it with an existing section would be confusing or significantly difficult to use, establishing a new section should be considered.

The evolutionary and advanced reactor designs clearly contain some new systems relative to those contained in current generation plants (e.g., the CANDU-3 horizontally injected liquid poison system). Also, future reactor applications are expected to incorporate unique technology or the unique application of existing technology that may not be adequately addressed in the
SRP. A decision must then be made by NRR if the appropriate course of action is to expand the scope of current sections or develop new sections.

The decision whether to expand an SRP section or create a new one will require evaluation on a case-by-case basis and the following set of criteria can help to make this determination. Topics or subjects meeting any of the following criteria would generally be considered for a new section:

- The system or concept is so unique relative to current technology that it would be inappropriate or confusing to include its description in a current SRP section.

- The subject matter is sufficiently extensive that it would justify separate treatment.

- The subject matter is sufficiently different from the most closely related SRP section that a different primary review branch would be needed to adequately review the subject.

- The system uses existing technology in such new or unconventional ways so as to require separate review.

A number of generically applicable topics could be considered for inclusion in the SRP as part of existing sections or new sections, including issues related to the following: probabilistic risk assessment, accident management, environmental impact, systems interaction, maintenance, overall safety (conflicting requirements), "other-than-normal" conditions (including outages), amendments, deferred construction restart, and aging management for structures, systems, and components. Other topics that could be added to this list should be identified, and the entire list should be evaluated to determine whether new sections are warranted. The final list of topics will be subjected to the prioritization activities described in Sections 3.2 and then evaluated for continued consideration.

A potential topic for a new SRP section is related to plant layout considerations. The spatial configuration and the physical design and geometry of structures, systems, and components have been shown in evaluations of operating experience to have potential impacts on the reliability and safety of nuclear power plant operations. In particular, plant layout issues should be considered in the design of future plants to minimize the potential for adverse systems interactions.

It is also noted that the industry has taken steps to specify design processes which will consider plant layout issues and related regulatory requirements. A primary focus of industry efforts is to enhance maintainability and 
operability of the plant and to incorporate human factors considerations early in the design process. A new SRP section would specify the regulatory bases for plant layout issues and discuss the related regulatory issues in areas such as seismic system analyses, high energy line break hazards, radiation protection, fire protection, internal flooding and water intrusion, inservice inspection and testing, missile protection, and pipe rupture and impingement protection. Specific acceptance criteria and review procedures for these regulatory issues would be provided in the specific SRP sections which cover these areas.

As part of the integration of the SRP, the Environmental Standard Review Plan (ESRP) will be incorporated in the safety review SRP. The ESRP will be included as a new chapter. At a later date, license renewal review will also be incorporated in the safety review SRP. The area of license renewal will be addressed in at least three new SRP chapters. One chapter will address license renewal for current reactors. One chapter will address license renewal for future reactor applications (to be developed). One chapter will address environmental assessment for license renewal (see NUREG-1425). Other standard review plans or SRP-like documents may also be incorporated in the NUREG-0800 SRP. These various standard review plan documents will have to be considered in establishing new SRP chapters and sections.

Sections that are newly identified by NRR will be added to the SRP. The resulting list of sections will form the basis for the subsequent tasks required to update and upgrade the SRP. Implementation of Procedure 3.1 may also identify areas where certain existing sections might need to be updated (e.g., to incorporate a BTP); these potential updates are essentially "SRP impacts" as discussed in Section 2.4 and should be provided as inputs to Procedure 2.4.

\subsubsection{Procedure for Identifying New SRP Sections}

\section{Purpose and Scope of This Procedure}

This procedure is intended to identify any potential new review areas that could result in new SRP sections, evaluate the potential review areas, and develop a list of new sections to be added to the current SRP section listing. The scope of this procedure is limited to SRP appendices and BTPs, new systems, unique technology, or the unique application of existing technology developed for future reactor applications for which SRP sections do not currently exist, and generically applicable topics not adequately addressed in the current SRP. In those instances where pertinent information on unique technology or the unique application of existing technology developed for future reactor applications is not yet available, the current status of this information will be noted as a "placeholder" in the revised SRP. When the necessary information becomes available, the SRP will be upgraded accordingly.

\section{Prerequisites for Performing This Procedure}

Technical Skills and Knowledge Levels. Persons performing this procedure should have a working knowledge of nuclear plant systems, design, construction, operations, and licensing requirements, and the current SRP.

Document Availability. In order to complete this procedure, documents must be available that adequately describe the designs of evolutionary and advanced reactors and associated staff safety evaluation reports (to the extent that they are available). The SRP is also required and is readily available.

Completion of Prior Procedures. This is the first of the procedures that apply specifically to updating and upgrading SRP sections. No other procedures need to have been initiated or completed prior to performing this procedure.

\section{Overview of This Procedure}

The process of identifying potential new SRP sections consists of several steps. First, the appendices and BTPs contained in the SRP are evaluated for incorporation in an existing or new SRP section. Second, new aspects of future reactor applications are reviewed against the SRP to identify areas that are not adequately covered. Third, generic issues are considered to determine if they merit coverage in a separate section of the SRP. (In actuality, these first three steps may be performed in any order or even simultaneously.) Finally, the new candidate sections are added to the list of existing sections, and all of the resulting sections are then processed in accordance with subsequent procedures. Potential existing section updates are also identified and used as input for Section 2.4.

\section{Results of This Procedure}

Written Product. Since the effort described in this procedure is performed off-line (i.e., it is not performed using the SRP Modification Database), the product of this procedure, the list of new SRP sections combined with existing sections, may be taken as a written product to be entered into the SRP Modification Database when it becomes available. A written justification for identifying new sections is also included. 
Other. An additional output of this procedure is the identification of potential SRP section updates. The results of this effort are used as input in Section 2.4.

\section{Detailed Procedure}

This section specifies the step-by-step sequence to be followed, grouped by directives (major intermediate outputs), to be accomplished through a series of specific steps.

Directive 1: Review appendices and BTPs to identify potential new SRP sections.

Step 1 Obtain a current copy of the SRP and review each appendix and BTP contained therein.

Step 2 For each appendix and BTP, identify those SRP sections that address the same subject(s) as the appendix or BTP. In general, there will be at least one SRP section that references the appendix or BTP. The analyst will attempt to identify any additional sections dealing with related subject matter.

Step 3 Compare the material covered in the appendix or BTP with the subjects covered in the sections identified in Step 2. Evaluate whether it would be appropriate to merge the appendix or BTP with a section or to maintain the integrity of the material in the appendix or BTP by creating a new section.

Step 4 Develop and document the bases behind each recommendation for each evaluation performed in Step 3.

Directive 2: Identify potential new SRP sections based on new systems and concepts in future reactor design.

Step 1 Obtain documents describing evolutionary and advanced reactor designs.

Step 2 Compare the evolutionary reactor designs against the SRP on a system-by-system basis. Identify any areas where the SRP is unable to adequately support the staff's technical review (e.g., a system is not addressed or, due to advances in a particular system, the SRP section needs to be upgraded). For each area so identified, determine whether a new section is needed or an upgrade to an existing section would suffice. Develop and document a justification for each recommendation.
Directive 3: Identify potential new SRP sections based on generic licensing and safety issues.

Step 1 Beginning with the list of generic issues provided in Section 3.1.1, convene a panel of experts to expand the list by adding any other issues that can be identified.

Step 2 For each item on the Step 1 list, obtain from the panel an evaluation of the need for creating a new SRP section to address the issue. Consider the possible incorporation of the issue in specific existing SRP sections. Document the results of the evaluation, including justification for the conclusions reached.

Directive 4: Obtain NRR approval for new SRP sections.

Step 1 Compile the information resulting from Directives 1 through 3, including the recommendations regarding the need for new sections and associated justifications.

Step 2 Provide the information resulting from Step 1 to the PTSB for NRR review and approval. Typically, approvals will be obtained from the appropriate associate director.

Step 3 Consistent with NRR approval, develop a list of new sections.

Directive 5: Prepare information for project use.

Step 1 Add the new sections resulting from Directive 4, Step 3, to the current list of SRP sections. Add the new sections in the appropriate locations, using a numbering system consistent with the current system. The resulting list will be an input to Procedure 3.2.

Step 2 Compile the need for updates to existing sections resulting from implementation of Directives 1 through 3. Enter each needed update into the SRP Modification Database using forms and directions specified in Procedure 2.4.

Directive 6: Perform the previous directives for other review areas.

Step 1 In consultation with PTSB, determine the additional review areas (environmental, license renewal, etc.) to be incorporated in the SRP.

Step 2 For each of those review areas, repeat Directives 1-5. 


\subsection{Identifying New SRP Sections}

Directive 7: Repeat the previous directives periodically to capture new and ongoing developments.

Step 1 Establish a schedule for performing periodic updates of the work described in this procedure. More frequent updates may be preferred as the project approaches completion.

Step 2 Perform the relevant portions of Directives 1 through 6 according to the schedule developed in
Step 1. The scope of this step should be restricted to developments that have occurred since the last time the process described in this procedure was exercised.

\section{Forms}

No new forms are used in this procedure. 


\subsection{Prioritizing SRP Sections for Updating and Upgrading}

\subsubsection{Approach}

The effort to update and upgrade the SRP for future reactor license applications and the unique technology and unique application of existing technology in future reactor designs is expected to take several years. Clearly, however, work on all SRP sections cannot and should not be undertaken simultaneously. Limited resources will require that portions of this effort be completed in a phased manner over the course of the SRP Update and Development Program. A phased approach is also desirable because it will facilitate program enhancements over time through mid-course corrections based on lessons learned in applying the implementing procedures and in using the SRP Modification Database.

To determine a recommended sequence in which the work should proceed, it will be beneficial to prioritize the SRP sections (both existing SRP sections and the new SRP sections identified through implementation of Procedure 3.1). This prioritization will be based on two considerations: (1) safety significance, and (2) NRR program priorities, such as the review schedule for the ABWR. It should be noted that this prioritization of SRP sections, including the determination of safety significance, is only being done to support the SRP Update and Development Program and is not intended to be used for any other purpose. It should also be noted that work priorities are always subject to change due to changing programmatic needs and the resolution of technical issues.

The safety significance of SRP sections is determined by establishing safety categories, evaluating the content of the section within the context of each safety category, and appropriately combining the results of the evaluations in each category. The results for each SRP section may be compared against the others, thereby leading to a safety hierarchy that numerically ranks SRP sections according to safety significance.

Safety categories help characterize the safety implications of SRP sections. The following are examples of safety categories: safety system, safety function, operational experience, and safety issues. These safety and other potential categories result from various types of safety studies that have been performed, such as probabilistic risk assessment, LER case studies, severe accident insights, and analysis of significant operational occurrences, as well as combinations of the various studies. The categories define the perspectives from which each SRP section will be analyzed. Also inherent in establishing the categories is establishing the evaluation criteria associated with them. Evaluation criteria provide a means of positioning an SRP section within the safety hierarchy for a given category.

Finally, the safety significances in each category are combined using a prescribed, weighted-average algorithm. A weighted-average algorithm is an algebraic equation that provides the average of a number of values where different weights or importance are given to the various values. As a simple example, the weighted average of 1 and 3 where 1 is five times as important as 3 is:

$((5 \times 1)+(1 \times 3)) /(5+1)=1-1 / 3$

In general, a weighted average algorithm would take the form:

$(a x+b y+c z+\ldots) /(a+b+c+\ldots)$

where $x, y, z, \ldots$ are the values to be averaged and $a, b$, c, ... are the weights assigned to each value. The result is a measure of the overall safety significance of the SRP section. This process is repeated for each SRP section. Then all of the sections are ranked based on their safety significance. Because the technique of determining safety significance is inherently imprecise, the results are typically presented in a semi-qualitative way; that is, using a high-medium-low measure or using percentile measures. The results are helpful in prioritizing sections. Again, it should be noted that they are not intended for any other use.

Some of the work required for this activity has already been accomplished; for example, a hierarchy of safety systems has been developed. It is the intent that the result of any previously performed work be used to the maximum extent possible.

The product of this activity is envisioned to be one or more matrices correlating SRP sections with safety categories. The matrix will be filled with the evaluated safety significance within each category, work is expected to be performed off-line. Only the final matrix or matrices will be entered into the SRP Modification Database.

NRR program priorities will reflect NRR's relative need for updated or upgraded SRP sections in meeting its regulatory and safety responsibilities. For example, NRR is in the process of reviewing designs for such evolutionary reactors as the ABWR and System 80+ and the review schedule will affect the SRP revision schedule. NRR program priorities will be provided by PTSB. It is anticipated that programmatic priorities will change over time. 


\subsection{Prioritizing SRP Sections}

An additional consideration in the prioritization of SRP sections for evolutionary and advanced reactor designs is the completion of section updating to reflect current technology and NRC requirements. Evolutionary and advanced reactor SRP sections will generally build on the base SRP section (i.e., modify requirements from the set of current requirements). It is necessary, therefore, to ensure that base SRP sections are updated before the evolutionary or advanced reactor sections that depend on them.

Safety significance and NRR program priority considerations will be integrated through a simple ordering scheme. One likely candidate is an ordering that gives primacy to NRR program priorities. Under this approach, SRP sections with the most urgent NRR program priority would be assigned the highest overall priority; SRP sections within that group would be prioritized according to their safety ranking. SRP sections with the next most urgent NRR program priority would be assigned the next highest overall priority; again, SRP sections within that group would be prioritized by safety ranking. Ordering would continue in this manner for each level of NRR program priority. Thus, using this scheme, SRP sections with high NRR program priority and low safety significance would have a higher overall priority than SRP sections with low NRR program priority and high safety significance. It should be noted that safety significance is an important element of NRR programmatic prioritization.

The prioritization methodology is illustrated in Table 5 . This example assumes that NRR has determined that control and instrumentation SRP sections are of highest programmatic priority and human factors sections are of second highest priority. Seven SRP sections are included in SRP Chapter 7, Instrumentation and Controls, and three sections in SRP Chapter 18, Human Factors Engineering. The example assumes that the sections have a safety ranking, from highest to lowest, of Sections 7.4, 7.2, 7.3, 18.2, 7.5, 7.6, 18.0, 7.7, 7.1, and 18.1. With these assumptions, Table 5 would indicate an overall SRP section priority of $7.4,7.2,7.3,7.5,7.6,7.7,7.1,18.2$, 18.0, and 18.1. This would then be the order in which to recommend updating the SRP sections. Of course, the actual prioritization activity would address all of the SRP sections.

It is anticipated that prioritizations will be updated periodically to reflect completion of work and changing NRR program priorities.

Table 5. Example of SRP Section Prioritization

\begin{tabular}{lcc}
\hline NRR Programmatic Priority & Safety Ranking & Overall Priority \\
\hline Instrumentation and Controls & 7.4 & 7.4 \\
Human Factors Engineering & 7.2 & 7.2 \\
& 7.3 & 7.3 \\
& 18.2 & 7.5 \\
& 7.5 & 7.6 \\
& 7.6 & 7.7 \\
& 18.0 & 7.1 \\
& 7.7 & 18.2 \\
& 7.1 & 18.0 \\
& 18.1 & 18.1 \\
\hline
\end{tabular}

\subsubsection{Procedure for Prioritizing SRP Sections}

\section{Purpose and Scope of This Procedure}

This procedure specifies how existing and newly identified SRP sections are to be assigned relative priority for updating and upgrading. This prioritization will be used in setting schedules and allocating resources for completion of the SRP Update and Development Program. Included in this procedure is a process to be used in determining the safety significance of SRP sections and ranking them according to safety significance. Also included in this procedure is certain developmental work required for establishing the safety categories and associated evaluation scales. Previously performed work is to be used whenever it is available and meets project needs. 
Prerequisites for Performing This Procedure

Technical Skills and Knowledge Levels. Developmental work regarding safety significance requires significant technical and analytic experience, particularly in the areas of probabilistic risk assessment, severe accident analysis, and operational experience. Actual evaluation of SRP sections will require a working knowledge of nuclear plant systems, design, construction, operations, and licensing requirements, and the current SRP. Prioritization should be performed or closely directed by managers within the SRP Update and Development Program with comprehensive knowledge of and responsibility for the SRP Update and Development Program and knowledge of NRR programmatic priorities.

Document Availability. Performance of this procedure requires the availability of the following types of documents from sources outside the SRP Modification Database: probabilistic risk assessments, analyses and assessments of severe accident scenarios, and assessments of operational experience and events. Specific document requirements will be established by the analysts performing the work. Performance of this procedure also requires a statement of program priorities regarding SRP section update and development from PTSB.

Completion of Prior Procedures. This procedure may be initiated at any time. Any new SRP sections will have to be identified through implementation of Procedure 3.1 before they can be addressed by Procedure 3.2.

\section{Overview of Steps in This Procedure}

Safety categories and associated evaluation criteria are first developed. Each SRP section is then evaluated under each category, and the results are recorded in the safety matrix. Overall safety significance is next determined by using a specified algorithm to combine the individual safety elements. The SRP sections are then ranked based on relative safety significance. NRR program priorities are next obtained from PTSB. Finally, these two sets of priorities are integrated to yield recommendations for overall priorities for SRP section updating and upgrading.

\section{Results of This Procedure}

The products of this procedure are matrices containing the safety significance determinations for SRP sections, including notes and explanations regarding their development, a listing of relative priority assigned to each existing or newly identified SRP section. The safety significance matrices and the SRP section priority listing will also be entered into the SRP Modification Database.

\section{Detailed Procedure}

This section specifies the step-by-step sequence to be followed, grouped by directives (major intermediate outputs), to be accomplished through a series of specific steps.

Directive 1: Develop safety categories, including evaluation criteria, for approval by NRR.

Step 1 Identify the documents that will be required and obtain them.

Step 2 Identify the set of safety categories that will be used. Document the rationale for the selection.

Step 3 Establish the evaluation criteria for each safety category.

Step 4 Establish the tagging system within each category that will be used to indicate safety implications in the completed matrix.

Step 5 Prepare instructions for evaluating SRP sections and completing the safety matrix. Define the algorithm to be used to combine the safety significances in the individual categories, and prepare instructions for its use.

Directive 2: Evaluate SRP sections for safety significance.

Step 1 Obtain the list of SRP sections (current and new) from the implementation of Procedure 3.1. If Procedure 3.1 has not been completed at this point, the steps in this directive will have to be iterated one or more times until it has been completed.

Step 2 Evaluate each SRP section according to the instructions prepared in Directive 1, Step 5.

Step 3 Complete the safety matrix by entering the results of Step 2 for each evaluated SRP section.

Directive 3: Rank SRP sections according to safety significance.

Step 1 Combine the safety significances in each category for each SRP section according to the specified algorithm. Enter the overall safety significance in the safety matrix. 
Step 2 Prepare an ordered list of SRP sections ranked by safety significance. The list should be presented in groups of sections, with the groups indicated in order of decreasing safety significance.

Step 3 Enter the data in the safety matrix or matrices into the SRP Modification Database.

\section{Directive 4: Determine NRR program priorities.}

Step 1 In consultation with PTSB, establish the appropriate measure of NRR program priority for the updating and upgrading of SRP sections.

Step 2 Confirm that PTSB has available a list that includes all current SRP sections plus the new sections identified as a result of Procedure 3.1.

Step 3 In consultation with PTSB, rank the list of existing and newly identified SRP sections in accordance with the NRR program priority measure established above.

Directive 5: Prioritize SRP sections.

Step 1 In consultation with PTSB, confirm that the general procedure for ordering overall SRP section priorities will be to group sections in accordance with NRR program priorities and to assign priority within those groups in accordance with safety significance.

Step 2 Prepare a draft priority listing in accordance with the procedure confirmed in Step 1.

Step 3 By conferring with those responsible for developing safety significance, identify any SRP sections believed to be of such critical safety significance that they should be assigned a higher overall priority.

Step 4 In consultation with PTSB, revise the draft of overall priorities as appropriate.

Step 5 Obtain NRR approval of the overall prioritization. Enter it into the SRP Modification Database.

Step 6 Monitor changing NRR programmatic priorities and adjust the prioritization scheme accordingly.

\section{Forms}

No forms are used in this procedure. 


\subsection{Integrating Impacts}

\subsubsection{Approach}

The purpose of this activity is to establish the groundwork for further, detailed evaluation of impacts. It is not the purpose of this activity to perform detailed evaluations of impacts, nor to make any decisions regarding the need for revision or development of SRP sections, or to actually revise or develop SRP sections. These activities are covered in subsequent procedures.

This activity serves the following objectives:

- Obtaining the list of potential impacts associated with the assigned SRP section.

- Integrating the information contained in the potential impacts by combining related impacts and identifying any conflicts between impacts, thereby establishing actual impacts.

- Determining the significance of identified impacts.

Each objective is described in more detail in the following paragraphs.

The first objective, obtaining the list of potential impacts related to each SRP section, is accomplished by querying the SRP Modification Database. The SRP Modification Database already contains the assignment of potential impacts to SRP sections (Procedure 2.4), and the analyst need only request a list of potential impacts for the section under consideration. The analyst may then, if necessary, consult the documents from which potential impacts were identified for additional information.

Once the potential impacts associated with the SRP section under consideration have been obtained, the second objective is met by integrating the information contained in the potential impacts. Relationships among certain potential impacts (for example, several potential impacts may address the same topical area) are likely and there may be some conflicts between potential impacts. Related potential impacts are best handled by grouping them, characterizing their combined implications, identifying any conflicts among them, and proceeding with the remaining steps by viewing the combined potential impacts as one actual impact.

A worksheet is provided in the procedure that follows that will assist the analyst in performing the integration of potential impacts.
The third objective of this procedure, determining the significance of impacts, is accomplished through the use of two measures. The first measure addresses level of detail; impacts may range from too broad to be addressed effectively in an SRP section to too detailed to be of generic concern, including a segment of this spectrum where impacts are of the appropriate level of detail for treatment in the SRP. The second measure concerns the amount of revision that would be required if a decision were made to revise a section, ranging from a minor change (change of a parameter value or several words or sentences) to a major change (perhaps a complete rewriting of the section). In this activity, both of the above measures of significance will be characterized in terms of specific categories for each measure.

The level-of-detail measure includes three categories:

1. Too broad to be useful - the impact is stated with a lack of specificity that renders it unusable (e.g., the maintenance program needs to be improved).

2. Consistent with SRP -- the level-of-detail is reasonably matched to that presented in the current SRP and could be easily incorporated.

3. Too specific to be useful - the level-of-detail is so specific that the impact cannot be applied generically or would unduly restrict the reviewer's ability to consider reasonable alternatives.

The amount-of-revision measure as related to each impact includes four categories:

1. Major revision -- the section will largely have to be rewritten.

2. Significant revision -- a major subsection will have to be rewritten.

3. Moderate revision -- a number of minor revisions will be required throughout the section,.

4. Minor revision -- small word, sentence, or parameter value changes.

The results of the foregoing assessments will be compiled, within the SRP Modification Database, on an SRP section-by-section basis. The system will prompt the analyst for each required piece of information through the use of electronic forms described in the procedure that follows. 


\subsubsection{Procedure for Evaluating Impacts}

\section{Purpose and Scope of This Procedure}

The purpose of this procedure is to assess, based on specified criteria, the potential impacts that have been identified for each SRP section. The results of this procedure will be used as a starting point for the implementation of Procedure 3.7. This procedure will be applied to each potential impact related to the given SRP section.

\section{Prerequisites for Performing This Procedure}

Technical Skills and Knowledge Levels. The analysts performing this procedure require a technical background and experience in working with nuclear power plant designs and systems and with applicable regulatory materials, including the SRP. Personnel will be used most efficiently if they are matched to SRP sections addressing topics with which they are familiar. It should also be noted that analysts are encouraged to consult with technical experts on an as-needed basis.

Document Availability. It is anticipated that most of the needed documents will be available in the SRP Reference Document Database electronic library or in a hard-copy library established to maintain such documents until their entry into the database. Specific reference documents that are not in the system may be required from time to time, and it will be the responsibility of the analyst to identify such needs, obtain the necessary documents, and arrange for their entry into the SRP Reference Document Database (see Procedure 2.2).

Completion of Prior Procedures. Procedure 2.4 must be initiated before this procedure may be initiated. The effectiveness of this procedure will be enhanced by completing as much of Procedure 2.4 as is possible prior to beginning this procedure.

\section{Overview of the Steps in This Procedure}

Preparatory work, namely, assigning analysts to sections and familiarizing analysts with their assigned sections, is performed first. Section-related potential impacts are identified, organized, and combined as necessary. Then the potential significance of each potential revision is assessed, using a form specified in this procedure. Finally, information packages are provided to the organizations assigned to perform detailed impact evaluation and SRP section updating and upgrading.

\section{Results of This Procedure}

Written Product. The product of this procedure is an information package consisting of applicable impacts, completed Impact/Section Consistency Forms and Impact Integration Worksheets, and Revision Options Checklist Forms completed through Part B.

\section{Detailed Procedure}

This section specifies the step-by-step sequence to be followed, grouped by directives (major intermediate outputs), to be accomplished through a series of specific steps.

Directive 1: Make assignments (responsibility of Project Manager or Project Manager's designee).

Step 1 Identify the analysts who will be responsible for implementing this procedure.

Step 2 Record assignments on the Work Assignment Form (see Procedure 2.1).

Directive 2: Perform preparatory functions.

Step 1 Become familiar with the contents and subject matter of the assigned SRP section, and the criteria and requirements set forth in Section 3.3.1 regarding the evaluations to be performed.

Step 2 Obtain, from the SRP Modification Database, the potential impacts related to the SRP section under consideration.

Directive 3: Perform impact integration.

Step 1 Complete the Impact/Section Consistency Form for each potential impact. Indicate the need to retain each potential impact for further evaluation by answering the questions on the form. Potential impacts that were incorrectly assigned to the SRP section will be eliminated from further consideration at this point. Potential impacts that are already consistent with the SRP or need not be considered further for other reasons will be removed from consideration after completion of the Impact Integration Worksheet. Potential impacts that will be used to develop technical rationales for the acceptance criteria will not be eliminated from further consideration; all questions will be answered "No" for such potential impacts. 
Step 2 Review the potential impacts and group them by topical areas. The Impact Integration Worksheet should be used to facilitate completion of this and the following steps.

Step 3 Review the potential impacts within each topical area group to identify impacts that are closely related and best treated as a single impact.

Step 4 Identify any conflicts among potential impacts in each topical area group, and ensure that such conflicting potential impacts are included as closely related impacts to be treated as a single impact.

Step 5 Remove from further consideration any potential impacts that are already incorporated in the SRP (see Step 1), except for those that support Acceptance Criteria technical rationales or are associated with an identified conflict. The SRP Modification Database system will facilitate this removal if the computerized version of the Revision Options Checklist Form (Procedure 3.7) is used.

Step 6 Characterize the related potential impacts (i.e., prepare a brief (several sentence) summary of the overall impact of the component impacts) and enter the information under Part $A$ of the Revision Options Checklist Form.
Step 7 Determine the significance of each impact (or group of related impacts) by completing Part B of the Revision Options Checklist Form.

Step 8 Indicate any identified conflicts between documents by completing the first three lines of Part E of the Revision Options Checklist Form. Fill in the first three lines of a separate Part E for each conflict identified.

Step 9 If new documents or potential impacts are identified in the preceding steps, the analyst should arrange for their entry into the SRP Reference Document Database (see Procedure 2.2).

\section{Forms}

Three forms and a worksheet are used to implement this procedure. The Work Assignment Form is used to assign analysts for each SRP section. This form is discussed in Procedure 2.1. The Impact/Section Consistency Form is used to identify any potential impacts that would not necessitate SRP section revisions. The Impact Integration Worksheet assists the analyst in combining the information contained in the potential impacts. The Revision Options Checklist Form, consisting of six parts, structures the analyst's review of impacts on, and the resulting potential revisions to, SRP sections and provides the SRP Modification Database with the information needed to generate Option Papers and Type II Reports. This form is described in Procedure 3.7. 
Sample Forms

\section{Impact/Section Consistency Form}

Work Assignment

Assigned Analyst

SRP Section No.

Impact No.

Impact Source Document Accession No.

Impact Source Document Type

Impact Source Document No.

Impact Source Document Title

Publication/Revision Date

Revision No.

Impact Location(s)

_ Entire Document __ $\quad$ Block(s) as follows:

From:

To:

Impact Summary

Impact Criteria 


\section{Impact/Section Consistency Form (continued)}

1. Is this potential impact already incorporated in the SRP?

Yes

No

2. Was this potential impact incorrectly assigned to this SRP section?

Yes

No If yes, indicate reason

3. Should this potential impact be eliminated from further consideration for some other reason?

Yes

No

If yes, indicate reason

Analyst

Date of Analysis

Reviewer

Date of Review 
3.3 Integrating Impacts

\section{Impact Integration Worksheet}

Topic

SRP Section No.

Impact Number

Notes

Impact Summary 


\section{How to Complete the Forms}

\section{Impact/Section Consistency Form}

This preliminary review of all associated potential impacts is intended to substantially reduce the number of impacts that the analyst will have to address in detail. The potential impacts that are already incorporated in the current SRP will be so tagged by the SRP Modification Database system, and, after impact integration, should be removed from the set of impacts that the analyst needs to consider further if the impacts are not involved in any document conflicts or do not support Acceptance Criteria technical rationales.

\section{Computer:}

- The computer will provide the work assignment number, the name of the assigned analyst, the SRP section number, impact number, impact source document accession number, document type, document number and title, publication/revision date and revision number, the impact location in the source document (refer to Procedure 2.4 for additional instruction in completing this entry), impact summary, and impact criteria if the analyst is working on the SRP Modification Database system.

- The project clerk or the analyst will provide the above information if the form is completed in hard copy.

Analyst:

- Enter the answer to the three questions posed at the bottom of the form by placing an "X" after each "Yes" or "No" response.

- If the potential impact will be used to develop the technical rationale for SRP Acceptance Criteria, answer all questions as "No."

- If the second or third question is answered "Yes," provide the reason for not considering the potential impact further in the space provided.

Note: A "Yes" response to any of the three questions will set a flag in the SRP Modification Database that will cause the potential impact to be dropped from further consideration at the proper time in the integration process. For the first and third questions, that time is when the Revision Options Checklist Form (Procedure 3.7) is filled in. For the second question, that time is after completion of this form.
- Enter the analyst's signature and date of analysis.

\section{Reviewer:}

- If an independent review of this work is performed according to Procedure 6.0, enter the signature of the reviewer and the date that incorporation of all comment resolutions is completed.

\section{Impact Integration Worksheet}

This worksheet is provided for the convenience and use of the analyst in organizing and integrating the potential impacts relevant to the SRP section under consideration. The analyst may use as many worksheets as necessary for each SRP section.

- Consider the first potential impact. The potential impact will deal with a topic, and the analyst will provide a name for the topic and enter it on the first worksheet, along with the SRP section number.

- Enter the impact number along with any brief notes (e.g., an indication of the specific impact concern, potential conflicts, Type I/Type II information).

- Consider the second potential impact. If the topic is the same as the first potential impact, the second potential impact number will be added to the first worksheet along with pertinent notes. If the topic is different from the first potential impact, a new worksheet will be started with the second potential impact as the first entry.

- Handle the third potential impact in the same way, and so forth, until all potential impacts have been addressed.

- If necessary, revise the topic name on a worksheet as more potential impacts are reviewed and added to the worksheet.

- Identify any conflicts among potential impacts.

- Develop an impact summary that captures the essence of the entire group of impacts for each worksheet; this summary will be entered at the bottom of the worksheet.

- After completing the worksheets for the assigned SRP section, fill out Parts A and B and the first three lines of Part E of the Revision Options Checklist Form. This form is presented in Section 3.7. 


\section{Revision Options Checklist Form (See Procedure 3.7)}

\section{Part A}

- Enter the impact number or set of related impact numbers from the Impact Integration Worksheet.

- Enter the summary description of the impact or group of impacts from the worksheet. From this point on, the group of impacts will be considered as one impact.

\section{Part B}

- Enter an "X" in the appropriate category under "Level of Detail."

- Enter an "X" in the appropriate category under "Amount of Revision."

\section{Part E}

- Complete the first three lines of part E. If no conflicts have been identified, place an " $\mathrm{X}$ " in the "No" blank and enter "N/A" on the second and third lines. If a conflict has been identified, place an "X" in the "Yes" blank and indicate the numbers of the impacts involved on the second line, and provide a description of the conflict on the third line.

- If more than one conflict has been identified, complete a separate Part E for each conflict according to the instructions above.

The remaining parts of this form are completed as specified in Procedure 3.7. 


\section{Sample Forms}

\section{Impact/Section Consistency Form}

Work Assignment 1716

Assigned Analyst Florence Anderson

SRP Section No. 5.2 .4

Impact No. 342

Impact Source Document Accession No. 3386

Impact Source Document Type $\underline{\text { REG }}$

Impact Source Document No. 10 CFR 50.XXX

Impact Source Document Title Special Requirements for Reactor Coolant Pressure Boundary Components

Impact Location(s)

Entire Document $\quad \underline{X}$ Block(s) as follows:

From: $\quad \$ 50 . \mathrm{XXX}(\mathrm{a})(1)$

To:

Impact Summary RCPB check valves are required to be tested every six months. This requirement was imposed in response to a series of valve failures reported in operating power plants.

Impact Criteria 1 - Applicant or licensee requirement or staff position. 
3.3 Integrating Impacts

Impact/Section Consistency Form (continued)

1. Is this potential impact already incorporated in the SRP?

Yes

Yes

No $\mathrm{X}$ If yes, indicate reason

3. Should this potential impact be eliminated from further consideration for some other reason?

Yes — No $\underline{\mathrm{X}}$

If yes, indicate reason

Analyst Florence Anderson

Date of Analysis $\underline{05 / 22 / 92}$

Reviewer N/A

Date of Review N/A 


\section{Impact Integration Worksheet}

Topic RCPB Check Valve Testing

SRP Section No. 5.2 .4

Impact Number

$\underline{342}$

126

2189

Impact Summary RCPB check valves should be tested every six months due to high failure rates. Disassembly and inspection of components is required at the time of testing because functional testing alone has proven to be inadequate. 6-month test conflict with 126

3-month test conflict with 342

Disassembly of valve suggested

Notes

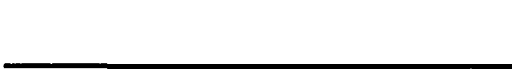


-
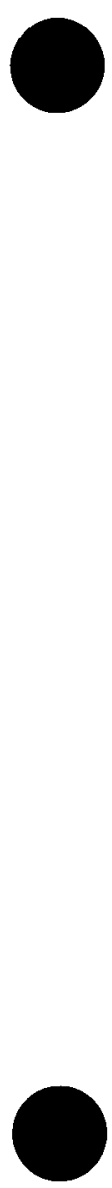


\subsection{Reviewing USIs/GSIs for Applicability to Future Reactor Designs}

\subsubsection{Approach}

Unresolved Safety Issues (USIs) and Generic Safety Issues (GSIs) have been prioritized and evaluated in the past based on conventional reactor design and operation. Inasmuch as future (evolutionary and advanced) reactors use design concepts that have some radical departures from current generation plants, USIs and GSIs will be reviewed to establish potential applicability to future reactor designs. In cases where a USI or GSI is found to have such applicability, it is not intended that further evaluation will be conducted as a part of the SRP Update and Development Program. Rather, such issues will be identified as candidates for future work (see Procedure 7.0).

The process envisioned for revisiting issues is largely judgmental. In order to facilitate the process and make it as objective as possible, a series of criteria have been developed; these are presented below in a checklist format. For each criterion, a "Yes" answer means that the next criterion needs to be considered. A complete series of "Yes" answers leads to the conclusion that the issue needs to be reconsidered. Any "No" answer terminates the analysis. The following criteria should be applied to each reactor design under consideration and for each issue:

1. Is the issue related to any structure, system, or component included in the future reactor design or to any anticipated facility operations?

2. Does the issue bear on any safety function associated with the facility design, any occupational radiation protection concern, or any safeguards or security issue?

3. Is the rationale for originally rejecting or downgrading (if rejected or downgraded) the priority of the issue insufficient for taking the same action with the advanced design?

Any issue that passes the above test will become a candidate for further evaluation in relation to future reactors.

USIs and GSIs are described in NUREG-0933 and in other documents indexed in NUDOCS. Of particular concern are those issues that have been dropped with respect to conventional reactor designs. Such issues may have relevance to future reactor designs.

\subsubsection{Procedure for Reviewing USIs/GSIs}

Purpose and Scope of This Procedure

This procedure is intended to identify USIs or GSIs that were previously identified and evaluated based on conventional reactor needs and which could have safety impacts on future reactor designs.

\section{Prerequisites for Performing This Procedure}

Technical Skills and Knowledge Levels. This procedure will require working knowledge of reactor systems, safety functions, and NRC regulatory instruments.

Document Availability. Documents required to perform this procedure include those that provide a sufficient description of the future reactor designs and those that describe GSIs and USIs and/or their status.

Completion of Prior Procedures. No prior procedures need be completed before initiating this procedure.

\section{Overview of the Steps in This Procedure}

Issues are first identified. For each future reactor design, and each issue, the criteria described in Section 3.4.1 are applied. The results of each test and the associated rationale are documented. A recommendation is then made as to whether any issues are possible candidates for future work in accordance with Procedure 7.0, and such issues are reported to the PTSB.

\section{Results of This Procedure}

Written Product. This procedure will provide documented recommendations regarding the applicability of previously identified USIs and GSIs to the various future reactor designs. This information will be captured in the SRP Modification Database.

Other. This procedure may result in the identification of potential future work (regulatory or research).

\section{Detailed Procedure}

This section specifies the step-by-step sequence to be followed, grouped by directives (major intermediate outputs), to be accomplished through a series of specific steps.

Directive 1: Make assignments (responsibility of Project Manager or Project Manager's designee).

Step 1: Identify the analysts who will be responsible for implementing this procedure. 


\subsection{Reviewing USIs/GSIs}

Step 2: Record assignments on the Work Assignment Form (see Procedure 2.1).

Directive 2: Obtain necessary documents.

Step 1 Obtain documents that provide a sufficient description of the advanced reactor designs. These documents will be the same as the documents obtained through Procedure 3.1, Directive 2, Step 1.

Step 2 Obtain NUREG-0933.

Step 3 Obtain other needed supporting documents. This step will be performed on an as-needed basis.

Directive 3: Perform applicability evaluation.

Step 1 For each issue, apply the criteria set forth in Section 3.4.1 with respect to each future reactor design by completing an Issue Applicability Form. Provide a discussion on the scope and results of the review. Include the bases for the answers to the three questions.

Step 2 Determine the SRP sections to which the issue is applicable. To make this determination, use applicable portions of Procedure 2.4 , including a supplemental descriptive word search of the SRP on RECALL.

Step 3 Consider all applicable issues as candidates for future work. Complete a Research/Regulatory Action Needs Form (Procedure 7.0) for those issues that require research, regulatory action, or codes/standards development to resolve the issues.

Forms

Two forms are used to implement this procedure. The Work Assignment Form is used to assign analysts for performance of the work. This form is discussed in Procedure 2.1. The Issue Applicability Form is used to structure the review of each GSI and USI with respect to each reactor design. The form may be filled out electronically or manually depending on the availability of the SRP Modification Database.

All organizations implementing this procedure must record their work on the indicated forms and forward the completed forms to the PTSB upon completion of the work. 
Sample Form

Issue Applicability Form

GSI/USI Number

GSI/USI Title

Reference

Reactor Design

1. Is the issue in any way related to any structure, system, or component included in the future reactor design or to any anticipated facility operations?

Yes

2. Does the issue in any way bear on any safety function associated with the facility design, any occupational radiation protection concern, or any safeguards or security issue?

Yes

3. Is the rationale for originally rejecting or downgrading (if originally rejected or assigned low priority) the priority of the issue insufficient for taking the same action with the advanced design?

Yes

Discussion

Affected SRP Sections (only for issues with "Yes" answers for all three questions)

Analyst

Date

Reviewer

Date 


\subsection{Reviewing USIs/GSIs}

\section{How to Complete the Form}

- Characterize the USI or GSI by title and issue number in the first two blanks of the form. The reference blank is included to indicate a report number or similar information regarding the source of the issue.

- Enter the reactor design concept.

- Answer the three questions by indicating a "Yes" or a "No" with an "X" after the appropriate response.

Answer question 3 with a "Yes" if it is not applicable to the issue under consideration. Any "No" answer will terminate the analysis, and the computer will accept no additional entries except for discussion. Provide a discussion on the scope and the results of the review and explain the answers to the questions.

- If all three questions are answered with a "Yes," enter the SRP sections determined to be affected by the issue.

- Finally, the analyst's name and date as well as those of the reviewer (if assigned per Procedure 6.0) should be entered. 


\section{Sample Completed Form}

\section{Issue Applicability Form}

GSI/USI Number G-58

GSI/USI Title Generic Consideration in the Use of Electric Isolation Devices in Safety-Related Circuits

\section{Reference NUREG-XXXX}

\section{Reactor Design PRISM}

1. Is the issue in any way related to any structure, system, or component included in the future reactor design or to any anticipated facility operations?

Yes $\mathrm{X}$ No

2. Does the issue in any way bear on any safety function associated with the facility design, any occupational radiation protection concern, or any safeguards or security issue?

Yes $\mathrm{X}$ No

3. Is the rationale for originally rejecting or downgrading (if originally rejected or assigned low priority) the priority of the issue insufficient for taking the same action with the advanced design?

Yes $\mathrm{X}$ No

Discussion (Provide a discussion of the scope and results of the applicability review including the bases for the answers to the three questions.)

Affected SRP Sections (only for issues with "Yes" answers for all three questions) $\underline{6.4 .1,7.6 .2,18.3}$

Analyst John Smith

Reviewer Mary Jones
Date 09/04/92

Date 10/08/92 
-

-

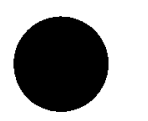




\subsection{Integrating Impacts for Future Reactor Designs}

\subsubsection{Approach}

The purpose of this activity is to establish the basis for revising or developing SRP sections to accommodate review needs for future (evolutionary and advanced) reactor designs.

The objectives associated with this procedure are as follows:

- Identifying and obtaining documents that contain information needed to upgrade the section;

- Identifying impacts; and

- Organizing the impacts.

The first objective, identifying and obtaining needed documents is accomplished by obtaining draft and final staff Safety Evaluation Reports for future reactor design approval applications, any pertinent documents referenced in the Safety Evaluation Reports, and pertinent

Commission policy guidance. An example of a pertinent referenced document is the EPRI Requirements Document for Advanced Light-Water Reactors. Examples of pertinent Commission guidance include, in SECY 90-016, "Evolutionary Light Water Reactor (LWR) Certification Issues and their Relationship to Current Regulatory Requirements;" in SECY 91-078, "Chapter 11 of the Electric Power Research Institute's (EPRIs) Requirements Document and Additional Evolutionary Light Water Reactor (LWR) Certification Issues;" and in SECY 91229, "Severe Accident Mitigation Design Alternatives for Certified Standard Designs (SAMDAS)." Similar papers are expected in the future for passive designs. Any documents obtained and used for development of sections will be entered into the SRP Reference Document Database using the pertinent portions of Procedures 2.1 and 2.3.

The second objective, identifying impacts, requires some explanation of the use of the term "impacts" with regard to this activity. The strict definition of "impact" is basically the same as that employed in Implementing Procedures Document Section 2.4. However, an impact here will be that portion of the definition that pertains to criteria 3,4 , and 5 , i.e., design or analysis information, or evaluation of design or analysis information, that could be helpful in establishing licensing requirements for future reactor designs, or information that could be helpful in establishing the technical rationales for SRP Acceptance Criteria. An impact is a portion of a document that pertains to a single topic, and topic definition is provided by the analyst. Therefore, it may be in the analyst's interest to define topics more broadly than might be done for impacts pertaining to conventional reactor technology. Identifying a smaller number of more broadly defined topics may facilitate development of new sections. In any case, impacts will be identified using pertinent portions of Procedure 2.4 and forms contained therein.

The third objective, organizing the impacts, is the combination of impacts by subject matter to facilitate further upgrading of the SRP.

The results of this procedure are used as the starting point in the implementation of Procedure 3.8.

\subsubsection{Procedure for Integrating Impacts for Future Reactor Designs}

Purpose and Scope of This Procedure

The purpose of this procedure is to identify and organize information potentially useful in upgrading SRP sections for future reactor designs. This procedure applies to those SRP sections identified in the implementation of Procedure 3.1.

\section{Prerequisites for Performing This Procedure}

Technical Skills and Knowledge Levels. The analysts performing this procedure require a technical background and experience in working with nuclear power plant designs and systems, and a thorough understanding of the use and application of NRC regulatory documents. Personnel will be used most efficiently if they are matched to SRP sections addressing topics with which they are most familiar. It should also be noted that analysts are encouraged to consult with technical experts on an as-needed basis.

Document Availability. Documents of the type described in Section 3.5.1 will need to be available, or at least obtainable, in order to best accomplish this activity. Unavailability of the needed documents will result in the identification of more future work items. Also, final or preliminary drafts of corresponding section updates for conventional reactor technology, and the rationales behind them, would greatly facilitate the work to be performed here.

Completion of Prior Procedures. Completion of Procedures 3.1 and 3.2 would be very helpful; initiation of these procedures is required. Completion of Procedures 3.3 and 3.7 for corresponding SRP sections for conventional reactor technology would facilitate accomplishment of this procedure. 


\section{Overview of the Steps in This Procedure}

Assignment of analysts and obtaining information from work already performed for conventional reactor technology are performed first. Then a set of generally applicable documents is identified and obtained. Impacts are identified and organized to facilitate implementation of Procedure 3.8.

\section{Results of This Procedure}

Written Product. The written product resulting from implementation of this procedure is a set of impact information packages, one for each SRP section, for use in performing Procedure 3.8.

Other. Other results include inputs to Procedure 7.0 (needs for future work).

\section{Detailed Procedure}

This section specifies the step-by-step sequence to be followed, grouped by directives (major intermediate outputs), to be accomplished through a series of specific steps.

Directive 1: Make assignments (responsibility of Project Manager or Project Manager's designee).

Step 1 Identify the analysts who will be responsible for implementing this procedure.

Step 2 Record assignments on the Work Assignment Form (see Procedure 2.1).

Directive 2: Perform preparatory functions.

Step 1 Assess the status of work performed for conventional reactor technology under Procedures 3.3 and 3.7. Obtain copies of products of those procedures for use in performing this procedure.

Step 2 Maintain cognizance of on-going Procedures 3.3 and 3.7 work and incorporate products and insights gained from that work.

Directive 3: Obtain needed documents and identify impacts.

Step 1 Obtain draft and final staff Safety Evaluation Reports related to applications for design approvals for future reactor designs. Obtain any pertinent documents referenced in the staff Safety Evaluation Reports.
Step 2 Enter bibliographic information regarding the documents in the SRP Modification Database by implementing pertinent portions of Procedure 2.1, including completion of the Document Entry Log. Enter the documents into the SRP Reference Document Database by implementing pertinent portions of Procedure 2.3.

Directive 4: Build list of impacts.

Step 1 Review the combined impacts associated with the base section for conventional reactor technology (see Procedure 3.4). Particularly, review any discounted impacts that could be applicable to future reactors. Identify the impacts to be considered for the upgrade.

Step 2 Review the documents obtained under Directive 3. Identify information pertinent to the SRP section under consideration and record such pertinent information on Impact Identification Forms (see Procedure 2.4).

Step 3 Review the results of Steps 1 and 2 to determine the adequacy of the collected information to upgrade an SRP section. Invoke Procedure 7.0 for any areas where required information cannot be located, or needed regulatory requirements or guidance is not available.

Directive 5: Assess impacts.

Step 1 Review impacts and group them by topical areas. The Impact Integration Worksheet of Procedure 3.4 should be used to facilitate completion of this and the following steps.

Step 2 Review the impacts within each topical area group to identify impacts that are closely related and best treated as a single impact.

Step 3 Identify any conflicts between impacts in each topical area group, and ensure that such conflicting impacts are included as closely related impacts to be treated as a single impact.

Step 4 Characterize the related impacts (i.e., prepare a brief summary of the overall impact of the component impacts) and enter the information under Part A of the Upgrade Impact Assessment Form.

Step 5 If any document conflicts are identified, complete the first three lines of Part $\mathrm{C}$ of the Upgrade Impact Assessment Form. 
Directive 6: Develop impact information packages.

Step 1 Collect information (impact descriptions, completed Impact Integration Worksheets, and Part A and Part C, if applicable, of Upgrade Impact Assessment Form) to be included in the SRP section-by-section information packages.

Step 2 Provide the information packages to the assigned organizations.

\section{Forms}

One form and a worksheet are used to implement this procedure.

The Impact Integration Worksheet (presented in Procedure 3.3) assists the analyst in organizing the information contained in the impacts.

The Upgrade Impact Assessment Form assists the analyst in evaluating impacts (see Procedure 3.8).

All organizations implementing this procedure must record their work on the indicated forms and forward the completed forms to the PTSB upon completion of the work.

How to Complete the Forms

Upgrade Impact Assessment Form (See Procedure 3.8)

Part A

- Enter the SRP section number and the impact number or numbers of related impacts (from the completed Impact Integration Worksheet).
- Enter the impact summary description (from the Impact Integration Worksheet).

- The new impact number will be assigned by the computer system at the time of data entry.

- From this point on, the group of impacts will be considered as a new, single impact.

Part C

- If a potential conflict has been identified, place an "X" in the "Yes" blank on the first line. If no conflicts have been identified, place an " $\mathrm{X}$ " in the "No" blank and skip the next three bullets.

- Indicate the impact numbers of the impacts associated with the conflict.

- Enter a description of the nature of the conflict.

- Complete an additional Part C (first three lines) for each additional conflict identified.

Parts B and C (except for the first three lines) are completed per the instructions in Procedure 3.8. 
-
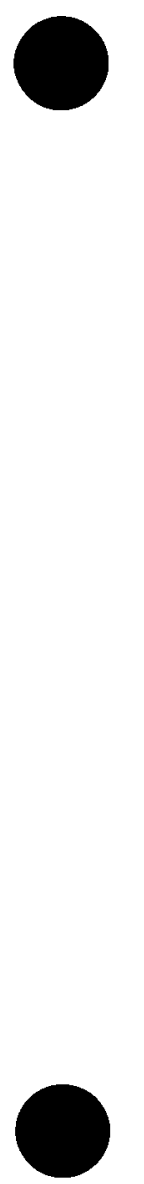


\subsection{Assigning Work by the PRB}

\subsubsection{Approach}

In the revision and development of SRP sections, it is necessary that the PRB decide which resources that it will use in evaluating impacts and preparing draft sections and resolving comments on the drafts. It should be noted that all SRP sections will require revision to include at least technical rationales for the Acceptance Criteria. The PRB may select from three options that are available to accomplish the work:

1. The PRB may perform the work in-house.

2. The PRB may enlist a contractor of its choosing to assist in performing the work.

3. The PRB may request that PTSB arrange for the work to be done, assisted by PNL. If this option is used, PTSB will provide the PRB with the initial draft of the revised SRP section for their review and approval.

It should be noted that the final draft of a revised or new SRP section will only be accepted from the PRB and, independent of which of the above options is chosen, the final draft will be considered a PRB product.

In general, for each SRP section Procedures 3.7 and 3.8 should be assigned to a work group such that the analyst that performs the update per Procedure 3.7 will have a close working relationship with the analyst(s) that perform upgrades for future reactor designs per Procedure 3.8. In this way, the updating of an SRP section can be closely coordinated with the upgrading of the same section. Also, section upgrading will be performed after the updating is completed.

\subsubsection{Procedure for Determining Revisions}

\section{Purpose and Scope of This Procedure}

The purpose of this procedure is to obtain PRB determination of the organization they will assign to evaluate impacts and prepare draft SRP section revisions. Regardless of the organization used, the PRB will be responsible for the draft revisions.

\section{Prerequisites for Performing This Procedure}

Technical Skills and Knowledge Levels. The PRB staff will perform this procedure.
Document Availability. Supporting documentation that is not already in the possession of the PRB will be made available in electronic form (if available) or as a hard-copy printout from the SRP Modification Database or SRP Reference Document Database.

Completion of Prior Procedures. Procedure 3.1 needs to be completed before this procedure is completed.

\section{Overview of the Steps in This Procedure}

The PRB selects contractors of its choosing to assist in evaluating impacts and drafting SRP section revisions. The PRB records its decisions on the provided form, and the information is transferred to the SRP Modification Database.

\section{Results of This Procedure}

Written Product. The written product is the completed PRB SRP Section Assignment Form for the sections for which the PRB is responsible.

Other. Information from the completed forms described above is entered into the SRP Modification Database and retained there for future use.

\section{Detailed Procedure}

This section specifies the step-by-step sequence to be followed, grouped by directives (major intermediate outputs), to be accomplished through a series of specific steps.

Directive 1: PRB to determine resources to be used.

Step 1 Select the resource option to be used to implement Procedures 3.7 and 3.8. For the review of evolutionary and advanced reactors, the PRB may also use this procedure for assigning portions of Procedures 3.1, 3.4, and 3.5 for various reactor designs.

Step 2 Complete a PRB SRP Section Assignment Form for each SRP section for which the PRB is responsible.

Step 3 Forward completed PRB SRP Section Assignment Forms to the PTSB for entry into the SRP Modification Database. 


\subsection{Assigning Work}

\section{Forms}

The single form used to implement this procedure is the PRB SRP Section Assignment Form. Its purpose is to provide a vehicle for the PRB to record its decisions regarding the resources to be used to perform Procedures
3.7 and 3.8. The form will likely be produced and filled out in hard copy.

All organizations implementing this procedure must record their work on the indicated forms and forward the completed forms to the PTSB. 


\section{Sample Form}

\section{PRB SRP Section Assignment Form}

PRB

SRP Section Number

Assigned Organization

Assigned Tasks

Authorized Signature

Date 


\subsection{Assigning Work}

\section{How to Complete the Form}

- Enter the name of the PRB.

- Enter the number of the SRP section to which the assignment pertains.
- Enter the name of the organization being assigned to perform the work.

- Describe the tasks being assigned.

- Enter the signature and date of the PRB person authorized to approve assignments. 
Sample Form

PRB SRP Section Assignment Form

PRB Plant Systems Branch (SPLB)

SRP Section Number 9.4 .3

Assigned Organization PNL

Assigned Tasks Perform all impact evaluation and SRP section drafting specified in Procedures 3.7 and 3.8.

Date 
-
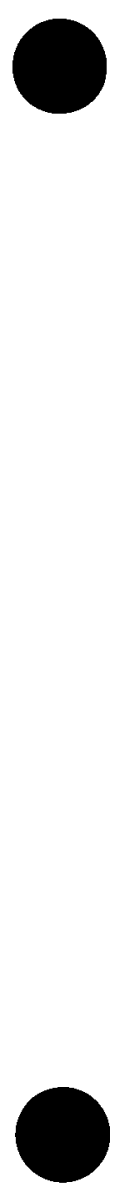


\subsection{Updating SRP Sections}

\subsubsection{Approach}

This section contains the procedure to be followed in evaluating impacts, determining the SRP revisions that will be made, and drafting revised or newly identified SRP sections to reflect current technology. Procedure 3.7 should be followed regardless of which resource option the PRB has selected for accomplishing the revision (that is, the PRB itself, a contractor of the PRB's choosing, or the PTSB). (See Procedure 3.6.)

This procedure can be viewed as accomplishing three distinct tasks. First, an evaluation of SRP impacts is performed based on information packages developed in Procedure 3.3. This activity results in the development of Option Papers. Second, the PRB reviews the Option Papers and decides which revisions to the SRP will be made. In the course of its review, the PRB may incorporate other document impacts based on its experience. Third, an actual SRP section revision is drafted. These three tasks are briefly discussed, in turn, in the following paragraphs.

Evaluation of impacts consists of the following four steps:

- Characterizing the types of changes suggested by impacts, i.e., developing a brief description of the actual changes that would be required to be made to an SRP section.

- Developing revision options and associated pro and con arguments for each option.

- Identifying conflicts between SRP-affecting documents.

- Characterizing potential revisions as Type I or Type II.

Suggested changes are characterized in a brief narrative summarizing what would be revised and how the revision would be accomplished. The following example (fictional) illustrates what is intended:

The SRP currently suggests calculating the entire combustible loading for an area and then dividing by the total area to develop an average fire loading. The average fire loading is then used to develop fire intensities and durations for the area. The Regulatory Guide states that, in areas where combustible materials are concentrated in a small portion of the overall area, an areal average fire loading grossly underrates the deleterious effects on local fire barriers. The Regulatory Guide stipulates that areas containing localized combustible materials be evaluated based on local fire loadings and the effects on local fire barriers. Also, it provides criteria to characterize situations where this methodology should be applied and Acceptance Criteria to reflect the higher temperatures and possibly longer durations. Alternatives, such as separation of concentrated combustibles or provision of local fire barriers, could also be used. The Acceptance Criteria, Review Procedures, and Evaluation Findings would be changed to reflect the indicated changes.

An analysis, similar to the one shown above, will be prepared for each identified impact.

Evaluating the suggested changes involves the development of options and pro and con arguments regarding each option. In cases where impacts suggest several alternative actions, each reasonable option should be briefly described. In all cases, when the options are evaluated, maintaining the status quo should be considered as one of the options. No specific criteria are called for or presented for evaluating alternative actions. The analyst must retain objectivity in performing this function. Pros and cons may be suggested within the current SRP section, the documents referenced in the SRP section, or the document suggesting the change; if so, these arguments should be indicated and referenced. The analyst will also have to develop arguments based on judgment and experience. The pro and con arguments should be presented fairly and objectively so that they may be used in subsequent NRC decision making. An evaluation of suggested changes will be prepared for each identified impact.

Conflicts between impacts are to be expected; they can arise because of differing opinions, changing conditions over time, or other reasons. Resolution of conflicts can be facilitated by several means; the hierarchy among documents will be taken into consideration when suggesting which will control. Usually, impacts derived from more current documents will supersede older impacts; newer documents better reflect current thinking. These and other considerations must be used on a case-by-case basis to attempt to determine the impact that will prevail. Initially, the analyst will be called upon to indicate how the conflict might be resolved. The analyst's work will be accompanied by arguments pro and con. The conflict will be brought to the attention of the PRB, as part of the Option Paper described in this procedure. In some cases, it may not be possible to resolve the conflict, given existing information, and the conflict may become a source of potential new work per Procedure 7.0. 
All revisions added to the SRP to cover future reactor designs are Type II revisions and will be handled by the SRP Update and Development Program. Type II revisions that affect current technology generally will not be handled by the SRP Update and Development Program but will be separated from the program and dealt with by existing means, i.e., the Backfit Rule.

Characterizing proposed revisions as Type I or Type II requires an assessment of previous NRC approvals and justification for including each suggested revision in one of the two categories. The categories are defined in Enclosure 1 to NRR Office Letter No. 800, dated November 24, 1987, as follows:

\section{Type I - Revisions to the SRP Without Public Comments}

- Revisions that incorporate new or revised requirements or guidance that have received public comment and have been approved by the Director, NRR, and for which additional public comments are not necessary (e.g., implementation or referencing in the SRP of Commission Policy Statements or instructions, Regulatory Guides, Standards and Resolution of Generic Issues including approved Three Mile Island (TMI) Action Plan items).

- Revisions that incorporate new positions that have been approved by the Director, NRR, and by the Committee to Review Generic Requirements (CRGR) and the Executive Director of Operations (EDO) as being so clearly needed that a public comment period would cause an unacceptable delay in implementing them.

- Clarifications, corrections, changes in names or assignments of branches, deletions of unused references or other similar minor changes.

\section{Type II - Revisions to the SRP With Public Comments}

- Revisions that incorporate proposed new or revised requirements, positions, or guidance that have not been reviewed and approved by the Director, NRR, CRGR and the EDO, or include proposed new sections for the SRP.

The definitions are stated in terms of criteria, and these criteria will form the basis for the Type I/Type II determination. However, a rationale will also be developed by the analyst to assist decision makers in assessing the results provided. The rationale will be a brief description of how and why the proposed revision meets the Type I or II criteria.
For updating the SRP, Type I revisions will be handled (that is, incorporated into the SRP) by the SRP Update and Development Program. New SRP sections relating to future reactor designs identified under Procedure 3.1 that reflect current, approved requirements will be handled by the SRP Update and Development Program as Type II revisions. Other potential Type II revisions will be identified, but such potential revisions, if they relate to updating SRP sections for current technology, will be provided as input to other existing NRC programs. As the Type II revisions are resolved by other programs, they eventually will be addressed by the SRP Update and Development Program, as the resolution documentation is issued, and processed as a Type I revision.

Responsibility for updating each SRP section rests with the PRB. The PRB is also responsible for determining which SRP impacts will be incorporated in the SRP and which will not.

This determination is accomplished using an Option Paper. The Option Paper summarizes identified impacts, suggests various ways (options) to handle the impacts, and provides pro and con arguments related to each option. The Option Paper is also used to allow the PRB to indicate its decisions regarding SRP section updates.

The information identified, processed, evaluated, and organized by previous steps and procedures assists the PRB in determining the need for SRP section updates. All of these activities result in the preparation of Option Papers that summarize proposed changes from the many documents reviewed and present recommendations regarding the actions that could be taken. The Option Papers will be provided to the PRBs by the assigned organization and will be used by the PRBs, along with the extensive knowledge and experience contained within the PRB staff, to determine which changes need to be made and which do not.

Option Papers will address entire SRP sections, but each individual impact resulting in a proposed change will be reported separately. This will allow the PRB not only to determine whether a section needs revision, but also to select from the proposed changes.

Decisions of the PRBs will need to be recorded in the SRP Modification Database. To this end, the PRBs will be asked to record their decisions on comment blanks that will be included in the Option Paper. The completed forms will be returned to the PTSB, and data entry will be accomplished by PNL on behalf of the PTSB.

It is expected that each PRB will have its own specific criteria for deciding whether revisions are justified. In general, for SRP updates, it would be expected that 
approved regulatory changes should be incorporated in the SRP, since the SRP serves as a definitive, comprehensive source of NRC licensing requirements. The SRP maintains consistency of review for PRBs as staff changes occur and serves as a source of agency requirements and positions for the regulated industry.

It should be noted that one of the premises of the SRP Update and Development Program is that technical rationales will be developed to support the Acceptance Criteria contained in each SRP section. Therefore, even if no other technical revisions will be made to a section, Acceptance Criteria technical rationales, along with supporting bibliographies, will still be developed and added. As a result, all sections will be modified as part of this program.
The final task of Procedure 3.7 is to translate impacts into complete draft SRP sections that follow the standard format for SRP sections, to consist of six subsections. The general approach set forth here follows these subsections.

Several of the Environmental Standard Review Plan subsections will have to be reformatted to match the standard format (see Detailed Procedure of this section). Such reformatting will not require any technical changes. The correlations between SRP and ESRP subsections are shown in Table 6, and the required reformatting of ESRP sections is discussed in the paragraphs that follow. The ESRP will be incorporated as a separate chapter (or chapters) in the SRP.

Table 6. SRP/ESRP Subsection Correlations

\begin{tabular}{ll}
\hline \multicolumn{1}{c}{ SRP } & \multicolumn{1}{c}{ ESRP } \\
\hline I. $\quad$ Areas of Review & $\frac{\text { Review Inputs. Environmental Report Sections, }}{\text { Environmental Reviews, and Other }}$ \\
& $\frac{\text { Review Outputs }}{\text { I. Purpose and Scope }}$ \\
& V. Input to Environmental Statement (Portions) \\
II. Acceptance Criteria & $\frac{\text { Review Inputs. Standards and Guides }}{\text { IV. Evaluation }}$ \\
III. Review Procedures & II. Required Data and Information \\
IV. Evaluation Findings & III. Analysis Procedures \\
V. Implementation & V. Input to Environmental Statement (Portions) \\
VI. References & None \\
\hline
\end{tabular}

In order to implement the Commission's metrification policy, all parameter values in the SRP will be presented in both metric and English units. The correct format is to present the value in metric units first, then present the English equivalent immediately following in parentheses. The following sentence illustrates this format: Nearby industrial and military facilities located within $8 \mathrm{~km}(5$ miles) of the plant should be identified.

The general approach for preparing draft SRP sections is presented below for each of the subsections.

\section{Areas of Review}

This subsection describes the scope of the review for which the SRP section provides guidance--that is, the structures, systems, components, or other topics being reviewed by the PRB. This subsection also specifies the information needed or review expected from other branches to enable the PRB to complete its review. For ESRP sections, this section will specify interactions between review groups, including development and use of information (this information is typically available in current introductory subsections, Review Inputs and Review Outputs, and Subsection V, Input to Environmental Statement).

The Areas of Review subsections in the current SRP vary quite substantially in their level of detail. At a minimum, new or revised Areas of Review subsections should contain the following:

- The objectives of the review--that is, the determinations regarding the systems, structures, 
components, or other topics to be made by the reviewers

- The scope of the review--that is, the particular systems, structures, components, or other area to be reviewed

- Review interfaces with other branches--that is, the relationship of other related reviews to the review conducted under this section

In addition, the following items should be included where they would help clarify the scope of the review:

- An explanation of the review topic--that is, a general description of the systems, structures, components, or other topics under review and their function

- The information on which the review is based--that is, the particular materials submitted by the applicant (typically, in the Safety Analysis Report) that the reviewers will rely on

- The considerations that go into the review--that is, the factors that the reviewers will take into account in determining whether the objectives of the review are met

\section{Acceptance Criteria}

This subsection tells the reviewer how to determine the acceptability of the applicant's submission with respect to the topic under review. This subsection generally identifies the applicable NRC requirements (10 CFR sections and General Design Criteria), refers to the guidance to be followed in meeting the requirements (such as Regulatory Guides, NUREG reports, and industry codes and standards), and provides narrative statements of how the applicant may demonstrate that the requirements have been met.

A significant objective of the SRP Update and Development Program is the development of technical rationales for the Acceptance Criteria in each SRP section. The technical rationales will be narrative explanations of the identified requirements and the solutions and approaches determined to be acceptable in the past by the staff. They provide the technical basis for determining the acceptability of the design or the programs within the scope of the area of review of the SRP section.

The technical rationales to be developed will serve several potential uses. First, they will provide pertinent background information to the staff reviewer that will assist the reviewer in determining acceptability of proposed designs. Second, they will assist applicants in understanding $\mathrm{NRC}$ requirements and how and why they are applied. In addition, they may be relied upon to support the indicated Acceptance Criteria in hearings and other licensing-related activities. Therefore, it is essential that the bases contain sufficient technical reasoning, including references to supporting documents, to justify the stated Acceptance Criteria.

The following example illustrates a rather comprehensive technical rationale. This example pertains to a hypothetical SRP Acceptance Criterion that requires a BWR Standby Liquid Control System to be able to safely shut down the reactor without the aid of control rods.

General Design Criterion 26 requires that two independent reactivity control systems of different design principles shall be provided. The standby liquid control system is used in the BWR as the second such system, the first being the control rods and their drive system. General Electric Company in NEDO-XXX presented the results of core reactivity calculations assuming various injection rates of sodium pentaborate solution of various concentrations. It was reported that injection of 35 gallons per minute of sodium pentaborate at a concentration of 1200 parts per million would provide $\$ 22$ of negative reactivity, more than enough to shut down the reactor and maintain it in shutdown. In fact, the $\$ 22$ of negative reactivity represents a $20 \%$ margin considering that the total core reactivity is approximately $\$ 18$.

In the staff's safety evaluation of the NEDO report (NUREG-XXXX), the staff concluded through an independent analysis that the calculations were correct, but wished to provide an additional safety margin to allow for potential sodium pentaborate plateout in the storage tanks. Therefore, it was determined that 43 gallons per minute would satisfy the shutdown requirements with adequate margin. Two parallel systems using redundant active components and redundant sodium pentaborate storage tanks are required to provide adequate assurance that the required flow rate would be delivered assuming a single active failure. NUREG-XXXX also concluded that appropriate technical specifications need to be incorporated to assure that the sodium pentaborate solution in the storage tanks be maintained at a temperature of greater than $95^{\circ} \mathrm{F}$ to avoid plateout and to include a monthly surveillance test of actual sodium pentaborate solution concentration. It was determined that the storage tank heaters did not have to be safety-grade, due to the safety margins included in system design and the relatively high 
ambient temperatures maintained at the storage tank locations, which would prevent significant sodium pentaborate plateout even if tank heaters were to fail.

As shown by this example, enough technical detail should be provided to succinctly explain why the Acceptance Criterion is considered applicable and adequate. Specific references to supporting documents are to be provided, and a separate reference list for the Acceptance Criteria technical rationales included.

In some cases, as appropriate, the technical rationales could be more general in nature, and the details of solutions and acceptable approaches could be left to the reference documents or the subsection dealing with the review procedures. In fact, existing review procedures may already contain discussions of the approaches and solutions that have been found acceptable to the staff in the past.

Because of the need to clearly represent the Acceptance Criteria, a new format has been adopted within the Acceptance Criteria subsection. First, the applicable requirements and guidance are presented in tabular format. Then the Acceptance Criteria are stated. Finally, the technical rationale is presented and technical rationale references are provided. The reference list for Acceptance Criteria technical rationales should list the materials relied on in establishing the technical rationales for the Acceptance Criteria. Because Acceptance Criteria technical rationales are being added to all SRP sections, this reference list must be created for each SRP section, as the technical rationales are developed.

The new Acceptance Criteria format is illustrated in the Draft SRP Section Form described at the end of this procedure.

For ESRP sections, the requirements and guidance will generally be available from the Review Inputs - Standards and Guides subsection. These tend to be federal, state, and local laws and ordinances, unlike SRP sections, which tend to rely on Commission regulations. Acceptance Criteria will primarily be taken from the Evaluation subsection. The Evaluations subsection will be reformatted (and renamed) to more closely match the structure of the SRP Acceptance Criteria subsection. Other subsections of the ESRP section may also have to be reviewed to identify regulatory guides or other references that establish environmental Acceptance Criteria.

\section{Review Procedures}

This subsection indicates how the review is accomplished. In the current SRP, this discussion usually begins by indicating that the procedures that follow are used during the construction permit review to determine that the design or plans as set forth in the Preliminary Safety Analysis Report meet the Acceptance Criteria and during the operating license review to verify that the design or plans have been appropriately implemented as set forth in the Final Safety Analysis Report. The subsection then specifies a sequence of numbered steps to be followed by the reviewer. Each step tells the reviewer to review a particular body of information in order to reach a particular determination. Some steps also tell the reviewer to obtain advice or analysis from some other branch responsible for a related aspect of the review. The concluding steps typically tell the reviewer how to integrate the conclusions of the initial steps in order to determine whether the Acceptance Criteria have been met.

For ESRP sections, the Required Data and Information subsection and the Analysis Procedures subsection will be merged to form the Review Procedures subsection.

Required data will be presented first so that the reviewer will be able to immediately determine if the review may proceed. Then the review procedures will be provided. No technical changes will result from the reformatting.

\section{Evaluation Findings}

This section presents the type of conclusion expected to result from the review, which is generally published in the staff's Safety Evaluation Report.

In the current SRP, this subsection typically begins with an introductory statement to the effect that the reviewer verifies that the applicant has provided sufficient information and that the reviewer's evaluation is sufficiently complete to support conclusions of the following type, to be included in the Safety Evaluation Report. The subsection then provides what are essentially model conclusions or findings--language of the type that the reviewer is expected to include in the Safety Evaluation Report (or Environmental Statement for ESRP sections), stating that the information provided by the applicant enabled the reviewer to conclude that the system, structure, component, or other topic under review meets the applicable Acceptance Criteria. If findings are required from an SRB, model language for that purpose is also provided. Where background information on the facility under review would assist the reader in understanding the findings, the subsection indicates that such information should be provided along with the findings themselves. 
For ESRP sections, the reformatting required here will be quite straightforward. Interfaces with other reviewers will already have been relocated in the Areas of Review subsection. The remaining information will be maintained essentially intact.

When an existing SRP section is being revised, the Evaluation Findings subsection will need to be revised only to the extent particular findings are affected by applicable impacts approved for incorporation by the PRB. When a new SRP section is being developed, a complete set of findings will need to be developed.

\section{Implementation}

This subsection generally contains the following standard language:

The following is intended to provide guidance to applicants and licensees regarding the NRC staff's plans for using this SRP section.

Except in those cases in which the applicant proposes an acceptable alternative method for complying with specified portions of the Commission's regulations, the method described herein will be used by the staff in its evaluation of conformance with Commission regulations.

Implementation schedules for conformance to parts of the method discussed herein are contained in the referenced [Regulatory Guides or other materials.]

This language will already be in current SRP sections and should be included in new sections as well.

ESRP sections currently do not contain an Implementation subsection. In order to facilitate translation of ESRP sections into the SRP format, the following standard language has been developed for inclusion on the Draft SRP Section Form for ESRP sections:

The following is intended to provide guidance to applicants and licensees regarding the NRC staff's plans for using this SRP section.

The method described herein will be used by the staff in its evaluation of conformance with applicable environmental regulations. Inasmuch as the review method set forth in this section represents current staff practice, implementation will be immediately effective.

\section{References}

This is the last subsection. It contains a reference list for the SRP section. At present, the completeness of the reference list appears to vary among SRP sections. Ideally, all generally applicable materials on which the staff relies in reaching its findings should be included, provided that the use of the reference materials is obvious or made evident in the SRP section text. The reference list should also be kept current (for example, by referring to the latest revisions of the cited materials.)

When an existing SRP section is being revised, the References subsection will need to be revised only to the extent particular references are affected, although a check of the currency of all references should be made. Current references should also be checked for appropriateness and to ensure that their use will be evident to the reader. When a new SRP section is being developed, a complete reference list will need to be constructed.

\subsubsection{Procedure for Updating and Developing SRP Sections}

\section{Purpose and Scope of This Procedure}

This procedure specifies how to evaluate impacts, determine which revisions will be made, and draft SRP section updates or new SRP sections. This procedure applies regardless of which management option is chosen by the PRB for performance of the work.

\section{Prerequisites for Performing This Procedure}

Technical Skills and Knowledge Levels. The analysts performing this procedure require a technical background and a working knowledge of nuclear power plant designs and systems and applicable regulatory materials, including the SRP. Personnel should possess detailed knowledge of the systems, structures, components, or processes covered by the assigned SRP section. Analysts will consult with other technical experts on an as-needed basis.

Document Availability. The analyst should have access to Impact Identification Forms and the supporting portions of source documents for the SRP section being updated or developed. These materials will be available in the SRP Modification Database and the SRP Reference Document Database. If additional documents are necessary, it will be the analyst's responsibility to identify and obtain them.

Completion of Prior Procedures. Initiation of this procedure requires the completion of Procedures 3.3 and 3.6 for the SRP section being updated or developed. 


\section{Overview of Steps in This Procedure}

After obtaining and reviewing pertinent information, an evaluation of impacts is performed by identification and assessment of revision options, identification of conflicts, and determination as to SRP revision type (Type I or Type II). Evaluation information is provided to the PRB on the Option Paper Report. The PRB uses this information to determine those SRP revisions that will be incorporated. Then each of the subsections in an SRP section is updated or developed. Finally, the analyst reviews the completed draft for internal consistency and conformance with requirements.

\section{Results of This Procedure}

Written Product. The written product resulting from implementation of this procedure includes completed forms, Option Papers with PRB decisions indicated on them, and a draft SRP section.

Other. If in drafting the SRP section the analyst identifies impacts on other sections, an Impact Identification Form (from Procedure 2.4) is completed and entered into the SRP Modification Database so that the impact will be reflected in those sections.

\section{Detailed Procedure}

This section specifies the step-by-step sequence to be followed, grouped by directives (major intermediate outputs), to be accomplished by a series of specific steps. Each of Directives 7 through 13 addresses preparation of a separate SRP subsection. In the Implementation of Directives 7 through 13, provide all parameter values in metric and English equivalent units and present both values according to the format prescribed in Section 3.7.1.

Directive 1: Make assignments (responsibility of Project Manager or Project Manager's designee).

Step 1 Identify the analysts who will be responsible for implementing this procedure.

Step 2 Record assignments on the Work Assignment Form (see Procedure 2.1).

Directive 2: Perform preparatory activities.

Step 1 Obtain and review the current version of this SRP section.

Step 2 Determine expert contacts, including a contact within the PRB (when draft preparation is performed outside of the PRB), who may be contacted when questions arise.

Step 3 If, during section updating, the analyst identifies impacts on other SRP sections that have not previously been identified, prepare an Impact Identification Form from Procedure 2.4 using the instructions contained in that procedure.

Step 4 If, during section updating, the analyst discovers a need for research, regulatory action, or codes/standards development, identify such needs by implementing Procedure 7.0.

Directive 3: Evaluate impacts (Assigned organization responsibility).

Step 1 Obtain impact information packages from implementation of Procedure 3.3.

Step 2 Characterize the changes suggested by impacts by completing Part $\mathrm{C}$ of the Revision Options Checklist Form.

Step 3 Assess the suggested changes by completing Part D of the Revision Options Checklist Form.

Step 4 Report conflicts among impacts (identified in Procedure 3.3, Directive 3, Step 4), suggested resolutions, and rationale by completing Part $\mathrm{E}$ of the Revision Options Checklist Form.

Step 5 Recommend whether revisions are Type I or Type II by completing Part F of the Revision Options Checklist Form.

Directive 4: Produce Type II Reports. (To be performed by appropriate task manager.)

Step 1 Use the SRP Modification Database to produce Type II reports.

Step 2 Provide the reports to the PTSB for approval and transmittal to the appropriate NRC organizations.

Directive 5: Obtain PRB decisions as to the updates to be implemented.

Step 1 Forward the Option Papers to the responsible PRBs, including notification of response date and any other explanatory instructions.

Step 2 The PRB will review the Option Paper and determine which updates should be incorporated in the SRP section. The PRB will indicate its 
decisions by entering comments in the comment blanks in the Option Paper.

Step 3 The PRB will return the completed Option Paper to the organization assigned to draft the SRP section.

Step 4 The PRB will resolve any identified document conflicts in the manner it deems appropriate. In cases where the resolution of a conflict involves other NRC organizations, the PRB will be responsible for providing coordination.

Directive 6: Reformat the SRP section (performed for existing SRP sections only).

Step 1 Review the information in the existing SRP section and reorganize that information into the format prescribed in the Draft SRP Section Form.

Step 2 Convert all parameter values to metric and English equivalent units and present both values according to the format prescribed in Section 3.7.1.

Step 3 Update the reformatted section as specified in Directives 7 through 13.

Directive 7: Draft Areas of Review subsection.

Step 1 If this SRP section already exists, determine whether any PRB-approved update affects Areas of Review.

Step 2 If the answer to the question in Step 1 is "Yes" or if this is a new SRP section, complete the Areas of Review portion of the Draft SRP Section Form.

Step 3 If the section is from the ESRP, retitle the subsection and perform any editorial revision necessary to be consistent with the standard SRP content of this section. Remove from the Review Inputs and Review Outputs Subsections I and $V$, any interfaces between different reviewers, and incorporate such interfaces in this subsection.

Directive 8: Draft Acceptance Criteria subsection.

Step 1 If this is an ESRP section, use the Review Input - Standards and Guides subsection to establish the bases and the Evaluation subsection to establish the Acceptance Criteria. Perform any necessary format or editorial changes necessary to make the subsection consistent with standard SRP subsection content.

Step 2 If this SRP section already exists, determine whether any PRB-approved updates affect the Acceptance Criteria.

Step 3 If this SRP section already exists, convert the description of requirements and guidance into tabular format and modify the description appropriately. For new sections, develop the requirements and guidance in tabular format. The tabular format is as indicated on the Draft SRP Section Form.

Step 4 For existing sections, review the Review Procedures subsection and identify any Acceptance Criteria that are contained therein.

Step 5 Revise (or develop) the Acceptance Criteria in consideration of PRB-approved updates and any Acceptance Criteria identified in Step 4.

Step 6 For existing SRP sections, remove any Acceptance Criteria (identified in Step 4) from the Review Procedures subsection. Replace such criteria with a requirement to review against the criterion which is now located in the Acceptance Criteria subsection.

Directive 9: Draft technical rationales for Acceptance Criteria subsection.

Step 1 Review requirements and guidance applicable to the Acceptance Criteria (i.e., the General Design Criteria, Regulatory Guides, or the like) specified in the Acceptance Criteria subsection.

Step 2 If the referenced requirements or guidance state or imply a technical rationale, determine whether the rationale is adequate. The standard to be used in determining adequacy is that the rationale clearly shows how the Acceptance Criteria implement the underlying requirements, and that the rationale could not be substantially improved based on existing information. If the rationale is adequate, go to Step 6 .

Step 3 If the referenced requirements or guidance do not state or imply a technical rationale, obtain and review any documents cited therein from the SRP Reference Document Database, determine whether they state or imply a technical rationale, and, if so, whether it is adequate. If the rationale is adequate, go to Step 6. 
Step 4 If neither Step 2 nor Step 3 has yielded an adequate technical rationale, develop a rationale based on best professional judgment; if necessary, consulting documents in the topic area from the SRP Reference Document Database. If an adequate rationale is developed, go to Step 6.

Step 5 If none of the above steps has yielded an adequate technical rationale, invoke Procedure 7.0 to either develop additional information through research activities or modify Acceptance Criteria bases through regulatory action.

Step 6 Develop the technical rationale for the Acceptance Criteria by summarizing the information identified in Step 2, 3, 4, or 5 or provide appropriate references. (See Implementing Procedures Document Section 3.7.1 for guidance regarding developing the technical rationale.) Enter the technical rationale on the Draft SRP Section Form.

Step 4 Develop a separate reference list for those documents referenced in the technical rationale for the Acceptance Criteria and include this list under the Technical Rationale References heading.

Directive 10: Draft Review Procedures subsection.

Step 1 If this SRP section already exists, determine whether any PRB-approved updates affect the review procedures.

Step 2 If the answer to the question in Step 1 is "Yes" or if this is a new SRP section, complete the Review Procedures portion of the Draft SRP Section Form.

Step 3 Add steps in the review procedure for any Acceptance Criteria added under Directive 8. The steps should direct the reviewer to check for conformance with the new criteria.

Step 4 For ESRP sections, use the Required Data and Information subsection and the Analysis subsection, in that order, to generate this SRP subsection. Perform any necessary editorial corrections to accommodate the new format.

Directive 11: Draft the Evaluation Findings subsection.

Step 1 For existing sections, ensure that all Acceptance Criteria, including those added as part of this update, are appropriately addressed in the Safety
Evaluation Report conclusions suggested in this subsection.

Step 2 For ESRP sections, use the portion of the Input to Environmental Statement subsection that is left after the interface requirements have been removed to form this subsection. Perform any necessary editorial corrections needed to accommodate the new format.

Step 3 For all sections, including the ESRP, update or develop this subsection based on updates approved by the PRB.

\section{Directive 12: Draft Implementation subsection.}

Step 1 Ensure that the correct Implementation paragraphs (see Section 3.7.1 of this Implementing Procedures Document) already exist or are added.

Directive 13: Draft the References subsection.

Step 1 For existing SRP and ESRP sections, check the list of references to ensure that all entries are appropriately referenced in the text of the section. If any reference is not indicated in the text, attempt to reconstruct the reason for its inclusion and correct accordingly. If the reasons for inclusion cannot be determined, delete the reference. If a series of documents of a site-specific type are included (e.g., a series of United States Geological Service maps), consolidate them into a single entry, if at all possible, and make any necessary corrections to references in the text.

Step 2 For existing SRP sections, verify that all currently listed references still exist and update references, including dates of more recent revisions, as appropriate. Note that a number of Regulatory Guides have been withdrawn and, in many cases, replaced by other documents.

Step 3 Add all documents used in the updating of the other subsections to the reference list. Make sure that all such documents have been properly referenced in the section text.

Directive 14: Review the work performed under Directives 6 through 13 for compliance with requirements stated in this procedure and proper format.

Step 1 Review the draft SRP section for internal consistency. In particular, when something is 
added to one subsection, make sure that other subsections that are also affected have been appropriately updated. For example, the addition of an Acceptance Criterion will usually require the addition of a review step to ensure compliance, a finding that compliance was determined, and appropriate references.

Step 2 Make sure that all PRB-approved updates have been appropriately incorporated.

Step 3 Review each subsection to ensure compliance with the stated requirements in this procedure.

Step 4 Ensure that all parameter values have been stated in both metric and English units.

Step 5 Perform or have performed an editorial review of the completed draft.

Step 6 For drafts prepared by contractors at the direction of the PRB, provide the completed draft to the PRB for review per Procedure 4.1.

Forms

Two forms and two reports are used to implement this procedure. The Revision Options Checklist Form structures the analyst's review of impacts and the resulting potential revisions to SRP sections and provides the SRP Modification Database with the information needed to generate Option Papers and Type II Reports.

The Option Paper provides the PRB with the information needed to decide if and how an SRP section will be modified. Type II Reports are used to identify any Type II impacts that will or may be pursued outside of the scope of the SRP Update and Development Program.

The Draft SRP Section Form provides a vehicle for the analyst from the PRB-assigned organization to use in drafting new or revised SRP sections. Electronic versions of the current SRP section will be made available to the analyst. The Draft SRP Section Form, and, hence, the draft SRP section should be prepared in electronic format. Note that all values included in each new or revised section will be presented in metric and English units.

All organizations implementing this procedure must record their work on the indicated forms and forward the completed forms to the PTSB upon completion of the work. 
Sample Forms

\section{Revision Options Checklist Form}

Part A - Impact Identification

SRP Section No.

Enter Impact No. or Related Impact Nos.

New Impact No.

Enter Brief Description of the Impact

Part B - Determination of Impact Significance

(Note: Only one blank may be checked in each column)

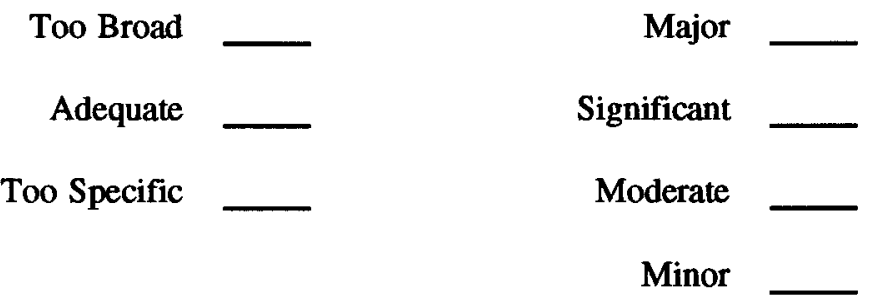

Part C - Characterization of Type and Nature of Change

Enter Brief Narrative 


\section{Revision Options Checklist Form (continued)}

Part D - Discussion of Possible Changes

Statement of Option

Pros

Cons

Is potential research indicated?

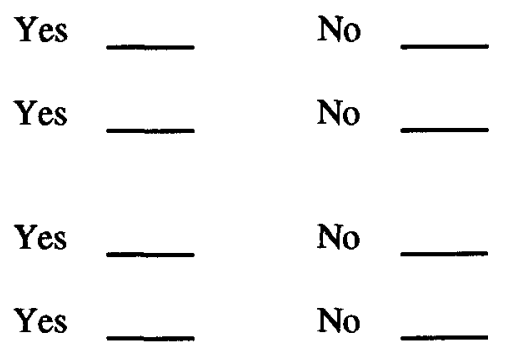

Are there additional options?

(Note: "Yes" to "additional options" will require completion of another Part D.) 


\section{Revision Options Checklist Form (continued)}

Part E - Identification of Conflicts

Conflict Identified?

Yes $\longrightarrow \quad$ No

Conflicting Impact Nos.

Description of Conflict

Potential Resolution

Rationale

Is potential research indicated?

Is potential rulemaking, regulatory guide revision, or other regulatory action indicated?

Is potential codes/standards development indicated?

Are there additional options?

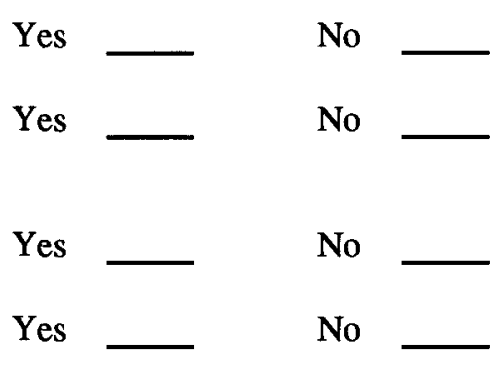

(Note: "Yes" to "additional options" will require completion of another Part E.) 


\section{Revision Options Checklist Form (continued) \\ Part F - Type I/Type II Determination}

\section{Type I - Revisions to the SRP Without Public Comments}

1. Do the suggested revisions incorporate new or revised requirements or guidance that have received public comment and have been approved by the Director, NRR, and therefore do not require additional public comments?

Yes

$$
\text { No }
$$

2. Do the suggested revisions incorporate new positions that have been approved by the Director, NRR, and by CRGR and EDO as being so clearly needed that a public comment period would cause an unacceptable delay in implementing them?

Yes

$$
\text { No }
$$

3. Do the suggested revisions involve only minor changes, such as clarifications, corrections, changes in names or assignments of branches, or deletions of unused references?

Yes

$$
\text { No }
$$

Type II - Revisions to the SRP with Public Comments

1. Do the suggested revisions incorporate proposed new or revised requirements, positions, or guidance that have not been reviewed and approved by the Director, NRR, CRGR and the EDO, or which could result in new sections for the SRP?

Yes

No

Provide Rationale for Above Determination 
Option Paper for SRP Section

SRP Section Title

Primary Review Branch

The SRP Update and Development Program has identified documents that have a potential impact on SRP Section Provided below are descriptions of each impact, options for handling the impact, and a discussion of the pros and cons associated with each option. These impacts and discussions are offered for your consideration in determining how the SRP section should be updated.

Please review the options for each potential impact and indicate your decisions in the applicable blanks provided in this Option Paper. Return the completed Option Paper to the PTSB at the time you send your completed draft SRP Section

1. Impact Description:

Impact No:

[Description of impact from Revision Options Checklist Form, Part A, Procedure 3.3]

Type and Nature of Indicated Change:

[Brief narrative from Revision Options Checklist Form, Part C, Procedure 3.7]

PRB Comments:

\section{Impact Significance:}

The level of detail appears to be (too broad)(adequate)(too specific) to be used in updating the SRP section. The amount of revision associated with this impact is anticipated to be (major)(significant)(moderate)(minor). [Selections made from Revision Options Checklist Form, Part B, Procedure 3.3.]

\section{Type I/Type II Determination:}

This impact has been categorized as a Type (I)(II) change based on the criteria contained in NRR Office Letter No. 800. The rationale for this determination is as follows: [from Revision Options Checklist Form, Part F, Procedure 3.7]

PRB Comments: 
3.7 Updating SRP Sections

Option Paper for SRP Section (continued)

\section{OPTIONS}

Option A:

[from Revision Options Checklist Form, Part D, Procedure 3.7]

Pros:

Cons:

PRB Comments:

Option B:

[from Revision Options Checklist Form, Part D, Procedure 3.7]

Pros:

Cons:

PRB Comments:

2. Impact Description: [as above]

3. Impact Description: [as above] 
Option Paper for SRP Section (continued)

\section{CONFLICTS}

(No conflicts have)(The following conflict(s) has(have)) been identified in this review area.

Conflict No.

Impact No.

Source Document Accession No.

Source Document Type

Source Document No.

Source Document Title

Publication/Revision Date

Revision No.

Impact Location(s)

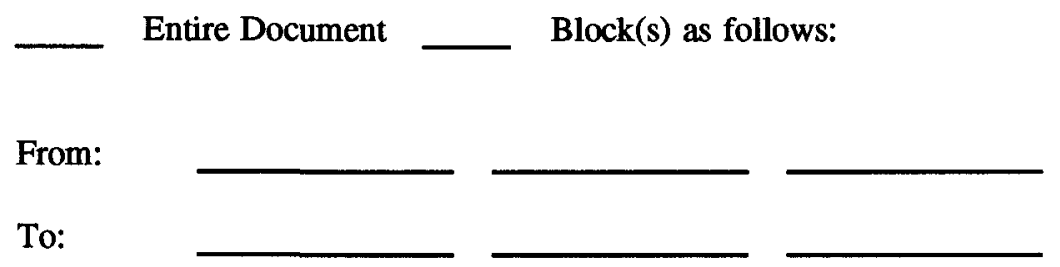

[Nature of conflict and potential resolution from Revision Options Checklist Form, Part E, Procedure 3.7]

Potential research, regulatory action, or need for code or standard development (is)(is not) indicated for this conflict.

PRB Comments

Conflict No.

[Repeat, as above, for each identified conflict.] 
Type II Report

To:

From:

Date:

Subject: Identification of Potential Type II SRP Change Outside the Scope of the SRP Update and Development Program

The SRP Update and Development Program has identified a potential SRP change that has been classified as Type II based on the definition provided in NRR Office Letter 800 . This potential change pertains to an SRP modification that would apply to future license applications not involving evolutionary or advanced reactor designs, and therefore is outside of the scope of the SRP Update and Development Program. The following information is provided for your use in determining the appropriate disposition for the potential change.

SRP Section No.

SRP Section Title

Source Document(s):

(Document number, title, and date, and page and line numbers of start and end points of impact description in the document)

Rationale for Type II Determination:

(Paragraph from Part F of Revision Options Checklist Form, Procedure 3.7)

Description of Potential Change:

(Two paragraphs, taken from the narratives included in Parts A and C of the Revision Options Checklist Form, Procedures 3.3 and 3.7) 
Section No.

Section Title

\section{Review Responsibilities}

I. Areas of Review

Objectives of the Review

Scope

Review Interfaces

\section{Acceptance Criteria}

Requirements and Guidance

Table (SRP Section Number)-1

\begin{tabular}{|c|l|c|c|}
\hline Requirements & Guidance & $\begin{array}{c}\text { Affected Structures, } \\
\text { Systems, Components, or } \\
\text { Processes }\end{array}$ & $\begin{array}{c}\text { Failure Mechanisms } \\
\text { or Issues }\end{array}$ \\
\hline \hline & & & \\
\hline & & & \\
\hline & & & \\
\hline & & & \\
\hline
\end{tabular}

Technical Rationale

\section{Technical Rationale References}

A.

B.

C. 


\section{Draft SRP Section Form (continued)}

\section{Review Procedures}

Purpose

Procedure

IV. Evaluation Findings

\section{Implementation}

The following is intended to provide guidance to applicants and licensees regarding the NRC staff's plans for using this SRP section.

Except in those cases in which the applicant proposes an acceptable alternative method for complying with specified portions of the commission's regulations, the method described herein will be used by the staff in its evaluation of conformance with Commission regulations.

Implementation schedules for conformance to parts of the method discussed herein are contained in the referenced [regulatory guides or other materials.]

[or, for ESRP sections]

The following is intended to provide guidance to applicants and licensees regarding the NRC staff's plans for using this SRP section.

The method described herein will be used by the staff in its evaluation of conformance with Commission environmental regulations. Inasmuch as the review method set forth in this section represents current staff practice, implementation will be immediately effective.

\section{References}

1.

2.

3. 


\section{How to Complete the Form}

\section{Revision Options Checklist Form}

Parts A and B (and possibly the first three lines of Part E) will have already been completed per the instructions in Procedure 3.3.

Part C

- Enter a brief but complete narrative description of the type and nature of the change suggested by the impact.

Part D

- Enter a brief statement of the first option.

- Provide pro and con arguments regarding the option under consideration.

- Indicate the potential need for research, regulatory action, or codes/standards development associated with the option by placing an " $\mathrm{X}$ " in the appropriate "Yes" or "No" responses. If the answer is "Yes," perform the requirements of Procedure 7.0.

- Indicate "Yes" in response to the question regarding additional options. (The option to leave the SRP section as is should always be included.)

- Enter the next option and the other information indicated above.

- Indicate "Yes" or "No" as to whether there are any more options to be considered.

- Continue to enter options until there are none remaining.

\section{Part E}

- The first three lines of Part E may have already been completed per the instructions in Procedure 3.3. Review the indicated results and make any necessary corrections.

- Indicate with an "X" as to whether a conflict has been identified. If the answer is "No," proceed to Part F.

- Enter the impact numbers of the conflicting impacts.

- Enter a description of the conflict, suggested potential resolutions, and rationales.
- Indicate the need for additional research or regulatory action by placing an " $\mathrm{X}$ " in the appropriate blanks.

- Indicate if another conflict has been identified. If so, repeat the foregoing steps. If not, proceed to Part F.

Part $F$

- Answer the four questions by placing an " $\mathrm{X}$ " in the appropriate blanks. There should be one "Yes" and three "No" answers.

- Provide a brief description of how and why the above questions were answered in the way they were.

\section{Option Papers}

Option Papers are generated by the SRP Modification Database system or the assigned organization based, primarily, on the information provided on the Revision Options Checklist Form. An Option Paper is generated for each SRP section. It contains a description of the impacts associated with the SRP section, options for handling the impact, pro and con statements for each option, and a description of any document conflicts that have been identified.

\section{Type II Reports}

Type II Reports are generated by the SRP Modification Database system based on the information provided on the Revision Options Checklist Form. These reports identify SRP impacts related to future applications not involving evolutionary or advanced reactor designs that have been categorized as Type II. They do not include new SRP sections addressing generically applicable topics. Reports are generated periodically as required by the PTSB and are forwarded by the PTSB to the cognizant NRC organization for disposition in accordance with established NRC procedures.

\section{Draft SRP Section Form}

- Complete the initial portion of the form by indicating the SRP section number and title.

- The computer provides the remainder of the form as a template for use by the analyst in drafting the SRP section in the appropriate format (for example SRP as opposed to ESRP). The computer will also provide the table number under Subsection II by adding a "-1" to the SRP section number. Otherwise, the form will be available in hard-copy format. 


\subsection{Updating SRP Sections}

- Use the template to revise or create an updated or developed SRP section. An example of an SRP section in correct format is provided in Appendix A of this Implementing Procedures Document. (Note that
Appendix A also includes a separate Acceptance Criteria subsection for applicants seeking a 60 -year design life review. This subsection is discussed in Procedure 3.8) 
Sample Completed Forms

\section{Revision Options Checklist Form (first example) \\ Part A - Impact Identification}

SRP Section No. 6.2 .5

Enter Impact No. or Related Impact Nos. 165

New Impact No. 3160

Enter Brief Description of the Impact BWR plants that use external recombiners for post-accident consumable gas

control should provide containment penetrations dedicated to that service or shared with other systems which meet 50.44 requirements. Any additional valves should be subjected to Appendix $\mathrm{J}$ leak testing and the technical specifications modified accordingly.

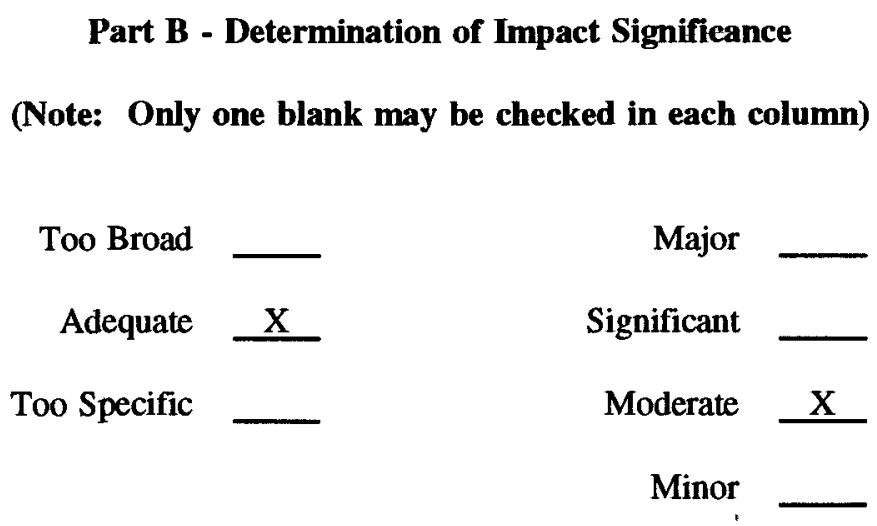

Part C - Characterization of Type and Nature of Change

Enter Brief Narrative A new general Acceptance Criterion (related to 10 CFR 50.44) would be added to include a requirement that dedicated penetrations be added or that penetrations shared with other systems (in accordance with $\$ 50.44)$ be used on BWR plants that use external recombiners or purge-repressurization systems for post-accident combustible gas control. Corresponding review procedures and evaluation findings would also be added. 


\subsection{Updating SRP Sections}

\section{Revision Options Checklist Form (first example, continued)}

Part D - Discussion of Possible Changes

Statement of Option Revise the SRP as indicated above.

Pros This impact has been codified in Part 50 at $\$ 50.44(\mathrm{c})(3)$ (ii) and, therefore, represents a legal requirement. If this option is not implemented, the SRP will not reflect the NRC's current rules.

Cons No con arguments have been identified.

Is potential research indicated?

$\begin{array}{ccc}\text { Yes } & \text { No } & \mathrm{X} \\ \text { Yes } & & \text { No } \\ \text { Yes } & & \\ \text { Yes } & \text { No } & \mathrm{X} \\ & \text { No }\end{array}$

Is potential rulemaking, regulatory guide revision, or other regulatory action indicated?

Is potential codes/standards development indicated?

Are there additional options?

(Note: "Yes" to "additional options" will require completion of another Part D.) 


\section{Revision Options Checklist Form (first example, continued)}

Part D - Discussion of Possible Changes

Statement of Option Do not revise the SRP.

Pros None identified.

Cons The impact represents a codified NRC requirement. If the SRP is not revised, the SRP will fail to achieve its goal of accurately reflecting current NRC requirements and guidance.

Is potential research indicated?

Is potential rulemaking, regulatory guide revision, or other regulatory action indicated?

Is potential codes/standards development indicated?

Are there additional options?

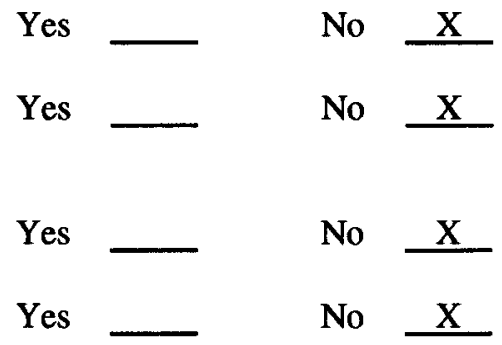

(Note: "Yes" to "additional options" will require completion of another Part D.) 
3.7 Updating SRP Sections

Revision Options Checklist Form (first example, continued)

Part E - Identification of Conflicts

Conflict Identified?

Yes $\longrightarrow$ No $\mathrm{X}$

Conflicting Impact Nos.

Description of Conflict

Potential Resolution

Rationale

Is potential research indicated?

$\begin{array}{ll}\text { Yes } & \text { No }- \\ \text { Yes } & \text { No }\end{array}$

Is potential rulemaking, regulatory guide revision, or other regulatory action indicated?

Is potential codes/standards development indicated?

$\begin{array}{ll}\text { Yes } & \text { No } \\ \text { Yes } & \text { No }\end{array}$

Are there additional options?

(Note: "Yes" to "additional options" will require completion of another Part E.) 


\section{Revision Options Checklist Form (first example, continued)}

\section{Part F - Type I/Type II Determination}

Type I - Revisions to the SRP Without Public Comments

1. Do the suggested revisions incorporate new or revised requirements or guidance that have received public comment and have been approved by the Director, NRR, and therefore do not require additional public comments?

Yes $\mathrm{X}$ No

2. Do the suggested revisions incorporate new positions that have been approved by the Director, NRR, and by CRGR and EDO as being so clearly needed that a public comment period would cause an unacceptable delay in implementing them?

Yes _ No $\quad \mathrm{X}$

3. Do the suggested revisions involve only minor changes, such as clarifications, corrections, changes in names or assignments of branches, or deletions of unused references?

Yes

Type II - Revisions to the SRP with Public Comments

1. Do the suggested revisions incorporate proposed new or revised requirements, positions, or guidance that have not been reviewed and approved by the Director, NRR, CRGR and the EDO, or which could result in new sections for the SRP?

Yes _ No

Provide Rationale for Above Determination The impact is included in Part 50 and has undergone a formal rulemaking.

Therefore, all pertinent NRC approvals have been obtained, including an opportunity for public comments. 
3.7 Updating SRP Sections

\section{Revision Options Checklist Form (second example) \\ Part A - Impact Identification}

SRP Section No. 6.2 .5

Enter Impact No. or Related Impact Nos. $\underline{3007}$

New Impact No. 5667

Enter Brief Description of the Impact The impact requires the licensee to provide operating instructions for operating the

hydrogen recombiners because the combustible gas control system is safety related.

\begin{tabular}{l} 
Part B - Determination of Impact Significance \\
(Note: Only one blank may be checked in each column) \\
Too Broad - Major - Significant - \\
Adequate \\
Too Specific \\
\hline
\end{tabular}

Part C - Characterization of Type and Nature of Change

Enter Brief Narrative A specific Acceptance Criterion (related to GDC-41) would be added to require development of hydrogen recombiner operating instructions according to guidance provided in ANSI N18.7-1976/ANS-3.2.

Corresponding review procedures and evaluation findings would also be added. 


\section{Revision Options Checklist Form (second example, continued) \\ Part D - Discussion of Possible Changes}

Statement of Option Revise the SRP as indicated above.

Pros The indicated change would make this SRP section consistent with Regulatory Guide 1.33. There currently is no guidance in Section 6.2.5 to ensure that necessary operating instructions are developed. Such instructions are an essential part of successful system operation when needed.

Cons None identified.

Is potential research indicated?

Is potential rulemaking, regulatory guide revision, or other regulatory action indicated?

\begin{tabular}{|c|c|c|c|}
\hline Yes & & No & $\mathbf{X}$ \\
\hline Yes & & No & $X$ \\
\hline Yes & & No & $X$ \\
\hline Yes & $\mathbf{X}$ & No & \\
\hline
\end{tabular}

Are there additional options?

(Note: "Yes" to "additional options" will require completion of another Part D.) 
3.7 Updating SRP Sections

Revision Options Checklist Form (second example, continued)

Part D - Discussion of Possible Changes

Statement of Option Do not revise the SRP.

Pros None identified.

Cons Failure to revise the SRP would cause an approved Regulatory Guide position not to be reflected in the SRP.

Is potential research indicated?

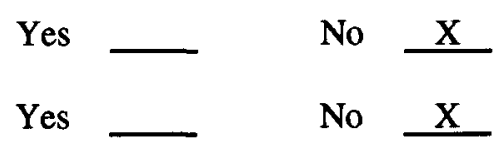

Is potential rulemaking, regulatory guide revision, or other regulatory action indicated?

Is potential codes/standards development indicated?

Yes

No

Are there additional options?

Yes

No

(Note: "Yes" to "additional options" will require completion of another Part D.) 


\section{Revision Options Checklist Form (second example, continued)}

\section{Part E - Identification of Conflicts}

Conflict Identified?

Yes

Conflicting Impact Nos.

Description of Conflict

Potential Resolution

Rationale

Is potential research indicated?

Is potential rulemaking, regulatory guide revision, or other regulatory action indicated?

Is potential codes/standards development indicated?

Are there additional options?

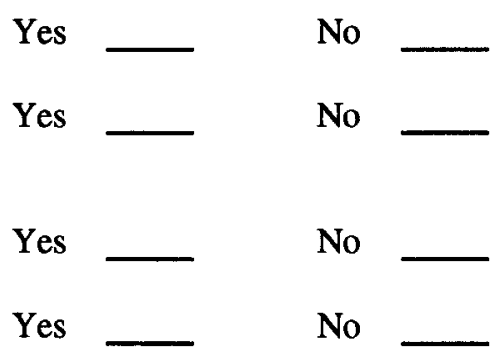

(Note: "Yes" to "additional options" will require completion of another Part E.) 
3.7 Updating SRP Sections

\section{Revision Options Checklist Form (second example, continued)}

Part F - Type I/Type II Determination

Type I - Revisions to the SRP Without Public Comments

1. Do the suggested revisions incorporate new or revised requirements or guidance that have received public comment and have been approved by the Director, NRR, and therefore do not require additional public comments?

Yes $\mathrm{X}$ No

2. Do the suggested revisions incorporate new positions that have been approved by the Director, NRR, and by CRGR and EDO as being so clearly needed that a public comment period would cause an unacceptable delay in implementing them?

Yes _ No

3. Do the suggested revisions involve only minor changes, such as clarifications, corrections, changes in names or assignments of branches, or deletions of unused references?

Yes _ No $\quad$ N

Type II - Revisions to the SRP with Public Comments

1. Do the suggested revisions incorporate proposed new or revised requirements, positions, or guidance that have not been reviewed and approved by the Director, NRR, CRGR and the EDO, or which could result in new sections for the SRP?

Yes _ No

Provide Rationale for Above Determination The SRP change would be consistent with an approved Regulatory Guide position. 


\section{Revision Options Checklist Form (third example)}

Part A - Impact Identification

SRP Section No. 6.2 .5

Enter Impact No. or Related Impact Nos. 1981

New Impact No. 4130

Enter Brief Description of the Impact Requires licensees of Westinghouse PWRs to review operating modes and procedures with regard to their ability to handle significant amounts of hydrogen gas following a plant transient or accident.

\begin{tabular}{l} 
Part B - Determination of Impact Significance \\
(Note: Only one blank may be checked in each column) \\
\begin{tabular}{rrr} 
Too Broad & $\mathrm{X}$ & Major \\
Adequate & - & Significant \\
Too Specific & - & Moderate \\
\hline
\end{tabular} \\
\hline
\end{tabular}

Part C - Characterization of Type and Nature of Change

Enter Brief Narrative The impact would require the addition of review procedures to assess the analyses performed by Westinghouse PWR licensees regarding the ability of their facilities to handle post-accident combustible gases. An Acceptance Criterion and an associated evaluation finding would also have to be established. 
3.7 Updating SRP Sections

\section{Revision Options Checklist Form (third example, continued) \\ Part D - Discussion of Possible Changes}

Statement of Option Revise the SRP as indicated above.

Pros The action indicated in this Bulletin has since been codified in Part 50, although with more specificity. Therefore, the SRP should be updated.

Cons The specific requirements in Part 50 should be addressed directly (see other impacts). The direction provided in the Bulletin was preliminary and does not adequately represent current requirements.

Is potential research indicated?

Is potential rulemaking, regulatory guide revision, or other regulatory action indicated?

Is potential codes/standards development indicated?

Are there additional options?

$\begin{array}{lll}\text { Yes } & \text { No } \frac{\mathrm{X}}{\mathrm{X}} \\ \text { Yes } & & \text { No } \\ \text { Yes } & & \text { No } \frac{\mathrm{X}}{} \\ \text { Yes } & \mathrm{X} & \text { No }\end{array}$

(Note: "Yes" to "additional options" will require completion of another Part D.) 


\section{Revision Options Checklist Form (third example, continued)}

Part D - Discussion of Possible Changes

Statement of Option Make no SRP revisions, use other impacts.

Pros Other impacts are approved regulations and will form a better basis for SRP changes. Other impacts are also more specific in their requirements.

Cons None identified.

Is potential research indicated?

Is potential rulemaking, regulatory guide revision, or other regulatory action indicated?

\begin{tabular}{ll} 
Yes & No \\
Yes & No \\
\hline
\end{tabular}

Is potential codes/standards development indicated?

$\begin{array}{lll}\text { Yes } & \text { No } \frac{\mathrm{X}}{} \\ \text { Yes } & \text { No } \underline{\mathrm{X}}\end{array}$

Are there additional options?

(Note: "Yes" to "additional options" will require completion of another Part D.) 
Revision Options Checklist Form (third example, continued)

Part E - Identification of Conflicts

Conflict Identified? $\quad$ Yes $ـ \quad$ No $\underline{\mathrm{X}}$

Conflicting Impact Nos.

Description of Conflict

Potential Resolution

Rationale

Is potential research indicated?

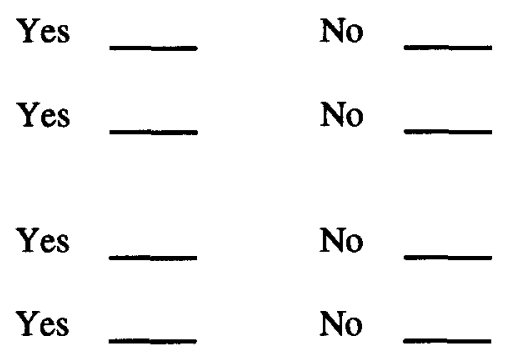

Are there additional options?

(Note: "Yes" to "additional options" will require completion of another Part E.) 


\section{Revision Options Checklist Form (third example, continued) \\ Part F - Type I/Type II Determination}

\section{Type I - Revisions to the SRP Without Public Comments}

1. Do the suggested revisions incorporate new or revised requirements or guidance that have received public comment and have been approved by the Director, NRR, and therefore do not require additional public comments?

Yes

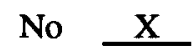

2. Do the suggested revisions incorporate new positions that have been approved by the Director, NRR, and by CRGR and EDO as being so clearly needed that a public comment period would cause an unacceptable delay in implementing them?

Yes $\mathrm{X} \quad$ No

3. Do the suggested revisions involve only minor changes, such as clarifications, corrections, changes in names or assignments of branches, or deletions of unused references?

Yes _ No

\section{Type II - Revisions to the SRP with Public Comments}

1. Do the suggested revisions incorporate proposed new or revised requirements, positions, or guidance that have not been reviewed and approved by the Director, NRR, CRGR and the EDO, or which could result in new sections for the SRP?

Yes

$$
\text { No }
$$

Provide Rationale for Above Determination This requirement was issued as a Bulletin and, therefore, represents an NRCapproved requirement. Furthermore, the essence of this requirement has since been codified in Part 50. 


\section{Option Paper for SRP Section 6.2.5}

NOTE: The following example of a completed Option Paper is provided solely to facilitate understanding of the Option Paper Format. The three example impacts (from the Revision Options Checklist examples) are real, but represent a very small sample of the many actual impacts that affect SRP Section 6.2.5.

SRP Section Title Combustible Gas Control in Containment

Primary Review Branch Plant Systems Branch (SPLB)

The SRP Update and Development Program has identified documents that have a potential impact on SRP Section 6.2.5. Provided below are descriptions of each impact, options for handling the impact, and a discussion of the pros and cons associated with each option. These impacts and discussions are offered for your consideration in determining how the SRP section should be updated.

Please review the options for each potential impact and indicate your decisions in the applicable blanks provided in this Option Paper. Return the completed Option Paper to the PTSB at the time you send your completed draft SRP Section 6.2.5.

\section{Impact Description:}

Impact No: 3160

BWR plants that use external recombiners for post-accident combustible gas control should provide containment penetrations dedicated to that service or shared with other systems which meet $\$ 50.44$ requirements. Any additional valves should be subjected to Appendix $J$ leak testing and the technical specifications modified accordingly.

Type and Nature of Indicated Change:

A new general acceptance criterion (related to 10 CFR 50.44) would be added to include a requirement that dedicated penetrations be added or that penetrations shared with other systems (in accordance with \$50.44) be used on BWR plants that use external recombiners or purge-repressurization systems for post-accident combustible gas control. Corresponding review procedures and evaluation findings would also be added.

PRB Comments:

\section{Impact Significance:}

The level of detail appears to be adequate to be used in updating the SRP section. The amount of revision associated with this impact is anticipated to be moderate. 
Option Paper for SRP Section 6.2.5 (continued)

\section{Type I/Type II Determination:}

This impact has been categorized as a Type I change based on the criteria contained in NRR Office Letter No. 800 . The rationale for this determination is as follows:

The impact is included in Part 50 and has undergone a formal rulemaking. Therefore, all pertinent NRC approvals have been obtained, including an opportunity for public comments.

PRB Comments:

\section{OPTIONS}

\section{Option A:}

Revise the SRP as indicated above.

Pros: This impact has been codified in Part 50 at $\$ 50.44(c)(3)(i i)$ and, therefore, represents a legal requirement. If this option is not implemented, the SRP will not reflect the NRC current rules.

Cons: No con arguments have been identified.

PRB Comments:

\section{Option B:}

Do not revise the SRP.

Pros: None Identified.

Cons: The impact represents a codified NRC requirement. If the SRP is not revised, the SRP will fail to achieve its goal of accurately reflecting current NRC requirements and guidance.

PRB Comments: 
Option Paper for SRP Section 6.2.5 (continued)

2. Impact Description:

Impact No: 5667

The impact requires the licensee to provide operating instructions for operating the hydrogen recombiners because the combustible gas control system is safety related.

Type and Nature of Indicated Change:

A specific acceptance criterion (related to GDC-41) would be added to require development of hydrogen recombiner operating instructions according to guidance provided in ANSI N18.7/ANS-3.2. Corresponding review procedures and evaluation findings would also be added.

PRB Comments:

\section{Impact Significance:}

The level of detail appears to be adequate to be used in updating the SRP section. The amount of revision associated with this impact is anticipated to be moderate.

\section{Type I/Type II Determination:}

This impact has been categorized as a Type I change based on the criteria contained in NRR Office Letter No. 800 . The rationale for this determination is as follows:

The SRP change would be consistent with an approved Regulatory Guide position.

PRB Comments:

\section{OPTIONS}

\section{Option A:}

Revise the SRP as indicated above.

Pros: The indicated change would make this SRP section consistent with Regulatory Guide 1.33. There currently is no guidance in Section 6.2.5 to ensure that necessary operating instructions are developed. Such instructions are an essential part of successful system operation when needed. 


\section{Option Paper for SRP Section 6.2.5 (continued)}

Cons: No con arguments have been identified.

PRB Comments:

\section{Option B:}

Do not revise the SRP.

Pros: None Identified.

Cons: Failure to revise the SRP would cause an approved Regulatory Guide position not to be reflected in the SRP.

PRB Comments:

3. Impact Description:

Impact No: $\underline{4130}$

The impact requires licensees of Westinghouse PWRs to review operating modes and procedures with regard to their ability to handle significant amounts of hydrogen gas following a plant transient or accident.

\section{Type and Nature of Indicated Change:}

The impact would require the addition of review procedures to assess the analyses performed by Westinghouse PWR licensees regarding the ability of their facilities to handle post-accident combustible gases. An Acceptance Criterion and an associated evaluation finding would also have to be established.

PRB Comments:

\section{Impact Significance:}

The level of detail appears to be too broad to be used in updating the SRP section. The amount of revision associated with this impact is anticipated to be significant. 


\section{Option Paper for SRP Section 6.2.5 (continued)}

Type I/Type II Determination:

This impact has been categorized as a Type I change based on the criteria contained in NRR Office Letter No. 800 . The rationale for this determination is as follows:

This requirement was issued as a Bulletin and, therefore, represents an NRC-approved requirement. Furthermore, the essence of this requirement has since been codified in Part 50.

PRB Comments:

\section{Option A:}

\section{OPTIONS}

Revise the SRP as indicated above.

Pros: The action indicated in this Bulletin has since been codified in Part 50, although in more specificity. Therefore, the SRP should be updated.

Cons: The specific requirements in Part 50 should be addressed directly (see other impacts). The direction provided in the Bulletin was preliminary and does not adequately represent current requirements.

PRB Comments:

\section{Option B:}

Make no SRP revisions; use other impacts.

Pros: Other impacts are approved regulations and will form a better basis for SRP changes. Other impacts are also more specific in their requirements.

Cons: None identified.

PRB Comments:

\section{CONFLICTS}

No conflicts have been identified in this review area. 


\section{Draft SRP Section Form}

A completed sample Draft SRP Section Form is provided in Appendix A to this Implementing Procedures Document. 
-

-

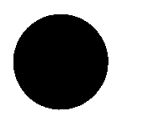




\subsection{Upgrading SRP Sections for Future Reactor Designs}

\subsubsection{Approach}

This section contains the procedure to be followed in evaluating impacts, determining which impacts will be incorporated in the SRP, and drafting upgrades to existing SRP sections or drafting newly identified SRP sections to provide the review guidance for future (evolutionary and advanced) reactor designs. Procedure 3.8 should be followed regardless of which resource option the PRB has selected for accomplishing the revision (that is, the PRB itself, a contractor of the PRB's choosing, or the PTSB).

Because future reactor designs are not complete, the SRP upgrades addressing such a design are not intended to be complete until after a design review for the reactor type has been performed.

For those structures, systems, and components of future reactor designs that use conventional reactor technology, this activity requires preparation of an outline to summarize changes to current SRP sections. For the future reactor structures, systems, and components that are truly revolutionary, this activity supports new section development. Whether an existing SRP section is being upgraded or a new one is being developed, the basic approach is the same.

This procedure assumes that SRP sections that will be upgraded will have already been processed according to Procedures 3.3 and 3.7 with regard to updating to current technology. Therefore, impacts regarding conventional reactor technology will have already been considered and Option Papers will have been prepared and will have received PRB approval.

For future reactor SRP sections that will be upgraded from existing SRP sections, the approach will be to obtain the impact assessments performed for conventional reactor technology (resulting from Procedures 3.3 and 3.7), reassess these impacts in view of the specific reactor design, and then consider additional information as described in the following paragraphs.

SRP sections that need to be developed (where no existing sections cover the review area) will rely heavily on existing requirements and guidance to the extent that such requirements and guidance apply to the reactor design under consideration. It is anticipated that much of the technology used in future reactor designs will be the application of current technology in ways that are different in scope from their application to current designs. The new applications of this technology, applications of current technology in a unique manner, or use of new technology will necessitate development of new Acceptance Criteria or review procedures to supplement existing criteria and procedures. In those cases where new criteria or procedures need to be developed, the analyst will require specific, pertinent information (such as staff Safety Evaluation Reports on the reactor design under consideration). Obtaining such information is included as a part of this procedure.

The objectives associated with this procedure are as follows:

- Characterizing the informational content of the impact;

- Identifying any areas where current regulations are inadequate or where additional research is required to establish a licensing basis for future reactor technology;

- Obtaining PRB decisions as to which impacts are to be incorporated in the SRP upgrades; and

- Drafting the SRP upgrades in accordance with PRB decisions.

Characterizing the informational content of impacts is the determination of how the information can be used to develop a licensing basis. Assessment of the pertinent facts, and their correlation with current requirements or the establishment of new requirements, is the primary product of this activity.

Identifying needs for regulatory development or research (future work) will be accomplished by identifying the "holes" left after relevant information has been evaluated for the development of the SRP section. It is anticipated that, in certain cases, adequate bases for section development will not be available. These bases will have to be established based on regulatory and/or information development. Such items will be handled in accordance with Procedure 7.0.

Responsibility for upgrading each SRP section rests with the PRB. The PRB is also responsible for determining which SRP impacts will be incorporated in the SRP and which will not.

This determination is accomplished using an Upgrade Outline Report. This report summarizes identified impacts that would assist in establishing licensing requirements. The Upgrade Outline Report has spaces to allow the PRB to indicate its decisions.

The information identified, processed, evaluated, and organized by previous steps and procedures assist the PRB in determining the need for SRP section upgrades. 
All of these activities result in the preparation of Upgrade Outline Reports that summarize proposed changes from the many documents reviewed and present recommendations regarding the actions that could be taken. Upgrade Outline Reports will be provided to the PRBs by the assigned organization and will be used by the PRBs, along with the extensive knowledge and experience contained within the PRB staff, to determine which changes need to be made and which do not.

Upgrade Outline Reports will address entire SRP sections, but each individual impact resulting in a proposed change will be reported separately. This will allow the PRB not only to determine whether a section needs revision, but also to select from the proposed changes.

Decisions of the PRBs will need to be recorded in the SRP Modification Database. To this end, the PRBs will be asked to record their decisions on comment blanks that will be included in the Upgrade Outline Report packages. The completed forms will be returned to the PTSB, and data entry will be accomplished by PNL on behalf of the PTSB.

It is expected that each PRB will have its own specific criteria for deciding whether revisions are justified. In general, for SRP upgrades, it would be expected that any inputs useful in establishing requirements for future reactor licensing should be incorporated.

It should be noted that development of new sections, and in most cases, the revision of existing sections to cover future reactor designs, results in the development or application of new requirements. Accordingly, it would be expected that most aspects of section upgrading or development would fall under the Type II category. Future reactor SRP sections will be reviewed in accordance with NRC policy, and the review will, in large part, deal with the establishment of adequate safety requirements for new types of plants.

In upgrading SRP sections, special emphasis will be placed on ensuring that plant layout considerations are appropriately considered in the revision process. The spatial configuration and physical design and geometry of structures, systems, and components have been shown in evaluations of operating experience to have potential impacts on the reliability and safety of nuclear power plant operations.

As discussed in Section 3.1, the development of a new SRP section on the generic implications of plant layout issues is being evaluated. Results of that evaluation will provide document impacts for the revision of individual SRP sections which cover regulatory issues in areas such as seismic system analyses, high energy line break hazards, radiation protection, fire protection, internal flooding and water intrusion, inservice inspection and testing, missile protection, and pipe rupture and impingement protection. As an example, SRP section 3.4.1 on flood protection will need to be revised to incorporate results from the resolution of Unresolved Safety Issue A-17 on adverse systems interactions. The resolution document, Generic Letter 89-18, stated that the staff plans to develop an SRP for future plants which would include specific guidance regarding protection from internal flooding and water intrusion events.

An important topic that will be addressed in the upgrading of SRP sections for future reactor designs is 60-year design life review. As stated in SECY 89-013, dated January 19, 1989, for applications proposing a 60 year design life, the staff will review the designs for a 60-year life notwithstanding the fact that a 40 -year license term limitation is presently specified in the Atomic Energy Act and the NRC's regulations. It will be the applicant's responsibility to identify the components and systems that are affected. Applications for design certification will have to provide information and programs to support design life, and the reviews for such issues as fatigue, corrosion, and thermal aging. In those SRP sections for which applications proposing a 60 -year design life will require such additional staff review, the revised SRP will include a separate Acceptance Criteria subsection for 60 -year design life review.

The final task of Procedure 3.8 is to translate approved and required concepts into complete draft SRP sections that follow the standard format for SRP sections.

It should be noted that ESRP sections are updated in Procedure 3.7. Since the ESRP sections are almost completely independent of the type of facility to be located at a site, no additional upgrade is anticipated for future reactor designs. Only SRP sections normally associated with the staff's safety review are addressed in this procedure.

In order to implement the Commission's metrification policy, all parameter values in the SRP will be presented in both metric and English units. The correct format is to present the value in metric units first, then present the English equivalent immediately following in parentheses. The following sentence illustrates this format: Nearby industrial and military facilities located within $8 \mathrm{~km}(5$ miles) of the plant should be identified.

The general approach for preparing draft SRP sections is presented below for each subsection. 


\section{Areas of Review}

This subsection describes the scope of the review for which the SRP section provides guidance--that is, the structures, systems, components, or other topics being reviewed by the PRB. This subsection also specifies the information needed or review expected from other branches to enable the PRB to complete its review.

The Areas of Review subsections in the current SRP vary quite substantially in their level of detail. At a minimum, new or revised Areas of Review subsections should contain the following:

- The objectives of the review--that is, the determinations regarding the systems, structures, components, or other topics to be made by the reviewers

- The scope of the review--that is, the particular systems, structures, components, or other area to be reviewed

- Review interfaces with other branches--that is, the relationship of other related reviews to the review conducted under this section

In addition, the following items should be included where they would help clarify the scope of the review:

- An explanation of the review topic--that is, a general description of the systems, structures, components, or other topics under review and their function

- The information on which the review is based--that is, the particular materials submitted by the applicant (typically, in the Safety Analysis Report) that the reviewers will rely on

- The considerations that go into the review--that is, the factors that the reviewers will take into account in determining whether the objectives of the review are met

\section{Acceptance Criteria}

This subsection tells the reviewer how to determine the acceptability of the applicant's submission with respect to the topic under review. This subsection generally identifies the applicable NRC requirements (10 CFR sections and General Design Criteria), refers to the guidance to be followed in meeting the requirements (such as Regulatory Guides, NUREG reports, and industry codes and standards), and provides narrative statements of how the applicant may demonstrate that the requirements have been met.
A significant objective of the SRP Update and Development Program is the development of technical rationales for the Acceptance Criteria in each SRP section. The technical rationales will be narrative explanations of the identified requirements and the solutions and approaches determined to be acceptable in the past by the staff. They provide the technical basis for determining the acceptability of the design or the programs within the scope of the area of review of the SRP section.

The technical rationales to be developed will serve several potential uses. First, they will provide pertinent background information to the staff reviewer that will assist the reviewer in determining acceptability of proposed designs. Second, they will assist applicants in understanding $\mathrm{NRC}$ requirements and how and why they are applied. In addition, they may be relied upon to support the indicated Acceptance Criteria in hearings and other licensing-related activities. Therefore, it is essential that the bases contain sufficient technical reasoning, including references to supporting documents, to justify the stated Acceptance Criteria.

The following example illustrates a rather comprehensive technical rationale. This example pertains to a hypothetical SRP Acceptance Criterion that requires a BWR Standby Liquid Control System to be able to safely shut down the reactor without the aid of control rods.

General Design Criterion 26 requires that two independent reactivity control systems of different design principles shall be provided. The standby liquid control system is used in the BWR as the second such system, the first being the control rods and their drive system. General Electric Company in NEDO-XXX presented the results of core reactivity calculations assuming various injection rates of sodium pentaborate solution of various concentrations. It was reported that injection of 35 gallons per minute of sodium pentaborate at a concentration of 1200 parts per million would provide $\$ 22$ of negative reactivity, more than enough to shut down the reactor and maintain it in shutdown. In fact, the $\$ 22$ of negative reactivity represents a $20 \%$ margin considering that the total core reactivity is approximately $\$ 18$. In the staff's safety evaluation of the NEDO report (NUREG-XXXX), the staff concluded through an independent analysis that the calculations were correct, but wished to provide an additional safety margin to allow for potential sodium pentaborate plateout in the storage tanks. Therefore, it was determined that 43 gallons per minute would satisfy the shutdown requirements with adequate margin. Two parallel systems using redundant 


\subsection{Upgrading for Future Designs}

active components and redundant sodium pentaborate storage tanks are required to provide adequate assurance that the required flow rate would be delivered assuming a single active failure. NUREG-XXXX also concluded that appropriate technical specifications need to be incorporated to ensure that the sodium pentaborate solution in the storage tanks be maintained at a temperature of greater than $95^{\circ} \mathrm{F}$ to avoid plateout and to include a monthly surveillance test of actual sodium pentaborate solution concentration. It was determined that the storage tank heaters did not have to be safety-grade due to the safety margins included in system design and the relatively high ambient temperatures maintained at the storage tank locations, which would prevent significant sodium pentaborate plateout even if tank heaters were to fail.

As shown by this example, enough technical detail should be provided to succinctly explain why the Acceptance Criterion is considered applicable and adequate. Specific references to supporting documents are to be provided, and a separate reference list for the Acceptance Criteria technical rationales included.

In some cases, as appropriate, the technical rationales could be more general in nature, and the details of solutions and acceptable approaches could be left to the reference documents or the subsection dealing with the review procedures. In fact, existing review procedures may already contain discussions of the approaches and solutions that have been found acceptable in the past.

Because of the need to clearly represent the Acceptance Criteria, a new format has been adopted within the Acceptance Criteria subsection. First, the applicable requirements and guidance are presented in tabular format. Then the Acceptance Criteria are stated. Finally, the technical rationale is presented and the technical rationale references are provided. The reference list for Acceptance Criteria technical rationales should list the materials relied on in establishing the technical rationales for the Acceptance Criteria. Because Acceptance Criteria technical rationales are being added to all SRP sections, this reference list must be created for each SRP section, as the technical rationales are developed. SRP sections that will require additional information from applicants and additional staff review if 60-year design life review is requested will include an additional Acceptance Criteria subsection in the same format. The new Acceptance Criteria format is illustrated in the Draft SRP Section Form described at the end of Procedure 3.7.

\section{Review Procedures}

This subsection indicates how the review is accomplished. In the current SRP, this discussion usually begins by indicating that the procedures that follow are used during the construction permit review to determine that the design or plans as set forth in the Preliminary Safety Analysis Report meet the Acceptance Criteria and during the operating license review to verify that the design or plans have been appropriately implemented as set forth in the Final Safety Analysis Report. It should be noted that for future reactor designs the review procedure will have to reflect the one-step review process envisioned in the new Part 52 for a combined construction permit/operating license. The subsection then specifies a sequence of numbered steps to be followed by the reviewer. Each step tells the reviewer to review a particular body of information in order to reach a particular determination. Some steps also tell the reviewer to obtain advice or analysis from some other branch responsible for a related aspect of the review. The concluding steps typically tell the reviewer how to integrate the conclusions of the initial steps in order to determine whether the Acceptance Criteria have been met.

When an SRP section is being upgraded, the Review Procedures subsection will need to be revised only to the extent particular steps are affected by identified impacts approved for implementation by the PRB. When a new SRP section is being developed, a complete sequence of steps will need to be developed.

It is the intention to establish a plant layout section in the SRP and to address plant layout concerns in existing SRP sections, as appropriate. The spatial configuration or arrangement of structures, systems, and components within a nuclear power plant can greatly influence the safe operation of the facility. The design objective is to achieve a balance between separation and interaction of the vital and non-vital structures, systems, and components of the facility, while ensuring the capability to operate and maintain each item commensurate with its level of safety. The approach to this topic is in development and will be more completely specified in the next revision to this Implementing Procedures Document.

\section{Evaluation Findings}

This section presents the type of conclusion expected to result from the review, which is generally published in the staff's Safety Evaluation Report.

In the current SRP, this subsection typically begins with an introductory statement to the effect that the reviewer verifies that the applicant has provided sufficient information and that the reviewer's evaluation is 
sufficiently complete to support conclusions of the following type, to be included in the Safety Evaluation Report. The subsection then provides what are essentially model conclusions or findings--language of the type that the reviewer is expected to include in the Safety Evaluation Report, stating that the information provided by the applicant enabled the reviewer to conclude that the system, structure, component, or other topic under review meets the applicable Acceptance Criteria. If findings are required from a Secondary Review Branch, model language for that purpose is also provided. Where background information on the facility under review would assist the reader in understanding the findings, the subsection indicates that such information should be provided along with the findings themselves.

When an existing SRP section is being upgraded, the Evaluation Findings subsection will need to be revised only to the extent particular findings are affected by applicable impacts approved for incorporation by the PRB. When a new SRP section is being developed, a complete set of findings will need to be developed.

\section{Implementation}

This subsection generally contains the following standard language:

The following is intended to provide guidance to applicants and licensees regarding the NRC staff's plans for using this SRP section.

Except in those cases in which the applicant proposes an acceptable alternative method for complying with specified portions of the Commission's regulations, the method described herein will be used by the staff in its evaluation of conformance with Commission regulations.

Implementation schedules for conformance to parts of the method discussed herein are contained in the referenced [Regulatory Guides or other materials.]

This language will already be in current SRP sections and should be included in new sections as well.

\section{References}

This is the last subsection, and it will contain a reference list for the SRP section. Ideally, all generally applicable materials on which the staff relies in reaching its findings should be included in the reference list for the SRP section generally, provided that the use of the reference materials is obvious or made evident in the SRP section text. The reference list should also be kept current (for example, by referring to the latest revisions of the cited materials.) When an existing SRP section is being revised, the References subsection will need to be revised only to the extent particular references are affected. References should also be checked for appropriateness and to ensure that their use will be evident to the reader. When a new SRP section is being developed, a complete reference list will need to be constituted.

\subsubsection{Procedure for Upgrading and Developing SRP Sections for Future Reactor Technology}

Purpose and Scope of This Procedure

This procedure specifies how to evaluate SRP impacts, decide which impacts to incorporate in the SRP, and draft SRP section upgrades or new SRP sections. This procedure applies regardless of which management option is chosen by the PRB for performing the work.

\section{Prerequisites for Performing This Procedure}

Technical Skills and Knowledge Levels. The analysts performing this procedure require a technical background and a working knowledge of nuclear power plant designs and systems and applicable regulatory materials, including the SRP. Personnel should possess detailed knowledge of the systems, structures,components, or processes covered by the assigned SRP section. Analysts will consult with other technical experts on an as-needed basis.

Document Availability. The analyst should have access to Impact Identification Forms and Subpart A of the Upgrade Outline Input Form for the SRP section being upgraded or developed as well as to the documents referenced in each. A draft of the updated version of the corresponding SRP section (Procedure 3.7) should also be obtained. These materials will be available in the information package resulting from implementation of Procedure 3.5, the SRP Modification Database and the SRP Reference Document Database. If additional documents are necessary, it will be the analyst's responsibility to identify and obtain them.

Completion of Prior Procedures. Initiation of this procedure requires the completion of Procedures 3.5 and 3.6 for the SRP section being upgraded. Completion of Procedure 3.7 for the corresponding SRP section would be very helpful.

\section{Overview of Steps in This Procedure}

The information package from Procedure 3.5 is evaluated, and an Upgrade Outline is developed. The PRB uses the Upgrade Outline to determine the upgrades that will be 
made. Each of the subsections in an SRP section is upgraded. The analyst then reviews the completed draft for internal consistency and conformance with requirements.

\section{Results of This Procedure}

Written Product. The written product resulting from implementation of this procedure is a draft SRP section.

Other. If in drafting the SRP section the analyst identifies impacts on other sections, an Impact Identification Form (from Procedure 2.4) is completed and entered into the SRP Modification Database so that the impact will be reflected in those sections.

\section{Detailed Procedure}

This section specifies the step-by-step sequence to be followed, grouped by directives (major intermediate outputs), to be accomplished by a series of specific steps. Each of Directives 5 through 11 addresses preparation of a separate SRP subsection. In the implementation of Directives 5 through 11, provide all parameter values in metric and English equivalent units and present both values according to the format prescribed in Section 3.8.1.

Directive 1: Make assignments (responsibility of Project Manager or Project Manager's designee.)

Step 1 Identify the analysts who will be responsible for implementing this procedure.

Step 2 Record assignments on the Work Assignment Form (see Procedure 2.1).

Directive 2: Review pertinent materials.

Step 1 Obtain and review the current updated draft, if any, of this SRP section. This draft will result from implementation of Procedure 3.7.

Step 2 Obtain and review design information relevant to the SRP section. If available, a Safety Analysis Report is a good source of such information.

Step 3 Obtain and review the PRB-completed Option Paper for this SRP section (from Procedure 3.7).

Step 4 Obtain and review the Impact Identification Form(s) (from Procedure 2.4) and reference documents for this SRP section, as required.

Step 5 Obtain the information package resulting from implementation of Procedure 3.5.
Step 6 Query the SRP Modification Database to determine the appropriate expert contact within the PRB (when draft preparation is performed outside of the PRB), who may be contacted when questions arise.

Step 7 If, during section upgrading, the analyst identifies impacts on other SRP sections that have not previously been identified, prepare an Impact Identification Form from Procedure 2.4 using the instructions contained in that procedure.

\section{Directive 3: Develop upgrade outlines.}

Step 1 Characterize the types of requirements suggested by impacts (or groups of related impacts) by completing Part B of the Upgrade Impact Assessment Form.

Step 2 Report any conflicts in impacts on Part C of the Upgrade Impact Assessment Form.

Step 3 Develop information needed to generate upgrade outlines by completing the Upgrade Outline Input Form.

Step 4 Prepare an Upgrade Outline Report through use of the SRP Modification Database system or manually by using input from the Upgrade Outline Input Form.

Directive 4: Obtain PRB decisions as to the upgrades to be implemented.

Step 1 Forward the Upgrade Outline Report to the responsible PRBs, including notification of response date and any other explanatory instructions.

Step 2 The PRB will review the Upgrade Outline Report and determine which upgrades should be incorporated in the SRP section. The PRB will indicate its decisions by entering comments in the comment blanks in the Upgrade Outline Report.

Step 3 The PRB will return the completed Upgrade Outline Report to the organization assigned to draft the SRP section.

Directive 5: Draft Areas of Review subsection.

Step 1 If this SRP section already exists, review the Procedure 3.7 updated draft to determine applicability to the advanced reactor design. 
Step 2 If this SRP section already exists, use the results of Step 1 and any PRB approved upgrades to appropriately upgrade the existing section. Complete the Areas of Review portion of the Draft SRP Section Form.

Step 3 If this is a new section, develop a new draft section. Complete the Areas of Review portion of the Draft SRP Section Form.

Step 4 Determine whether plant layout elements should be considered in upgrading the SRP section. (This step is in development and will be more completely specified in the next revision of this Implementing Procedures Document.)

Directive 6: Draft Acceptance Criteria subsection.

Step 1 If this SRP section already exists, review the Procedure 3.7 updated draft to determine applicability to the evolutionary or advanced reactor design. Also identify PRB-approved upgrades to be incorporated.

Step 2 If this SRP section already exists, convert the Acceptance Criteria requirements and guidance into tabular format and delete the description. For new sections, develop the requirements and guidance in tabular format. The tabular format is as indicated on the Draft SRP Section Form.

Step 3 Upgrade the Acceptance Criteria in consideration of PRB-approved upgrades.

Step 4 If this SRP section will require additional information from applicants and additional staff review to support a 60 -year design life review, repeat steps 1-3 to draft an additional Acceptance Criteria for 60-year design life review.

Directive 7: Draft technical rationales for Acceptance Criteria subsection.

Step 1 Review the Acceptance Criteria requirements and guidance (i.e., the General Design Criteria, Regulatory Guides, or the like) specified in the Acceptance Criteria subsection.

Step 2 If the referenced requirements or guidance state or imply a technical rationale, determine whether the rationale is adequate. The criterion to be used in determining adequacy is that the rationale clearly shows how the Acceptance Criteria implement their underlying requirements, and that the rationale could not be substantially improved based on existing information. If the rationale is adequate, go to Step 6.

Step 3 If the referenced requirements or guidance do not state or imply a technical rationale, obtain and review any documents cited therein from the SRP Reference Document Database, determine whether they state or imply a technical rationale, and, if so, whether it is adequate. If the rationale is adequate, go to Step 6.

Step 4 If neither Step 2 nor Step 3 has yielded an adequate technical rationale, develop a rationale based on best professional judgment, if necessary consulting documents in the topic area from the SRP Reference Document Database. If an adequate rationale is developed, go to Step 6.

Step 5 If none of the above steps has yielded an adequate technical rationale, either develop the option of revising the Acceptance Criteria, or invoke Procedure 7.0 to either develop additional information through research activities or modify Acceptance Criteria bases through regulatory action.

Step 6 Develop the technical rationale for the Acceptance Criteria by summarizing the information identified in Step 2, 3, 4, or 5 or provide appropriate references. (See Implementing Procedures Document Section 3.8.1 for guidance regarding the development of the technical rationales.) Enter the technical rationale on the Draft SRP Section Form.

Step 7 Develop a separate reference list for those documents referenced in the technical rationale for the Acceptance Criteria and include this list under the Technical Rationale References heading.

Directive 8: Draft Review Procedures subsection.

Step 1 If this SRP section already exists, review the Procedure 3.7 updated draft to determine applicability to the advanced reactor design. Also identify PRB-approved upgrades to be incorporated in the upgrade.

Step 2 Upgrade the review procedures in consideration of the results of Step 1.

Step 3 Include steps in the Review Procedures for any Acceptance Criteria added under Directive 6. 
Directive 9: Draft the Evaluation Findings subsection.

Step 1 If this SRP section already exists, review the Procedure 3.7 updated draft to determine applicability to the future reactor design. Also identify PRB-approved upgrades to be incorporated in the upgrade.

Step 2 Upgrade the Evaluations Findings subsection in consideration of the results of Step 1.

Step 3 Ensure that all Acceptance Criteria, including those added as part of this upgrade, are appropriately addressed in the Safety Evaluation Report Conclusions suggested in this subsection.

Directive 10: Draft Implementation subsection.

Step 1 Ensure that the correct Implementation paragraphs (see Section 3.8.1 of this Implementing Procedures Document) already exist or are added.

Directive 11: Draft the References subsection.

Step 1 Add all documents used in the upgrading of the other subsections to the reference list. Make sure that all such documents have been properly referenced in the section text.

Step 2 Delete any references not applicable to the reactor design. Also, remove any such textual references.

Directive 12: Review the work performed under Directives 5 through 11 for compliance with requirements stated in this procedure and in proper format.

Step 1 Review the draft section upgrade for internal consistency. In particular, when something is added to one subsection, make sure that other subsections that are also affected have been appropriately upgraded. For example, the addition of an Acceptance Criterion will usually require adding a review step to ensure compliance, a finding that compliance was determined, and appropriate references.

Step 2 Make sure that all PRB-approved upgrades have been appropriately incorporated.

Step 3 Review each subsection to ensure compliance with the stated requirements in this procedure.

Step 4 Ensure that all parameter values have been stated in both metric and English units.

Step 5 Perform or have performed an editorial review of the completed draft.

Step 6 For drafts prepared by contractors at the direction of the PRB, provide the completed draft to the PRB for review per Procedure 4.1.

\section{Forms}

Three forms and a report are used in implementing this procedure. The Upgrade Impact Assessment Form is used to characterize potential SRP section changes and to identify any conflicts between documents. The Upgrade Outline Input Form assists the analyst in organizing the impacts to facilitate drafting SRP section upgrades or developments. This form also provides the input needed to allow computer generation of Upgrade Outlines for the use of the PRB. The Upgrade Outline Report is a report that summarizes the potential upgrades/developments for the PRB and allows the PRB to decide on the upgrades/developments to be used in drafting SRP sections. The Draft SRP Section Form is described in Procedure 3.7. Note that all parameter values included in each new or revised SRP section will be presented in metric and English units.

All organizations implementing this procedure must record their work on the indicated forms and forward the completed forms to the PTSB upon completion of the work. 
Sample Forms

\section{Upgrade Impact Assessment Form}

Part A - Impact Identification

SRP Section No.

Enter Impact or Related Impact Nos.

New Impact No.

Enter Brief Description

Part B - Characterization of Type and Nature of Upgrade

Enter Brief Narrative

Is potential research indicated?

Is potential rulemaking, regulatory guide revision, or other regulatory action indicated?

Is potential codes/standards development indicated?

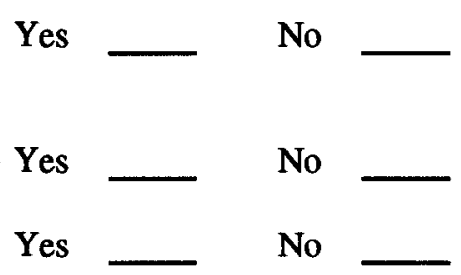


Upgrade Impact Assessment Form (continued)

Part C - Identification of Conflicts

Conflict Identified?

Yes

No

Conflicting Impact Numbers

Description of Conflict

Potential Resolution

Rationale

Is potential research indicated?

Is potential rulemaking, regulatory guide revision, or other regulatory action indicated?

Is potential codes/standards development indicated?

Are there additional conflicts?

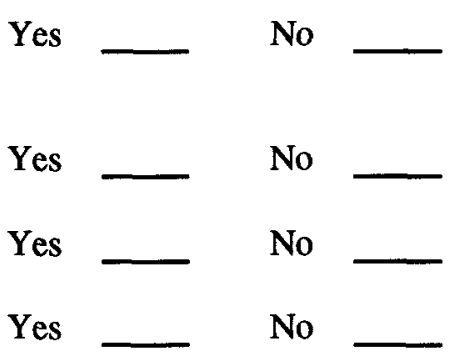

(Note: "Yes" to "additional conflicts" will require completion of another Part C.) 


\section{Upgrade Outline Input Form}

SRP Section No.

SRP Section Title

SRP Subsection

Action

Impact No.

SRP Subsection

Action

Impact No.

SRP Subsection

Action

Impact No.

SRP Subsection

Action

Impact No. 
3.8 Upgrading for Future Designs

\section{Upgrade Outline Report}

Primary Review Branch

SRP Section Number

SRP Section Title

SRP Section (provided by computer) is (a new SRP section) (an existing SRP section requiring an upgrade) in support of the (ABWR) (PRISM) (etc.) reactor concept. Please review the following outline to determine whether it will support your review needs in this review area. Indicate your comments in the spaces provided, provide an authorized signature at the bottom of this report, and return the completed report to the assigned organization. Copies of referenced impacts are attached to this report.

Part 1 - Areas of Review

(1)

Impact Reference(s)

PRB Comments

Part 2 - Acceptance Criteria Requirements and Guidance

(2)

Impact Reference(s)

PRB Comments

Part 3 - Acceptance Criteria Technical Rationale

(3)

Impact Reference(s)

PRB Comments 
Upgrade Outline Report (continued)

\section{Part 4 - Review Procedures}

(4)

Impact Reference(s)

PRB Comments

\section{Part 5 - Evaluation Findings}

(5)

Impact Reference(s)

PRB Comments

\section{Part 6 - Implementation}

(6)

Impact Reference(s)

PRB Comments

Part 7 - References

(7)

Impact Reference(s)

PRB Comments 
3.8 Upgrading for Future Designs

\section{Upgrade Outline Report (continued)}

\section{Part 8 - Future Work and Comments}

Need For Future Regulatory Action/Research (has) (has not) been identified.

General Comments

PRB General Comments

\section{Part 9 - Conflicts}

(No conflicts have)(The following conflict(s) has(have)) been identified in this review area.

Conflict (Conflict number assigned by computer)

Conflicting Impacts (Impact numbers)

Conflicting Impacts (Document Titles and Numbers)

[Nature of conflict and potential resolution from Upgrade Impact Assessment Form, Part C, Procedure 3.8]

Potential research or regulatory action (is)(is not) indicated for this conflict.

PRB Comments:

Conflict (Conflict number assigned by computer):

Authorized PRB Signature

Date 


\section{How to Complete the Form}

\section{Upgrade Impact Assessment Form}

Part A will have already been completed per the instructions in Procedure 3.5. The first three items of Part C may also have been completed previously.

\section{Part B}

- Enter a narrative description characterizing the nature and type of the proposed upgrade. Although brevity is highly valued, the analyst may use as many lines as are required.

- Indicate the potential need for research, regulatory action, or codes/standards development by placing an " $\mathrm{X}$ " after the correct response.

Part C

- Indicate if a conflict has been identified by placing an "X" after the "Yes" or "No" response. A "No" response will complete this form.

- Enter the impact numbers of the conflicting impacts.

- Provide a brief description including the nature of the conflict, potential resolution, and rationale.

- Indicate a potential need for research, regulatory action, or codes/standards development by placing an "X" after the correct response.

- If there are any other conflicts to report, place an "X" after the "Yes" response to the last question. This will prompt the computer to provide another Part C. A "No" response will complete the form.

\section{Upgrade Outline Input Form}

- Enter the SRP section number and title.

- Enter the name of the SRP subsection (e.g., "Acceptance Criteria") and the action statement for the first impact. Action statements should begin with "Add," "Delete," or "Revise" and should describe the change in sufficient detail to allow a PRB staff member to understand what is intended. The reasons for the action should also be provided in a sentence or two. Provide the impact number(s).

- Repeat the previous instructions for the remaining impacts.

- Number all of the pages used by completing the "page of " entries at the bottom of the form.

\section{Upgrade Outline Report}

This report is generated in its entirety by the SRP Modification Database upon request or by the assigned organization. All referenced impacts associated with the report will also be provided by the computer system or by the assigned organization (in electronic or hard-copy form).

All blanks on the report are provided for the use of the PRB. The PRB will indicate choices and guidance in the comment fields provided. An empty comment field will be interpreted to indicate approval of the indicated action statements. After the PRB completes its evaluation of the report, the Branch Chief or other designated representative should sign and date the report. 


\section{Sample Completed Forms}

Upgrade Impact Assessment Form

Part A - Impact Identification

SRP Section No. $9.2 .5 \mathrm{C}$

Enter Impact or Related Impact Nos. 664, 1492, 7878

New Impact No. $\underline{9102}$

Enter Brief Description These impacts suggest that passive air cooling systems could be significantly affected by meteorological conditions, particularly wind, at the time the systems are needed. Terrain and design-specific scale tests are suggested to determine system efficacy.

\section{Part B - Characterization of Type and Nature of Upgrade}

Enter Brief Narrative The impacts suggest that passive air cooling systems may be affected by prevalent wind conditions, in particular, if wind is in such a direction and of such a magnitude that natural convective forces are counteracted. The implication is that this SRP section should require a scale model test, taking into consideration the terrain and design. This will be an interface problem that will have to be resolved on a site-specific basis.

Is potential research indicated?

Yes $\mathrm{X} \quad$ No

Is potential rulemaking, regulatory guide revision, or other regulatory action indicated?

Yes — No $\mathrm{X}$

Is potential codes/standards development indicated?

Yes _ No $\mathrm{X}$ 


\section{Upgrade Impact Assessment Form (continued)}

Part C - Identification of Conflicts

Conflict Identified? $\quad$ Yes $\_$No $\quad \mathrm{X}$

Conflicting Impact Numbers

Description of Conflict

Potential Resolution

Rationale

Is potential research indicated?

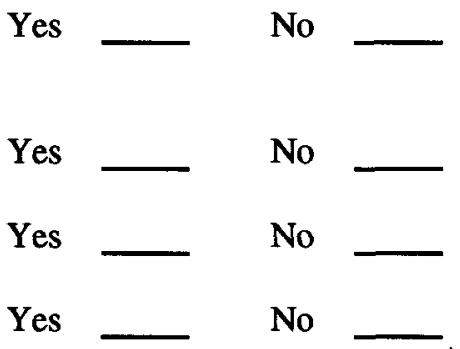

Are there additional conflicts?

(Note: "Yes" to "additional conflicts" will require completion of another Part C.) 
-

-

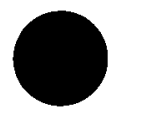




\subsection{Review and Approval of SRP Revisions}

This chapter contains the procedures to be followed in reviewing and approving revisions of the SRP developed through implementation of the procedures presented in Chapter 3.

Chapter $\mathbf{4}$ is organized as follows, and is summarized in Table 7.

- Draft SRP sections are reviewed by the PRB (Section 4.1).
- PRB-approved revisions are reviewed for consistency with format and procedural requirements established by this Implementing Procedures Document (Section 4.2).

- Further NRC review necessary for the issuance of SRP revisions is accomplished (Section 4.3).

Table 7. Summary of Chapter 4

\begin{tabular}{|c|c|c|}
\hline Chapter 4 Sections & Pages & Description of Section Content \\
\hline$\frac{\text { Section 4.1: PRB Review of Draft }}{\text { Sections }}$ & 4.1-1 & $\begin{array}{l}\text { Presents recommended procedures for use by the } \\
\text { PRB in reviewing draft SRP sections for which the } \\
\text { PRB is responsible. } \\
\text { - Provides general guidance for the PRB's review. }\end{array}$ \\
\hline Section 4.2: Consistency Review & $4.2-1$ & $\begin{array}{l}\text { Presents procedures for review of draft SRP } \\
\text { sections to ensure consistency with the procedural } \\
\text { and format requirements of this Implementing } \\
\text { Procedures Document. } \\
\text { - Presents procedures for editorial review of each } \\
\text { draft SRP section. }\end{array}$ \\
\hline$\frac{\text { Section 4.3: NRC Review and }}{\text { Approval }}$ & $4.3-1$ & $\begin{array}{l}\text { Provides direction on how proposed SRP revisions } \\
\text { are to be reviewed and approved in accordance } \\
\text { with current NRC practice }\end{array}$ \\
\hline
\end{tabular}


-

-

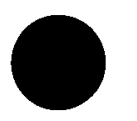




\subsection{PRB Review of Draft SRP Sections}

\subsubsection{Approach}

Draft SRP sections for inclusion in the SRP will only be accepted from the PRB and/or considered a PRB product, independent of who the PRB assigned to assist it in writing the draft. Therefore, the PRB must approve all drafts before they are submitted for inclusion in the SRP.

It should be noted that the intent of this section is to provide for PRB review of draft SRP sections; where other procedures that require such a review currently exist, those procedures may be used in lieu of this procedure. The guidance provided in this procedure is general in nature, recognizing that the PRBs have developed their own methods based on the specific requirements associated with their review areas.

It should be also noted that, in order to implement the Commission's Interim Policy Statement on Improving Technical Specifications issued in February 1987, the PRBs should consult the Technical Specifications Branch when the Acceptance Criteria or review procedures of an SRP section could affect the plant's technical specifications.

\subsubsection{Procedure for PRB Review of Draft SRP Sections}

\section{Purpose and Scope of This Procedure}

The purpose of this procedure is to recommend a review process for the PRB to review SRP draft sections for which the PRB is responsible, and to provide general guidance for that review. This procedure applies to updated and upgraded SRP sections resulting from the SRP Update and Development Program, and it applies to a PRB only for those sections for which it has primary responsibility. Obviously, the application of this section by the PRB is a PRB decision. The only program requirement on the PRB is that it approve all draft SRP sections that it forwards to the PTSB for inclusion in the revised SRP and that all relevant evaluation forms in Chapters 3, 4, 6, and 7 that are completed by the PRB assignee accompany the submitted draft.

\section{Prerequisites for Performing This Procedure}

Technical Skills and Knowledge Levels. The PRB will perform this procedure.

Document Availability. Supporting documentation will already have been provided to the PRB as a result of implementation of Procedures 3.7 and 3.8. Additional copies will be made available upon request.
Completion of Prior Procedures. Procedure 3.7 or 3.8 must be completed for a particular SRP section before this procedure may be implemented for that section.

\section{Overview of the Steps in This Procedure}

Different steps are used for drafts prepared with contractor assistance and drafts prepared by PRB or other NRC staff. For either case, the draft is reviewed for consistency. Comments are appropriately resolved, the draft is revised accordingly, the draft is reviewed and approved by PRB management, and the draft is transmitted to the PTSB with all the required forms completed. The primary difference between contractor assisted drafts and internally prepared drafts is in the resolution of PRB comments. Although there may be discussion between PRB staff and contractors, PRB staff will make all decisions which are then implemented by contractor personnel. In the case of NRC staff-prepared drafts, comments are resolved between reviewers and preparers with the resulting resolutions being incorporated in the draft. Finally, the completed draft is forwarded to the PTSB. It should be noted that a draft SRP section must be accompanied by the appropriate completed forms.

\section{Results of This Procedure}

The written product resulting from the implementation of this procedure is a PRB-approved draft of an SRPupdated or upgraded section. Any intermediate review drafts, comments, or comment resolutions resulting from the review are the responsibility of the PRB and are not maintained as part of the SRP Update and Development Program.

\section{Detailed Procedure}

This section specifies the step-by-step sequence to be followed, grouped by directives (major intermediate outputs), to be accomplished through a series of specific steps. Any or all of the following steps may be superseded by existing procedures that accomplish the same goals. For any given SRP section, either Directive 1 or 2 will apply, depending on the resources used in preparing the draft section.

Directive 1: Perform review of drafts prepared with contractor assistance.

Step 1 Assign the PRB staff member(s) responsible for reviewing the draft and resolving comments.

Step 2 Review the draft to ensure that PRB objectives are met. Verify that the draft provides adequate review guidance, is technically correct, and is 
consistent with NRC and NRR policy and procedures. Ensure that all appropriate forms have been included.

Step 3 Revise the draft, as necessary, to incorporate the results of the review. Revisions may be made by PRB staff, or the PRB staff may direct the contractor to do so.

Step 4 Review the revised draft to ensure proper implementation of review results. Iterate Steps 3 and 4 until the draft is in a satisfactory form.

Step 5 Provide the draft section to the Branch Chief or designated individual for approval review.

Step 6 Obtain the Branch Chief's or designated individual's signature and the date on the SRP Draft Section Transmittal Form.

Directive 2: Perform review of drafts prepared by PRB staff.

Step 1 Assign the PRB staff member(s) responsible for reviewing the draft and resolving comments. The assigned reviewer should not have had significant involvement with the preparation of the portion of the document being reviewed.

Step 2 Review the draft to ensure that PRB objectives are met. Verify that the draft provides adequate review guidance, is technically correct, and is consistent with NRC and NRR policy and procedures.

Step 3 Resolve comments between the reviewer(s) and section preparer(s).
Step 4 Revise the draft, as necessary, to incorporate comment resolutions.

Step 5 Review the revised draft to ensure proper implementation of review results. Iterate Steps 4 and 5 until the draft is in a satisfactory form.

Step 6 Provide the draft section to the Branch Chief or designated individual for approval review.

Step 7 Obtain the Branch Chief's or designated individual's signature and date on the SRP Draft Section Transmittal Form.

Directive 3: Forward SRP section draft and associated forms to the PTSB.

Step 1 Assemble the forms that were completed in evaluating impacts and drafting of the section revision. Use the Forms Checklist to assure that all forms have been assembled.

Step 2 Forward the draft section to the PTSB, along with the completed Forms Checklist and all forms indicated on the Checklist.

\section{Forms}

Two forms are associated with the implementation of this procedure. The SRP Draft Section Transmittal Form is used by the PRB to transmit completed draft SRP sections to the PTSB for further processing and to document its review and approval of the draft section. The Forms Checklist is used by the PRB to assure that all supporting forms have been assembled for transmittal to the PTSB. 


\section{Sample Forms}

\section{SRP Draft Section Transmittal Form}

Attached is the PRB draft of the SRP section indicated below. This draft has been reviewed and approved by the PRB. Also attached are the appropriate completed forms associated with the section submitted.

SRP Section Number

Date of Draft

Name of PRB

Signature

Date 
4.1 PRB Review

Forms Checklist

SRP Section Number

Section Updates (Procedure 3.7)

Revision Options Checklist Form

Option Paper for SRP Section

Research/Regulatory Action Needs Form(s) (if used)

Draft SRP Section Form

SRP Draft Section Transmittal Form

Section Upgrades (Procedure 3.8)

Upgrade Impact Assessment Form

Upgrade Outline Input Form

Upgrade Outline Report

Research/Regulatory Action Needs Form(s) (if used)

Draft SRP Section Form

SRP Draft Section Transmittal Form 


\section{How to Complete the Form}

\section{SRP Draft Section Transmittal Form}

(The entire form is completed by the PRB.)

- Enter the section number and date of the draft along with the name of the PRB (initials are sufficient).

- The Branch Chief or designated individual then signs and dates the form.

- Attach the completed form to the draft described on the form, and forward the package to the PTSB for further processing.

\section{Forms Checklist}

- The form consists of two parts; one is for SRP section updates per Procedure 3.7, one is for SRP section upgrades per Procedure 3.8. Complete either or both sections depending on which is or are applicable to the $\operatorname{draft}(\mathrm{s})$ being forwarded to the PTSB.

- Place an "X" in each blank as each form is located and included in the transmittal package.

- Include the checklist form in the transmittal package along with the other forms. 
4.1 PRB Review

Sample Completed Forms

\section{SRP Draft Section Transmittal Form}

Attached is the PRB draft of the SRP section indicated below. This draft has been reviewed and approved by the PRB. Also attached are the appropriate completed forms associated with the section submitted.

SRP Section Number $4.4 .2-\mathrm{C}$

Date of Draft $10 / 15 / 92$

Name of PRB SRXB

Signature

Date 


\section{Forms Checklist}

SRP Section Number 9.4 .3

Section Updates (Procedure 3.7)

Revision Options Checklist Form

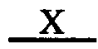

Option Paper for SRP Section

$\underline{\mathrm{X}}$

Research/Regulatory Action Needs Form(s) (if used)

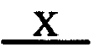

Draft SRP Section Form

$\underline{\mathrm{X}}$

SRP Draft Section Transmittal Form

Section Upgrades (Procedure 3.8)

Upgrade Impact Assessment Form

Upgrade Outline Input Form

Upgrade Outline Report

Research/Regulatory Action Needs Form(s) (if used)

Draft SRP Section Form

SRP Draft Section Transmittal Form 

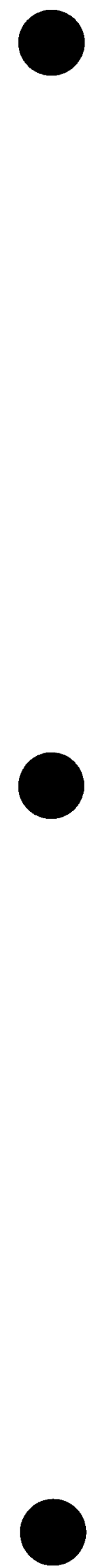


\subsection{Consistency Review}

\subsubsection{Approach}

Procedure 4.1 provides for a technical and policy review of each SRP section update or upgrade by the PRB. Procedure 4.2 provides for a review of each section for consistency with format and procedural requirements established by this Implementing Procedures Document. The consistency review makes three determinations: (1) whether the revised SRP section meets the requirements set forth in this Implementing Procedures Document (primarily the ones included in Procedures 3.7 and 3.8), (2) whether the revised SRP section is consistent with established format, and (3) whether the revised SRP section meets basic editorial requirements.

Procedures 3.7 and 3.8 set forth the basic requirements for the updating and upgrading of SRP sections. These requirements include such items as the development of Acceptance Criteria technical rationales, incorporation of applicable issues such as probabilistic risk assessment and individual plant examination concerns, presentation of parameter values in metric and English units, and incorporation of requirements approved by the PRB. Most of the procedures preceding Procedures 3.7 and 3.8 develop supporting information and will not directly contribute to this consistency check. Therefore, the first check performed by this procedure is to determine whether the substantive requirements set forth in this Implementing Procedures Document are addressed in each SRP section draft.

The second check performed in this procedure is to determine whether each SRP section draft is prepared in accordance with the established SRP format. The format is established by Procedure 3.7 or 3.8. Within that format, it is also necessary to ensure consistency of writing style and appropriate level of detail. Certain human factors improvements (to increase readability and user friendliness) will be considered and incorporated at this point, as approved by the PTSB.

The final check to be performed will be an editorial review. This will include correction of misspellings, punctuation, and grammar.

The PTSB has designated PNL to perform the consistency check for all draft updates and upgrades. In cases where the draft is found not to meet the requirements established in this Implementing Procedures Document, it will generally be returned to the PRB for rework. Format or editorial corrections will generally be performed by PNL as part of the consistency check.

\subsubsection{Procedure for Performing Consistency Review}

\section{Purpose and Scope of This Procedure}

This procedure provides direction as to the conduct of the consistency review of each revised SRP section. This procedure will be applied to all section drafts received from PRBs after completion of the PRB Review (Procedure 4.1).

\section{Prerequisites for Performing This Procedure}

Technical Skills and Knowledge Levels. Performance of the requirements check will require a technical background and familiarity with the SRP and the requirements set forth in this Implementing Procedures Document. Performance of the remainder of this procedure will require the skills associated with technical editing and technical word processing.

Document Availability. The documents (the SRP, the Implementing Procedures Document) necessary to perform this procedure will be generally available, available from the SRP Reference Document Database (reference documents), available from the SRP Modification Database (lists of reference documents), or will be provided by the PRBs (draft SRP sections). Consistency analysts will need access to PRB-approved Option Papers and Upgrade Outline Reports, impact descriptions (including bibliographic information associated with documents from which impacts originated), and the Type I/Type II determination (including rationale) associated with the SRP section being reviewed.

Completion of Prior Procedures. Procedure 4.1 will need to be completed for any SRP sections to be subjected to the consistency review directed by this procedure.

\section{Overview of the Steps in This Procedure}

This procedure specifies a two-step review process. First, a review of draft SRP section revisions against procedural requirements included in this Implementing Procedures Document is performed. Any substantive deviations from the requirements are provided to the PRB, which then redrafts the section revision. This process is iterated until the draft is considered satisfactory. Then, a format and editorial review is conducted, and the draft is corrected accordingly. The draft revision will, at this point, be ready for the formal NRC review and approval process as discussed in the next procedure (Procedure 4.3). 


\section{Results of This Procedure}

Implementation of this procedure will result in draft SRP section revisions that are ready to undergo the NRC review and approval process (Procedure 4.3). Such drafts will meet procedural requirements, be consistent with the established format, and be editorially correct. Depending on the number of iterations that are required, intermediate drafts and associated comments may also result.

\section{Detailed Procedure}

This section specifies the step-by-step sequence to be followed, grouped by directives (major intermediate outputs), to be accomplished through a series of specific steps.

Directive 1: Make assignments (responsibility of Project Manager or Project Manager's designee).

Step 1 Identify the analysts who will be responsible for implementing this procedure.

Step 2 Record assignments on the Work Assignment Form (see Procedure 2.1).

Directive 2: Perform the consistency review regarding Implementing Procedures Document requirements for SRP revisions.

Step 1 Review the draft SRP revision (updates and upgrades) to ensure conformance with the procedural requirements set forth in this Implementing Procedures Document. Complete Part A, B, or C, as appropriate, of the Consistency Review Form; these parts contain a review checklist that will facilitate the review.

Step 2 Proceed to Step 3 if any substantive comments result from the review. Proceed to Step 6 if there are no substantive comments.

Step 3 Return the draft section to the PRB, through the PTSB, with a computer generated Request for Redraft report. The Request for Redraft report will contain the substantive comments (e.g., the elaboration of the Acceptance Criteria technical rationales was not provided) and a due date for return of the redraft.

Step 4 Redraft the returned SRP section to resolve the comments noted on the Request for Redraft report. Return the redrafted section to PNL, through the PTSB, by completing the Request for Redraft report and attaching it to the redraft. (PRB responsibility)
Step 5 Log the return of the redrafted section on Part A, $\mathrm{B}$, or $\mathrm{C}$, as appropriate, of the Consistency Review Form. Review the redraft in light of the previous comments to determine the adequacy of the redraft. If the redraft is adequate, complete Part A, B, or C of the Consistency Review Form. If it is inadequate, record the reason and repeat Steps 3 through 5 until the draft is adequate. Then proceed to Directive 3.

Step 6 Indicate any non-substantive comments of the Consistency Review Form. Resolve such comments by telephone with the PRB staff, and make any necessary modifications to the section draft.

Directive 3: Perform the consistency review regarding format and editorial needs.

Step 1 Review the draft SRP revision to ensure conformance with format and editorial needs. Record the results of the review on Part D of the Consistency Review Form.

Step 2 Make any necessary corrections to the section draft. Substantive or technical changes are not to be made at this time. Complete Part $D$ of the Consistency Review Form.

Step 3 If changes are made in Step 2 or if changes were made in Directive 2, Step 6, submit the revised draft to the PRB for approval. Provide the PRB a marked-up copy and revised copy to facilitate its review. Complete Part E of the Consistency Review Form.

Directive 4: Circulate draft SRP sections among the PRBs for information (PTSB responsibility).

Step 1 Provide a copy of each completed draft SRP section to those PRBs not involved in preparation of the draft. Circulation of drafts is for information and coordination between the PRBs.

\section{Forms}

The single form used to implement this procedure is the Consistency Review Form. Its purpose is to structure the consistency review and to control redrafting of the revision. A computer-generated report, the Request for Redraft report, is also used in the implementation of this procedure. The Request for Redraft report is prepared by the SRP Modification Database system, but contains some blanks to be completed by the PRB when it returns the redrafted material. 


\section{Sample Forms}

\section{Consistency Review Form}

Assigned Review Analyst

Work Assignment No.

Assigned Editor

Work Assignment No.

SRP Section No.

Primary Review Branch

PRB Contact

Date Draft Section Reviewed

Type of Consistency Review:

Conventional Technology Update (Complete Part A)

Future Technology Upgrades (Complete Part B)

ESRP Update (Complete Part C)

Assigned Editor to Complete Part D 
4.2 Consistency Review

Consistency Review Form (continued)

Part A - Requirements Review (Conventional Technology Updates)

SRP Section No.

Name of Review Analyst

1. Have each of the impacts approved for inclusion by the PRB actually been incorporated?

Yes No

2. Have the Acceptance Criteria requirements and guidance been accurately converted into tabular format?

Yes

No

3. Has the technical rationale for the Acceptance Criteria been provided?

Yes

No

4. Have Acceptance Criteria provided in the Review Procedure subsection been relocated to the Acceptance Criteria subsection?

Yes

No

5. Do the review procedures cover all Acceptance Criteria and associated technical rationales?

Yes

No

6. Do the evaluation findings reflect all Acceptance Criteria and technical rationales, particularly any added as a result of identified impacts?

Yes

No

7. Has the appropriate Implementation discussion been included?

Yes

$$
\text { No }
$$

8. Have all pertinent references been added? Are all references properly cited in the section text? Is a separate bibliography included for Acceptance Criteria technical rationales?

Yes

$$
\text { No }
$$

9. Will SRP section revisions, as drafted, retain the same Type I/Type II determination reached in Procedure 3.7?

Yes

$$
\text { No }
$$

Comments 


\section{Consistency Review Form (continued)}

\section{Part A - Requirements Review (Conventional Technology Updates)}

Date Comments Forwarded to PRB

Date Redraft Received from PRB

Comment Satisfactorily Resolved? Yes __ No

Review Analyst's Signature

Date of Consistency Review 
4.2 Consistency Review

\section{Consistency Review Form (continued)}

Part B - Requirements Review (Future Technology Upgrades)

SRP Section No.

Name of Review Analyst

1. Have each of the impacts in the PRB-approved upgrade package actually been incorporated?

Yes _ No

2. Have the Acceptance Criteria requirements and guidance been accurately converted into, or developed in, tabular format?

Yes

No

3. Has the technical rationale for the Acceptance Criteria been provided?

Yes

$$
\text { No }
$$

4. Do the review procedures cover all Acceptance Criteria and associated technical rationales?

Yes _ No _

5. Do the evaluation findings reflect all Acceptance Criteria and technical rationales, particularly any added as a result of identified impacts?

Yes _ No

6. Has the appropriate Implementation discussion been included?

Yes _ No

7. Have all pertinent references been added? Are all references properly cited in the section text? Is a separate bibliography included for Acceptance Criteria technical rationales?

Yes __ No

Comments 


\section{Consistency Review Form (continued)}

Part B - Requirements Review (Future Technology Upgrades)

Date Comments Forwarded to PRB

Date Redraft Received from PRB

Comment Satisfactorily Resolved? Yes _ $\quad$ No

Review Analyst's Signature

Date of Consistency Review 
4.2 Consistency Review

Consistency Review Form (continued)

Part C - Requirements Review (ESRP Updates)

SRP Section No.

Name of Review Analyst

1. Has general reformatting been properly accomplished?

Yes _ No

2. Have each of the impacts or the upgrade package approved for inclusion by the PRB actually been incorporated?

Yes__ No

3. Has the Areas of Review subsection incorporated the contents of the Review Inputs (Environmental Report Sections, Environmental Reviews, and Other), Review Outputs, Purpose and Scope, and Input to Environmental Statement (interface requirements) subsections in the old ESRP format?

Yes

4. Has the Acceptance Criteria subsection incorporated the contents of the Review Inputs (Standards and Guides) and Evaluation subsections in the old ESRP format?

Yes _ No

5. Have the Acceptance Criteria requirements and guidance been accurately converted into, or developed in, tabular format?

Yes _ No _

6. Has the technical rationale for the Acceptance Criteria been provided?

Yes

No

7. Has the Review Procedures subsection incorporated the contents of the Required Data and Information and the Analysis Procedures in the old ESRP format in the proper new format?

Yes

No

8. Has the Evaluations Findings subsection incorporated the contents of the Input to Environmental Statement (less the interface requirements) in the old ESRP format?

Yes

No

9. Has the appropriate Implementation discussion been included?

Yes

No 


\section{Consistency Review Form (continued)}

Part C - Requirements Review (ESRP Updates)

10. Have all pertinent references been added? Are all references properly cited in the section text? Is a separate bibliography included for Acceptance Criteria technical rationales?

Yes__ No ___

Comments

Date Comments Forwarded to PRB

Date Redraft Received from PRB

Comment Satisfactorily Resolved? Yes _ _ No

Review Analyst's Signature

Date of Consistency Review 


\section{Consistency Review Form (continued)}

Part D - Format/Editorial Review

SRP Section No.

Editor

1. Is draft consistent with standard format as specified in Procedure 3.7 or 3.8 ?

Yes No

2. Have all parameter values been presented in both metric and English units?

Yes No

Comments

Corrections have been made?

Yes

No

3. Has an editorial review been performed and have corrections been made?

Yes __ No

Editor's Signature

Date of Editorial Review 


\section{Consistency Review Form (continued)}

\section{Part E - PRB Review of Non-Technical Changes}

[Note: When format/editorial changes are made or when new substantive comments are identified and telephone resolutions are sufficient, use the following to document PRB approval.]

SRP Section No.

Revised Draft Sent to PRB for Approval (date)

PRB Approval Received (date)

Approver's Name 
To

From

Date

The draft revision to SRP Section provided to the PTSB by (PRB initials), dated , has been found to contain certain potential discrepancies. The potential discrepancies are briefly described as follows:

Please incorporate the above items in a redraft of the SRP section, and provide the redraft to the PTSB by (date).

To (PTSB contact)

From (PRB initials)

Attached is the requested redraft of SRP Section . The redrafted portions have been reviewed within the (PRB initials) to the same standards as the original draft provided previously.

Date 


\section{How to Complete the Forms}

\section{Consistency Review Form}

- Upon receipt of a draft section revision from the PRB (through the PTSB), the project clerk completes the first page by entering the names of the assigned review analyst and editor and the respective work assignment numbers, the SRP section number, the initials of the PRB, the name of the PRB contact for the SRP section (this will be available from the SRP Modification Database), and the date received (in $\mathrm{MM} / \mathrm{DD} / \mathrm{YY}$ format). The type of SRP section revision is indicated by placing an " $\mathrm{X}$ " in the correct blank.

- The review analyst completes Parts A, B, or C, depending on the blank checked at the bottom of the first page of the form. Only one of these parts will be completed on each form.

\section{Parts $A, B$, and $C$}

- The review analyst answers each question in Part A, $\mathrm{B}$, or $\mathrm{C}$ with an "X" after the "Yes" or "No" response, as appropriate. Any "No" answer(s) requires the review analyst to summarize comment(s) in sufficient detail to allow the PRB to perform a redraft of the section.

- The review analyst or project clerk enters the date that comments are forwarded to the PRB.

- The review analyst enters "N/A" if non-substantive comments were identified and resolved or no comments resulted from the review.

- The project clerk enters the date that the redraft is received.

- The review analyst indicates satisfactory resolution by placing an " $\mathrm{X}$ " after the "Yes" or "No" answer, as appropriate. A "Yes" answer terminates the technical portion of the consistency review. A "No" answer requires that the process be repeated and documented on another copy of the applicable part of the form.

- The comment/resolution cycle will repeat as many times as necessary until a "Yes" answer is made under satisfactory resolution.

\section{Part D}

- The editor completes Part D. The editor indicates satisfactory format and editorial content, including writing style, level of detail, and any human factors considerations by placing an " $\mathrm{X}$ " after the "Yes" or "No" response, as appropriate, to Question 1.

- The editor verifies that all parameter values have been specified in metric and English units and places an "X" in the "Yes" or "No" response, as appropriate, to Question 2.

- A "No" answer to Question 1 or 2 requires an exploration of the nature of the problem and how it is to be resolved.

- Upon completing corrections to the draft section, the editor places an " $\mathrm{X}$ " after the "Yes" answer to the "Corrections have been made" question. A "No" answer may be used if the correction must be deferred for some reason, and the form will be maintained in an active status until a "Yes" is indicated at a later time.

- Upon completion of the editorial review and the making of any necessary corrections in the draft, the reviewer will indicate a "Yes" in response to Question 3. A "No" answer will be handled in a manner similar to that for a "No" answer to the "Corrections have been made" question.

\section{Part E}

- The project clerk completes Part E by entering the date that the final draft is returned to the PRB for approval, the date on which PRB approval is received, and the name of the authorized PRB representative who approves the final draft are recorded.

- PRB approval is requested for changes made in the resolution of non-substantive comments and for changes made as a result of the format/editorial review. A marked-up copy and final copy are sent to the PRB for its review.

\section{Request for Redraft}

- Most of the information on this report is provided by the project clerk or review analyst using the computer based on information entered in the consistency review and other information already available in the SRP Modification Database.

- The PRB will provide the signature and date at the bottom of the report upon return of the redrafted section. 
4.2 Consistency Review

Sample Completed Forms

\section{Consistency Review Form}

Assigned Review Analyst Wilma Weston

Work Assignment No. 5295

Assigned Editor Candace Jensen

Work Assignment No. $\mathbf{5 2 9 6}$

SRP Section No. 4.2-B

Primary Review Branch SRXB

PRB Contact Jeffrey Young

Date Draft Section Reviewed 05/15/93

Type of Consistency Review:

Conventional Technology Update (Complete Part A)

$\mathrm{X}$ Future Technology Upgrades (Complete Part B)

ESRP Update (Complete Part C)

Assigned Editor to Complete Part D 


\section{Consistency Review Form (continued)}

Part B - Requirements Review (Future Technology Upgrades)

SRP Section No. 4.2-B

Name of Review Analyst Wilma Weston

1. Have each of the impacts in the PRB-approved upgrade package actually been incorporated?

Yes _ No

2. Have the Acceptance Criteria requirements and guidance been accurately converted into, or developed in, tabular format?

Yes $\underline{X}$ No

3. Has the technical rationale for the Acceptance Criteria been provided?

Yes _ No

4. Do the review procedures cover all Acceptance Criteria and associated technical rationales?

Yes $\mathrm{X}$ No

5. Do the evaluation findings reflect all Acceptance Criteria and technical rationales, particularly any added as a result of identified impacts?

Yes $\mathrm{X}$ No

6. Has the appropriate Implementation discussion been included?

Yes $\mathrm{X}$ No

7. Have all pertinent references been added? Are all references properly cited in the section text? Is a separate bibliography included for Acceptance Criteria technical rationales?

Yes $\mathrm{X}$ No

Comments A technical rationale in the Acceptance Criteria subsection was not provided. Approved impact 2345 was not incorporated. 
4.2 Consistency Review

$$
\text { Consistency Review Form (continued) }
$$

Part B - Requirements Review (Future Technology Upgrades)

Date Comments Forwarded to PRB 05/25/93

Date Redraft Received from PRB 06/28/93

Comment Satisfactorily Resolved? Yes __ No $\quad$ X

Review Analyst's Signature

Date of Consistency Review 


\section{Consistency Review Form (continued)}

\section{Part B - Requirements Review (Future Technology Upgrades)}

SRP Section No. $\underline{4.2-B}$

Name of Review Analyst Wilma Weston

1. Have each of the impacts in the PRB-approved upgrade package actually been incorporated?

Yes _ No

2. Have the Acceptance Criteria requirements and guidance been accurately converted into, or developed in, tabular format?

Yes $\mathrm{X}$ No

3. Has the technical rationale for the Acceptance Criteria been provided?

Yes $\underline{\mathrm{X}}$ No

4. Do the review procedures cover all Acceptance Criteria and associated technical rationales?

Yes $\mathrm{X} \quad$ No

5. Do the evaluation findings reflect all Acceptance Criteria and technical rationales, particularly any added as a result of identified impacts?

Yes $\underline{X}$ No

6. Has the appropriate Implementation discussion been included?

Yes $\mathrm{X} \quad$ No

7. Have all pertinent references been added? Are all references properly cited in the section text? Is a separate bibliography included for Acceptance Criteria technical rationales?

Yes $\underline{\mathrm{X}}$ No

Comments Approved impact 2345 was not incorporated. 
4.2 Consistency Review

\author{
Consistency Review Form (continued)
}

Part B - Requirements Review (Future Technology Upgrades)

Date Comments Forwarded to PRB 06/30/93

Date Redraft Received from PRB $07 / 15 / 93$

Comment Satisfactorily Resolved? Yes $\mathrm{X}$ No

Review Analyst's Signature

Date of Consistency Review 


\section{Consistency Review Form (continued) \\ Part D - Format/Editorial Review}

SRP Section No. $4.2-\mathrm{B}$

Editor Candace Jensen

1. Is draft consistent with standard format as specified in Procedure 3.7 or 3.8 ?

Yes _ No

2. Have all parameter values been presented in both metric and English units?

Yes $\mathrm{X}$ No

Comments References were provided out of sequence with their citations in the SRP section. References need to be reordered.

Corrections have been made?

Yes $\mathrm{X} \quad$ No

3. Has an editorial review been performed and have corrections been made?

Yes $\mathrm{X} \quad$ No

Editor's Signature

Date of Editorial Review 
4.2 Consistency Review

\section{Consistency Review Form (continued)}

Part E - PRB Review of Non-Technical Changes

[Note: When format/editorial changes are made or when new substantive comments are identified and telephone resolutions are sufficient, use the following to document PRB approval.]

SRP Section No. 4.2-B

Revised Draft Sent to PRB for Approval (date) 08/15/93

PRB Approval Received (date) $\underline{09 / 15 / 93}$

Approver's Name Jeffrey Young 


\author{
Request for Redraft
}

To SRXB, Jeffrey Young

From PTSB, Donna Easterly

Date May 25, 1993

The draft revision to SRP Section 4.2-B provided to the PTSB by SRXB, dated May 15, 1993, has been found to contain certain potential discrepancies. The potential discrepancies are briefly described as follows:

A technical rationale for the Acceptance Criteria subsection was not provided. Approved impact 2345 was not incorporated.

Please incorporate the above items in a redraft of the SRP section, and provide the redraft to the PTSB by June 6, 1993.

To (PTSB contact) PTSB, Donna Easterly

From (PRB initials) SRXB, Jeffrey Young

Attached is the requested redraft of SRP Section 4.2-B. The redrafted portions have been reviewed within the (PRB initials) to the same standards as the original draft provided previously.

Authorized Signature

Date 
-
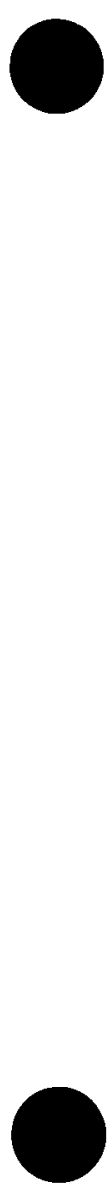


\subsection{NRC Review and Approval}

\subsubsection{Approach}

This procedure addresses the various reviews and approvals that are required in order to issue SRP sections. Included are NRC management, the Committee to Review Generic Requirements (CRGR), the Advisory Committee on Reactor Safeguards (ACRS), and Commission reviews and approvals and provision for any required public comments and comment resolution. This procedure reflects current NRR practice and guidance, in particular NRR Office Letter No. 800, dated November 24, 1987. It is the intent of the SRP Update and Development Program that for review purposes, revised or new SRP sections will be grouped into "revision packages," each of which will generally address one SRP chapter. Review should be facilitated by the fact that the revisions to the SRP made as a result of the SRP Update and Development Program will neither add to nor subtract from regulations or positions of the Agency. For current reactor designs, the revised SRP will only include existing requirements. For future reactor designs, the revised SRP will follow specific certification rules.

Responsibilities for implementing this procedure will follow the direction provided in NRR Office Letter No. 800. In general, the PTSB will be responsible for overall management and oversight of the review and approval process (including tracking progress) and reporting progress to NRR management. The PRBs will be responsible for preparing update and upgrade review packages for the CRGR, the ACRS, the Commission, and public comment; making CRGR presentations; resolving public comments; revising section drafts; and coordinating with interfacing NRR divisions and branches. The SRBs will provide technical support to the PRBs as requested by the PRBs, but at a minimum will have an opportunity to review and comment on all drafts.

\subsubsection{Procedure for Obtaining NRC Review and Approval}

\section{Purpose and Scope of This Procedure}

This procedure provides direction as to how proposed revisions to the SRP are to be reviewed and approved; this direction reflects current NRC practice as stated in NRR Office Letter No. 800. The scope of this procedure includes all proposed SRP revisions.

\section{Prerequisites for Performing This Procedure}

Technical Skills and Knowledge Levels. Much of this procedure will be implemented by NRC staff. Contractor personnel should have expertise in the design or operational area of concern and experience in the use and application of NRC regulations and guidance documents.

Document Availability. In general, necessary reference documents will be available through the SRP Reference Document Database or will be available from the implementation of previous procedures. The PTSB, with assistance from PNL, will make hard copies of documents available upon request.

Completion of Prior Procedures. Procedure 4.2 will need to be completed prior to performance of this procedure.

\section{Overview of the Steps in This Procedure}

Updates and upgrades are reviewed by appropriate NRR divisions, the Office of General Counsel, the CRGR, the ACRS, the Commission, and all comments are addressed. The revision is then noticed in the Federal Register for public comments, public comments are resolved, and the revised SRP section is subjected to the same NRC reviews and approvals noted above.

\section{Results of This Procedure}

Written Product. Written products resulting from the implementation of this procedure will include various review packages, status reports, Federal Register notices, and approved versions of SRP section revisions along with comment resolution and approval histories.

Other. Other results include presentations to the CRGR and others, as requested.

\section{Detailed Procedure}

This section specifies the step-by-step sequence to be followed, grouped by directives (major intermediate outputs), to be accomplished through a series of specific steps. It is intended that this procedure will be implemented on a "revision package" basis, generally consisting of one SRP chapter.

Directive 1: Obtain internal NRC reviews/approvals for revised or new SRP sections.

Step 1 Record the accomplishment of each milestone on the Review/Approval Status Form. (PTSB responsibility with assistance from PNL.)

Step 2 Prepare a draft SRP revision package including a draft memorandum to the CRGR for the signature of the Director, NRR, that summarizes and explains the need for the revision. 
Step 3 Forward the draft revision package to appropriate NRR divisions, other technical offices, and the Office of General Counsel for review. Resolve comments to the extent possible. (PRB responsibility.)

Step 4 Forward the revision package to the PTSB, including comments, resolutions thereof, and any divergent views that could not be resolved. (PRB responsibility.)

Step 5 Forward the revision package to the Director, NRR, at least four weeks prior to the scheduled submission to the CRGR. (PTSB will coordinate this activity with assistance from PNL.)

Step 6 Support any dry run CRGR presentations requested by the Director, NRR, and revise the revision package and transmittal memorandum in accordance with any comments and instructions from the Director, NRR. (PRB responsibility.)

Step 7 Once the Director, NRR, has approved the revision package, schedule a meeting with the CRGR. Transmit the package, with the memorandum signed by the Director, NRR, to the CRGR. (PTSB will coordinate this activity with assistance from PNL.)

Step 8 Make necessary presentations to the CRGR and resolve any CRGR comments. Prepare a response to CRGR comments for transmittal by the Director, NRR, within one week of receiving the comments. (PRB responsibility.)

Step 9 Prepare a memorandum to the ACRS, over the signature of the Director, NRR, transmitting the revision package. The memorandum should summarize the revision, explain the need for the revision, and include the regulatory analysis. Forward the draft memorandum to the PTSB. (PRB responsibility.)

Step 10 Review the draft memorandum, resolve any comments with the PRB, obtain concurrence of NRR's ACRS coordinator, obtain the signature of the Director, NRR, and forward the memorandum and revision package to the ACRS. (PTSB will coordinate with assistance from PNL.)

Step 11 Support any presentations to the ACRS, resolve any ACRS comments, modify the revision package, and forward the package to the PTSB. (PRB responsibility.)
Step 12 Provide the revision package to the Commission for review and approval. (PRB responsibility.)

Step 13 Make any presentations and provide any other support as directed by the Commission. (PRB responsibility.)

Step 14 Resolve any Commission comments and directives and redraft the SRP section revision, as required, and forward the revised revision package to the PTSB. (PRB responsibility.)

Directive 2: Obtain and resolve public comment.

Step 1 Assemble the revision package, prepare a Federal Register Notice of Intent to revise the SRP, and forward the Federal Register notice to the Division of Freedom of Information and Publications Services under the signature of the Branch Chief, PTSB. Also forward the proposed SRP revision to the Division of Information Support Services for reproduction and distribution for public comment. (PTSB responsibility with assistance from PNL.)

Step 2 Assure entry of public comments received into the SRP Modification Database, and forward comments to PRBs for resolution. (PTSB responsibility with assistance from PNL.)

Step 3 Resolve each substantive comment, making the necessary modifications to the draft SRP section revision. Maintain a record of comment resolutions and accompanying SRP changes. Prepare a final revision package. Forward the final revision package, along with comment resolution records, to the PTSB. (PRB responsibility.)

Step 4 Enter comment resolution records into the SRP Modification Database. Enter the final section revision into the Updated SRP Database. (PTSB responsibility with assistance from PNL.)

Directive 3: Obtain final internal NRC reviews/approvals.

Step 1 Repeat Directive 1, Steps 3 through 14, for the final section revision package. Responsibilities remain as indicated in those steps.

Step 2 Update the SRP Modification Database and SRP Update Database with appropriate information resulting from implementation of Step 1. Maintain the final revision package for 
processing in accordance with Procedure 5.0. (PTSB responsibility with assistance from PNL.)

Step 3 Upon completion of Procedure 5.0, prepare a Federal Register notice of SRP revision and forward the notice to the Division of Freedom of Information and Publications Services under the signature of the Branch Chief, PTSB. (PTSB responsibility with assistance from PNL.)

\section{Forms}

The single form used to implement this procedure is the Review/Approval Status Form. The purpose of this form is to allow tracking of formal review and approval for each SRP section and to provide a vehicle for entering status information into the SRP Modification Database. 


\subsection{NRC Review}

\section{Sample Form}

\section{Review Approval Status Form}

SRP Section Nos.

Complete milestone history to be presented?

$$
\text { Yes }
$$

No

\section{CRGR Review}

\section{Milestone}

Final draft of SRP section revision provided to PRB:

PRB cover memo to CRGR drafted, revision package completed, package sent to PTSB:

Revision package forwarded to Director, NRR:

CRGR meeting held:

CRGR comments resolved:

\section{ACRS Review}

Draft ACRS memorandum forwarded to PTSB:

ACRS memorandum transmitted:

ACRS comments resolved:

\section{Commission Review}

Revision package forwarded to Commission:

Commission comments resolved:

\section{$\underline{\text { Public Comment }}$}

Federal Register notice sent to Division of Freedom of Information and Publications Services:

Federal Register notice published:

Public comment response date:

Public Comments resolved: 


\section{Review Approval Status Form (continued)}

Second CRGR Review

Milestone

Date Completed

PRB cover memo to CRGR drafted, revision package completed, package sent to PTSB:

Revision package forwarded to Director, NRR:

CRGR meeting held:

CRGR comments resolved:

\section{Second ACRS Review}

Draft ACRS memorandum forwarded to PTSB:

ACRS memorandum transmitted:

ACRS comments resolved:

Second Commission Review

Revision package forwarded to Commission:

Commission comments resolved:

Final Draft Complete:

$\underline{\text { Public Comment }}$

Federal Register notice sent to Division of Freedom of Information and Publications Services:

Federal Register notice published:

Comments 


\section{How to Complete the Form}

- Enter the SRP section numbers for those sections whose status is being updated. Any number of section numbers may be entered at one time.

- Answer the question as to whether the complete milestone history should be provided by placing an "X" after "Yes" or "No." A "Yes" response will cause the computer to fill in as many of the "Date Completed" blanks as data in the SRP Modification Database will support. A "No" response, which is the default response, will result in all blanks being left blank. This feature will only be available if one and only one SRP section is indicated; multiple sections would likely have different histories which could not be presented on the form. This question does not have to be answered.

- Proceed to the correct milestone and enter the date on which that milestone was accomplished. The new data will be recorded in the SRP Modification Database for each of the SRP sections indicated on the first line of the form. Data for more than one milestone may be entered at one time. If an entry is made for a milestone that already has a date entered for it, the computer will notify the person entering the data and request confirmation before making the date change.

- A comment field is provided at the bottom of the form. Any comments entered in this field will be linked to the milestone(s) for which new data has just been entered.

- Enter an "N/A" or any milestones that are not applicable to the review and approval of SRP section updates, thus making it clear that the milestones do not apply. The computer will add an "N/A" in any blanks for which a date has not been entered and a subsequent milestone has had a date entered, but only after notifying the user and requesting confirmation. 
Sample Completed Form

Review Approval Status Form

SRP Section Nos. 7.2-D

Complete milestone history to be presented? Yes $\mathrm{X}$ No

CRGR Review

Milestone

Final draft of SRP section revision provided to PRB:

PRB cover memo to CRGR drafted, revision package completed, package sent to PTSB:

Revision package forwarded to Director, NRR:

CRGR meeting held:

CRGR comments resolved:
Date Completed

$08 / 03 / 93$

$08 / 12 / 93$

$08 / 15 / 93$

$10 / 02 / 93$

$10 / 15 / 93$

Draft ACRS memorandum forwarded to PTSB:

$10 / 26 / 93$

ACRS memorandum transmitted:

$10 / 30 / 93$

ACRS comments resolved:

$12 / 04 / 93$

Commission Review

Revision package forwarded to Commission:

N/A

Commission comments resolved:

N/A

\section{Public Comment}

Federal Register notice sent to Division of Freedom of Information and Publications Services:

$12 / 15 / 93$

Federal Register notice published:

$01 / 01 / 94$

Public comment response date:

$04 / 01 / 94$

Public Comments resolved:

$06 / 01 / 94$ 


\section{Review Approval Status Form (continued)}

\section{Second CRGR Review}

\section{Milestone}

Date Completed

PRB cover memo to CRGR drafted, revision package completed, package sent to PTSB:

Revision package forwarded to Director, NRR:

$06 / 08 / 94$

CRGR meeting held:

$08 / 10 / 94$

CRGR comments resolved:

$08 / 24 / 94$

\section{Second ACRS Review}

Draft ACRS memorandum forwarded to PTSB:

$09 / 10 / 94$

ACRS memorandum transmitted:

$09 / 14 / 94$

ACRS comments resolved:

$11 / 01 / 94$

Second Commission Review

Revision package forwarded to Commission:

N/A

Commission comments resolved:

N/A

Final Draft Complete:

\section{Public Comment}

Federal Register notice sent to Division of Freedom of Information and Publications Services:

Federal Register notice published:

Comments The Commission has directed that SRP sections pertaining to this reactor type will not be reviewed by the Commission in a memo to the EDO, dated January $15,1993$. 


\subsection{Integration of the SRP}

This chapter, summarized in Table 8 , provides procedures for compiling the various SRP sections into an integrated SRP.

Table 8. Summary of Chapter 5

\begin{tabular}{ll}
\hline Chapter & \multicolumn{1}{c}{ Description of Chapter Content } \\
\hline Chapter 5: Integration of the SRP & $\begin{array}{l}\text { Presents procedures for incorporating all SRP } \\
\text { sections into an integrated whole. }\end{array}$ \\
& $\begin{array}{l}\text { Operates on only those SRP section revisions that } \\
\text { have been reviewed and approved under Procedure } \\
\\
4.3 \text { and other SRPs that have been reviewed and } \\
\text { approved when this procedure is implemented. }\end{array}$ \\
\end{tabular}

\subsection{Approach}

By the time this procedure is implemented, groups of approved, revised SRP sections (or perhaps the entire set of approved, revised SRP sections) will be available.

The revised SRP sections from NUREG-0800 will be integrated into a single SRP. At present, it also appears that the ESRP and the SRP and ESRP for license renewal will be compiled into a single, integrated SRP along with the NUREG-0800-based SRP. Other types of SRPs may also be included.

In support of future maintenance of the SRP, the SRP Update and Development Program is developing an automated SRP system known as the Updated SRP Database. This system will be used as a full-text storage system for the revised and integrated SRP, and it will provide useful tools to facilitate use of the SRP and future revisions to it. There will be a read-only mode that will allow anyone with access to the database to read the SRP in electronic format and have direct access to electronic versions of documents referenced in the SRP. There will be an interactive mode for authorized individuals that will allow such individuals to set markers in the electronic text to indicate needs for revision to the SRP. The markers will carry such information as the location of the problem area within the SRP, the name and telephone number of the individual setting the marker, and comments regarding the nature of the problem. The Updated SRP Database will interface with the SRP Modification Database so that markers placed in the SRP electronic text can be processed and managed by staff responsible for maintaining the SRP.

The approach to be used in this procedure is quite straightforward. Approved, revised SRP sections will already be in correct format as a result of implementation of previous procedures. Individual sections will be loaded into the Updated SRP Database in accordance with organizational directives already established in other procedures. The SRP table of contents will be updated. An SRP distribution methodology will be developed and implemented. Finally, as the SRP nears completion, a review of the overall document will be performed to identify any areas where improvement is needed (e.g., missing review areas, inconsistent approaches).

\subsection{Procedure for Integration of the SRP}

\section{Purpose and Scope of This Procedure}

This procedure provides direction for incorporating all SRP sections into an integrated whole. This procedure will operate on only those SRP section revisions that have been reviewed and approved under Procedure 4.3 and other SRPs that have been approved at the time of implementation of this procedure.

\section{Prerequisites for Performing This Procedure}

Technical Skills and Knowledge Levels. The various tasks covered by this procedure require different skills. Incorporation into the Updated SRP Database requires familiarity with word processing and the Updated SRP Database system. The overall document review requires a technical background, familiarity with the SRP as revised, and working knowledge of licensing procedures and technical issues.

Document Availability. The performance of the overall review called for by this procedure will require the availability of all, or at least a majority, of the individual SRP sections that are to be integrated. 
Completion of Prior Procedures. The completion of Procedure 4.3 for any revised sections that are to be incorporated in the integrated SRP may or may not be needed, depending on whether the SRP is integrated before or after the NRC review/approval process. Sections from other, previously approved, SRPs may also be incorporated.

\section{Overview of This Procedure}

Revised SRP sections are loaded into the Updated SRP Database and appropriately maintained. A methodology for distributing or otherwise making the SRP available within and outside the NRC is developed and implemented. An overall review of the completed SRP is then performed.

\section{Results of This Procedure}

Written Product. The written product resulting from the implementation of this procedure will be an integrated SRP loaded into the Updated SRP Database. A print-ready hard copy of the SRP will also be produced.

Other. The non-written result of this procedure is a determination as to how the hard-copy version of the SRP will be distributed or otherwise be made available to the industry and general public.

\section{Detailed Procedure}

This section specifies the step-by-step sequence to be followed, grouped by directives (major intermediate outputs), to be accomplished through a series of specific steps.

\section{Directive 1: Build and maintain Updated SRP Database.}

Step 1 Enter each SRP section into the Updated SRP Database.
Step 2 Update the SRP table of contents and perform any other needed maintenance of the Updated SRP Database as sections are added.

Step 3 Track the completion of the integrated SRP and periodically report progress.

Directive 2: Prepare for SRP distribution.

Step 1 Explore potential methods of SRP distribution, both within and outside of the NRC. Questions of particular concern include distribution of hard-copy versions inside and outside of the Agency and the distribution or making available the electronic version outside of the Agency. Work with cognizant NRC organizations in this regard.

Step 2 Obtain NRC decisions on the distribution methods to be used.

Step 3 Provide print-ready hard copies and/or access to the Updated SRP Database, as required, to implement the decision reached in Step 2.

Directive 3: Perform overall review of integrated SRP.

Step 1 Establish the criteria to be used in performance of the review.

Step 2 Review the completed SRP according to the established review criteria. Identify any areas where corrections or further work is required, and apply Procedure 7.0 as appropriate to the areas identified.

Forms

No forms are used to implement this procedure. 


\subsection{Independent Review of Work}

This chapter, summarized in Table 9, presents a mechanism to provide a quality check of work performed for this program by PNL. This section is included in the
Implementing Procedures Document as an example of an acceptable quality assurance procedure and may be used by other organizations if they wish.

Table 9. Summary of Chapter 6

\begin{tabular}{ll}
\hline \multicolumn{1}{c}{ Chapter 6 } & \multicolumn{1}{c}{ Description of Chapter Content } \\
\hline Chapter 6.0: Independent Review of & $\begin{array}{l}\text { Presents procedures for independent review of } \\
\text { work performed for the SRP Update and } \\
\text { Development Program. }\end{array}$ \\
\hline
\end{tabular}

\subsection{Approach}

The mechanism that will be used is a review of work by a reviewer independent of the initial performance of the work. This procedure is written with generic applicability and may be used by any organization involved in the performance of program work. Existing procedures may be used in lieu of this procedure by the PRBs if they ensure the purpose of this procedure, i.e., the accomplishment of high quality work.

This procedure is intended to ensure an independent review of work. The independence criterion is taken to mean that the reviewer may not have been directly involved in the actual accomplishment of the work. An analyst may not review the analyst's own work; two persons working together on the same work may not review each other's work. In general, a reviewer would not report organizationally to the supervisor of the analyst performing the original work.

Independent reviews will be performed using the following criteria.

\section{Work Performed on a Document-By-Document Basis}

- Review $100 \%$ of work products for the first week for each analyst.

- Review $10 \%$ to $20 \%$ of work products after each analyst has performed such work for at least one week. Review should be related to analyst's experience and performance of the work.

\section{Work Performed on an SRP Section-By-Section Basis}

- Review the first three sections the analyst worked on.

- Review one in four of the analyst's subsequent sections.
At PNL, application of this procedure is mandatory for all Revision Option Checklist Forms prior to their transmittal to the PRB or any other PRB-designated organizations. The final reviewer of this material will be an expert on the subject matter who has a working knowledge of NRC's regulatory process. The reviewer will pay particular attention to interpretations of regulatory citations contained in the impact descriptions.

The method of review used is also dependent on the nature of the work. In general, the reviewer is assumed to be sufficiently qualified and experienced to be able to determine the most appropriate review method. Several review methods are described below, but the list is not exhaustive and the review methods are not mutually exclusive.

Independent Performance of the Work. The reviewer may perform the same task as was originally performed, and then compare the results with the original results. The method used by the reviewer may be the same as the original analyst's, or some other method. This review method is typically used where the preparation process is not documented, and judgment cannot be used to adequately evaluate work products.

Audit of the Work. In cases where the analyst documents the accomplishment of the work, the reviewer may simply audit the process used and the accompanying results.

Review of Repetitive Work. In cases where a specific process is repeated many times, the reviewer may review a portion of the work product to determine adequacy. The amount of review of each product depends on the results of previous reviews. If the results indicate good work performance, future review may be reduced. If results are poor, more review or a complete audit may be indicated. 
The result of a review is typically the generation of a set of comments, including potentially no comments. Part of the review process is the resolution of comments, i.e., a process in which the preparer and reviewer resolve any inaccuracies in the work and any differences of opinion regarding the work or how it was performed. This activity assumes that the analyst and reviewer will communicate directly (a meeting or telephone conversation) in order to resolve all comments, and that work will be appropriately revised to reflect the resolutions reached. Most forms used for data entry contain lines for preparers and reviewers to indicate their approval of the work represented by the form.

It is not intended that either the analyst or reviewer will be a dominant figure in resolution of comments. Rather, it is hoped that through discussion and negotiation the parties will be able to reach agreement. In cases where agreement cannot be reached, the issue will be elevated to higher levels of program management until a resolution is reached, by edict, if necessary. In such cases, the name of the resolving manager should be indicated on the appropriate forms.

\subsection{Procedure for Review of Work}

\section{Purpose and Scope of This Procedure}

This procedure provides a process for independent review of program work and resolution of comments resulting from the review for use by PNL. Existing procedures may be used by other organizations in lieu of this one if they choose. If organizations elect not to use this procedure, it is expected that an appropriate alternative quality check be used.

\section{Prerequisites for Performing This Procedure}

Technical Skills and Knowledge Levels. The technical skills and knowledge levels of reviewers are determined on a task-by-task basis. In general, the reviewer should meet at least the same requirements as the individual originally performing the work (see appropriate procedures for a statement of requirements), and, if possible, should have more experience than the original work performer (analyst).

Document Availability. The reviewer will generally require access to the same documents needed by the analyst. Necessary documents are specified in each applicable procedure.

Completion of Prior Procedures. Review of work will generally require that the applicable procedure has been completed for the parcel of work being reviewed.

\section{Overview of Steps in This Procedure}

The first step is assigning reviewers and the parcels of work to be reviewed. A review of the designated work is performed. Any comments are resolved between the reviewer and analyst, and resulting resolutions are incorporated in the work. Analysts and reviewers enter their names on the pertinent forms. Periodic trend analysis will be performed regarding the results of independent reviews.

\section{Results of This Procedure}

Written Product. The written product resulting from this procedure is a set of comment forms containing the reviewer's comments and accompanying resolutions of those comments.

Other. The intended result of this procedure is the assurance of high quality work products, i.e., products that meet the criteria specified in procedures, that are accurate in their representation of the facts, and that are technically competent.

\section{Detailed Procedure}

This section specifies the step-by-step sequence to be followed, grouped by directives (major intermediate outputs), to be accomplished through a series of specific steps.

\section{Directive 1: Make assignments.}

Step 1 Assign reviewers using the Work Assignment Form (Procedure 2.1). Due dates for reviews are based on program schedules.

Step 2 Notify reviewers of their assignments and provide them with work products and access to necessary documents.

Directive 2: Review assigned work.

Step 1 Review completed work using an appropriate review method. Ensure compliance with applicable procedures, accurate characterization of information, and technical adequacy.

Step 2 Fill out Comment/Resolution Form(s) for each parcel of work reviewed; each form should be filled out for work performed or assigned to one analyst. Indicate comments on the form.

Step 3 Return Comment/Resolution Form(s) to the analyst. Notify SRP Modification Database data entry personnel of the completion of the review 
by completing the Independent Review Completion Form.

Directive 3: Resolve comments.

Step 1 Review the comments indicated on the Comment/Resolution Form.

Step 2 Hold a meeting or telephone conversation between the analyst and reviewer to discuss the comments and attempt to reach resolutions on disposition of the comments. Indicate resolutions on the Comment/Resolution Form.

Step 3 Involve higher-level management to resolve any issues that cannot be negotiated between the analyst and reviewer. Indicate resolutions on the Comment/Resolution Form.

Step 4 Incorporate appropriately the resolutions in the originally prepared work.

Step 5 Review the incorporation of resolutions. The analyst and reviewer will indicate proper incorporation on the Comment/Resolution Form by their signatures on the form.

Step 6 Return to the original forms and enter the signatures of the analyst and the reviewer. At this point, the information on the original form is deemed approved for entry into the appropriate database.

Directive 4: Perform trends analysis (PNL responsibility).
Step 1 Periodically review the results of independent reviews performed by PNL in accordance with this procedure.

Step 2 Critically review the results of Step 1 to identify any trends or programmatic concerns that could compromise the quality of program work and products.

Step 3 Investigate the root causes of any identified problems.

Step 4 Implement corrective actions identified in Step 3.

Step 5 Re-audit the areas of concern after implementation of corrective actions to verify the efficacy of the corrective actions.

\section{Forms}

This procedure uses one form. This form will be used by PNL. Other organizations are not required to use this form, but may use it if they wish. Whether or not this particular form is used, the organization performing the work is responsible for recording any comments and resolutions associated with the independent review. Upon submission of the finished product, the PRB must certify that appropriate quality assurance procedures have been followed and that associated documentation is retained by the PRB. The Comment/Resolution Form provides a means to record review comments and facilitate communication between analysts and reviewers. This form may be used in hard copy or in electronic form, and it will be retained as a program record in hard-copy form. Review results will be auditable. 
6.0 Independent Review

Sample Form

\section{Comment/Resolution Form}

Page

of

Work Being Reviewed

Work Procedure

Reference

Comment

Resolution

Resolution Verified to be Incorporated

Analyst

Date

Telephone

Reviewer

Date

Telephone 
How to Complete the Form

Comment/Resolution Form

Reviewer

- Indicate each comment by providing a reference to the work to which the comment applies (i.e., the work being reviewed, the associated work procedure, including the assignment code, and reference information) and an explanation of the comment. Any number of sheets may be used, but the current page and total number of pages should be indicated on the line provided. It is suggested that purely editorial corrections be noted and tracked on a separate piece of paper; inclusion of editorial comments on the standard form would quickly become burdensome if there were many such corrections.
Analyst or Reviewer

- Enter the resolution for each comment after discussing the comments.

- Enter a check in the blank indicating completion of resolution incorporation.

- After all comments have been resolved, incorporated, and verified, both the analyst and reviewer will sign their names and provide date of signature.

- If resolutions need to be obtained at higher management levels, the decision maker should also sign the form in the area of the comment description and resolution. 
6.0 Independent Review

Sample Form

\section{Comment/Resolution Form}

Page 1 of 1

Work Being Reviewed Potential Impact No. 456

Work Procedure 24A - Manual Impact Identification, Procedure 2.4

Reference Impact Identification Form, Part B - Impact Criteria

Comment The classification of the impact as No. 1 is incorrect. The impact only supports development of bases for Acceptance Criteria and should be classified as No. 5.

Resolution Classification will be changed as noted.

Resolution Verified to be Incorporated

Analyst Jane Doe

Date $06 / 18 / 92$

Telephone (509) 376-4444

Reviewer James Row

Date $\underline{06 / 19 / 92}$

Telephone (509) 376-5555 


\subsection{Identification of Candidates for Future Work}

This chapter, summarized in Table 10, presents procedures to ensure that needs for research, regulatory action, or codes and standards development are brought to the attention of cognizant NRC organizations.

Table 10. Summary of Chapter 7

\begin{tabular}{ll}
\hline \multicolumn{1}{c}{ Chapter 7 } & \multicolumn{1}{c}{ Description of Chapter Content } \\
\hline Chapter 7.0: Identification of & - $\begin{array}{l}\text { Presents procedures to ensure that needs for } \\
\text { research, regulatory action, and codes and } \\
\text { standards development identified through } \\
\text { Candidates for Future Work }\end{array}$ \\
& $\begin{array}{l}\text { implementation of other procedures, are brought to } \\
\text { the attention of cognizant NRC organizations for } \\
\text { resolution. } \\
\text { - Presents procedures for tracking of the identified } \\
\text { research and regulatory needs. }\end{array}$ \\
\hline
\end{tabular}

\subsection{Approach}

The SRP Update and Development Program recognizes that in certain situations completion of SRP section updates or upgrades may require action outside the scope of the Program itself. Examples of such situations are where the information necessary to establish requirements or make decisions is not currently available and must be developed through research; where regulatory requirements or positions are insufficient to establish a basis for the SRP and regulatory action should be taken; where additional regulatory guidance is needed; and where codes and standard need to be developed or revised.

This procedure will generally be invoked as a result of activities conducted under the other procedures, particularly Procedures 3.3 and 3.5 through 3.8. Once needs for research or regulatory action are identified, this procedure will ensure that cognizant organizations within the NRC are made aware of such needs, and will cause the Agency's response to be tracked so that, once resolved, they may be factored into the SRP update and development process. It is not the intent or purpose of this procedure to actually perform research or develop regulatory requirements or guidance.

\subsection{Procedure for Identification of Candidates for Future Work}

\section{Purpose and Scope of This Procedure}

The purpose of this procedure is to ensure that needs for research or regulatory action, identified in the implementation of other procedures, are brought to the attention of cognizant NRC organizations for resolution.
The scope of this procedure is limited to communicating such needs and tracking their resolution.

\section{Prerequisites for Performing This Procedure}

Technical Skills and Knowledge Levels. Analysts involved in performing other procedures will be primarily responsible for developing the information used in this procedure. The technical skills and knowledge levels set forth in those procedures will qualify analysts to perform this procedure.

Document Availability. Documents already available in performance of other procedures are the only ones required to be available. No additional documents are necessary.

Completion of Prior Procedures. No other procedures need be completed, although there is an implicit requirement that other procedures are being implemented so that needs for research or regulatory action may be identified.

\section{Overview of the Steps in This Procedure}

Needs for research or regulatory action are identified in the implementation of other procedures. Once a need is identified, this procedure prescribes the steps regarding recording the information necessary to characterize the need, providing the information to the PTSB for approval and routing to cognizant $\mathrm{NRC}$ organizations, and tracking resolution activities.

\section{Results of This Procedure}

Written Product. Written products will include brief reports for transmittal to cognizant NRC organizations for 
action and periodic status reports of outstanding needs for research and regulatory action.

Other. Other results of this procedure include SRP Modification Database tracking of identified needs for research and regulatory action.

\section{Detailed Procedure}

This section specifies the step-by-step sequence to be followed, grouped by directives (major intermediate outputs), to be accomplished through a series of specific steps. This detailed procedure assumes that a need has already been identified through completion of a form included in another procedure, although this procedure may be applied if a need is identified through some other mechanism.

\section{Directive 1: Prepare reports of needs for research and} regulatory action.

Step 1 Prepare a Research/Regulatory Action Needs Form for each need identified. Completion of this form is the responsibility of the analyst who identifies the need.

Step 2 Periodically request the SRP Modification Database system to prepare Research and Regulatory Needs Reports.

Step 3 Provide Research and Regulatory Needs Reports to the PTSB for approval and transmittal to the PRB for approval.

Step 4 The PRB approves or disapproves the Research and Regulatory Needs Report and returns it to the PTSB.

Step 5 The PTSB forwards approved Research and Regulatory Needs Reports to the cognizant organizations within the NRC for further action.
Directive 2: Track outstanding needs.

Step 1 Assign individuals to coordinate the tracking of identified and approved needs.

Step 2 Coordinate the tracking of identified and approved needs. Enter information regarding the status of such needs on the Research/Regulatory Action Status Form.

Step 3 Determine the frequency at which the PTSB would like to receive status reports regarding outstanding needs.

Step 4 Request status reports from the SRP Modification Database system at the determined frequency, and forward such reports to the PTSB.

Step 5 Monitor the completion of activities to satisfy program needs (responsibility of the PTSB).

\section{Forms}

Two forms and two reports are used in the implementation of this procedure. The Research/Regulatory Action Needs Form is used to identify potential needs and to obtain PRB and PTSB approvals. The Research/Regulatory Action Status Form is used to record information regarding the status of approved needs. The Research/Regulatory Action Needs Report is used by the PTSB to notify cognizant NRC organizations of approved needs. The Research/Regulatory Action Needs Status Report is used to inform NRC management of the status of approved needs.

All organizations implementing this procedure must record their work on the indicated forms and forward the completed forms to the PTSB upon completion of the work. 


\section{Sample Forms}

\section{Research/Regulatory Action Needs Form}

Need Number

Need Title

Need Source

SRP Section(s)

Research Need

Regulatory Guide Development/ Revision Need
Rulemaking Need

Other Regulatory Action Need

Codes/Standards Development Needs

Description of Need

References

Analyst's Name (print)

Signature

Date

Analyst's Supervisor's Approval

Date

PTSB Approval Yes $\_$No

PTSB Signature

Date 
7.0 Identification of Future Work

Research/Regulatory Action Status Form

Need Number

Need Title

Responsible NRC Organization

Date Sent to Responsible Organization

Response of Responsible Organization

Response Date

Status Comment

Action Completion Date

Action Description

Notification of Program Personnel Complete (Date)

Name of Assigned Individual

Signature of Assigned Individual 


\section{Research/Regulatory Action Needs Report}

To: (NRC Organization Responsible for the Need)

From: (PTSB representative)

Date:

Subject: Research/Regulatory Action Need Identified by the SRP Update and Development Program

The SRP Update and Development Program has identified a potential Research/Regulatory Action Need. The Policy Development and Technical Support Branch (PTSB), NRR, has assigned Need Number to this need to uniquely identify it; please refer to this number in future communications with the PTSB. Information required to understand the need is provided below. Please assess this information, determine the appropriate action, and notify the PTSB of your decision as soon as possible.

The need has been identified as a potential (research)(rulemaking)(Regulatory Guide development)(regulatory action other than rulemaking or Regulatory Guide development) (codes/standards development) item. It has been titled "[Need Title from Research/Regulatory Action Needs Form]." The need is associated with (updating the SRP to reflect current technology)(upgrading the SRP to reflect future reactor technology). This need originates from the implementation of SRP Update and Development procedures and is associated with SRP Section Number(s) [Section Numbers to be taken from the Research/Regulatory Action Needs Form].

The need can be briefly described as follows.

[Description of Need from the Research/ Regulatory Action Needs Form.]

Pertinent reference documents are as follows:

[References taken from the Research/Regulatory Action Needs Form, but accession numbers will be translated into document numbers and titles.] 
7.0 Identification of Future Work

Research/Regulatory Action Needs Status Report

Report Date

At present, a total of needs have been identified and approved for further consideration; of these needs have been closed out, of these needs are still pending
new needs have been identified,

The last report was prepared on . Since

that report, needs have been closed out.

The following statistics apply to the needs that are still pending.

Number of Research Needs

Number of Rulemaking Needs

Number of Regulatory Guide Needs

Number of Other Regulatory Action Needs

Number of Codes/Standard Development Needs

Responsible NRC Organization
Number of Pending Assigned Needs

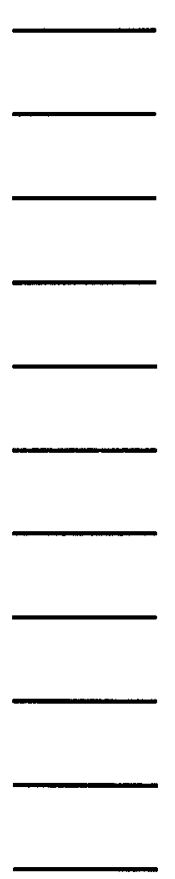




\section{How to Complete the Form}

\section{Research/Regulatory Action Needs Form}

- Obtain the need number from the project clerk and enter it on the form.

- Enter a title and source for the need and the SRP section or sections associated with the need. The title is created by the analyst and should convey the essence of the need. The source is the procedure being performed when the need is identified.

- Indicate the nature of the need (research, rulemaking, regulatory guide development/revision, other regulatory action, or codes/standards development).

- Indicate the basis of the need (i.e., how it will be used) by placing an $\mathrm{X}$ after the correct response.

- Enter a brief description of the need and indicate any applicable reference documents. Documents may be referenced simply by accession number if they are cataloged in the SRP Modification Database.

- Print and sign your name and enter the date.

- The next line is signed and dated by the approver (usually the analyst's project supervisor or designated member of project management).

- The PTSB indicates its approval or disapproval of a suggested need on the PTSB approval line by placing an "X" in the correct response. A PTSB-authorized signature and date are then entered.

\section{Research/Regulatory Action Status Form}

- Enter the need number and title of the need under consideration.

- Determine the NRC organization that is responsible for handling the identified need. Enter its designation on the form.

- Record the date that the Research/Regulatory Action Needs Report is sent to the responsible organization.

- Upon receipt of the responsible organization's response, summarize and record that response and the date that the response is received.
- Use the Status Comment blank to record any pertinent information that is not adequately captured in the other blanks, including any information to characterize the progress of resolving the need.

- Fill in the Action Completion Date and Action Description after the need has been resolved by the responsible NRC organization. The "action" may be the issuance of a report, a regulatory change, a change in a regulatory or guidance document, a determination that some other course of action is appropriate, etc.

- Enter the date that program personnel notification, regarding the closure of the need, is completed.

- Enter the printed name and signature of the person assigned responsibility for following this need.

For tracking purposes, the entry of an Action Completion Date will transfer the need from a pending item to a closed item on the Research/Regulatory Action Needs Status Report. If a reassignment of the need is required, an amendment is made to the Responsible NRC Organization entry. The computer will request confirmation and, upon receipt of same, will archive the original record and begin a new record for the subject need. The Status Report will not register a new need or closure of an existing need, but will make necessary changes to the data provided in the report.

\section{Research/Regulatory Actions Needs Report}

This report is generated by the SRP Modification Database system. It uses input from PTSB-approved Research/Regulatory Action Needs Forms and presents the information in a memorandum format for PTSB transmittal to the cognizant NRC organization. There are no blanks to be filled in on this report. This report will be used, as appropriate, consistent with NRR office policy and procedures.

\section{Research/Regulatory Action Needs Status Report}

This report is generated by the SRP Modification Database system. It uses input from the Research/Regulatory Action Needs Status Forms and provides a management-type report summarizing the status of approved needs. 
7.0 Identification of Future Work

Sample Completed Forms

Research/Regulatory Action Needs Form

Need Number N006

Need Title Effectiveness of Passive Air Cooling Systems

Need Source Procedure 3.8 - PRB Approval of Development Options

SRP Section(s) 9.2.5-C

Research Need

$\underline{X}$

Rulemaking Need

Regulatory Guide Development/

Revision Need

Other Regulatory Action Need

Codes/Standards Development Needs

Description of Need It is suggested that passive air cooling systems may be affected by prevalent wind conditions. Only a scale model-test using the design configuration and local terrain and meteorological conditions can reliably confirm system operational effectiveness. Additional research is needed to determine if the scale model test can be performed generically such that a terrain envelope may be defined. The concern is the reliability of applying the envelope conditions to particular sites.

References 592, 3802, 7271. Impact 11012.

Analyst's Name (print)

Signature

Date

Analyst's Supervisor's Approval

Date

PTSB Approval Yes $\_$No

PTSB Signature

Date 


\section{Research/Regulatory Action Status Form}

Need Number N006

Need Title Effectiveness of Passive Air Cooling Systems

Responsible NRC Organization Plant Systems Branch (SPLB)

Date Sent to Responsible Organization 10/12/92

Response of Responsible Organization This issue will require development, modelling, and model validation and verification. Reassign to the Office of Research (RES).

Response Date 10/30/92

Status Comment

Action Completion Date 10/30/92

Action Description Reassigned to RES.

Notification of Program Personnel Complete (Date) N/A

Name of Assigned Individual Craig Johnson

Signature of Assigned Individual 
7.0 Identification of Future Work

\section{Research/Regulatory Action Status Form}

Need Number N006

Need Title Effectiveness of Passive Air Cooling Systems

Responsible NRC Organization Office of Research (RES)

Date Sent to Responsible Organization 11/01/92

Response of Responsible Organization RES has an ongoing project to evaluate passive air cooling systems. The concerns expressed in this need will be factored into this ongoing work. Project completion is scheduled for about six months from now.

Response Date 11/14/92

Status Comment

Action Completion Date 06/27/92

Action Description RES has published a report (NUREG-XXXX) addressing the technical issues associated with passive air cooling. A Regulatory Guide will be developed to implement the report recommendations.

Notification of Program Personnel Complete (Date) 07/05/93

Name of Assigned Individual Craig Johnston

Signature of Assigned Individual 


\section{Research/Regulatory Action Needs Report}

To: Richard Moore, Plant Systems Branch (SPLB)

From: Tracy Warren (PTSB)

Date: October 12, 1992

Subject: Research/Regulatory Action Need Identified by the SRP Update and Development Program

The SRP Update and Development Program has identified a potential Research/Regulatory Action Need. The Policy Development and Technical Support Branch (PTSB), NRR, has assigned Need Number N006 to this need to uniquely identify it; please refer to this number in future communications with the PTSB. Information required to understand the need is provided below. Please assess this information, determine the appropriate action, and notify the PTSB of your decision as soon as possible.

The need has been identified as a potential research item. It has been titled "Effectiveness of Passive Air Cooling Systems." The need is associated with upgrading the SRP to reflect future reactor technology). This need originates from the implementation of SRP Update and Development procedures and is associated with SRP Section Number 9.2.5-C.

The need can be briefly described as follows.

It is suggested that passive air cooling systems may be affected by prevalent wind conditions. Only a scale model test using the design configuration and local terrain and meteorological conditions can reliably confirm system operational effectiveness. Additional research is needed to determine if the scale-model test can be performed generically such that a terrain envelope may be defined. The concern is the reliability of applying the envelope conditions to particular sites.

Pertinent reference documents are as follows:

NUREG-YYYY, "Effects of Meteorological Conditions on Passive Air Cooling Systems in Advanced Reactor Designs." January 1992.

NUREG/CR-ZZZZ, "Evaluation of Advanced Reactor Design Criteria." ABC National Laboratory, September 1991. 
7.0 Identification of Future Work

Research/Regulatory Action Needs Status Report

Report Date February 1, 1994

At present, a total of 122 needs have been identified and approved for further consideration; 45 of these needs have been closed out, 77 of these needs are still pending. The last report was prepared on January 3, 1994. Since that report, 2 new needs have been identified, 3 needs have been closed out.

The following statistics apply to the needs that are still pending.

\begin{tabular}{lc} 
Number of Research Needs & 57 \\
Number of Rulemaking Needs & 4 \\
\hline Number of Regulatory Guide Needs & 11 \\
\hline Number of Other Regulatory Action Needs & 3 \\
\hline & \\
Number of Codes/Standard Development Needs & 2 \\
\hline
\end{tabular}

\section{Responsible NRC Organization}

Office of Research

$\underline{\text { Plant Systems Branch }}$

Reactor Systems Branch

Human Factors Assessment Branch

Mechanical Engineering Branch

Instrumentation and Control Branch

Radiation Protection Branch

\section{Number of Pending Assigned Needs}

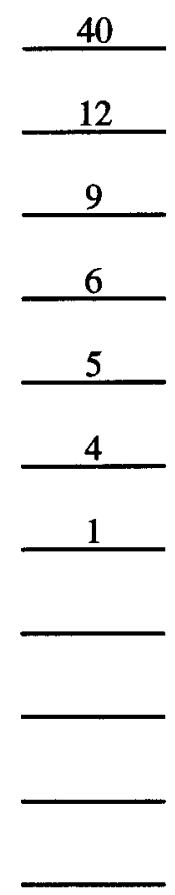




\subsection{Control and Revision of Implementing Procedures Document}

This chapter, summarized in Table 11, presents procedures that provide document control for this Implementing Procedures Document.

Table 11. Summary of Chapter 8

\begin{tabular}{ll}
\hline Chapter 8 & \multicolumn{1}{c}{ Description of Chapter Content } \\
\hline Chapter 8.0: Control and Revision of & $\begin{array}{l}\text { Presents document control procedures for this } \\
\text { Implementing Procedures Document, including } \\
\text { control of revisions. }\end{array}$ \\
\hline
\end{tabular}

\subsection{Approach}

The purposes of this procedure are to:

- Ensure that the program personnel who require access to procedures will have such access.

- Ensure that program management has information regarding who has the document and what version it is.

- Ensure that document users are provided with up-to-date copies of document procedures.

- Ensure that revisions to this document are properly controlled.

Document control includes maintenance of document originals (from which copies are made), establishment and maintenance of distribution lists, distribution of the document and any future revisions thereto according to the distribution list, control of document receipt by those on the distribution list, handling of superseded Implementing Procedures Documents, and control of revisions to the Implementing Procedures Document.

It is anticipated that this document will be reissued, in total, whenever revisions to any part of it are made. In this way, problems regarding updating parts of the document will be avoided.

Normal good practices will be applied to the maintenance of Implementing Procedures Document originals (backing up computer files, maintaining a hard-copy version, restricting access to avoid unauthorized changes). The review and approval of the first issue and all subsequent revisions will be coordinated by the PTSB prior to issuance, release, and use.

Several frequently used techniques will be used to control the circulation of the Implementing Procedures Document.
A distribution list of individuals needing copies of the document will be developed and maintained. Document copies will be numbered, and records will be maintained of who has each copy. Implementing Procedures Document receipt forms will be completed by document recipients and maintained in program files. Superseded copies of the document will be returned by the users and appropriately dispositioned (retained, but clearly marked "superseded," disposed of, etc.), and distribution records will be updated accordingly.

The Implementing Procedures Document is a living document that will have to be revised to account for experience gained in implementing the procedures contained herein and to accommodate changes in the focus of the SRP Update and Development Program (e.g., changes from initial development activities to routine maintenance activities as the program proceeds to later phases). The procedures for controlling revisions attempt to balance several considerations. It is essential that adequate control be maintained to ensure that numerous spurious and non-essential changes are not made. On the other hand, provision must be made to accommodate changes in those cases where changes are required. Any section or procedure in this document, including this procedure, may be changed using the instructions provided in this procedure.

\subsection{Procedure for Controlling Revisions}

\section{Purpose and Scope of This Procedure}

This procedure establishes requirements for the control, distribution, and revision of this Implementing Procedures Document and all procedures contained therein.

\section{Prerequisites for Performing This Procedure}

Technical Skills and Knowledge Levels. Skills required to implement this procedure include writing and editing skills and familiarity with word processing systems and 
good organizational skills. Working knowledge of the SRP Update and Development Program is required for revising this document.

Document Availability. The only document required to implement this procedure is the currently approved version of the Implementing Procedures Document (either the original document or a subsequent revision).

Completion of Prior Procedures. No other procedures need to have been completed or initiated in order to implement this procedure.

\section{Overview of This Procedure}

The guidance in this procedure is provided in three parts. First, control of the Implementing Procedures Document originals, both in electronic form and hard copy, is addressed. Second, control of document distribution is addressed. Finally, control of document revisions is addressed.

\section{Results of This Procedure}

Written Product. The written products of this procedure include Implementing Procedures Document distribution lists; controlled copies of the Implementing Procedures Document; and records of document distribution, receipt, and return.

Other. This procedure will result in a system that ensures that program personnel are using current and approved procedures in accomplishing their work.

\section{Detailed Procedure}

This section specifies the step-by-step sequence to be followed, grouped by directives (major intermediate outputs), to be accomplished through a series of specific steps.

Directive 1: Control document maintenance.

Step 1 Designate an individual to be responsible for Implementing Procedures Document control.

Step 2 Ensure that the current, updated version of the Implementing Procedures Document is entered and maintained on an appropriate electronic system. Provide suitable backup provisions.

Step 3 Print and maintain a hard-copy reference version of the Implementing Procedures Document. Apply suitable controls to ensure the integrity of this hard copy.
Step 4 Obtain NRR approval, as coordinated by PTSB, prior to distribution or use of the Implementing Procedures Document and revisions thereto.

Directive 2: Control document distribution.

Step 1 Establish an Implementing Procedures Document Distribution List. Include all potential users of the document, except that a supervisor or manager may be designated as an Implementing Procedures Document recipient for the supervisor's staff. Enter distribution list data into the SRP Modification Database.

Step 2 Review the distribution list periodically and update it as necessary. Obtain input from program and project supervisory personnel. Enter distribution list update data into the SRP Modification Database.

Step 3 Maintain records of present and past distribution lists.

Step 4 Mark each distribution copy of the Implementing Procedures Document with a unique copy number for control purposes.

Step 5 Distribute copies of the Implementing Procedures Document and its subsequent revisions to personnel on the distribution list. Include an Implementing Procedures Document Receipt Form with each transmittal.

Step 6 Sign and return the Implementing Procedures Document Receipt Form upon receipt of an Implementing Procedures Document or revision thereto. In cases of document revisions, also return the superseded version of the document. (Responsibility of document users.)

Step 7 Record receipt of Implementing Procedures Document Receipt Forms and superseded documents, and properly dispose of superseded documents.

Step 8 Maintain records of document distribution, including personnel receiving a copy, the copy number sent to each individual, the signed Implementing Procedures Document Receipt Forms, and return of superseded documents. Maintenance of the records may be performed by the SRP Modification Database. 


\subsection{Control of This Document}

Directive 3: Control document revision.

Step 1 Determine when revisions to the Implementing Procedures Document are required. Consider potential additions, changes, and deletions as suggested by program personnel.

Step 2 Characterize the suggested change by developing a strawman revision. Obtain NRR approval of the proposed change, modifying it as necessary.

Step 3 Perform necessary word processing to incorporate the change in the Implementing Procedures Document.

Step 4 Obtain NRR approval, as coordinated by PTSB, of the revision and a determination of the urgency of the revision.

Step 5 Notify document holders of the approved revision to the Implementing Procedures Document and the necessity of immediate implementation, for those cases in which it has been determined that the revision is urgent. Non-urgent changes may be accumulated before re-issuing the document. Document holders should be notified of such non-urgent changes, once they are approved by NRR, and be allowed to implement them prior to document re-issue.

Step 6 Issue the Implementing Procedures Document revision in accordance with Directive 2.

\section{Forms}

The single form used in this procedure is the Implementing Procedures Document Receipt Form. This form is used to ensure that the Implementing Procedures Document and its revisions are received by persons on the Implementing Procedures Document Distribution List.

All organizations implementing this procedure must record their work on the indicated forms and forward the completed forms to the PTSB upon completion of the work. 


\subsection{Control of This Document}

\section{Sample Form}

\section{Implementing Procedures Document Receipt Form}

Implementing Procedures Document Revision No.

Copy No.

Implementing Procedures Document Recipient

I acknowledge receipt of the hard-copy document described above and certify that I have returned the superseded version to the address indicated below.

(Assigned Individual)

Mail Stop (TBD)

Pacific Northwest Laboratory

P.O. Box 999

Richland, WA 99352

Signature

Date 
How to Complete the Form

- The person assigned to distribute the Implementing Procedures Document will complete the first two lines, including the Implementing Procedures Document revision number, copy number, and the Implementing Procedures Document holder's name with holder's organizational affiliation indicated in parentheses.
- Enter the name and mail stop of the designated person in the address portion of the form.

- The Implementing Procedures Document holder will sign and date the form upon receipt of the document (and return the superseded version). 


\subsection{Control of This Document}

\section{Sample Form}

\section{Implementing Procedures Document Receipt Form}

Implementing Procedures Document Revision No.

0

Copy No.

15

Implementing Procedures Document Recipient John Doe (PNL)

I acknowledge receipt of the hard-copy document described above and certify that I have returned the superseded version to the address indicated below.

(Assigned Individual)

Mail Stop (TBD)

Pacific Northwest Laboratory

P.O. Box 999

Richland, WA 99352

Signature

Date 


\section{Appendix A: Standard Review Plan Format}

This Appendix provides guidance as to the format to be used in updating and upgrading SRP sections in accordance with Procedures 3.7 and 3.8. In general, the prescribed format retains the essential features of the existing SRP since the NRR staff and licensees are familiar with the current format, and most existing safety analysis reports are written in this format. Certain enhancements, based on human factors insights, are being incorporated to facilitate understanding and use of the SRP.

\section{Numbering of SRP Sections}

The existing numbering structure of the SRP will be preserved. It is preferable to fit new concepts into existing SRP sections whenever it is reasonable to do so. However, some new SRP sections will need to be added, and such new sections should be numbered in such a way that existing sections are not renumbered. This will generally require that new sections be added at the end of chapters or series of related sections.

\section{Incorporation of Future Reactor Designs}

The SRP currently addresses two types of reactor designs: boiling water reactors (BWRs) and pressurized water reactors (PWRs). The SRP Update and Development Program will expand the current SRP scope to include a number of diverse, evolutionary, and advanced reactor designs. Many of the design concepts for the future reactors will incorporate conventional reactor technology; some will use unconventional applications of existing technology and application of new technology. New reactor types will be incorporated in the SRP using the following format. (The indicated format parallels the format currently used in the SRP for BWRs and PWRs).

Any of the following formats is acceptable. However, the order in which the formats are presented represents a definite preference. Method (1) is preferred to (2), (2) is preferred to (3), and (3) is preferred to (4).

1. Make SRP sections generically applicable to all reactor types addressed in the SRP. Some sections are relatively insensitive to differences in reactor design and can be made to apply to all designs without exceptions. The SRP sections in Chapter 2 (Site
Characteristics) and Chapter 17 (Quality Assurance) are examples of fully generic sections.

2. Make SRP sections as generic as possible while allowing for the inclusion of design-specific reviewer guidance within the Roman numeral subsections of the SRP section. Refer to SRP Section 5.4.7 (Residual Heat Removal System) for an example of this format.

3. Create an introductory SRP section that addresses common aspects of design of different reactor concepts, and then develop a series of SRP sections that address each design specifically. The series of SRP sections would carry the same section number as the introductory section with an alphabetic digit added (e.g., 6.2.1, 6.2.1.A, 6.2.1.B, etc.). Reíer to SRP Section 6.2.1 and its subsections for an example of this format.

4. Create a design-specific SRP section. In cases where a design concept is unique to a particular reactor type, there is no reasonable alternative to the preparation of a unique section for that concept. Examples of this format are provided by SRP Sections 5.4.1.1 (Pump Flywheel Integrity), 5.4.8 (Reactor Water Cleanup System), and 5.4.11 (Pressurizer Relief Tank).

\section{Format for Individual SRP Sections}

The existing six-part division (Roman numerals I through VI) of existing SRP sections will be preserved. This format will be enhanced by further dividing each Roman numeral subsection into parts introduced by headings. Certain headings will appear in all SRP sections; others will appear only if the topic is pertinent to the particular SRP section (e.g., plant layout considerations). The standard format for SRP sections is established by the Draft SRP Section Form in Procedure 3.7. An example SRP section exhibiting the recommended format follows.

\section{Sample SRP Section in Recommended Format}

Note: The following sample form is taken from the actual SRP Section 9.1.1 to illustrate the intended format for revised SRP sections. This example is intended solely to be illustrative of format; no impacts have yet been incorporated in this sample section nor has the technical accuracy of the section been verified. 
Appendix A

\section{Draft SRP Section Form}

\subsubsection{New Fuel Storage}

\section{Review Responsibilities}

Refer to NRR Office Letter 800 to determine the NRR branch responsible for this review.

\section{Areas of Review}

This SRP section addresses the review of the storage facilities for new fuel. The quantity of new fuel to be stored varies from plant to plant, depending on the specific design of the plant and the individual refueling requirements.

\section{Objectives of the Review}

The objectives of this review are to ensure that:

1. The storage facility maintains the new fuel in a subcritical array.

2. The new fuel is maintained in a safe condition during all credible storage conditions.

\section{Scope}

The scope of the review of Section 9.1.1 of the applicant's Safety Analysis Report (SAR) includes a review of:

1. The quantity of new fuel to be stored.

2. The design and arrangement of the storage racks for maintaining a subcritical array during all storage conditions.

3. The degree of subcriticality, and the supporting analysis and associated assumptions.

4. The effects of external loads and forces on the new fuel storage racks and vault (e.g., safe shutdown earthquake (SSE), crane uplift forces).

5. The effects of sharing in multi-unit complexes, and failures of other plant equipment close to the new fuel storage facility.

6. The protection of new fuel from natural events and equipment failures under the SRP sections indicated:

a. Flood protection as specified under SRP Section 3.4.1.

b. Protection against internally generated missiles as specified under SRP Section 3.5.1.1.

c. Protection against externally generated missiles as specified under SRP Section 3.5.2.

d. Protection from high and moderate energy line breaks as specified under SRP Section 3.6.1.

7. the adequacy of equipment qualification as specified under SRP Section 3.11. 


\section{Review Interfaces}

The following areas of evaluation are relevant to the review described in this SRP section. The primary review branches assigned responsibility for review of each of these areas (see NRR Office Letter 800) should be consulted as necessary.

Reactivity of loaded storage racks will be evaluated by the branch responsible for core performance to verify the acceptability of the $\mathrm{K}_{\text {eff }}$ of loaded storage racks in cases where designs deviate significantly from previously accepted designs.

Seismic design of structures will be reviewed to determine the acceptability of the design analyses, procedures, and criteria used to establish the ability of seismic Category I structures housing the system and supporting systems to withstand the effects of natural phenomena such as the SSE, the probable maximum flood (PMF), and tornadoes and tornado missiles as part of the review responsibility for SRP Sections 3.3.1, 3.3.2, 3.5.3, 3.7.1 through 3.7.4, 3.8.4, and 3.8.5.

Seismic design of systems will be reviewed to determine that the components and structures are designed in accordance with applicable codes and standards as part of the review responsibility for SRP Sections 3.9.1 through 3.9.3. The acceptability of the seismic and quality group classifications for system components is also reviewed as part of the review responsibility for SRP Sections 3.2.1 and 3.2.2.

The radiation monitoring system is reviewed for adequacy as part of the review responsibility for SRP Sections 12.3 and 12.4 .

In-service inspection for components is verified as part of the review responsibility for SRP Section 6.6 and, upon request, the compatibility of the materials of construction with service conditions is reviewed.

Fire protection considerations are reviewed as part of the review responsibility for SRP Section 9.5.1.

Technical specifications are reviewed as part of the review responsibility for SRP Section 16.0.

Quality Assurance Program adequacy is reviewed as part of the review responsibility for SRP Section 17.0.

\section{Acceptance Criteria}

\section{Requirements and Guidance}

The requirements for this section are set forth in Table 9.1.1 and described in narrative form below.

Table 9.1.1-1 Requirements and Guidance for the Light Load Handling System (Related to Refueling)

\begin{tabular}{|l|l|l|l|}
\hline \multicolumn{1}{|c|}{ Requirements } & \multicolumn{1}{|c|}{ Guidance } & $\begin{array}{c}\text { Affected Structures, } \\
\text { Systems, Components, or } \\
\text { Processes }\end{array}$ & \multicolumn{1}{|c|}{\begin{tabular}{c}
\multicolumn{1}{c|}{ Failure Mechanisms } \\
or Issues
\end{tabular}} \\
\hline \hline GDC-2 & RG 1.29, C.1.1 & New fuel storage facilities & Earthquakes \\
\hline GDC-5 & N/A & $\begin{array}{l}\text { Shared new fuel storage } \\
\text { facilities }\end{array}$ & $\begin{array}{l}\text { Capability to perform } \\
\text { safety functions }\end{array}$ \\
\hline GDC-61 & ANS 57.1, ANS 57.3 & New fuel storage facilities & $\begin{array}{l}\text { Damage under normal or } \\
\text { accident conditions }\end{array}$ \\
\hline GDC-62 & ANS 57.1, ANS 57.3 & New fuel & Accidental criticality \\
\hline
\end{tabular}


Appendix A

1. Compliance with GDC-2 (Reference 1), as it relates to the ability of structures housing the new fuel storage facility and the facility components to withstand the effects of earthquakes, is based on meeting Regulatory Guide 1.29 (Reference 5), Position C.1.1, as it relates to seismic classification of facility structures and components.

2. Compliance with GDC-5 (Reference 2), as it relates to the sharing of structures, systems, and components important to safety, is based on showing that the other requirements set forth above are met for the total amount of new fuel to be stored for the shared units.

3. Compliance with GDC-61 (Reference 3), as it relates to ensuring safety under normal and postulated accident conditions, is based on meeting the relevant criteria in ANS 57.1, "Design Requirements for LWR Fuel Handling Systems," and ANS 57.3, "Design Requirements for New LWR Fuel Storage Facilities" (proposed) (References 6 and 7 , respectively).

4. Compliance with GDC-62 (Reference 4), as it relates to prevention of criticality for new fuel storage, is based on meeting the relevant criteria in ANS 57.1 and ANS 57.3 (proposed) (References 6 and 7, respectively).

\section{Technical Rationale}

The regulatory requirements set forth in Table 9.1.1-1 include those 10 CFR Part 50 requirements that are specifically applicable to new fuel storage facilities and equipment. GDCs 1,2,3, and 4 impose generic requirements that are addressed in other SRP sections. Coordination of the reviews of those sections are indicated in Subsection I, Branch Interfaces, of this SRP section. GDC Sections II through V are unrelated to fuel storage. GDCs 60, 63, and 64 are not applicable to new fuel storage because of the inherently low level of radioactivity associated with new fuel and the highly effective containment, within the new fuel cladding, of the little radioactivity that does exist. GDCs 60, 63, and 64 are directed at highly radioactive spent fuel and radioactive waste streams. The remainder of Part 50 does not impose any specific requirements on new fuel storage.

The application of the requirements set forth in Table 9.1.1-1 to the design of the new fuel storage facility and equipment is discussed in the following paragraphs.

1. GDC-2 requires, in relevant part, that structures, systems, and components important to safety be designed to withstand the effects of natural phenomena, including earthquakes. Preventing the new fuel from becoming configured in an array that could allow an accidental criticality is a safety function. Therefore, any structures and equipment that are relied upon to maintain the fuel in a subcritical array are subject to GDC-2 requirements and must be seismically designed.

Regulatory Guide 1.29 (Reference A) reflects staff practice in seismic classification and establishes the accepted standard for such classification. Application of this regulatory guide, therefore, ensures the correct seismic classification of the structures and equipment associated with storage of new fuel. Correct classification is all that is required in this review since review of seismic design and analysis is the subject of other SRP sections.

2. GDC-5 requires that shared structures, systems, and components important to safety must show that their ability to perform their safety functions is not impaired. Typically, a shared system or component would be designed to serve either of the units, but only one unit at a time, e.g., a diesel generator or hydrogen recombiner. In the case of new fuel storage, however, a single storage facility is provided to serve both or all units at all times. Also, the safety function performed by the storage facility is a passive one, i.e., providing the structural support to prevent inadvertent criticality. Therefore, the safety function finding required by GDC-5 is interpreted to mean that accidental criticality must be shown to be prevented by the storage system design, given the maximum amount of new fuel that will be stored in the facility for both or all units.

3. GDC-61 provides general design criteria for fuel storage and handling, among other things. Item (1) is the only item that applies to new fuel storage; this item requires the provision of capability to inspect and test components important to safety. The remaining items address fission product heat removal and radiation protection, which are not relevant to new fuel. 
The staff has reviewed industry standards ANS 57.1 and ANS 57.3 (References B and C) and found them to provide adequate and sufficient criteria to ensure capability to inspect and test those components of the new fuel storage facility that are important to safety.

4. GDC-62 requires that criticality be prevented for the storage and handling of nuclear fuel, preferably by use of geometrically safe configurations. Staff practice indicates that design of a configuration that maintains a $\mathrm{K}_{\mathrm{eff}}$ of less than about 0.95 , assuming a completely loaded array and flooding with potential moderating materials, such as nonborated water, will provide adequate protection against inadvertent criticality. Therefore, this criterion is taken to meet the GDC-62 requirement.

The staff has reviewed industry standards ANS 57.1 and ANS 57.3 (References B and C) and found them to contain adequate guidance to assure that the criticality criterion described above will be met.

\section{Technical Rationale References}

A. Regulatory Guide 1.29, "Seismic Design Classification."

B. ANS 57.1, "Design Requirements for Light-Water Reactor Fuel Handling Systems."

C. ANS 57.3, "Design Requirements for New LWR Fuel Storage Facilities" (proposed).

\section{II.B Acceptance Criteria: 60-Year Design Life Review}

This subsection provides Acceptance Criteria for applicants proposing a 60-year design life. The specific requirements will be developed and incorporated in the SRP at a later time.

\section{Requirements and Guidance}

[To be developed.]

\section{Technical Rationale}

[To be developed.]

\section{Technical Rationale References}

[To be developed.]

\section{Review Procedures}

\section{Purpose}

This subsection describes the procedures to be followed in reviewing the acceptability of the new fuel storage facility and equipment. The review ensures that the acceptance criteria set forth in subsection II of this SRP section are met. For typical storage systems, acceptability is determined by establishing comparability with previously approved designs. When the design deviates significantly from previously approved designs, the Plant Systems Branch (SPLB) will request coordinating review branches to provide input for the areas of review stated in Subsection I of this SRP section. The SPLB will incorporate such input as required to ensure that this review procedure is complete. 


\section{Appendix A}

\section{Procedure}

1. Review the SAR to determine the storage capacity provided by the design. The storage space provided is typically consistent with the number of new fuel assemblies used during the refueling cycle, i.e., approximately one-third of a core for each unit of a plant (e.g., 1/3 of a core for a single unit design and $2 / 3$ of a core for a dual unit design).

2. Evaluate the criticality safety of the new fuel storage facility. Similarity of design with previously approved designs constitutes criticality safety. For any significant deviations in design from previously approved designs, request the Reactor Systems Branch (SRXB) to perform an assessment of the design with respect to criticality safety. Elements to be considered in the criticality review include the following:

a. Spacing between fuel assemblies in the storage racks must be sufficient to maintain a $\mathrm{K}_{\mathrm{eff}}$ of less than about 0.95 , assuming a completely loaded array and flooding with potential moderating materials, such as nonborated water or fire extinguishing aerosols. Credit may be taken for neutron absorbing materials.

b. Design of the new fuel storage racks will ensure that the $\mathrm{K}_{\text {eff }}$ will not exceed 0.98 with fuel of the highest anticipated reactivity in place assuming optimal moderation. Credit may be taken for neutron-absorbing materials.

3. Review the design to ensure that a fuel assembly cannot be inserted anywhere in the racks other than in design locations.

4. Ensure that provisions have been made for drainage of the storage vault to prevent the accumulation of a fluid moderator.

5. Review the SAR evaluation of the effects of failures of nonsafety-related systems or non-seismic Category I structures located in the vicinity of the storage facility on the storage racks. Ensure that the maximum allowable value of $\mathrm{K}_{\text {eff }}$ will not be exceeded. Review the SAR description, the general arrangement and layout drawings, and the tabulation of seismic classifications for structures and systems to confirm the evaluation.

6. Confirm that the storage racks and their anchorages can withstand the maximum uplift forces available from lifting devices without an increase in $\mathrm{K}_{\text {eff }}$. A statement in the SAR that excessive forces cannot be applied due to the design of the lifting devices, is acceptable if justification is provided. Any such justification is reviewed according to the procedures stated in SRP Section 9.1.4.

7. Verify that the facility design basis and criteria, and the component classification tables, classify the new fuel storage facility, including the storage vaults and racks, as seismic Category I and that the facility will be designed to seismic Category I requirements.

8. Confirm that the new fuel storage racks and vault are protected from the effects of floods, hurricanes, tornadoes, and internally or externally generated missiles. Use the appropriate sections from SRP Chapter 3 to review flood and missile protection. Other branches provide review input regarding seismic design and seismic and quality group classifications as indicated in subsection I of this SRP section.

\section{Evaluation Findings}

The reviewer verifies that the information provided and his review support conclusions of the following type to be included in the staff's safety evaluation report:

The new fuel storage facility includes the fuel assembly storage racks, the concrete storage vault that contains the storage racks, and auxiliary components. Based on the review of the applicant's design criteria, design bases, and safety classification for the new fuel storage facility regarding the provisions necessary to maintain a subcritical array, the staff concludes that the design of the new fuel storage facility and supporting systems is acceptable and meets the requirements of General Design Criteria 2, 5, 61, and 62 with respect to the measures taken to provide protection against the effects of natural phenomena, missiles, environmental conditions, and the sharing of structures, systems, and components. 
Appendix A

This conclusion is based on the following:

1. The natural phenomena requirements of General Design Criterion 2 regarding earthquakes have been met since it conforms to position C.1.1 of Regulatory Guide 1.29.

2. The shared portions of the new fuel storage facility between nuclear power units meet the requirements of General Design Criterion 5 in that it was demonstrated that such sharing did not impair, under accident conditions, the ability of the shared structures, systems, and components to perform their safety functions.

3. The fuel storage and handling and radioactivity control aspects of General Design Criterion 61 and the criticality aspects of General Design Criterion 62 have been met based on the new fuel storage system meeting ANS 57.1 and ANS 57.3 as they relate to the prevention of criticality and radiological releases.

\section{Implementation}

The following is intended to provide guidance to applicants and licensees regarding the NRC staff's plans for using this SRP section.

Except in those cases in which the applicant proposes an acceptable alternative method for complying with specified portions of the Commission's regulations, the method described herein will be used by the staff in its evaluation of conformance with Commission regulations.

Implementation schedules for conformance to parts of the method discussed herein are contained in the referenced Regulatory Guide.

\section{References}

1. 10 CFR Part 50, Appendix A, General Design Criterion 2, "Design Bases for Protection Against Natural Phenomena."

2. 10 CFR Part 50, Appendix A, General Design Criterion 5, "Sharing of Structures, Systems, and Components."

3. 10 CFR Part 50, Appendix A, General Design Criterion 61, "Fuel Storage and Handling and Radioactivity Control."

4. 10 CFR Part 50, Appendix A, General Design Criterion 62, "Prevention of Criticality in Fuel Storage and Handling."

5. Regulatory Guide 1.29, "Seismic Design Classification."

6. ANS 57.1, "Design Requirements for Light-Water Reactor Fuel Handling Systems."

7. ANS 57.3, "Design Requirements for New LWR Fuel Storage Facilities" (proposed). 